UNIVERSIDAD NACIONAL DE LA PLATA

FACULTAD DE HUMANIDADES Y CIENCIAS DE LA EDUCACIÓN

\title{
DESARROLLO PROFESIONAL DEL PROFESOR DE MATEMÁTICAS: ESTUDIO DE CASO EN EL NIVEL MEDIO DE SECUNDARIA
}

TESIS DE DOCTORADO

Autor:

Mg. Isaac Lima Díaz

Director

Dr. José Villella

Ensenada, Provincia de Buenos Aires

República Argentina

Mayo de 2019 


\section{RESUMEN}

Título de la tesis: Desarrollo profesional del profesor de matemáticas: estudio de caso en el nivel medio de secundaria.

Autor: Mg. Isaac Lima Díaz

Director: Dr. José Villella, Profesor Asociado Ordinario de Didáctica de la Matemática, Investigador Categoría 1 en Didáctica de la Matemática CEDE UNSAM, Director del Diploma de Estudios Superiores en Enseñanza de la Matemática EHU UNSAM

Entidad: Universidad Nacional de La Plata, Facultad de Humanidades, Doctorado en Ciencias de la Educación

Palabras Clave: Conocimiento especializado del profesor de matemáticas, desarrollo profesional del profesor de matemáticas, concepciones, práctica del profesor de matemáticas, formación docente.

La tesis de doctorado que se presenta corresponde a una investigación acerca del desarrollo profesional de un profesor de matemáticas a través de un estudio de caso. EI caso para estudiar es el de un docente que dicta clase en grado décimo (equivalente al cuarto año de secundaria de la Ciudad Autónoma de Buenos Aires) durante dos años consecutivos en un colegio público de la ciudad de Bogotá. Aporta al campo de la educación matemática, en particular la línea de formación del profesor de matemáticas, que en la actualidad se ha centrado en las componentes del conocimiento especializado del profesor.

Surge a partir del planteamiento de preguntas acerca de cómo es la formación continua del profesor: ¿Qué necesita saber y saber hacer un profesor para enseñar matemáticas? ¿Cuáles son las creencias y concepciones de los profesores de matemáticas que caracterizan su actuación profesional? ¿Cuál y cómo es su conocimiento especializado? ¿Cómo es el desarrollo profesional de los profesores de matemáticas?

Estas preguntas fueron abriendo puertas acerca de diferentes temas a investigar, generando relaciones entre sus respuestas y fueron decantando una pregunta que se transformó en el problema de investigación: ¿Qué elementos caracterizan el desarrollo profesional de un profesor de matemáticas de la escuela secundaria? 
Para dar respuesta al problema se optó por analizar la práctica de un profesor a partir de una perspectiva cognitiva entendiendo que el profesor es un ser complejo que como profesional tiene una formación, unos problemas significativos que inciden directamente en sus concepciones y conocimiento profesional, los cuales a través de la práctica pueden conducir hacia un desarrollo de su ejercicio profesional.

Las memorias que dan cuenta de la presentación de la investigación inician con su respectiva introducción, seguidas de cuatro partes que corresponden a la linealidad del proceso realizado: La primera parte corresponde al marco teórico, en tres capítulos se presentan las bases teóricas de la investigación. El primero de ellos corresponde a la revisión sobre concepciones de profesores, el siguiente presenta elementos relativos a la investigación sobre conocimiento profesional del profesor de matemáticas en el que se incluye una revisión sobre varios modelos de conocimiento de los profesores finalizando en el empleado para el desarrollo de la investigación. El tercer capítulo corresponde al estudio del desarrollo profesional de los profesores de matemáticas.

La segunda parte está dedicada a la Metodología, describe el camino seguido en la investigación para alcanzar los objetivos propuestos. Está constituido por la caracterización y presentación de los objetivos del estudio; la descripción de los instrumentos de recolección y análisis de la información y la contextualización del trabajo de campo

La tercera parte se presenta el análisis detallado del desarrollo profesional del profesor de matemáticas los dominios, subdominios y categorías que lo componen; el análisis de las concepciones del profesor a quien se observó, y el establecimiento de posibles relaciones entre el conocimiento especializado y las concepciones del profesor sobre la enseñanza y aprendizaje de las matemáticas.

Finalmente, se exponen las conclusiones: allí están detallados los aportes de la investigación con relación a la teoría y de acuerdo con los objetivos planteados para tener un acercamiento a la respuesta de la pregunta de investigación, así como las limitaciones del estudio y la perspectiva hacia futuras investigaciones.

Las memorias finalizan con la presentación de las referencias bibliográficas y los anexos en versión digital. 


\section{SUMMARY}

Title: Professional development of the mathematics teacher: a case study at the high school.

Author: Mg. Isaac Lima Díaz

Director: José Villella, PhD, Regular Associate professor of didactic of mathematics, researcher in didactic of mathematics category 1 CEDE UNSAM, Director of the Diploma of higher studies in mathematics teaching EHU UNSAM

Entity: Universidad Nacional de La Plata, Faculty of Humanities, Education Sciences $\mathrm{PhD}$

Keywords: Mathematics Teacher's Specialized Knowledge, professional development of the mathematics teacher, conceptions, practice of the mathematics teacher, teacher training.

This doctoral thesis is an investigation about the professional development of mathematics teacher through a case study. The case study is a teacher who teaches in the first grade of high school for two consecutive years in a public institute in Bogota city. This research contributes to mathematical education, especially to formation of mathematics teacher line and the components of Mathematics Teacher's Specialized Knowledge.

This research arises from the approach of questions about the teacher's training: What does a teacher need to know and know how to teach math? What are the beliefs and conceptions of the mathematics teachers and how can them to characterize their professional performance? What and how is their specialized knowledge? How is the professional development of mathematics teachers?

These questions open different ideas to research, and this generated relationships between their answers and settling in a unique question which is the investigation problem: How is the professional development of a mathematics teacher in high school?

To answer this question, during the research we analyzed the practice of a teacher from a cognitive perspective, understanding that the teacher is a complex being, that, as a professional, he has a training and he has a significant problems that directly affect his 
conceptions and professional knowledge which, through practice, it can lead to a development on his professional exercise.

The research paper begins with the introduction, follow by four parts: the first one corresponds to the theoretical framework and, in the next three chapters, the theoretical bases of the research are presented: review of conceptions of teachers, Professional Mathematics Teacher's Knowledge and Professional development of mathematics teachers.

The second part is the methodology and describes the path followed in the research to achieve the proposed aims: characterization and presentation of the research aims, description of instruments for collecting and analyzing information, and contextualizing field work.

The third part presents the detailed analysis of the professional development of the mathematics teacher, domains, subdomains and categories that compose it; analysis of the teacher's conceptions, relations between the Specialized Mathematics Teacher's Knowledge and the teacher's conceptions about the teaching and learning of the mathematics.

Finally, the conclusions. In this part, we detailed the contributions of the investigation in relation to the theory and, according to the objectives, to have an approach to the answer of the research problem, the limitations of the study and the perspective to future researches. The report ends with the bibliographic references and annexes in digital version. 


\section{RESUMO}

Título da tese: Desenvolvimento profissional do professor de matemática: estudo de caso no nível de ensino médio secundário.

Autor: Mg. Isaac Lima Díaz

Diretor: José Villella, $\mathrm{PhD}$, Professor associado regular de didática de matemática, pesquisador da categoria 1 em didática de matemática CEDE UNSAM, Diretor do diploma de estudos superiores em ensino de matemática EHU UNSAM

Entidade: Universidad Nacional de La Plata, Faculdade de Humanidades e Ciências da educação, Doutorado em Ciências da educação

Palavras Clave: Conhecimento especializado do professor de matemática, desenvolvimento profissional do professor de matemática, concepções, prática do professor de matemática, formação de professores.

A tese de doutorado apresentada corresponde a uma pesquisa sobre o desenvolvimento profissional de um professor de matemática através de um estudo de caso. O caso para estudar é de um Professor que ministra classe na décima série (equivalente ao quarto ano do secundário da cidade autônoma de Buenos Aires) por dois anos consecutivos numa escola pública na cidade de Bogotá, Colômbia. A sua contribuição acontece no campo da instrução matemática, a linha de formação do professor da matemática, e focalizada nos componentes do conhecimento especializado do professor.

A pesquisa nasce de questionamentos sobre como é a formação continuada do professor: O que precisa saber e o que deve saber fazer um professor no ensino da matemática? Quais são as crenças e concepções dos professores de matemática que caracterizam seu desempenho profissional? Qual e como é o conhecimento especializado do professor de matemática? Como é o desenvolvimento profissional dos professores de matemática?

Essas questões abriram portas sobre diferentes temas para pesquisar, elas geraram relacionamentos entre as suas respostas e decantaram numa questão que tornou-se o problema da pesquisa: 0 que elementos caracterizam o desenvolvimento profissional de um professor de matemática do ensino médio?

Para responder ao problema decidiu-se analisar a prática de um professor a partir de uma perspectiva cognitiva, entendendo que um professor é um ser complexo que, como 
profissional, tem um treinamento, e tem problemas significativos que afetam diretamente suas concepções e conhecimentos profissionais, que através da prática pode levar a um desenvolvimento do seu exercício profissional.

Os relatórios que dão conta da apresentação da pesquisa começam com sua respectiva introdução, seguidos por quatro partes que correspondem à linearidade do processo realizado: A primeira parte corresponde ao referencial teórico, em três capítulos se apresentam as bases teóricas da pesquisa. O primeiro corresponde à revisão de concepções de professores; o segundo capítulo apresenta elementos relacionados à pesquisa sobre o conhecimento profissional do professor de matemática. Nesta ocasião inclui-se uma revisão sobre vários modelos de conhecimento dos professores que terminam no utilizado para a pesquisa. O terceiro capítulo corresponde ao estudo do desenvolvimento profissional dos professores de matemática.

A segunda parte é a metodologia, descreve-se o caminho seguido na pesquisa para alcançar os objetivos propostos. Consiste na caracterização e apresentação dos objetivos do estudo; a descrição dos instrumentos de recolha e análise de informação e a contextualização do trabalho de campo

A terceira parte apresenta a análise detalhada do desenvolvimento profissional do professor de matemática: os domínios, os subdomínios e as categorias que a compõem; a análise das concepções do professor que foi observado, e a declaração estabelecimento de possíveis relações entre o conhecimento especializado e as concepções do professor sobre o ensino e aprendizagem da matemática.

Finalmente, as conclusões apresentam as contribuições da pesquisa em relação à teoria e de acordo com os objetivos propostos se faz uma abordagem da resposta da questão da pesquisa as limitações do estudo e a perspectiva para pesquisas futuras.

Os relatórios terminam com a apresentação das referências bibliográficas e os anexos na versão digital. 
Gracias...

Pasaron alrededor de 50.000 horas desde el momento en que esta tesis nació y 43.000 desde que inició el proceso investigativo: algunos días con ella en mis ojos y mis dedos más de 20 horas diarias, algunos otros en los que la inspiración no venía,

no aparecía. La luna, el sol, Lila y Tita, Margarita y Agustina son testigos de esta aventura de 185.600 palabras que conforman esta memoria y sus respectivos anexos.

Tiene un padrino, José Villella. Mi director, pero más que ello es el amigo, el confidente, el hombre paciente detrás de cada asesoría, de cada mensaje, de cada llamada. Son 10 años aprendiendo de vos, descubriendo el gozo de ser profe de matemáticas.

Tiene un ahijado, Lucho. El profe detrás de esta investigación, a quien agradezco el resultado final de esta experiencia. Los aportes del área de matemáticas del IPN y el Departamento de Matemáticas de la UPN enriquecieron esta investigación.

Tiene dos abuelos, María y Carlos. Mi mamá siempre preguntando, preocupada por cada avance, celebrando cada paso; mi papá con su constante aliento. A ellos, mis padres les debo todo lo que soy.

Tiene un tío, David. Su sonrisa el primer día de 2014 cuando le conté que empezaría este proyecto fue el impulso constante de esta travesía.

Tiene una madrina, Cris. Cada impulso, cada palabra de aliento. No hay documento que haya recibido tal dosis de cariño como el que recibió esta memoria en su fase final.

Tiene dos nacionalidades: Argentina, recorridos en el tren de Buenos Aires a La Plata, mate y galletitas a lo largo de su elaboración.

Colombiana, con sabor a café, montañas y el aire fresco de la altura de Bogotá, y la inspiración que el Pedagógico le regaló. 


\section{TABLA DE CONTENIDO}

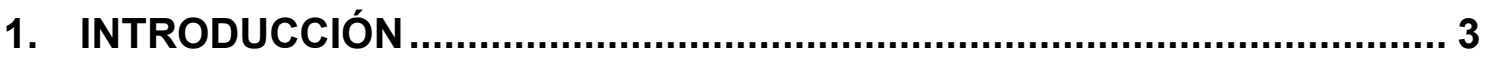

1.1. Contextualización y objeto de estudio de la investigación ......................4

1.2. Estructura de la memoria de investigación ................................................ 6

PRIMERA PARTE: MARCO TEÓRICO ….................................. 7

2. CONCEPCIONES: CONOCIMIENTO DECLARATIVO Y CONOCIMIENTO

EN LA ACCIÓN ...................................................................................... 7

2.1. Algunas definiciones sobre concepciones............................................ 7

2.2. Concepciones sobre la enseñanza y aprendizaje de las matemáticas..... 9

3. CONOCIMIENTO DEL PROFESOR DE MATEMÁTICAS ....................... 19

3.1. Conocimiento del profesor, conocimiento didáctico del contenido, conocimiento matemático para la enseñanza ....................................................21

3.2. Conocimiento especializado del profesor ............................................22

3.3. Naturaleza del Conocimiento Especializado ............................................ 25

3.4. Fuentes del Conocimiento Especializado................................................27

3.5. Componentes del Conocimiento Especializado del Profesor ..................31

4. DESARROLLO PROFESIONAL DEL PROFESOR DE MATEMÁTICAS 39

SEGUNDA PARTE: METODOLOGÍA........................................... 44

5. CARACTERIZACIÓN Y OBJETIVOS DE LA INVESTIGACIÓN ............... 44

5.1. Caracterización de la Investigación .......................................................... 44

5.2. Objetivos y problema de Investigación.......................................................46

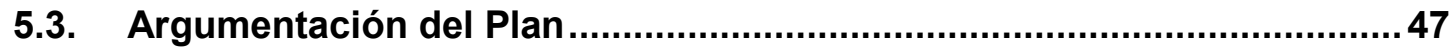

6. INSTRUMENTOS DE RECOLECCIÓN Y ANÁLISIS DE LA INFORMACIÓN 51

6.1. Instrumentos de recolección de información ...........................................51

6.2. Instrumentos de análisis de la información...........................................59

7. CONTEXTUALIZACIÓN DEL TRABAJO DE CAMPO ........................... 86

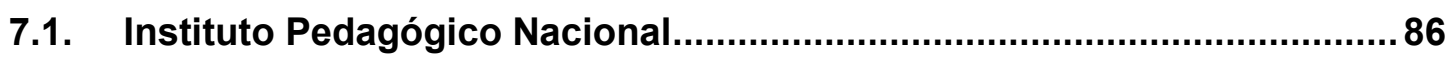


7.2. Lucho 87

7.3. Descripción general del proceso de observación .88

TERCERA PARTE: TRABAJO DE CAMPO Y ANÁLISIS ............ 90

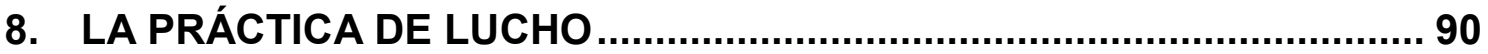

8.1. Bloque I. Primer momento de observación ............................................91

8.2. Bloque II. Segundo momento de observación.......................................129

8.3. Bloque III. Tercer momento de observación ....................................... 150

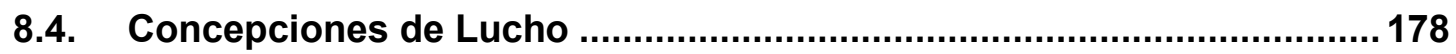

8.5. Conocimiento Especializado de Lucho............................................... 192

8.6. Desarrollo Profesional de Lucho ........................................................... 208

CUARTA PARTE: APORTES Y CONCLUSIONES .................... 218

9. CONCLUSIONES: DEL DESARROLLO DE UN PROFESOR AL APORTE

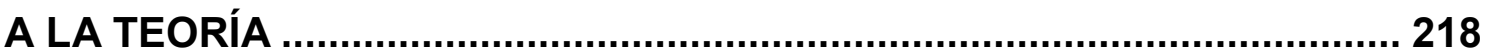

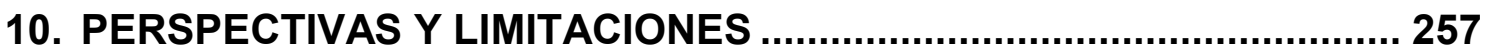

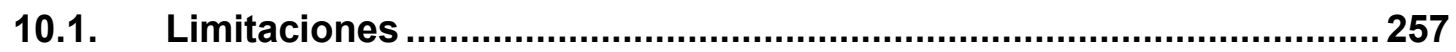

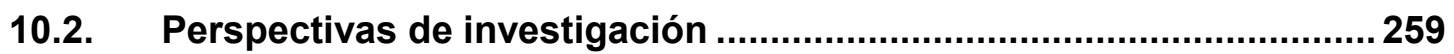

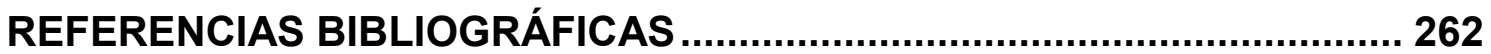

LISTA DE ANEXOS ................................................................................. 271 


\section{INTRODUCCIÓN}

La investigación se ha iniciado enlazándose con una motivación personal y profesional acerca de la educación matemática. Desde el rol profesional de la enseñanza de las matemáticas, interesa profundizar en diferentes campos de acción, en particular el referido al de la formación de docentes. Con experiencia en este campo, la preocupación gira sobre cómo abordar esa formación desde la óptica de la educación matemática. Cuestiones consideradas simples de formular y difíciles de responder como ¿Qué necesita un docente para la enseñanza de las matemáticas? ¿Cuáles son las concepciones de los profesores de matemáticas? ¿Cuál y cómo es su conocimiento profesional? ¿Cómo es el desarrollo profesional de los profesores de matemáticas? dirigen los principios del estudio.

La preocupación constante por optimizar los procesos de enseñanza y aprendizaje de los profesores de matemáticas constituye la motivación inicial para la realización de este estudio, considerando que el profesor debe reflexionar sobre la compleja tarea de enseñar matemáticas.

Es de gran relevancia realizar investigaciones que contribuyan a comprender el pensamiento y acciones del profesor en la enseñanza, y el aprendizaje. La mejora de las enseñanzas impartidas por los profesores en los salones de clases es clave para la mejora del aprendizaje, y aquí tiene un papel esencial el desarrollo profesional del profesor.

Así, el interés surge por profundizar en los procesos de desarrollo profesional del profesor de matemáticas a partir del estudio de sus concepciones y del conocimiento del profesor de matemáticas.

La investigación aquí presentada se enmarca dentro de las líneas de trabajo acerca del análisis de la práctica del profesor a partir de una perspectiva cognitiva, en particular el desarrollo profesional del profesor de matemáticas, entendido como la transformación de la práctica a través de la reflexión sobre lo que dice hacer y lo que hace a partir de sus concepciones sobre las matemáticas, las matemáticas escolares, la enseñanza y el aprendizaje y su conocimiento profesional, especializado, necesario para el ejercicio de su profesión (Figura 1.01): 


\section{ANÁLISIS DEL DESARROLLO PROFESIONAL DEL PROFESOR DE MATEMÁTICAS}

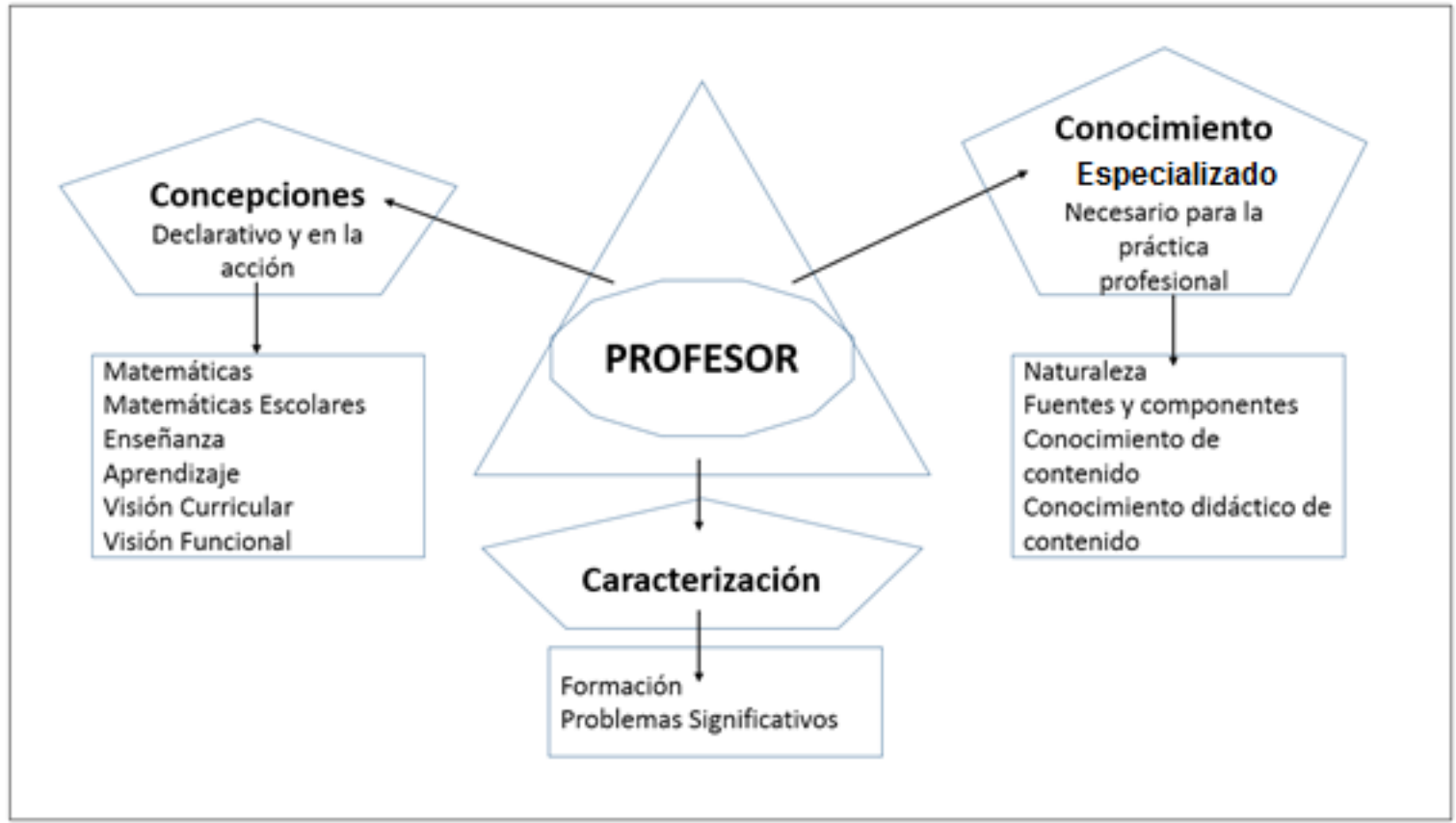

Figura 1.01. Análisis del Desarrollo Profesional del Profesor de Matemáticas. Fuente: propia

Este estudio se ubica, por tanto, en el marco del desarrollo profesional del profesor respecto de la enseñanza de las matemáticas para poder aprender más sobre las necesidades y posibilidades del docente respecto de la enseñanza de las matemáticas.

\subsection{Contextualización y objeto de estudio de la investigación}

En este estudio se propone caracterizar las componentes del desarrollo profesional del profesor de matemáticas que se ponen de manifiesto cuando desarrolla las actividades en una escuela secundaria. El caso para estudiar corresponde a un profesor que dicta clase en grado décimo durante dos años consecutivos en un colegio público de la ciudad de Bogotá, equivalente al cuarto año de secundaria de la Ciudad Autónoma de Buenos Aires. Para ello:

- Se hace un relevamiento teórico acerca de la caracterización del rol de profesor en el que se presentan fundamentos acerca de su formación y los problemas significativos del ejercicio de la profesión que se toman como referencia para caracterizar al sujeto informante del caso. 
- Se define la noción de creencias y concepciones a partir de referentes teóricos que las han estudiado, para hacer el estudio de concepciones sobre matemáticas y matemáticas escolares del sujeto informante del caso;

- Se caracteriza el conocimiento especializado para relacionarlo con la forma en la que el sujeto informante lleva a cabo su práctica de enseñanza

Se describen las componentes del desarrollo profesional del sujeto informante del caso.

El siguiente cuadro sintetiza cómo se relaciona lo descripto en un sistema que da dinamismo al trabajo que se presenta:

\begin{tabular}{|c|c|}
\hline ASPECTO A INVESTIGAR & FUNDAMENTACIÓN TEÓRICA \\
\hline \multirow[t]{3}{*}{ Caracterización del Profesor } & Caracterización del Profesor \\
\hline & Formación \\
\hline & Problemas Significativos \\
\hline \multirow[t]{4}{*}{ Concepciones } & Definiciones sobre creencias y concepciones \\
\hline & $\begin{array}{l}\text { Concepciones sobre la enseñanza y el } \\
\text { aprendizaje de las matemáticas }\end{array}$ \\
\hline & $\begin{array}{l}\text { Principios teóricos generales de las } \\
\text { concepciones }\end{array}$ \\
\hline & $\begin{array}{l}\text { Perspectivas de análisis de concepciones } \\
\text { sobre la enseñanza y el aprendizaje }\end{array}$ \\
\hline \multirow[t]{4}{*}{ Conocimiento Especializado } & Significado \\
\hline & Naturaleza \\
\hline & Conocimiento matemático \\
\hline & $\begin{array}{l}\text { Conocimiento didáctico de contenido } \\
\text { matemático }\end{array}$ \\
\hline \multirow[t]{3}{*}{ Desarrollo Profesional } & Significado \\
\hline & Términos en los que se describe \\
\hline & Reflexión \\
\hline
\end{tabular}

Tabla 1.01. Aspectos por investigar y fundamentación teórica. Elaboración: propia 


\subsection{Estructura de la memoria de investigación}

Esta memoria de investigación se compone de diez capítulos divididos en cuatro partes, referencias bibliográficas y anexos. En el presente capítulo, correspondiente a la Introducción, se expone la motivación y contextualización del estudio, y cómo está estructurado este trabajo.

La primera parte corresponde al marco teórico, en tres capítulos se presentan las bases teóricas de la investigación. El primero de ellos corresponde a la revisión sobre concepciones de profesores, el siguiente presenta elementos relativos a la investigación sobre conocimiento profesional del profesor de matemáticas en el que se incluye una revisión sobre varios modelos de conocimiento de los profesores finalizando en el empleado para el desarrollo de esta investigación. El tercer capítulo corresponde al estudio del desarrollo profesional de los profesores de matemáticas.

La segunda parte está dedicada a la Metodología, describe el camino seguido en la investigación para alcanzar los objetivos propuestos. Está constituido por la presentación de los objetivos del estudio; la contextualización del trabajo de campo y las técnicas o instrumentos de recolección de información y los instrumentos de análisis

En la tercera parte se presenta el análisis detallado del desarrollo profesional del profesor de matemáticas a partir de su práctica: los dominios, subdominios y categorías que lo componen; el análisis de las concepciones del profesor a quien se observó, correspondiente al establecimiento de posibles relaciones entre el conocimiento especializado y las concepciones del profesor sobre la enseñanza y aprendizaje de las matemáticas.

En la última parte se exponen las conclusiones. Alli están detallados los aportes de la investigación con relación a la teoría y de acuerdo con los objetivos planteados, así como las limitaciones del estudio y la perspectiva hacia futuras investigaciones.

Se presenta además el listado de referencias bibliográficas de la investigación, y el listado de anexos, los cuales se encuentran en versión digital. 


\section{PRIMERA PARTE: MARCO TEÓRICO}

Se presentan los componentes teóricos que sustentan el desarrollo de la investigación que han sido el eje conductor para el planteamiento y delimitación de los objetivos, la elección de la metodología, la elaboración los instrumentos de recolección y análisis de información, y la observación en campo y su respectivo análisis.

\section{CONCEPCIONES: CONOCIMIENTO DECLARATIVO Y CONOCIMIENTO EN LA ACCIÓN}

Las concepciones constituyen uno de los aspectos del pensamiento que han sido objeto de estudio en el análisis de la práctica del profesor. Se ha identificado que existe relación entre las creencias de los profesores, su práctica de enseñanza y el aprendizaje de los estudiantes (Abelson, 1979; Raymond, 1997; Clark \& Peterson, 1990; Wilson \& Cooney, 2002). La investigación sobre concepciones se centra en procesos que ocurren en la mente de los profesores y que, a pesar de tener carácter implícito, pueden dotar de sentido a su práctica (Abelson, 1979; Clark \& Peterson, 1990).

Estudiar las concepciones que se infieren de la actuación en el aula, permite analizar el desarrollo del profesor.

\subsection{Algunas definiciones sobre concepciones}

En la literatura académica existen diversas definiciones sobre concepciones que en algunos casos se toman como sinónimo de creencias, sin existir un límite claro entre ambos términos. (Ponte, 1994; Pajares, 1992; Jarauta \& Medina, 2009; Cross, 2009)

Algunas posturas diferencian creencias y concepciones, considerando las primeras como una componente afectiva del pensamiento del profesor y a las otras como una componente cognitiva. Ponte (1994) y Pajares (1992) definen creencias como verdades personales incontrovertibles que tiene cada persona, con una fuerte componente afectiva y evaluativa. Para ellos, las concepciones son esquemas subyacentes de organización de los conceptos de naturaleza cognitiva. Según estos autores, las creencias y las concepciones forman parte del conocimiento.

Jarauta \& Medina (2009), sólo toman en consideración las creencias y hacen la distinción entre éstas y el conocimiento a partir de dos supuestos: 
A. Las creencias surgen de la valoración afectiva y personal

B. Las creencias, son discutibles porque se justifican o se mantienen por razones que no satisfacen criterios utilizados para el desarrollo del conocimiento, y están a diferencia del conocimiento, más abiertas al debate.

Cross (2009), define creencias como ideas consagradas, conscientes e inconscientes y pensamientos sobre uno mismo, del mundo y la propia posición en él, se desarrollan por medio de la integración a diversos grupos sociales. Las creencias son personales y se salen del control inmediato del individuo y del conocimiento constituyendo para cada persona elementos de la verdad.

Porlán (1995) reconoce el carácter personal de las creencias y les atribuye un sentido de jerarquía, considerando que algunas son más influenciables que otras. Las creencias están asociadas a sistemas organizados y jerarquizados y tienen la misma influencia en la persona. La mayoría presentan un carácter más o menos dinámico y pueden cambiar con relativa facilidad, son aquellas más influenciables por la experiencia, más explícitas y que poseen un grado de abstracción menor. Otras, sin embargo, son muy estables y resistentes al cambio, permanecen en un nivel más oculto de la persona y poseen mayor grado de abstracción. Estas últimas constituyen el sustrato epistemológico y cognitivo del profesor.

Thompson (1991) se refiere a las concepciones del profesor incluyendo dentro de ellas a las creencias. En este sentido, considera a las concepciones como una estructura mental que incluye a las creencias, significados, conceptos, proposiciones, reglas, imágenes mentales, preferencias

Agudelo-Valderrama, Clarke \& Bishop (2007) parten de la idea de Thompson (1991) aunque consideran que las concepciones abarcan incluso el conocimiento. La concepción incluye conocimientos de los profesores, creencias y actitudes. Las creencias, a diferencia del conocimiento, pueden ser diferentes entre las personas y tienen un factor afectivo en ellas.

Arbeláez (2005), indica que las concepciones implican una creación resultante de la convergencia de los conceptos, los conocimientos, las ideas, las creencias, las opiniones sobre el contexto de las sensaciones y las percepciones; de allí que su estudio 
cobre tanta importancia cuando se trata de explicar las motivaciones que inducen las acciones de los profesores.

La figura 2.01 resume las diferentes definiciones de concepciones y creencias descritas hasta el momento:

Creencias: Sistemas organizados

y jerarquizados

(Porlán, 1995)

Las creencias: valoración afectiva y personal

(Jarauta \& Medina, 2009)

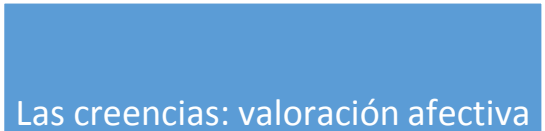

y personal

(Jarauta \& Medina, 2009)
Creencias: Pensamientos sobre uno mismo. Consagradas

(Cross, 2009)
Concepciones: Creación de la

convergencia de conceptos,

conocimientos, ideas y creencias

(Arbeláez, 2005)
Concepciones: Abarcan el

conocimiento. Las creencias

pueden ser diferentes en cada persona

(Agudelo-Valderrama, Clarke \& Bishop, 2007)

Figura 2.01. Estudios acerca de la noción de concepciones. Fuente: propia

En esta investigación, las creencias y concepciones serán entendidas como parte del conocimiento y en concordancia con Ponte (1994) y Montes, Flores-Medrano, Carmona y Flores (2014), se dispondrá de un tratamiento integrado evitando las diferencias explícitas entre ambos términos, considerados como sinónimos. Son definidas entonces como el conjunto de posicionamientos que el investigador interpreta posee el profesor de matemáticas a partir del análisis de su práctica en el aula y de sus opiniones sobre la enseñanza y aprendizaje (Blanco, 1991; Carrillo, 1998; Contreras, 1998; Climent, 2005).

\subsection{Concepciones sobre la enseñanza y aprendizaje de las matemáticas}

Las concepciones son, en esencia, factores que dan forma a las decisiones de los profesores sobre qué conocimiento es relevante, qué rutinas de enseñanza son apropiadas, qué objetivos deben lograrse y cuáles son las características importantes 
en el contexto de la clase. Lo que el profesor 'cree' y lo que 'hace' puede no coincidir. Hay diferentes elementos que pueden estar en conflicto o en armonía y que pueden cambiar con el tiempo.

Cómo los profesores conceptualizan su actuación en el aula, la elección de las actividades que en ellas proponen y las estrategias de enseñanza que utilizan, y que se relacionan con su sistema de concepciones sobre la naturaleza, la enseñanza y el aprendizaje de las matemáticas, se pueden caracterizar por medio de tendencias didácticas (Cross, 2009).

Las tendencias didácticas constituyen posturas respecto de cómo se comprende el proceso de enseñanza-y de aprendizaje. Carrillo (1998) y Carrillo y Rico (1999) diferencian cuatro tendencias didácticas: tradicional, tecnológica, espontaneista e investigativa. Junto con Contreras (1999 a) presentan una definición de cada una de ellas y es Climent (2005) quien agregó algunas características referidas la práctica del docente. En su conjunto brindan información acerca de las concepciones y posibles cambios en la forma de actuar de los profesores.

\subsubsection{Tendencia didáctica tradicional}

El profesor se dirige al estudiante de forma magistral, que conlleva a que no se establezcan relaciones entre los temas que se enseñan, siendo guiado por una programación rígida y elaborada externamente. La asignatura se enfoca en la adquisición de conceptos y reglas con una finalidad informativa, dando lugar a un aprendizaje memorístico. El proceso de aprendizaje es deductivo y el sentido de la interacción que se produce en el aula va en dirección profesor alumno, sin enfatizar en la argumentación por parte de los estudiantes. El profesor considera que el alumno debe trabajar de forma individual, sin participar ni directa ni indirectamente en el diseño didáctico, siendo su papel totalmente receptivo al dedicarse a escuchar, copiar y aceptar lo indicado por el docente, que es quien valida la información en el aula.

Caracteriza a aquellos profesores cuya forma de concebir el conocimiento matemático es racionalista y platónica: un saber objetivo, terminal, a-histórico y absoluto, que existe independientemente de quien lo aprende y que se considera superior a otras formas de conocimiento. Para estos profesores el conocimiento matemático constituye un cuerpo estático, que surge de los modelos deductivos de construcción 
del conocimiento.

El profesor que se aproxima a esta tendencia didáctica suele organizar la realidad y los conocimientos de forma acumulativa y aditiva, en la que aquella es entendida como una suma de sus componentes, sin que se reconozca habitualmente el carácter organizador de las relaciones (Porlán \& Rivero, 1998). Esta visión del mundo incide claramente en los otros niveles de organización del conocimiento profesional. Así, tiene también una idea acumulativa y fragmentaria del saber matemático, del currículo y del propio conocimiento escolar, por lo que suele entender las matemáticas como un conjunto formalista de temas inconexos (Oliva, 1995).

\subsubsection{Tendencia didáctica tecnológica}

Se caracteriza por la transmisión de los contenidos mediante la simulación de su proceso de construcción empleando estrategias expositivas, regida por una programación cerrada y lógica. La asignatura se orienta hacia la adquisición de conceptos y reglas e interesa el desarrollo de procesos lógicos y su reproductibilidad. El profesor considera que su finalidad a más de informativa es utilitaria, ya sea dentro de la propia matemática, en otras ciencias o en la vida cotidiana. Se produce un aprendizaje memorístico, con un proceso que, aunque tiene características inductivas termina siendo deductivo. El sentido de la interacción va en dirección profesor-alumno, pudiendo el estudiante explicitar con las palabras del profesor la comprensión del contenido (Climent, 2005).

El trabajo del alumno debe darse en forma individual, siendo su papel el de reproducir el proceso lógico transmitido por el profesor, que es quien valida la información en el aula a través de interrogantes a los alumnos. Se considera al estudiante como el principal responsable de los resultados del aprendizaje, siempre que el contexto elegido por el profesor sea adecuado. Al enfrentarse a cada una de sus tareas educativas, el alumno imita el estilo cognitivo del profesor, pues reproduce el proceso lógico mostrado por éste cuando transmite los contenidos de aprendizaje por procesos tecnológicos mediante exposición debido a su caracterización como técnico del contenido (Lima, 2014). 


\subsubsection{Tendencia didáctica espontaneista}

Se caracteriza por el diseño de actividades de manipulación de modelos, a través de los cuales se espera que se produzca, eventualmente, un conocimiento no organizado. La programación es un documento vivo que, por basarse en los intereses que, en cada momento, manifiestan los alumnos y en la negociación con ellos, no dispone de una organización inicial. No interesan tanto los conceptos como los procedimientos $v$ el fomento de actitudes positivas hacia el trabajo escolar. La clase posee un carácter formativo, con objeto de servir de instrumento para un cambio actitudinal del alumno.

Erofesor piensa que se aprende cuando el objeto de aprendizaje, que surge aleatoriamente del contexto, posee un significado para el alumno, produciéndose dicho aprendizaje, de manera espontánea cuando el alumno está inmerso en situaciones que propician el descubrimiento (Climent, 2005; Lima, 2014).

En relación con los aspectos ideológicos, en los profesores de la tendencia espontaneista, conciben el aprendizaje como la asimilación de significados académicos preestablecidos, bien aportando nuevos contenidos, bien dándoles un mayor grado de formalización, tratando de eliminar los errores de los alumnos en este proceso. Tienen también cierta preocupación por conseguir que los estudiantes 'construyan' sus aprendizajes desde los 'conocimientos previos' y les den significado.

\subsubsection{Tendencia didáctica Investigativa}

Se relaciona con un docente de perfil profesional coherente con la idea de profesorinvestigador. El profesor tiene una visión del mundo basada en una concepción compleja y relativa de la realidad, con un planteamiento ideológico crítico y una perspectiva constructivista, dinámica y evolutiva del conocimiento, visión que se concreta en:

Una concepción sistémica de la realidad, en general, y del medio escolar en particular.

Un enfoque relativista y descentrado del conocimiento matemático. 
Una consideración de los cambios, también de los cambios escolares, como procesos evolutivos e irreversibles.

El reconocimiento del carácter abierto y complejo de los problemas educativos y de la investigación como estrategia adecuada para el tratamiento de estos.

Una posición ideológica que pretende generar autonomía en profesores y alumnos.

Una concepción de las relaciones e intercambios basada en la tolerancia, el relativismo y el respeto crítico a la diversidad.

En esta tendencia, el conocimiento escolar se entiende como un conocimiento epistemológicamente diferenciado, resultado de la reelaboración e integración de conocimientos diversos, que pretende hacer más complejo el conocimiento cotidiano de los alumnos (Climent, 2005; Lima, 2014).

Una concepción dinámica y falible de la actividad matemática, tiene fuertes implicaciones en las ideas sobre las estrategias y habilidades que los estudiantes necesitan para aprender y los tipos y características de las actividades en los que, tanto los estudiantes como el profesor, deberían comprometerse durante las interacciones en el aula. Se entiende el aprendizaje de los alumnos como el proceso de desarrollar una 'disposición matemática' o un 'punto de vista matemático' (Shoenfeld, 2000b), así como adquirir conocimiento matemático y herramientas con las que trabajar y construir conocimiento (Henningsen \& Stein, 1997).

Por lo tanto, aprender matemáticas es, simultáneamente, una activa construcción de comprensión individual y social de la materia. La gestión en la clase es un constante cuestionamiento dirigido y basado en actividades que implican los cómo y los por qué de los conceptos matemáticos y los procesos (Artzt, 1999). Los profesores son facilitadores del aprendizaje de los estudiantes y el clima de clase está en consonancia con la orientación de las ideas actuales sobre la reforma de las matemáticas escolares (NCTM, 2000; Ferreira, 2004).

Tener una disposición matemática se caracteriza por aspectos tales como la búsqueda y exploración de patrones para comprender las estructuras matemáticas y las relaciones subyacentes, usar los recursos disponibles efectiva y apropiadamente para formular y 
resolver problemas, dar sentido a las ideas matemáticas, pensando y razonando de modo flexible: conjeturando, generalizando, justificando y comunicando las propias ideas matemáticas, también decidiendo si los resultados matemáticos son razonables (Shoenfeld, 1989). Estas actividades tienen mucho en común con los procesos de razonamiento propuestos como características de un nivel alto de pensamiento en una variedad de dominios académicos (Resnick, 1987). Todo ello en consonancia con los aspectos reseñados en la tendencia investigativa.

Para promover un aprendizaje matemático de esas características, el proceso de enseñanza se ha de apoyar en procesos de investigación escolar, concibiendo el aula y la escuela como sistemas complejos y singulares. En esta tendencia el profesor pretende el desarrollo global de la persona, en el plano individual y social, así como una mejor comprensión del mundo y una participación ética, activa y solidaria en la gestión de los problemas socio ambientales (Porlán \& Rivero, 1998). 
La tabla 2.01 resume elementos caracterizadores sobre el conocimiento escolar, metodología y evaluación de las tendencias didácticas:

\begin{tabular}{|c|c|c|c|c|}
\hline & $\begin{array}{c}\text { TENDENCIA } \\
\text { TRADICIONAL }\end{array}$ & $\begin{array}{c}\text { TENDENCIA } \\
\text { TECNOLÓGICA }\end{array}$ & $\begin{array}{c}\text { TENDENCIA } \\
\text { ESPONTANEISTA }\end{array}$ & $\begin{array}{c}\text { TENDENCIA } \\
\text { INVESTIGATIVA }\end{array}$ \\
\hline $\begin{array}{c}\text { CONOCIMIENTO } \\
\text { ESCOLAR }\end{array}$ & $\begin{array}{lr}\text { Simplificación } & \text { del } \\
\text { conocimiento matemático } \\
\text { disciplinar. Predominio de } \\
\text { terminología y } \\
\text { estándar, sin significatividad } \\
\text { para los alumnos y } \\
\text { procedimientos algorítmicos } \\
\text { repetitivos. }\end{array}$ & $\begin{array}{l}\text { Saberes disciplinares } \\
\text { actualizados, aunque se } \\
\text { pueden incorporar algunos } \\
\text { conocimientos no } \\
\text { disciplinares. Predominio } \\
\text { de procedimientos, tales } \\
\text { como algoritmos, destrezas, } \\
\text { razonamientos, etc }\end{array}$ & $\begin{array}{l}\text { Cierta improvisación. } \\
\text { Relevancia de los intereses } \\
\text { de los alumnos. Interés por } \\
\text { los contenidos matemáticos } \\
\text { presentes en la realidad } \\
\text { inmediata. Predominio de } \\
\text { procedimientos variados y } \\
\text { actitudes }\end{array}$ & $\begin{array}{l}\text { Conocimiento 'escolar', que } \\
\text { integra diversos referentes: } \\
\text { disciplinares, cotidianos, } \\
\text { problemática } \\
\text { ambiental, conocimiento } \\
\text { metadisciplinar. } \\
\text { de lntegración } \\
\text { procedimental y actitudinal. }\end{array}$ \\
\hline METODOLOGÍA & $\begin{array}{l}\text { basada en la transmisión del } \\
\text { profesor. } \\
\text { Actividades de aplicación } \\
\text { simple, directa e inmediata } \\
\text { de los contenidos expuestos } \\
\text { por el profesor y ejercicios } \\
\text { de repaso, sacados } \\
\text { principalmente del libro de } \\
\text { texto. }\end{array}$ & $\begin{array}{l}\text { Metodología vinculada a los } \\
\text { métodos del } \\
\text { área. Actividades de } \\
\text { distintos tipos. Secuencia } \\
\text { de actividades cerrada y } \\
\text { rígida, que sigue la lógica de } \\
\text { la materia. }\end{array}$ & $\begin{array}{l}\text { 'descubrimiento } \\
\text { espontáneo' por parte del } \\
\text { alumno. Actividades de } \\
\text { carácter abierto y flexible y } \\
\text { uso de recursos didácticos } \\
\text { que puedan favorecer la } \\
\text { motivación de los } \\
\text { alumnos. Secuencia de } \\
\text { actividades abierta y } \\
\text { flexible. }\end{array}$ & $\begin{array}{l}\text { Las actividades son de } \\
\text { diversos tipos, con varios } \\
\text { niveles de formulación, que } \\
\text { admiten diversas } \\
\text { estrategias de resolución o } \\
\text { soluciones múltiples. Uso } \\
\text { de recursos didácticos que } \\
\text { favorecen la motivación y el } \\
\text { aprendizaje de los alumnos. }\end{array}$ \\
\hline
\end{tabular}




\begin{tabular}{|c|c|c|c|c|}
\hline EVALUACIÓN & $\begin{array}{l}\text { Para calificar. } \\
\text { Centrada en 'reproducir' los } \\
\text { contenidos. } \\
\text { Atiende, sobre todo al } \\
\text { producto. } \\
\text { Realizada por el profesor al } \\
\text { final del proceso mediante } \\
\text { exámenes. }\end{array}$ & $\begin{array}{l}\text { Para calificar a los alumnos } \\
\text { y medir la consecución de } \\
\text { los objetivos prefijados. } \\
\text { Centrada en la medición } \\
\text { detallada de los } \\
\text { aprendizajes. } \\
\text { Atiende al producto, } \\
\text { intentando medir la } \\
\text { consecución de los } \\
\text { objetivos fijados. } \\
\text { Realizada por el profesor } \\
\text { y/o los alumnos al inicio y } \\
\text { final del proceso mediante } \\
\text { exámenes y plantillas } \\
\text { específicas de observación. }\end{array}$ & $\begin{array}{l}\text { Para comprobar el interés } \\
\text { de los alumnos y mejorar la } \\
\text { dinámica del aula. } \\
\text { Centrada en los } \\
\text { procedimientos y, en parte, } \\
\text { en las actitudes. } \\
\text { Atiende al proceso, aunque } \\
\text { no de forma sistemática. } \\
\text { Realizada periódicamente } \\
\text { por el profesor y los } \\
\text { alumnos mediante la } \\
\text { observación directa y } \\
\text { asistemática de la dinámica } \\
\text { de trabajo. }\end{array}$ & $\begin{array}{l}\text { Para valorar la evolución de } \\
\text { las ideas de los alumnos y } \\
\text { mejorar los procesos de } \\
\text { enseñanza y de } \\
\text { aprendizaje. } \\
\text { Centrada en el seguimiento } \\
\text { de la evolución del } \\
\text { conocimiento del alumno, la } \\
\text { actuación del profesor y el } \\
\text { desarrollo del proyecto. } \\
\text { Atiende con sistematización } \\
\text { a los procesos. forma } \\
\text { Realizada de de } \\
\text { continua por el profesor y } \\
\text { los alumnos con diversidad } \\
\text { de instrumentos de } \\
\text { seguimiento }\end{array}$ \\
\hline
\end{tabular}

Tabla 2.01. Elementos caracterizadores sobre el conocimiento escolar, metodología y evaluación de las tendencias didácticas. Elaboración: propia 
El análisis de la práctica del profesor de matemáticas implica hacer explícito el modelo de aprendizaje y de enseñanza que subyace en ésta (Gavilán-Izquierdo, García-Blanco \& Llinares, 2007), la cual se diferencia si la enseñanza y el aprendizaje se centra en el aprendiz, el contenido o el aula (Kuhs \& Ball,1986):

Centrado en el aprendiz, en las construcciones personales del conocimiento matemático por parte de los estudiantes, mediante la implicación activa en hacer matemáticas. El papel del profesor es de facilitador del aprendizaje de los alumnos. Estaría relacionado con una visión falible de las matemáticas, de resolución de problemas, cercana a la tendencia investigadora.

Centrado en el contenido, que refleja a su vez dos formas similares

Una cuando el énfasis se hace en la comprensión conceptual, focalizado en las relaciones lógicas entre las ideas matemáticas. Estaría relacionado con una visión absolutista y platónica de las matemáticas, cercana a la tendencia tradicional.

Otra, en la que el énfasis está más centrado en los resultados, focalizándose en las reglas y en el dominio de los procedimientos. Estaría también relacionado con una visión instrumentalista de las matemáticas, cercana también a la tendencia tradicional y, en parte, a la tecnológica.

Centrado en el aula que enfatiza la actividad de la clase en dos sentidos:

El primero considera el aula eficientemente organizada, donde el profesor presenta claramente la materia y los alumnos practican individualmente. Estaría relacionado con la tendencia tecnológica y la tradicional.

El segundo considera al aula como el espacio donde el profesor presenta las actividades, no muy organizadas y los alumnos practican fundamentalmente en grupos. Estaría relacionado con la tendencia espontaneista. 
Lo anterior se puede resumir en la figura 2.02:

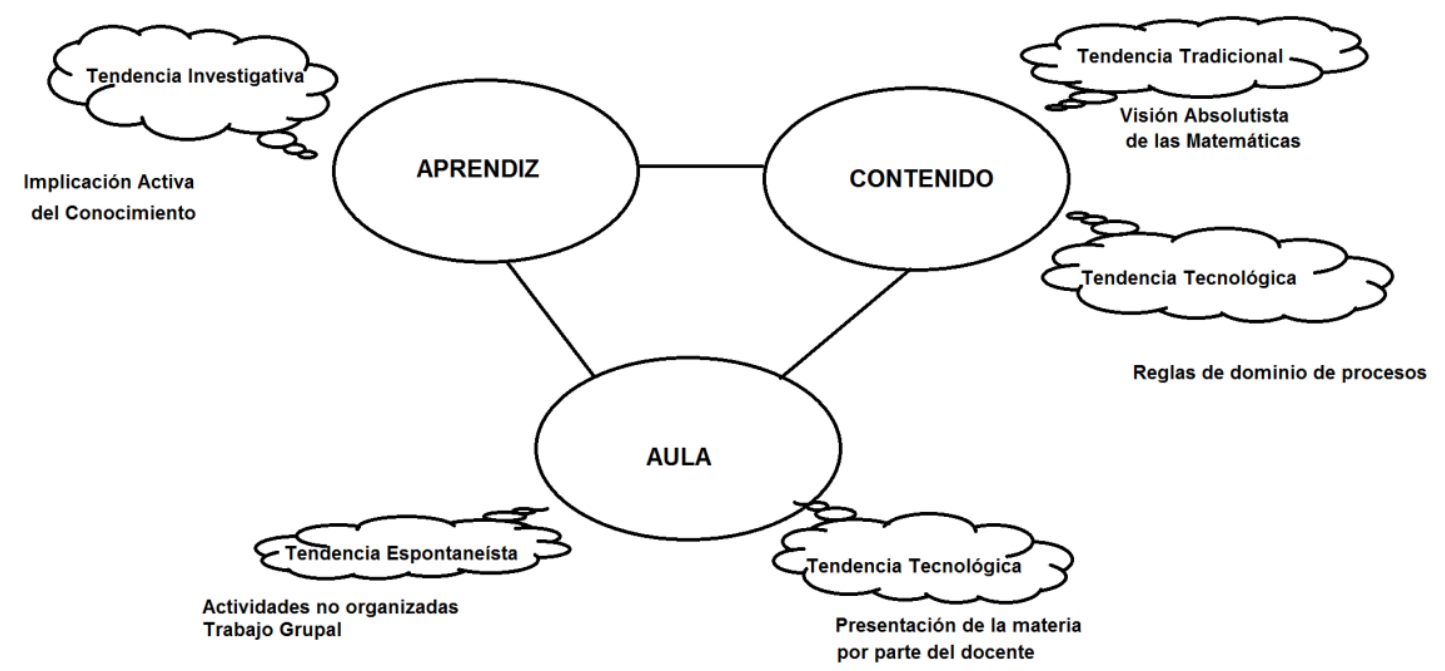

Figura 2.02. Perspectivas de Análisis de concepciones de la enseñanza y el aprendizaje. Fuente: propia

Abordado el concepto acerca de las concepciones, se procede a caracterizar el conocimiento que un profesor tiene para el ejercicio de su actividad profesional. 


\section{CONOCIMIENTO DEL PROFESOR DE MATEMÁTICAS}

Las investigaciones sobre la práctica del profesor han considerado a lo largo de varias décadas el conocimiento que éste debe tener al momento de su actuación como profesional. En este sentido, se han identificado terminologías para referirse al mismo: conocimiento del profesor, conocimiento práctico del profesor, conocimiento profesional del profesor, conocimiento especializado, aunque el fondo de sus marcos teóricos pueda diferir entre sí.

El estudio y el análisis del conocimiento que necesita el profesor supone una profundización en y desde la matemática, por lo que requiere estudiar los objetos matemáticos implicados, sus raíces epistemológicas, los fenómenos de los que emergen, sus relaciones con otros objetos matemáticos, la estructura que estas relaciones permiten construir, o la forma en que estos entes matemáticos se construyen. Referirse a dicho conocimiento como conocimiento del profesor puede ser considerado como un elemento amplio: el profesor tiene otros conocimientos que no necesariamente involucra con su actividad docente que hasta pueden ser contradictorios y no aportar al ejercicio de su profesión. El término conocimiento práctico lo puede limitar a su actividad en el aula de clase obviando elementos que en el desarrollo de la actividad no necesariamente provienen de lo práctico tal como la teoría o las propias concepciones. El término conocimiento profesional no permite colegir una significación como la que se pretende asignar (Guacaneme, 2006) dado las acepciones que tienen los términos profesional y profesión, aunque se reconoce la intención de conllevar al entendimiento de la actividad del profesor como una profesión que va más allá de la condición de oficio, labor técnica o tecnológica, arte, concibiendo al profesor como un profesional y no como un operario, técnico, artista o artesano. Así, el conocimiento requerido para desempeñarse en la profesión docente compila saberes académicos que provienen de diferentes disciplinas que se alimentan por medio de la investigación, se retroalimenta de la reflexión y se condiciona a partir de especificidades sociales, políticas y culturales.

En este sentido, el análisis de la práctica del profesor no se puede realizar sin una referencia a un conocimiento matemático (abordado a partir del contexto específico en el que se emplea) y a los procesos de enseñanza y aprendizaje de dicho conocimiento, otorgándole un carácter especializado y, por tanto, específico de la labor del profesor de matemáticas. De manera análoga que las matemáticas están constituidas por diversas ramas o especializaciones, el conocimiento matemático del profesor y la tarea que supone su identificación y análisis, pertenecerían a otro tipo de aplicación de las 
matemáticas en los ámbitos educativos (Azcárate, 2001). El análisis del conocimiento que necesita el profesor supone una profundización en y desde las matemáticas y las matemáticas escolares, por lo que requiere profundizar en los objetos matemáticos implicados, sus raíces epistemológicas, los fenómenos de los que emergen, sus relaciones con otros objetos matemáticos, la estructura que estas relaciones permiten construir, o la forma en que estos entes matemáticos se construyen, los errores y los obstáculos en su enseñanza y aprendizaje.

El enfoque del conocimiento especializado del profesor de matemáticas se centra en la aplicación específica en los procesos de enseñanza y aprendizaje, es decir, en cada momento en que interaccionan las matemáticas, los alumnos y el profesor. Ciertamente, otros factores influyen en esta interacción, como la cultura de la escuela, su entorno social, las normas del aula, entre otros. No obstante, interesan primordialmente el conocimiento del profesor sobre los temas que ha de enseñar, sobre las relaciones entre objetos matemáticos, o sobre la forma de hacer matemáticas, así como sobre estrategias y recursos para enseñar matemáticas, sobre las dificultades de aprendizaje de los alumnos o sus errores habituales, y sobre lo que puede esperarse que aprendan los alumnos en un nivel determinado.

Las diferentes investigaciones sobre el conocimiento especializado del profesor han mostrado que poseer un conocimiento adecuado del contenido no siempre se corresponde con la adecuada capacidad para enseñarlo (Azcárate, 2001; Ball \& Bass, 2009; Shulman, 1986), pero si una buena disposición para lograr dicha habilidad (Hill, Rowan \& Ball, 2005). Esto significa que, además de requerimientos de carácter psicológicos y pedagógicos, cuya utilidad no son el foco principal de esta investigación, los profesores adquieren un conocimiento de naturaleza diferente del contenido a enseñar. Ball, Thames \& Phelps (2008) realizaron un aporte relevante en este sentido, considerando dentro del dominio del conocimiento matemático un subdominio que se denomina Conocimiento Especializado del Contenido, diferente del Conocimiento Común que cualquier persona matemáticamente instruida puede poseer. El equipo de Ball (Ball, Thames \& Phelps, 2008; Ball \& Bass, 2009; Ball, Ben-Peretz \& Cohen, 2014) comenta que el Conocimiento Común hace parte de la cultura general de quien ha aprendido matemáticas, a diferencia del Conocimiento Especializado del Contenido que se refiere no solamente a dicha cultura general, sino que abarca otras situaciones como, por ejemplo, el conocer diferentes representaciones de un concepto matemático, las relaciones con matemáticas aplicadas y el tratamiento con la práctica matemática. 


\subsection{Conocimiento del profesor, conocimiento didáctico del contenido, conocimiento matemático para la enseñanza}

Al identificar y describir el conocimiento del profesor parece necesario diferenciar elementos que ayuden a precisar el contenido además de la organización y la estructura de este. Los elementos se pueden identificar como componentes del conocimiento, aunque algunos autores, para evitar confusiones, se refieren a ellos como tipos - del conocimiento dominante - y fuentes - del conocimiento deseable - (Porlán \& Rivero, 1998, Ball, Ben-Peretz \& Cohen, 2014).

A lo largo del tiempo se han considerado algunos términos para referirse al conocimiento que debe tener el profesor de matemáticas integrando el conocimiento disciplinar y el didáctico, diferenciando el Conocimiento de las Matemáticas y el Conocimiento Didáctico del Contenido. Shulman (1986) plantea que se debe enfocar el conocimiento necesario para enseñar la disciplina específica a través del concepto Conocimiento Didáctico del Contenido comprendiéndolo como un tipo de conocimiento del contenido que incorpora los aspectos el contenido más relacionados con la enseñanza (Shulman, 1986); no obstante, éste tipo de conocimiento no se puede identificar fácilmente en la práctica.

Consecuencia de lo anterior, Ball, Thames \& Phelps (2008) proponen organizar y operativizar el conocimiento del profesor de matemáticas por medio de investigaciones sobre la práctica las cuales compilan en lo que denominan Conocimiento Matemático para la Enseñanza, representando el conocimiento matemático, habilidades, hábitos de la mente (estrategias para cálculos, uso de propiedades de manera instantánea, estrategias para la solución de situaciones, entre otros), sensibilidad y otros elementos requeridos en el trabajo concreto de enseñar y en las tareas especializadas en las que los profesores necesitan conocer y usar las matemáticas.

En este modelo, el conocimiento de las matemáticas está compuesto por el conocimiento común del contenido referido al que se supone cualquier adulto culto posee (Ball, Thames \& Phelps, 2008), el conocimiento especializado del contenido que tiene sentido para el profesor de matemáticas y el conocimiento en el horizonte matemático que permite interrelacionar contendidos a lo largo del currículo y valorar y reconocer la validez de los razonamientos y resoluciones de los estudiantes ${ }^{1}$.

\footnotetext{
${ }^{1}$ Ball, Thames \& Phelps (2008) establecen que el Conocimiento del Horizonte Matemático es un tipo de conocimiento que se refiere a la conciencia del profesor sobre los conocimientos
} 
conocimiento especializado de contenido es un contenido estrictamente matemático que el profesor necesita y usa que no es necesariamente requerido por otros profesionales con formación matemática (Ball, Thames \& Phelps, 2008; Bass, Didis, Erbas, Cetinkaya, Cakiroglu \& Alacaci, 2013) ni tampoco es un subconjunto de lo que los matemáticos conocen.

El conocimiento didáctico del contenido está compuesto por el conocimiento del contenido y de cómo los estudiantes se apropian de él. Permite comprender el contenido desde la perspectiva del aprendizaje y la enseñanza e implica argumentar por qué un determinado material, recurso o representación es apropiada para explicar un determinado concepto.

\subsection{Conocimiento especializado del profesor}

El modelo del conocimiento matemático para la enseñanza aporta elementos a la conceptualización del conocimiento del profesor: redefine las ideas de las investigaciones de Shulman sobre el conocimiento didáctico del contenido, la idea del conocimiento del profesor como exclusivo y la visión transversal de las matemáticas escolares (Shulman \& Grossman, 1988; Wilson, Shulman \& Richert, 1987; Shulman, 1987). Asimismo, permite discutir sobre cuatro elementos: el conocimiento en el horizonte matemático, la manera en que se especializa el conocimiento del contenido, posible solapamiento de subdominios entre el conocimiento del contenido y el conocimiento didáctico del contenido y la falta de matematización del modelo.

La figura 3.01 presenta la variación acerca de la idea acerca del conocimiento del profesor que se detalló en los párrafos anteriores:

matemáticos previos y futuros presentes en el currículo. Esto implica que el profesor adquiera una visión global de la educación matemática de los estudiantes para ser empleada al enseñar matemáticas en el aula. 


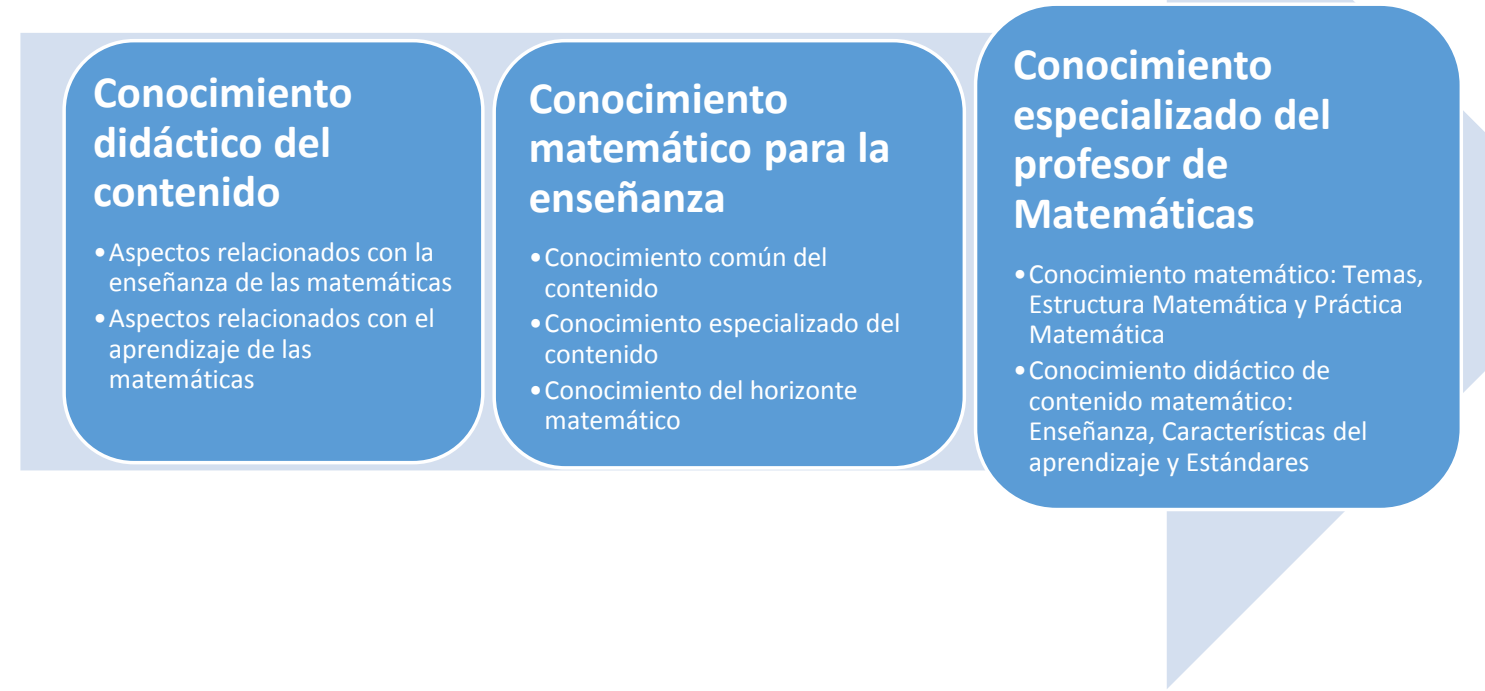

Figura 3.01. Modificaciones sobre las teorías acerca del Conocimiento de Profesor. Fuente: propia

Respecto del conocimiento en el horizonte matemático, Ball \& Bass (2009) afirman que éste incluye el conocimiento de ideas y estructuras de las matemáticas y las conexiones entre diferentes entes tales como conceptos y propiedades. Dichas conexiones se manifiestan de dos maneras: intraconceptuales e interconceptuales:

Las conexiones intraconceptuales establecen la proximidad con un concepto; determinan la equivalencia entre caracterizaciones o prueban la equivalencia entre dos definiciones, distinguiendo entre una condición suficiente de una necesaria.

Las conexiones interconceptuales ocurren cuando los conectores son tratados como ideas matemáticas que permiten vincular diferentes representaciones del mismo concepto o diferentes conceptos que los estudiantes afrontan en el mismo momento; o temporales cuando se dan entre conocimientos previos y futuros. El conocimiento de las ideas y estructuras matemáticas y las conexiones entre entes influyen en el conocimiento del profesor sobre los conocimientos previos y futuros de los estudiantes. Estas conexiones posibilitan estudiar otras propiedades de un concepto o procedimiento, o aplicar el conocimiento aprendido a situaciones nuevas o más complejas.

El conocimiento del horizonte matemático también vincula conocimiento de tipo sintáctico (Schwab, 1979), aspectos de la comunicación matemática, razonamiento y prueba, definiciones, relaciones, correspondencias y equivalencias. Resalta los valores 
de las matemáticas como el gusto por la coherencia de los argumentos y la precisión y cuidado en la consistencia del lenguaje matemático.

Acerca de la manera en la que se especializa el conocimiento de contenido, Ball \& Bass (2009) caracterizan el conocimiento común del contenido como aquel conocimiento que puede poseer una persona instruida. En este sentido, al momento de decidir si un episodio de información, entendido como el momento de la observación que brinda información sobre el conocimiento de horizonte matemático, aporta evidencias sobre conocimiento común del contenido, se debe comparar con un conocimiento hipotético de alguien que pueda tener ciertos conocimientos deseables obligando a establecer referentes y discusiones de lo que es o no común (Ball, Ben-Peretz, \& Cohen, 2014).

El conocimiento de contendido y el conocimiento didáctico del contenido se pueden solapar cuando el profesor necesita conocer de dónde vienen los errores y los canales en los que se lleva a cabo el razonamiento de los estudiantes. Este estudio es exclusivo del profesor de matemáticas y no se asocia con otras profesiones; sin embargo, el estudio de las dificultades y el momento en el que se cometen errores se asocia con el conocimiento del contenido y los estudiantes, a diferencia del estudio de la procedencia matemática del error la cual está situada en el conocimiento especializado del contenido.

El modelo de Ball (1990) es un refinamiento de las teorías de Shulman (1986) y no ha sido matematizado. A excepción del conocimiento en el horizonte matemático, los subdominios del conocimiento matemático para la enseñanza no son explícitos al contenido matemático o a las matemáticas aplicadas, comprendiendo su aplicación a la enseñanza.

Con base a esos cuatro puntos de discusión, Muñoz-Catalán, Contreras, Carrillo, Rojas, Montes \& Climent, (2015), consideran que la especialización del profesor deriva de su profesión (profesor de matemáticas) en el que el ejercicio de la enseñanza es un elemento definitorio y que el modelo de enseñanza de las matemáticas debe estar conceptualizado en el mismo hecho que (este modelo) se usa para comprender el conocimiento que el profesor de matemáticas usa para enseñar matemáticas. El conocimiento del profesor, en la forma como lo que sabe y sabe hacer respecto a la enseñanza de las matemáticas es una red de conocimientos y destrezas con diferentes niveles de asentamiento, integración, accesibilidad o activación en la práctica (Carrillo \& Otros, 2018; Climent \& Vasco, 2018). 


\subsection{Naturaleza del Conocimiento Especializado}

El conocimiento especializado es situado y contextualizado, es decir, está ligado a los contextos propios afectando la forma en que se genera y se conserva, de la manera que el contexto donde se desarrolla el conocimiento entra a formar parte de este (García, 1997). Aplicar el calificativo de 'situado' al conocimiento del profesor implica considerar la comunidad educativa, el entorno donde desarrolla el profesor su labor (i.e. una comunidad de práctica), donde la actividad de sus miembros, incluyendo los otros profesores, integra su aprendizaje. Así, el aprendizaje y el conocimiento del profesor se contemplan como procesos participados y compartidos socialmente por los miembros de la comunidad, y entonces, aprender y conocer serían vistos como partes de la práctica social.

El aprendizaje situado en el conocimiento del profesor toma relevancia en la actividad por medio de la cual se aprende a enseñar, haciendo parte de la misma y caracterizando la forma en que se aprende (Llinares \& Krainer, 2006; Llinares \& Valls, 2009), y le da, además otros valores que dependen de su ubicación y contexto: social e individual, personal, dinámico, integrado y complejo, parcialmente tácito, práctico y crítico:

Social e individual: Además del contexto también es necesario considerar al profesor como entidad autónoma en cuanto a sus decisiones, y por tanto, en cuanto al conocimiento que del profesor pone en juego al tomar dichas decisiones. Este conocimiento, así como el proceso de toma de decisiones se basa en múltiples factores, desde las propias concepciones y creencias con sus raíces sociales (Ponte, 2002; Ponte, 2012), como en el contexto en el que el propio docente desarrolla su actividad.

Las visiones del aprendizaje del profesor resaltan el carácter social del mismo; el aprendizaje situado no solamente lo está en espacio y tiempo de la práctica, es parte integral de toda actividad, genera un contraste con la teoría que afirma que la práctica está incluida en el proceso del aprendizaje y la teoría que asegura que el aprendizaje es un aspecto integral de la práctica en el sentido histórico - generativo (Matos, 2000).

Como consecuencia de lo anterior, el conocimiento especializado del profesor es social e individual; las acciones realizadas se pueden interpretar en un marco de concepciones existentes y posibilita el dar sentido a las situaciones y elegir alternativas. De esta manera, el conocimiento del profesor es propio del individuo y diferente del de otros, 
puesto que depende de sus concepciones, valores y actitudes (Blanco, Mellado \& Ruíz, 1995).

Personal: Climent (2005) y Climent \& Vasco (2018) proponen que el conocimiento profesional del profesor es diferente del de otro profesor, ya que depende de sus concepciones, valores y actitudes y recoge su experiencia, no solo como profesor, sino también todo el conjunto de experiencias que convierte al profesor en un individuo dentro de la sociedad en que vive. Esto pone el énfasis en el elevado margen de individualización que posee, con las características propias que le imprime el profesor.

Dinámico: No tiene sentido pensar en un profesor cuyo conocimiento sea invariante al tiempo, a las interacciones con sus alumnos y con otros profesores, o al cambio de contexto de enseñanza derivado del cambio de legislación educativa. Existe como entidad en un mundo en constante cambio, por lo que ha de adaptarse, y se adapta, a las circunstancias que le rodean para desarrollar su profesión lo más adecuadamente posible, en base a su sistema de conocimiento y concepciones (Climent, 2015; Climent \& Vasco, 2018).

Integrado y complejo: Es difícil pensar en un profesor que posea una jerarquización consciente de sus conocimientos con base a su origen o naturaleza, por lo que es natural afirmar que dicho conocimiento es integrado. Dada la gran cantidad de fuentes, contextos, y tipologías que puede tener dicho conocimiento, se afirma que es complejo. Sin embargo, es necesario aclarar que esto no entra en contradicción con el esfuerzo analítico que se intenta hacer desde el ámbito de la investigación por conceptualizar modelos que permitan comprender al profesor en mayor profundidad, a través de los diferentes modelos propuestos, ya que estos modelos pretenden determinar los diferentes tipos de conocimiento, o los contextos en los que se activan, teniendo siempre presente que el esfuerzo analítico es propio de la labor del investigador, y no se pretende llevar al profesor a una parcelación de su propio conocimiento (Climent, 2015; Climent \& Vasco, 2018).

Parcialmente tácito: Siguiendo a Schön (1983), los profesionales normalmente saben más de lo que alcanzan a decir y, por tanto, exhiben un conocimiento desde la práctica, esto lleva a reflexionar sobre la consciencia del profesor de su propio conocimiento. Un profesor no necesariamente es consciente del conocimiento que usa en un determinado momento; sin embargo, le lleva a tomar decisiones que, de no poseerlo, hubieran sido diferentes o simplemente no puede tomar. 
Práctico: El conocimiento del profesor es práctico en tanto es un conocimiento que usa en su actividad profesional (Schoenfeld, 2010). De especial relevancia es la reflexión de Ponte (1994), que entiende que el conocimiento profesional es conocimiento en acción, basado sobre conocimiento teórico que se lleva al ejercicio profesional (Climent 2005).

Crítico: Finalmente, aceptando la afirmación de Ponte, según la que el conocimiento del profesor está basado en la reflexión, la cual conlleva un proceso de autocrítica, en la que el propio profesor valora la efectividad de su forma de desarrollar su propia profesión, en pro de una transformación (Ponte, 2012).

Esta caracterización aporta diferentes aspectos que se pueden considerar en las fuentes del conocimiento especializado que se describen a continuación.

\subsection{Fuentes del Conocimiento Especializado}

El modelo que se adapta para esta investigación corresponde al planteado por el equipo de Muñoz-Catalán, Contreras, Carrillo, Rojas, Montes \& Climent (2015); (Carrillo \& Otros, 2018). En este apartado se describen las fuentes significativas del conocimiento especializado y que configuran sus diferentes componentes.

\subsubsection{Metadisciplinares}

El conocimiento metadisciplinar ofrece una determinada concepción epistemológica acerca de las matemáticas escolares. Planteamientos en torno al conocimiento matemático, lo conciben como un conocimiento relativo y evolutivo y no como un conocimiento absoluto, estático y aditivo, que conllevaría una visión finalista y uniforme para el tratamiento de los contenidos en el aula (Azcárate, 2001; Porlán, Martín del Pozo, Rivero, Harres, Azcaráte \& Camara, 2010). Resulta relevante contemplar el conocimiento de la historia de las matemáticas, centrada en los problemas y los obstáculos epistemológicos que originaron la construcción de los conocimientos matemáticos y en la comprensión del contexto social, histórico e ideológico donde se insertó cada problemática, sin lo cual dichos conocimientos aparecen como arbitrarios.

El conocimiento metadisciplinar constituye una cosmovisión que permite organizar la progresión del conocimiento profesional en diferentes niveles de formulación (Grupo Investigación en la Escuela, 1991). Los conocimientos metadisciplinares son 
conocimientos profesionales en el máximo nivel de generalidad, orientadores de la transformación del conocimiento profesional ya que la reflexión e interacción con las informaciones procedentes de estas fuentes permiten que los docentes elaboren su propia cosmovisión educativa (Porlán, Martín del Pozo, Rivero, Harres, Azcaráte \& Camara, 2010). En este sentido, las decisiones adoptadas por los profesores son el reflejo de las formas de entender el conocimiento, sus relaciones y elaboración que promueven concepciones ideológicas y valores que se constituyen en su marco global de referencia.

El análisis del conocimiento metadisciplinar permite reflexionar sobre el 'para qué enseñar' (Porlán, Martín del Pozo, Rivero, Harres, Azcaráte \& Camara, 2010), es decir, ubica la intervención docente en una determinada concepción de la cultura escolar que va más allá de los conocimientos matemáticos, insertando las cuestiones educativas y los fines sociales de la escuela. También ayuda a establecer el marco de referencia del conocimiento escolar y a caracterizar e interpretar los aportes del conocimiento cotidiano y las expresiones de las ideas de los estudiantes.

\subsubsection{Disciplinares}

Se refiere a aquellos saberes relacionados con las matemáticas y con los procesos de enseñanza y de aprendizaje. Aunque son muchos los campos de estudio que pueden aportar al conocimiento profesional, se consideran tres de especial relevancia: el conocimiento matemático, el psicopedagógico y el que aporta la didáctica de las matemáticas.

En primer lugar, es necesario un conocimiento adecuado de la materia. Ello implica conocer sus marcos conceptuales generales y la estructura interna básica del área, lo cual tiene gran importancia para que el profesor elabore mejores criterios en la determinación de los conceptos, procedimientos y relaciones básicas de las matemáticas (Porlán, Martín del Pozo, Rivero, Harres, Azcaráte \& Camara, 2010).

Las conexiones matemáticas, entre las que se incluyen conexiones entre diferentes conceptos matemáticos, sus propiedades y representaciones, forman una parte esencial de la comprensión matemática (Blanco, 1991 a). No se trata solamente de considerar las conexiones antes mencionadas, es importante establecer conexiones entre las distintas ramas de las propias matemáticas, así como con otras ciencias y con el saber 
cotidiano, es decir, las matemáticas no pueden entenderse como un compartimento estático.

El conocimiento de la materia debe complementarse con el estudio sobre cómo se genera el conocimiento matemático y los obstáculos que han debido superarse. Lo anterior permite a los profesores elaborar un conocimiento de las matemáticas que les ayude a abordar con cierto rigor el problema de la selección, formulación y organización de los contenidos de enseñanza y adecuarlos a sus alumnos de modo que enriquezca sus aprendizajes previos y los haga más complejos, a partir de los problemas que éstos planteen.

Además es necesario introducir un tipo de conocimiento que supone cierta actitud científica, el cual consiste en el interés por profundizar en los conocimientos y en adquirir otros nuevos (Gil, 1993), ya que los cambios curriculares o las cuestiones que plantean los alumnos, someten repetidamente al profesor a una serie de situaciones para las que puede no poseer, de entrada, la formación científica requerida. Esta característica, inherente a la labor profesional, demanda una cierta predisposición a la investigación y a la realización de nuevos aprendizajes por parte de los profesores (Porlán, Martín del Pozo, Rivero, Harres, Azcaráte \& Camara, 2010).

El conocimiento de las matemáticas debe relacionarse también con el conocimiento que aportan las ciencias de la educación, fundamentalmente los conocimientos relacionados con el pensamiento y la conducta del profesor, la formación del profesor y su desarrollo profesional, la naturaleza de la profesión docente, el aprendizaje de los alumnos, las características del desarrollo de los adolescentes, la relación entre desarrollo conceptual y afectivo, la interacción y comunicación en el aula, la dinámica psicosocial en los contextos escolares, la organización del aula y del centro, entre otros.

Los aportes de las investigaciones en didáctica de las matemáticas, son empleados por el profesor para reinterpretar los conocimientos del área y explicar los procesos de enseñanza y aprendizaje y para proponer pautas concretas de diseño y desarrollo curricular, configurando un conocimiento matemático escolar distinto del conocimiento de las matemáticas (Azcárate \& Cardeñoso, 1994; Azcárate, 2001). Desde la perspectiva didáctica, cuando un profesor está frente a la práctica en el ámbito de la educación matemática, se ve tentado a reflexionar sobre el tratamiento del conocimiento escolar, entendiendo que éste debe ser algo más que una mera simplificación del conocimiento formal. Al tener fines y objetivos distintos que las propias matemáticas, 
necesita de otras formas diferentes de aprender que están más vinculadas al contexto y a los problemas de su entorno, que a problemas matemáticos con principio y fin en las propias matemáticas (Porlán, Martín del Pozo, Rivero, Harres, Azcaráte \& Camara, 2010). El profesor ha de conocer las matemáticas más allá de una mera adaptación del conocimiento formal al contexto, es decir, necesita un conocimiento de índole didácticomatemático cuya estructura y naturaleza dista mucho de ser la del conocimiento formal matemático y que se organiza en torno a la reflexión e interacción con problemas relevantes que surgen desde la propia enseñanza de las matemáticas.

Schoenfeld (2010), propone una visión diferente del profesor, no exclusivamente centrada en su conocimiento, en el que desarrolla una teorización (y posterior comprobación en la práctica) de aquellas componentes que caracterizan las fuentes de dicho conocimiento:

- Las metas, aquellos objetivos que el profesor se plantea, consciente o inconscientemente (Schoenfeld, 2012). Estas metas poseen múltiples características, según plantea el autor, en términos de cuan alcanzables son, de si necesita sub-metas, o del momento en el que pueden alcanzarse, considerando metas a corto, medio o largo plazo (Lampert, 2001).

- Los recursos, en los que se hace un especial hincapié en el conocimiento, tales como los hechos, entendidos como elementos de conocimiento aislado, que no necesariamente han de estar fundamentados; el conocimiento procedimental, relativo al cómo aplicar algoritmos, reglas, en general, formas estandarizadas de proceder, más o menos complejas; y el conocimiento conceptual, relativo al saber por qué y cómo las relaciones matemáticas establecidas son válidas o no.

El conocimiento especializado no resulta solo de la suma de lo que aportan todas estas fuentes, sino que, entrando éstos en interacción, las integran, reelaborándose y haciéndose más complejo. 


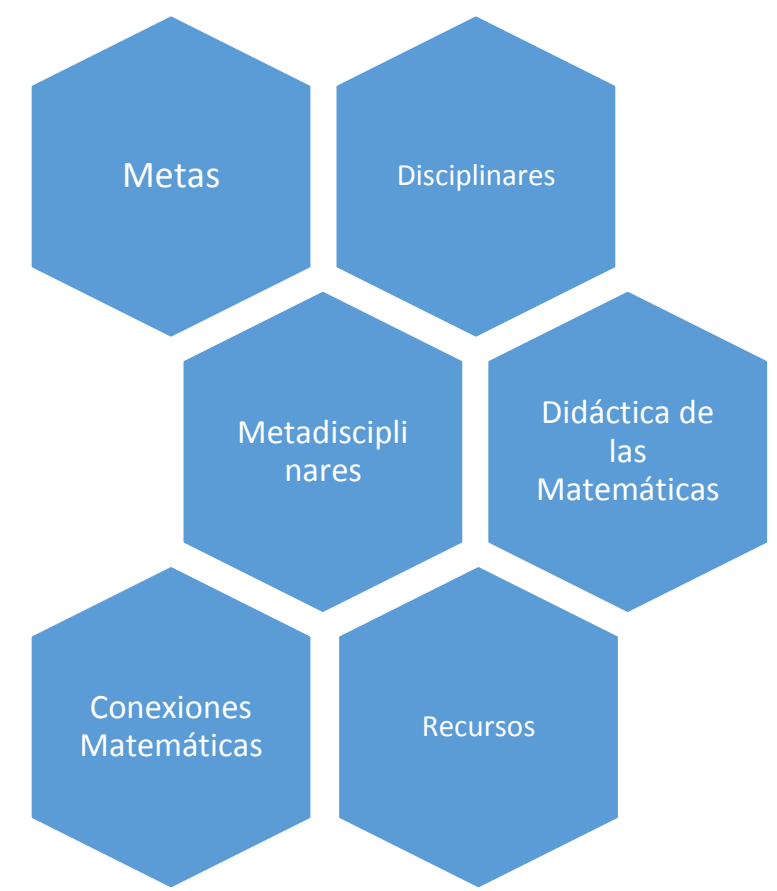

Figura 3.02. Fuentes del conocimiento especializado del profesor. Fuente: propia

\subsection{Componentes del Conocimiento Especializado del Profesor}

El Conocimiento Especializado del Profesor de Matemáticas puede ser analizado a partir de seis componentes (Muñoz-Catalán, Contreras, Carrillo, Rojas, Montes \& Climent, 2015; Carrillo \& Otros, 2018; Climent \& Vasco, 2018).

A- Las relativas al conocimiento matemático: conocimiento de los temas, de la estructura de la matemática y la práctica matemática.

B- Las relativas al conocimiento didáctico del contenido: conocimiento de la enseñanza de las matemáticas, de las características del aprendizaje de las matemáticas y de los estándares de aprendizaje de las matemáticas. 


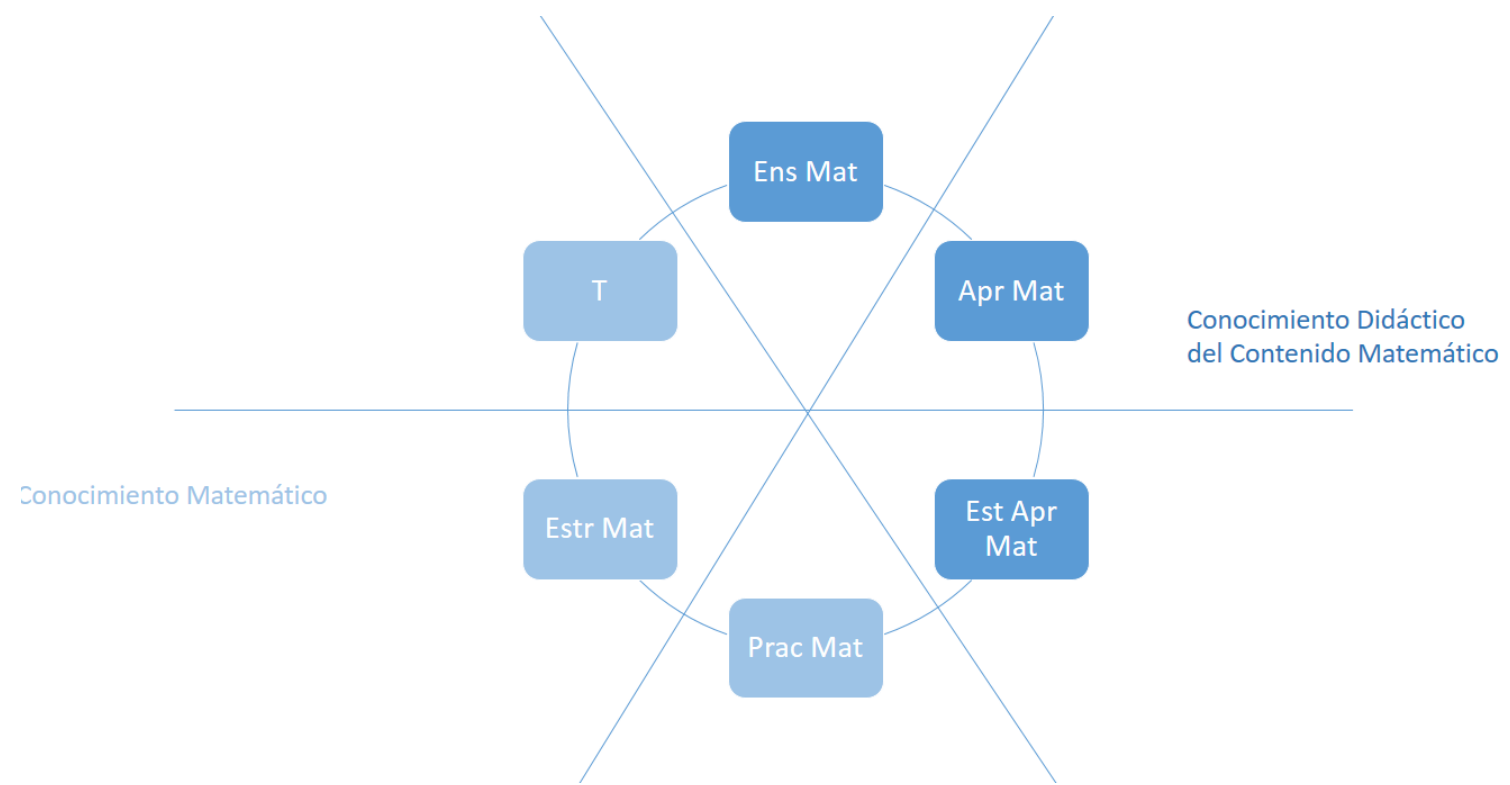

Figura 3.03. Componentes del conocimiento especializado del profesor. T: Temas. Estr Mat: Estructura de las Matemáticas. Prac Mat: Práctica Matemática. Ens Mat: Enseñanza de las Matemáticas. Apr Mat: Características del Aprendizaje de las Matemáticas. Est Apr Mat: Estándares del Aprendizaje de las Matemáticas. Fuente: Adaptación de: Muñoz-Catalán, Contreras, Carrillo, Rojas, Montes \& Climent (2015)

\subsubsection{Conocimiento de los temas}

Es un conocimiento del contenido escolar (se entiende que el profesor debe saber contenido más allá de lo que los estudiantes aprenden) e incluye aspectos de los conceptos que les permiten relacionarlos con contextos reales y aportar elementos epistemológicos ligados a las matemáticas que conllevan a la comprensión de diferentes significados que pueden atribuirse al contenido y los contextos en los que se sitúan. Este conocimiento no se limita al contenido objeto de enseñanza y de aprendizaje, va más allá del conocimiento de las matemáticas como disciplina, las matemáticas escolares, los fundamentos matemáticos, los procedimientos, estándares y formas de la representación de los diferentes temas.

Este conocimiento permite al profesor desenvolverse con el contenido que aborda en su práctica y le permite tener consciencia de los aspectos matemáticos que son indispensables y pueden surgir durante la explicación de una sesión, durante la fase de preparación de la clase, a la hora de seleccionar actividades, o en el momento en el que, después de la clase, decida evaluar el desarrollo de esta, así como su propia práctica. Por otro lado, permite responder a las demandas de conocimiento de sus alumnos cuando estos resuelven un problema por un algoritmo distinto del explicado en clase, o por alguna concatenación de razonamientos no "estándar"; este conocimiento permite hallar los razonamientos matemáticos que subyacen a dicho algoritmo, 0 reconocer la coherencia de los argumentos dados por los alumnos. 


\subsubsection{Conocimiento de la estructura matemática}

Esta componente integra relaciones con conceptos avanzados y conceptos elementales, permitiendo que el profesor comprenda las matemáticas escolares desde un punto de vista superior no solo en el contenido sino en la percepción de su organización (Muñoz-Catalán, Contreras, Carrillo, Rojas, Montes \& Climent, 2015; Carrillo \& Otros, 2018; Climent \& Vasco, 2018). Este conocimiento se puede interpretar como un sistema integrado de conexiones que le permita comprender y desarrollar conceptos avanzados desde perspectivas elementales y conceptos elementales mediante el tratamiento de visiones avanzadas.

De igual manera que en matemáticas existen propiedades locales, válidas en entornos de puntos, y propiedades globales, para las que se necesita tener en cuenta el comportamiento del objeto considerado desde una perspectiva más general, el conocimiento de matemáticas de un profesor puede ser el relativo a las distintas dimensiones 'locales' que puede conocer de un tópico matemático, o puede tener una visión superior, de conjunto, de cómo están distribuidas las matemáticas.

Este conocimiento es el constructo personal que el profesor desarrolla sobre la forma en que están secuenciados y conectados los tópicos matemáticos en las matemáticas, tanto científicas como escolares. En esta línea, la idea de Felix Klein de matemáticas avanzadas desde un punto de vista elemental y matemática elemental desde un punto de vista avanzado (Kilpatrick, 2009), constituye uno de los ejemplos más potentes, el cual se basa en una perspectiva de saber a una altura diferente respecto al elemento considerado, y así tener una visión de global de la organización del mismo.

Los procesos de complejización y simplificación del contenido matemático que pueda hacer un profesor muestran este tipo de conocimiento de una forma directa. Esta conexión puede no estar relacionada con el posible contenido de otros cursos, sino con la potencialidad de explotación de la noción matemática que el profesor piensa que tiene dicha noción, esto es, la noción de grandes ideas en matemáticas y la instrucción matemática (Kuntze, Lerman, Murphy, Kurz-Milcke, Siller \& Winbourne, 2011), caracterizadas como:

Ideas que pudieran tener un gran potencial matemático a la hora de alentar un aprendizaje que permitiera una comprensión conceptual. 
- Ideas que tuvieran una gran relevancia a la hora de construir metaconocimiento sobre matemáticas como ciencia.

- Ideas que apoyen las habilidades de comunicar con sentido las matemáticas y proveer argumentos matemáticos

- Ideas que deberían fomentar los procesos de reflexión de los profesores, conectadas con diseños instruccionales ricos y oportunidades de aprendizaje que activen la cognición de los alumnos, así como las ideas relacionadas con el acompañamiento y el sustento de los procesos de aprendizaje.

Estas grandes ideas que existen en matemáticas y que dan sustento a la propia matemática para permitir que se pueda articular y constituyen la esencia estructurante de la misma.

Una vez más en el terreno de las acciones, e incluso en el de las intenciones, un profesor puede hacer uso de sus conocimientos estructurales para ser consciente él mismo de en qué punto está del desarrollo de la construcción matemática, para poder, por ejemplo, definir una serie de etapas, o puntos conceptuales, por los que quiera pasar para que sus alumnos construyan el concepto que se plantee como objetivo. En este sentido, puede explicitar esa idea estructurada por etapas para transmitir a sus estudiantes la proyección que tienen sus explicaciones para su propia construcción de los contenidos del curso. Este conocimiento le permite afrontar con mayor solvencia situaciones de contingencia (Rowland, Turner, Thwaites \& Huckstep, 2009), al poder reconocer posibles conexiones establecidas por un alumno, o usar sus propias conexiones para responder a situaciones matemáticas inesperadas.

\subsubsection{Conocimiento de la práctica matemática}

Se orienta directamente con el conocimiento del profesor acerca de cómo desarrollar la clase: formas de mostrar y demostrar, criterios para establecer generalizaciones válidas, significado de definición, axioma y teorema como elementos constituyentes de las matemáticas, el conocimiento de la sintaxis matemática. Este componente es fundamental en el conocimiento de heurísticos en resolución de problemas que abarcan la estructura lógica en la que se desarrolla. En particular, se refiere a las formas de 
conocer, crear o producir en matemáticas, conocimiento de aspectos de la comunicación matemática, del razonamiento y la prueba.

Este tipo de conocimiento aparece en aquellos casos en los que el profesor necesita detectar el tipo de razonamiento que los estudiantes usan para resolver algún problema. De esta forma, el conocimiento sobre matemáticas puede permitir abordar muchos de los problemas de comprensión de los estudiantes, por ejemplo no saber detectar el sentido de una implicación, y considerar que en general siempre se da la doble implicación, y si un profesor es capaz de comprender, a nivel matemático, la lógica que subyace a una declaración de un estudiante donde aparezca este tipo de afirmación, será capaz de tomar medidas para conseguir que dicho estudiante comprenda de forma completa la idea de que una condición necesaria no implica que también sea suficiente.

El profesor puede decidir enseñar razonamiento matemático, para dar sentido a y en la actividad matemática (Rowland, Turner, Thwaites \& Huckstep, 2009), no sólo para proveer a los estudiantes de esa conciencia y sensibilidad sobre cómo establecer la verdad en matemáticas, sino para que le encuentren sentido a la necesidad de hacerlo.

\subsubsection{Conocimiento de la enseñanza de las matemáticas}

Esta componente está referida al conocimiento que tiene el profesor de las vías, recursos y formas de enseñar matemáticas. En particular del conocimiento que posee de diferentes estrategias y teorías, ya sean institucionales o personales de la enseñanza de las matemáticas. También, toma relevancia el conocimiento de diferentes recursos para la enseñanza de las matemáticas con relación al potencial y limitaciones para la enseñanza de contenidos. No está referido a un conocimiento superficial del recurso sino al conocimiento que se vincula con la naturaleza de los conceptos matemáticos entre sí.

Esta componente parece solaparse, en un principio, con el modelo general, ya que la especialización del conocimiento del profesor de matemáticas radica en que su labor es enseñar matemáticas, y, por tanto, puede englobar todo el modelo. Sin embargo, desde el punto de vista de la comunicación, la idea que fundamenta este subdominio es remarcar las habilidades que posee el profesor para la selección y el uso de distintos canales comunicativos, así como la conciencia de cómo y cuándo usarlos. Dichos canales pueden variar su naturaleza enormemente, pudiendo ser, por ejemplo, las 
distintas estrategias, a nivel conceptual o metodológico, que un profesor conozca o tenga a su disposición para el a bordaje de cada concepto.

Aparte de las estrategias que pudiera conocer el profesor, también existen elementos externos a la propia acción del profesor per se, como son los distintos recursos y materiales que se pueden usar para fomentar la construcción o facilitar la comprensión de algún concepto. Asimismo, el elenco de diferentes tipos de verbalización de posible elección en su docencia también forma parte de este subdominio.

Poseer más variedad de recursos, estrategias, o tipos de ayudas disponibles permitirá al profesor responder de una forma adecuada y óptima en función de los requerimientos de la situación. De esta manera, un profesor novel, por ejemplo, dispondrá de unas estrategias basadas probablemente en su formación académica, mientras que un profesor con una dilatada experiencia habrá desarrollado estrategias más acordes a su tendencia didáctica, así como según su forma de entender cómo se fomenta de una forma más adecuada el aprendizaje de las matemáticas.

\subsubsection{Conocimiento de las características del aprendizaje de las matemáticas}

Refleja el conocimiento que el profesor posee y desarrolla acerca de cómo se aprenden y piensan los contenidos matemáticos y las formas en que los estudiantes interactúan con cada contenido. Este tipo de conocimiento consiste en conocer las expectativas de aprendizaje que figuran en el currículo, o las que se hacen constar en la literatura de investigación, asociadas al nivel educativo en el que se aborda este aprendizaje. Un enunciado propio de este subdominio podría ser cómo en el currículo nacional se incluyen consideraciones relacionadas con las matemáticas en general y con cada contenido en particular, encontrando el conocimiento de teorías, personales e institucionales, de aprendizaje, el conocimiento de fortalezas, dificultades, obstáculos o errores asociados a cada contenido, el lenguaje que los estudiantes pueden usar en cada contenido, las ideas intuitivas que ellos desarrollan en cada concepto y las actitudes hacia las matemáticas (Hobbs, 2016).

Es necesario que el profesor identifique las múltiples dimensiones de compresión y relación con un determinado concepto que sus alumnos pudieran establecer, así como sus capacidades y falta de las mismas respecto al uso y comprensión del concepto (Hobbs, 2016). Así, saber cómo aprende matemáticas un estudiante, cómo se desarrolla 
su cognición del concepto abordado, es una de las dimensiones se incluyen en esta componente, ya que el profesor debe prever cómo adquirirán sus alumnos aquellos conocimientos que les enseña, si quiere organizar las sesiones en que desarrollará dichos conocimientos de forma que el aprendizaje de sus estudiantes sea óptimo.

Conocer las dificultades que ese estudiante pudiera experimentar, así como los obstáculos que pudiera encontrarse, y los errores que pudiera cometer, son algunas de las formas más directas de conocer cómo el estudiante interactúa con las matemáticas. No obstante, el profesor también puede tener conocimiento de qué ideas previas tienen los estudiantes acerca de las ideas matemáticas que se van a desarrollar en clase.

Este conocimiento permite al profesor adquirir una mayor consciencia del contexto en el que se desarrolla su docencia, y por tanto, pueda abordar la temática de una forma más personalizada, y ajustada a las necesidades de su interlocutor, en función del contexto en que sus alumnos se sitúen como aprendices de los elementos matemáticos seleccionados. Un profesor que conozca o prevea cómo sus alumnos van a desarrollar su actividad con relación al concepto abordado, podrá preparar las clases consciente de esto, intentando adaptar aquello que quiera transmitir a la manera más adecuada para conseguir una buena transmisión. Asimismo, conocer las características del pensamiento de sus estudiantes dará al profesor una familiaridad con los procesos de aprendizaje que le permitirán comprender situaciones contingentes con mayor soltura.

\subsubsection{Conocimiento de los estándares de aprendizaje de las matemáticas}

Desarrolla una visión de la noción del conocimiento curricular que abarca los grados de profundidad en que el profesor puede conocer el currículo oficial visto como el referente estandarizado (Muñoz-Catalán, Contreras, Carrillo, Rojas, Montes \& Climent, 2015) de los contenidos y capacidades que debe aprenderse y desarrollarse en un curso y las indicaciones de la forma en que deben enseñarse y aprenderse los contenidos. Dichos referentes pueden estar fuera del currículo, como las propuestas de asociaciones profesionales y la opinión de los profesores expertos en el conocimiento de la práctica docente sobre qué, cómo y cuándo explicar los contenidos matemáticos (Hobbs, 2016).

Además, contempla aquellos conocimientos que posee el profesor sobre los condicionantes que influyen en su enseñanza de las matemáticas cuya fuente no es su propia construcción de conocimiento. Se entiende acá un estándar de aprendizaje como 
un indicador, externo al profesor, que da cuenta del nivel de conocimiento matemático (en cantidad y profundidad), que debe poseer un alumno en un determinado momento de su escolarización. En este sentido se tiene en cuenta el conocimiento de los contenidos enseñables en un curso determinado, el conocimiento del grado de desarrollo conceptual esperable en un alumno en un curso determinado, y el conocimiento de la organización y secuenciación de los contenidos de un curso.

Este es el conocimiento usado para decidir la adecuación, por ejemplo, de un recurso o grado de complejidad de un concepto, a un determinado curso escolar, en función del grado de desarrollo esperable en los conocimientos y habilidades esperados en los alumnos, de lo que los documentos curriculares contemplan, o de la conveniencia o no de su abordaje en la secuencia organizativa de un curso (Hobbs, 2016).

A partir de las seis componentes anteriores y de lo abordado a lo largo del capítulo, el conocimiento especializado del profesor es entendido en esta investigación como el conjunto de saberes que se adquiere en la formación inicial sobre matemática y su enseñanza, la experiencia en el aula y los saberes que de ella se desprende, y los conocimientos teóricos que en la reflexión sobre la práctica generan un nuevo estatus de saber que es el que se está caracterizando. 


\section{DESARROLLO PROFESIONAL DEL PROFESOR DE MATEMÁTICAS}

Estudiadas las definiciones de concepción y conocimiento especializado, a continuación, se procede a definir el concepto de desarrollo profesional que se ha tenido en cuenta en esta investigación.

Diversos autores (Climent, 2005; Cochran \& Lytle, 2003; Guimarães, 2005) han constatado que, en el área de didáctica de las matemáticas, se suele utilizar el término sin que los investigadores hayan explicitado sus conceptos y cuadros teóricos de referencia; incluso se percibe una falta de consistencia en la terminología utilizada a partir del uso del término en diferentes contextos y significados.

Habitualmente, en la literatura sobre el desarrollo profesional se hace referencia a los procesos de cambio, mejora o crecimiento del docente considerado un profesional de la enseñanza, concretándolos en aspectos como el conocimiento, las concepciones y la práctica. Climent (2005) agrupa estos estudios en tres bloques diferenciados:

- A-Estudios que consideran que el desarrollo profesional viene definido por el acercamiento a un modelo determinado: puede ser: un modelo de profesor, habitual en los estudios que consideran que el profesor es aquel cuyas características coinciden con el modelo investigativo de las tendencias didácticas presentadas en el estudio de las concepciones de esta investigación, una perspectiva curricular específica o una perspectiva consistente con una visión constructivista del aprendizaje (Putnam \& Borko, 2000; Schifter \& Simon, 1992).

- B-Estudios que consideran el desarrollo profesional de manera integrada a partir de las concepciones, conocimiento y práctica: Del segundo grupo de estudios, Cooney (1998) considera que el referente del desarrollo profesional es la práctica reflexiva en la que el profesor adapta su actuación al contexto. Así, el desarrollo profesional se considera como un continuo en el que se adquiere la habilidad para monitorear las acciones de acuerdo con las circunstancias en las que el profesor enseña. La enseñanza es vista como ejercicio adaptativo coherente con la visión de las matemáticas como creación humana. El contexto es una parte fundamental de la conceptualización del desarrollo ya que tiene en cuenta aspectos de como una actividad puede ser o no efectiva. Así, lo práctico, 
reflexivo y adaptativo permite distinguir el desarrollo profesional a partir de cuatro gradientes:

1- Idealista ingenuo : contempla el conocimiento de modo no problemático.

2- Externo: adopta las ideas de los otros, pero de modo no crítico y sin incorporar su propia voz

3- Conexionista ingenuo: establece relaciones a través de la reflexión, pero no resuelve conflictos que involucran concepciones sobre las matemáticas ni de su enseñanza y aprendizaje,

4- Conexionista reflexivo: establece conexiones y toma varias posiciones en función del contexto y del sistema de creencias. Se centra en el desarrollo de las estructuras de concepciones de los profesores, de tal forma que evaluar las alternativas en la enseñanza sea habitual y el profesor se vea a sí mismo como una autoridad, que pueda evaluar materiales y prácticas en términos de sus propias concepciones; flexible para modificarlas cuando lo considere necesario.

- C-Estudios para explicar el conocimiento especializado del profesor de matemáticas: consideran que éste viene determinado por el aprendizaje tanto del propio contenido matemático como del conocimiento didáctico del contenido (Muñoz-Catalán, 2010).

Para esta investigación se va a considerar una visión del desarrollo profesional que combina estos grupos. La comprensión de la práctica es nodal en el quehacer profesional del profesor: genera teoría acerca de lo que sucede en la práctica; esa comprensión se realiza en un marco ideológico, praxeológico, axiológico particular enmarcada en un contexto que permite comprender por qué una determinada actuación es efectiva en unas determinadas situaciones y no en otras. De esta manera, el conocimiento especializado no es concebido sólo como herramienta para comprender, sino como producto de esa comprensión. La reflexión se convierte tanto en el medio a través del cual se promueve el desarrollo profesional como el referente para identificar el desarrollo logrado (Climent, 2005; Llinares \& Krainer, 2006), a través de tres acciones que se identifican como Conocimiento para, en y de la práctica tal como se describe en la tabla 4.01: 


\begin{tabular}{|c|c|c|c|}
\hline & $\begin{array}{c}\text { Conocimiento para } \\
\text { la práctica }\end{array}$ & $\begin{array}{c}\text { Conocimiento en la } \\
\text { práctica }\end{array}$ & $\begin{array}{c}\text { Conocimiento de la } \\
\text { práctica }\end{array}$ \\
\hline Cualidad & $\begin{array}{l}\text { Necesario para llevar } \\
\text { a la práctica }\end{array}$ & Surge en la Acción & $\begin{array}{l}\text { Producto de la reflexión } \\
\text { sobre lo actuado }\end{array}$ \\
\hline Naturaleza & $\begin{array}{l}\text { Conocimiento formal, } \\
\text { proposicional, } \\
\text { declarativo, de } \\
\text { naturaleza teórica. }\end{array}$ & $\begin{array}{l}\text { Conocimiento práctico: se } \\
\text { adquiere, crece y } \\
\text { manifiesta en la acción. } \\
\text { Inmerso en la praxis y en } \\
\text { las reflexiones de los } \\
\text { profesores sobre la } \\
\text { misma. }\end{array}$ & $\begin{array}{l}\text { Conocimiento que emerge } \\
\text { dialécticamente r entre } \\
\text { teoría y y práctica. } \\
\text { Indisociable del sujeto que } \\
\text { sonoce, del contexto donde } \\
\text { lo construye y surgido a } \\
\text { partir de indagaciones } \\
\text { intencionales. }\end{array}$ \\
\hline Componentes & & & $\begin{array}{l}\text { La interrelación entre la } \\
\text { teoría y la práctica para la } \\
\text { obtención } \\
\begin{array}{llll}\text { conocimiento } & & \text { local } \\
\text { significativo, } & & \\
\text { La necesidad } & \text { de } & \text { una } \\
\text { actitud } & \text { crítica } & \text { y } & \text { reflexiva } \\
\text { hacia la propia práctica } & \\
\text { La } & \text { participación } & \text { en } \\
\text { entornos colaborativos: }\end{array}\end{array}$ \\
\hline
\end{tabular}

Tabla 4.01. Comparación de las tres concepciones sobre el desarrollo profesional de Cochran \& Lytle (2003).

Elaboración: basada en (Guimarães, 2005)

Gráficamente el ciclo del desarrollo profesional puede ser presentado como sigue en la figura 4.01, tomando en cuenta que las líneas de puntos suponen cierre y apertura en forma simultánea (protección y permeabilidad) y que el aula, por ende, la práctica se constituye en el primer nodo del cual partir: 


\section{DESARROLLO PROFESIONAL}

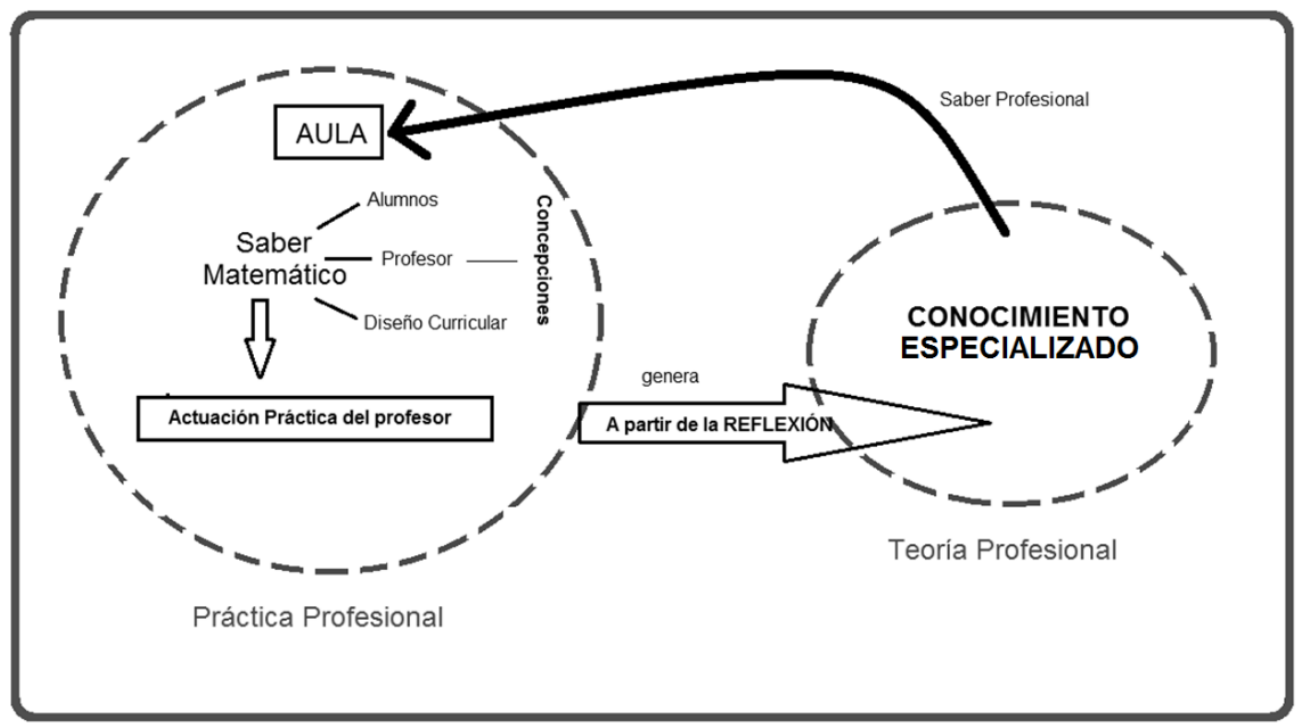

Figura 4.01. Desarrollo profesional del profesor de matemáticas. Fuente: Lima (2014)

El desarrollo profesional puede analizarse a través de los siguientes indicadores:

Comprensión de la práctica: permite la comprensión por parte del profesor del modo de pensar propio acerca de la enseñanza, de cómo aprenden los alumnos; de modos de hablar e interactuar, observar y describir elementos del entorno y la disposición hacia la acción y la interpretación, entre otros.

Descripción de concepciones: permite entender si los errores y obstáculos de los alumnos son considerados situaciones de aprendizaje tanto para el alumno como para el profesor en lugar de ser visto como carencias de los estudiantes; si existen alternativas en los procesos de enseñanza, etc.

Conocimiento de casos: permite replantear los argumentos propios y evaluar la forma de proponerlos tomando conciencia de las concepciones y aspectos que caracterizan la práctica propia.

Problematización de la práctica: permite definir la práctica como un conjunto de problemas en las que hay muchas maneras de actuar y muchos objetivos que plantear. Esto conlleva a la toma de consciencia de la complejidad de la misma y el compromiso hacia ella siempre con actitudes de cuestionamiento y aprendizaje continuo. 
Cambios en las prácticas: permiten al profesor desarrollar una metodología investigativa para determinar qué sucede en el aula cuando se implementan estrategias de enseñanza.

A partir de lo descrito en el apartado 1.1 acerca de cómo realizar el estudio, durante los capítulos 2, 3 y 4 se han definido y demarcado los elementos teóricos que permiten el análisis de la práctica del profesor de matemáticas cuando desarrolla las actividades en una escuela secundaria: concepciones, conocimiento especializado y desarrollo profesional.

Las concepciones son el conjunto de creencias y posicionamientos que el docente tiene sobre su práctica en relación con los temas relacionados con la enseñanza y aprendizaje de las matemáticas.

El conocimiento especializado del profesor es el conjunto de saberes que se adquieren en la formación inicial sobre matemáticas y su enseñanza, en la experiencia en el aula y los saberes que de ella se desprende, y en los conocimientos teóricos que en la reflexión sobre la práctica generan un nuevo estatus de saber, que es el que se está caracterizando.

El desarrollo profesional es la transformación de la práctica como consecuencia de la de la reflexión sobre lo que el profesor dice hacer y lo que hace en coherencia con sus concepciones sobre las matemáticas, las matemáticas escolares, la enseñanza y el aprendizaje y su conocimiento especializado, necesario para el ejercicio de su profesión 


\section{SEGUNDA PARTE: METODOLOGÍA}

Después de presentados los referentes teóricos con los que se llevará a cabo la investigación y el trabajo de campo, se da a conocer la caracterización y los objetivos que se han establecido para su desarrollo. También se describen los instrumentos de recogida y análisis de datos, finalizando con la contextualización del trabajo de campo.

\section{CARACTERIZACIÓN Y OBJETIVOS DE LA INVESTIGACIÓN}

\subsection{Caracterización de la Investigación}

En esta investigación se propone comprender cómo el proceso del desarrollo profesional del profesor de matemáticas tiene, a palabras de Latorre, Del Rincón \& Arnal (1997) fines ideográficos. No se busca obtener resultados que establezcan leyes generales: no se está haciendo la búsqueda de abstracciones universales y abstractas sino concretas y específicas.

Se decidió optar por llevar adelante un estudio de caso, entendido como el estudio de una singularidad en sus escenarios naturales (Bassey, 1999). Así, este estudio pretende comprender la singularidad del conocimiento de un profesor de matemáticas que trabaja en una institución educativa del sector público de la ciudad de Bogotá, en las condiciones más habituales del sistema educativo de la capital colombiana, al cual se le denominará Lucho.

Siguiendo la clasificación propuesta por Yin (1993), este estudio tiene rasgos descriptivos, dado que la intención es presentar una descripción completa de un fenómeno (Yin, 1993), asociado a estudio de caso exploratorios para 'descubrir teoría' a través de la observación de los fenómenos naturales en bruto (Bassey, 1999). La naturaleza de la 'observación' del fenómeno no se refiere en este caso a un aspecto meramente visual, ya que al ser el fenómeno de interés el conocimiento del profesor, lo que se observan son las producciones que genera dicho conocimiento, sea su naturaleza escrita, verbalizada, en acto, o la propia interacción con el investigador.

Los rasgos exploratorios, unidos al enfoque metodológico, desembocan en un estudio de búsqueda teórica (Bassey, 1999), en el que se estudia un ejemplo seleccionado como parte de un conjunto mayor, que puede dar información acerca de este. Lo anterior plantea la problemática de la posibilidad o imposibilidad de generalizar los 
resultados del estudio, para lo cual se usarán las así llamadas 'generalizaciones difusas' (Climent, 2005), generalizaciones de estudios cualitativos, considerados el tipo de predicción emergente de cuestionamientos empíricos, que afirman que algo puede pasar, pero sin mediciones ni probabilidades. Dichas generalizaciones:

- Conllevan un elemento de incertidumbre: Informan de que algo ha ocurrido bajo determinadas situaciones y que puede que también ocurra en otras circunstancias, es decir, expresan posibilidad, pero no seguridad.

- Son respetuosas con las verdades a las que podemos acceder en las ciencias sociales, caracterizadas por la existencia de una gran diversidad de variables que influyen en el caso.

- Invitan al lector a que entre en el discurso y a que las experimente en su contexto. No tiene que aceptarlas y creerlas tal cual, sino que promueve la comprobación y la experimentación, así como la consideración del contexto, las condiciones y los significados implicados que la sustentan.

- Dan la opción a la investigación para que se convierta en acumulativa.

La generalización difusa hay que considerarla junto al informe escrito que la apoya y le da crédito.

Así, en términos de la posible generalización de los resultados, se muestran las características del profesor estudiado, indicando la posibilidad de que puedan ser compartidas por otros profesionales de la enseñanza de las matemáticas. Esto es así debido a la comprensión de que este caso, esta singularidad, está condicionada por la multitud de aspectos que influyen en el fenómeno objeto de estudio.

La consideración de significados e intenciones que manifiesta el profesor implica indagar sobre su interpretación de los sucesos y contrastar sus interpretaciones. Los significados inmediatos y locales de las acciones son foco de interés de este trabajo, hecho con el cual, la investigación toma un enfoque interpretativo.

Se realiza el seguimiento de la práctica de un profesor, su reflexión sobre la misma, ideas sobre la enseñanza y el aprendizaje de las matemáticas en el cuarto año de secundaria. 


\subsection{Objetivos y problema de Investigación}

El proponer una investigación acerca de las transformaciones de la práctica de un profesor como la que se presenta en este documento supone que existe una problemática y unas necesidades de investigación dentro del área que deben ser satisfechas. Dicha problemática se ha formulado en forma de pregunta de investigación que será la inicial con relación al planteamiento de los objetivos necesarios para responderla. Una vez planteados y explicitados estos objetivos, se procede a abordarlos e intentar su consecución para dar respuesta a la pregunta de investigación. La pregunta de esta investigación es la siguiente:

\section{¿Qué elementos caracterizan el desarrollo profesional de un profesor de matemáticas de la escuela secundaria?}

Esta pregunta da lugar a varias cuestiones, de diferente naturaleza, que han marcado el desarrollo de la investigación y que son los objetivos principales de la investigación:

- Identificar qué componentes del desarrollo profesional de un profesor de matemáticas de secundaria se ponen en evidencia cuando lleva a la práctica su actividad docente.

- Asociar los aspectos de su conocimiento especializado y su práctica, a las componentes de su desarrollo profesional

- Describir los aspectos de su proceso de reflexión y modificación de su práctica,

Para lograr los objetivos, en el transcurso de la investigación se trata de:

1) Analizar aspectos de conocimiento y práctica que definen el desarrollo; posteriormente describir los cambios que se observan en esos aspectos y la relación entre ellos.

2) Registrar el proceso de reflexión y modificación de la práctica: cómo se produce y cómo se relaciona con el desarrollo.

3) Detectar las concepciones sobre el desarrollo, tanto los términos como la consideración en que se producen, su posible modificación y relación con el desarrollo producido.

4) Organizar la percepción del desarrollo y su relación con el conocimiento especializado. 
5) Recolectar información de la interpretación de propuestas para el aula de clase y cómo índice dicha interpretación en el desarrollo.

Con los resultados de esta investigación no se pretende dar una respuesta general a las cuestiones anteriores, pero si hacer una aproximación y contribución al debate en la comunidad comparando resultados y generando algunos patrones y redes conceptuales a partir de la metodología cualitativa. Es importante mencionar que en el principio no hay idea de lo que se va a obtener como resultado y tampoco si todas las preguntas van a tener alguna respuesta; no obstante, a partir de la consulta bibliográfica y la contextualización del marco teórico se puede partir de elementos concretos: El conocimiento de contenido del profesor de matemáticas su posible ampliación a través de las etapas de la investigación, en particular el cuestionamiento de la práctica, la forma en que posibles carencias puedan limitar su desarrollo y visión de necesidades de él.

En concordancia con el marco teórico es importante conocer las consideraciones del profesor respecto de su práctica con relación a la enseñanza de las matemáticas, las reflexiones que hace sobre la misma y a cuáles les centra su atención, saber hasta qué punto la enseñanza y el aprendizaje de las matemáticas son el centro de atención de dichas reflexiones y qué relación tiene todo lo anterior con su desarrollo; además de la visión del conocimiento profesional necesario para la enseñanza de las matemáticas y el vínculo con su desarrollo. A partir de lo considerado en el marco teórico y el trabajo de campo realizado, se quiere aportar información de la conceptualización del desarrollo profesional del profesor de matemáticas a partir de la observación de los aspectos anteriores.

\subsection{Argumentación del Plan}

Para perseguir los fines y objetivos deseados ha sido necesario realizar un estudio longitudinal. Se ha llevado a cabo el seguimiento de la práctica del profesor - Lucho que participa en la investigación, su reflexión sobre la misma, sus ideas sobre la enseñanza y el aprendizaje de las matemáticas, y su percepción de su propio desarrollo. Este ejercicio se ha realizado en dos momentos. Uno a lo largo del primer trimestre del 2015 y otro a lo largo del mismo periodo de 2016. En ellos se observó la práctica de Lucho en los procesos de enseñanza de ecuaciones lineales e inecuaciones lineales y no lineales. Además, se ha ampliado el estudio de este periodo con algunos datos sobre su práctica y la interpretación de su desarrollo posterior. 
La recogida de datos se ha realizado mediante diversos métodos, se ha obtenido información sobre su práctica directamente a través de la observación no participante de sesiones de aula. Esta información se ha complementado con la recogida de artefactos (Goetz \& Lecompte, 1988), para tener un acercamiento, a sus ideas, interpretaciones e intenciones respecto de su práctica y su desarrollo.

El diálogo con el profesor en momentos antes y después de la gestión en el aula, en el que ha reflejado su reflexión sobre las sesiones de clase, ha resultado un elemento especialmente rico para comprender la perspectiva de su práctica y su desarrollo.

La observación de aula ha sido grabada en audio y se han tomado notas de campo complementarias. Las grabaciones han sido transcritas haciendo hincapié en las intervenciones del profesor. Contienen casi la totalidad de la interacción del profesor con sus alumnos en el grupo grande y algunas notas sobre su interacción con éstos durante el trabajo de los alumnos en pequeños grupos. En la transcripción se han incorporado algunos comentarios que describen impresiones anotadas durante el transcurso de esta, diferenciándose de lo descriptivo, además de las notas de observación durante la misma, llevadas en el diario de campo de la investigación.

Se han realizado tres entrevistas semiestructuradas en las que se ha indagado sobre las visiones, percepciones e interpretaciones respecto de la enseñanza y el aprendizaje de las matemáticas, ideas sobre su propia práctica y su desarrollo. Estas entrevistas, realizadas al inicio, la mitad y al final del estudio se han llevado a cabo con el objetivo de recoger la visión a posteriori del proceso de desarrollo y explicaciones y se le ha unido el registro de sus declaraciones espontáneas durante las sesiones de trabajo. Éstas han sido usadas en lo que respecta a lo que aportan sobre el desarrollo. Las entrevistas han sido grabadas y posteriormente trascritas.

Como puede deducirse de lo anterior, se trata de una investigación que intenta llegar al descubrimiento frente a la verificación, siendo esta la distinción que Chiang, Miller y Rowan (1997) y Goetz y Lecompte (1988), atribuyen a los paradigmas cualitativos respecto de los cuantitativos.

En lo que se refiere al análisis de los datos, se ha realizado un análisis de la práctica de Lucho (Goetz \& Lecompte, 1988), partiendo de algunos focos de análisis previos y otros han surgido como resultado del propio análisis. En último caso, se consideran como 
focos del análisis aquellos aspectos del conocimiento especializado (incluyendo concepciones) y práctica profesional que permite explicar su desarrollo.

En el caso del estudio de las concepciones sobre la enseñanza y el aprendizaje de las matemáticas, se parte del instrumento de análisis construido teóricamente por Lima (2014), adaptando el de Carrillo (1998) y continuado por Villella (2007), respecto de las concepciones del profesor de matemáticas de Secundaria. En lo que se refiere a su visión de su desarrollo y su reflexión sobre la práctica., tanto los focos de atención como las categorías de análisis han surgido durante el estudio en la interfaz entre la teoría y los datos.

Se han diseñado distintos instrumentos que se distinguen entre instrumentos de primer orden para la obtención de datos, instrumentos de segundo orden para el análisis de los datos (Carrillo,1998). Para este caso:

Instrumentos de primer orden: Que se mencionan en el siguiente capítulo, denominados Instrumentos de recolección de información, que incluyen observaciones de aula, artefactos sobre la práctica de Lucho y su reflexión sobre ella, entrevistas y declaraciones, y cuestionarios sobre el conocimiento profesional deseable que él considera debe tener para la enseñanza de las matemáticas y sobre sus concepciones respecto de la enseñanza y el aprendizaje de la materia.

Instrumentos de segundo orden: también llamados instrumentos de análisis de la información: instrumento de análisis de las concepciones del profesor respecto de la enseñanza y el aprendizaje de las matemáticas, categorías de análisis de la reflexión sobre la práctica y las categorías de análisis de su visión del desarrollo profesional.

Lo expuesto anteriormente ofrece una visión general de la metodología seguida:

A. De acuerdo con (Latorre, Del Rincón \& Arnal, 1997), se puede decir que la presente es una investigación básica, es decir, tiene un fin teórico más que de aplicación directa.

B. Es una investigación de tipo longitudinal, descriptiva - explicativa ya que su intención es presentar la descripción del proceso de desarrollo de un profesor, explicaciones de este, aspectos que lo definen y las relaciones.

C. Es una investigación cualitativa, ideográfica y orientada al descubrimiento. 
Teniendo en cuenta las dimensiones de Goetz y Lecompte (1988), es una investigación inductiva, ya que se intenta descubrir una teoría que explique los datos y no encontrar datos que corroboren una teoría, generativa, porque trata de descubrir constructos y proposiciones a partir de los datos y no probar proposiciones ya formuladas; constructivista ya que las categorías y unidades de análisis surgen del propio análisis; y subjetiva porque las categorías de análisis no son externas al caso estudiado. 


\section{INSTRUMENTOS DE RECOLECCIÓN Y ANÁLISIS DE LA INFORMACIÓN}

La recolección de datos resulta fundamental, buscando información en profundidad en las propias 'formas de expresión' de las personas, comunidades, contextos, etc., objetos de estudio. Por tratarse de seres humanos, los datos que interesan son conceptos, percepciones, imágenes mentales, creencias, concepciones, emociones, interacciones, pensamientos, experiencias, procesos y vivencias manifestadas en el lenguaje de los participantes, ya sea de manera individual o colectiva. La finalidad de su recolección es su análisis y comprensión para responder a las cuestiones de la investigación y generar conocimiento (Goetz \& Lecompte, 1988). Esta clase de datos es muy útil para capturar de la manera más completa posible y comprender los motivos subyacentes, los significados y las razones internas del comportamiento humano, por lo que ha de ocurrir en los ambientes naturales y cotidianos de los participantes.

\subsection{Instrumentos de recolección de información}

Se describen en este apartado cada uno de los instrumentos de recolección de información, justificando por qué se ha considerado necesario su uso, sus características y a qué responden. Se intenta aclarar el carácter abierto, flexible y emergente atribuido a la investigación desde el punto de vista del diseño de la recogida de información. Antes de entrar en la descripción pormenorizada de cada instrumento, se presenta una clasificación de los instrumentos empleados.

\subsubsection{Entrevistas}

Es uno de los instrumentos más utilizados en las investigaciones cualitativas, con diferentes matices, siempre realizadas con la intención de recoger directamente, y con sus propias palabras, las justificaciones, ampliaciones, explicaciones, que los investigadores quieran obtener, para comprender mejor las concepciones y perspectivas de los profesores, en este caso, así como aquellas cuestiones que los entrevistados quieran plantear para aclarar, explicitar, ampliar o rectificar aspectos del estudio que se está realizando.

Se pueden recoger varios tipos de entrevistas, entre las que destacan las de respuestas cerradas, de afirmación o negación de las afirmaciones propuestas; las estructuradas, en las que el entrevistador se guía por preguntas muy específicas y se ciñe 
exclusivamente a ellas; las semi estructuradas, que parten de un guion flexible que conduce fundamentalmente el diálogo, aunque no es imprescindible ceñirse a él; las no estructuradas o abiertas, que son conversaciones informales, que discurren por derroteros cercanos a la investigación, pero no se ciñen a ningún esquema previo (Bernal, 2006). Mertens (2005) recomienda que las primeras entrevistas sean abiertas y que las realice el propio investigador, de modo que, a medida que éste vaya avanzando en el estudio, se vayan estructurando más. Cohen \& Manion (1994) y Cresswell (2005) consideran que deben ser abiertas, sin categorías preestablecidas, que irán surgiendo de las respuestas de los entrevistados. Bernal (2006) y Mertens (2005) señalan como características esenciales de las entrevistas cualitativas que su principio y final no se predeterminan con claridad; incluso se pueden efectuar en varias etapas y reiterar en diferentes episodios; esto implica que las preguntas y el orden dependen de los entrevistados ya que tanto el entrevistador como el entrevistado comparten el mismo ritmo y puesto que se tiene en cuenta el contexto social para la interpretación de significados.

Para esta investigación, se ha elegido el tipo de entrevista semi estructurada para obtener la información concisa del profesor estudiado y profundizar en aspectos relevantes que no aparecen suficientemente explicados.

Esta elección permitió, plantear y secuenciar cuestiones y tomar decisiones sobre la información a analizar; el ejercicio consistió en dejar hablar a Lucho, sin mediar demasiado en sus respuestas a partir de preguntas largas que pueden dar a entender es la visión del entrevistador y enfocar las preguntas a lo que Lucho creía que quería su interlocutor. Para ello fue importante evitar todo tipo de enjuiciamientos y críticas, para lograr que Lucho narrara sus experiencias y exponga sus puntos de vista libremente, con un trato sincero, respetuoso y genuino. El investigador debió lidiar con sus emociones, sin negarlas, pues son fuentes de datos, pero evitando que influyeran en los resultados (Bernal, 2006 y Mertens, 2005).

Todas las entrevistas han tenido el mismo esquema orientativo, aunque al ser la intencionalidad aclaratoria distinta en ambos casos, se diferencian en matices relativos a las dos situaciones a las que se han dirigido: la primera, profundizar en aspectos del diseño y la segunda, la puesta en práctica una vez realizada.

Entrevista Inicial: Se pretendió realizar el acercamiento inicial al proceso de seguimiento de la actividad profesional del docente. Se trata de una entrevista en la 
que se le va a comentar de manera formal lo que se va a realizar durante el periodo de observación. La intención primaria es conocer las ideas del profesor sobre el contenido del conocimiento profesional deseable del profesor de matemáticas, en particular con la enseñanza de las matemáticas escolares el grado correspondiente.

Pretende conocer qué aspectos de su conocimiento considera prioritarios abordar para su mejora profesional y cuáles está dispuesto a abordar. Esto es, qué perspectiva tiene de su desarrollo, respecto de las incidencias para éste y qué cuestiones de su conocimiento profesional está percibiendo en el proceso de reflexión sobre su práctica.

\section{Entrevista Inicial}

1. Saludo inicial y agradecimiento por la disposición para el proceso de observación

2. Indicaciones acerca del proceso de observación y finalidades de la investigación.

3. Percepción inicial del aprendizaje y la enseñanza de las matemáticas escolares.

4. Percepción personal acerca del proceso de enseñanza de las matemáticas

5. Expectativas del profesor acerca del proceso de desarrollo que se puede dar en el transcurso de la investigación.

Tabla 6.01. Formato de la Entrevista Inicial. Elaboración: propia

Entrevista Intermedia: Se realizó un alto en el camino en lo que se consideró la mitad del proceso de observación de Lucho. La intención de esta entrevista fue identificar elementos puntuales acerca de la percepción de desarrollo de Lucho a partir de la actividad realizada y el acompañamiento en aula.

Entrevista Final: Fue el diálogo final entre Lucho y el investigador, se trató de recolectar la visión de desarrollo obtenida por el mismo profesor a partir de las percepciones sobre sí mismo antes, durante y después de la observación. Tuvo como fin el hecho de que Lucho reconociera aquellos elementos que destaca de su propio desarrollo, en particular los elementos prioritarios descritos en las entrevistas anteriores. Esto es, identificar las cuestiones del conocimiento profesional percibido en el proceso de reflexión.

\section{Entrevista Final}

1. Saludo inicial y agradecimiento por la disposición durante el proceso de observación 
2. Reflexión por parte del profesor acerca del proceso de observación. Elementos positivos, elementos por mejorar.

3. Contraste entre lo que el profesor dice en entrevista inicial y entrevistas intermedias y lo que dice.

4. Si hubo modificación de las planificaciones en algún momento, ¿Qué originó esa modificación?

5. ¿Cambió su idea acerca del papel del profesor y de los estudiantes acerca de los procesos de enseñanza y aprendizaje?

6. Descripción del desarrollo por parte del profesor. Elementos que ha afianzado, transformado y oportunidades de mejorar

Tabla 6.02. Formato de la Entrevista Final. Elaboración: propia

Charla Previa: Es un pequeño diálogo que se realiza entre Lucho y el investigador para conocer las expectativas previas al desarrollo de cada sesión. La finalidad es conocer la visión del profesor acerca de lo que va a realizar, permitiendo identificar posibles contrastes entre lo que piensa y lo que hace.

\section{Charla Previa}

1. ¿Qué tema va a tratar el día de hoy?

2. ¿Se va apoyar en el uso de alguna metodología/ material/ indicación especial?

3. ¿Qué espera de los estudiantes?

Tabla 6.03. Formato de la Charla Previa. Elaboración: propia

Declaración Posterior: Corresponden a los comentarios entre Lucho y el investigador acerca de las primeras impresiones posteriores a cada clase. Se puede interpretar como una reflexión de la actividad docente. De manera similar a la charla previa, se realiza una después de cada observación de clase.

\subsubsection{Artefactos o Documentos}

Se consideran así a los materiales elaborados por el profesor antes de su práctica (planificación) y el material elaborado para el trabajo de sus alumnos (material para el estudiante), así como los materiales en los que se recoge su reflexión tras la práctica. Siguiendo algunas de las características con las que Goetz \& Lecompte (1988) los describen, los que se refieren directamente a su práctica son todos producciones del profesor; algunos privados (planificaciones) y otros públicos (material para los alumnos); 
aunque algunos son producidos a instancia del investigador, lo que no las hace menos personales o privadas pero se tiene consciencia de que va a servir también a terceros.

Fichas del diario El diario es instrumento que potencia la reflexión de manera más profunda y la recoge al mismo tiempo. En algunos momentos contesta a la pregunta sobre el porqué un determinado profesor continúa o no con la actividad, en otros es una manera de indagar sobre la propia visión del profesor sobre su práctica, esperando aportes sobre sus concepciones, aunque no tan importante como finalmente se convierte. Tomando como referencia a Carrillo (1998) se diseña una ficha con la siguiente información: nombre de la actividad, fecha, nivel, duración, objetivos y contenidos de la sesión, la descripción de la actividad diferenciándose en ella las etapas que se identifican y el papel del alumno y del profesor en cada etapa las dificultades que se dieron, las propuestas de mejora para éstas y las conclusiones que se extraen. Se le ha solicitado al profesor dividir las sesiones en episodios, entendidos como los principales momentos en el desarrollo de su clase que dan claridad acerca de los objetivos, contenidos y actividad abordados en el desarrollo de la clase. El formato de la ficha es el que sigue.

\begin{tabular}{|l|l|l|l|}
\hline Episodio & Objetivo & Contenido & Actividad \\
\hline & & & \\
\hline & & & \\
\hline & & & \\
\hline
\end{tabular}

\begin{tabular}{|l|l|}
\hline Episodio 01 & Papel del estudiante \\
\hline Papel del profesor & \\
\hline Recursos & Clima del Aula \\
\hline & \\
\hline
\end{tabular}

\begin{tabular}{|l|l|}
\hline Dificultades y Propuesta de mejora \\
\hline & \\
\hline & \\
\hline Tabla 6.04. Fichas del diario. Elaboración: propia
\end{tabular}

Además de las notas de campo tomadas durante las observaciones de aula se ha obtenido información sobre la práctica de Lucho a través de la recolección de artefactos que Lucho utiliza para la clase. En todos estos casos se trata de material elaborado por 
el profesor para uso propio e institucional y que ha sido facilitado para esta investigación. Como no se pretende que el docente modifique su práctica para el desarrollo de la investigación, no se toman elementos que el educador no realice en el contexto habitual ni tienen un formato específico. Estos artefactos sobre su práctica sirven para indagar sobre qué cuestiones se plantea el docente de antemano (mediante las planificaciones), sobre qué parece poner el énfasis y contrastarlo con lo que se observa en el aula y su visión posterior (las fichas del diario). En su conjunto, permiten conformar una imagen más completa de la práctica.

\subsubsection{Observaciones de Aula}

Las observaciones de aula pretenden recoger información directa sobre la práctica de Lucho, como complemento y contraste de sus declaraciones sobre la misma y lo que refleja en los diarios. El papel de la observación del autor de este documento ha sido no participante. Se presenta a los estudiantes como un investigador del aprendizaje de las matemáticas de los estudiantes en el colegio. No hay iniciativa del investigador a intervenir en el transcurso de la acción para alterar en la menor medida posible lo que sería su práctica habitual, y así ocurre en la mayor parte de las sesiones, si bien se hacen algunos llamados puntuales por parte de los profesores a observar el trabajo de los jóvenes y su disciplina.

Respecto de la posible distorsión que pudiera observarse en la actuación de los alumnos y el profesor por la grabación, se debe indicar que su familiarización ha sido inmediata por el contexto propio de la institución donde se ha realizado la investigación. Las transcripciones de las grabaciones son realizadas por el investigador y se describe lo que se observa cuando es necesario hacer algún comentario. Se transcribe casi la totalidad de las sesiones, salvo algunos trozos referidos a episodios del aula sin referencia a la investigación, señalándose sus omisiones. El discurso del profesor y el de los alumnos de las partes que se consideran relevantes se transcribe literalmente, aunque no se distingue quien de los estudiantes hace el diálogo. Estas transcripciones son un primer paso del análisis, pues se realiza ya en ellas una selección de la información. Como se ha explicado, se ha incorporado en ellas información (también descriptiva) de las notas de campo, diferenciándose de la transcripción.

Declaraciones Espontáneas Como se indica en la descripción general de la metodología y de los instrumentos de recogida de información, se cuenta con otro tipo de declaraciones, algunas de las cuales son espontáneas sobre su práctica que 
complementan los datos sobre su desarrollo en relación con ésta, por ejemplo, sus deseos de cambio, los aspectos que pretende modificar y por qué. El registro de estas declaraciones espontáneas se ha realizado mediante notas de campo durante el desarrollo de la observación, que posteriormente se han transcrito.

Notas de Observación: Son anotaciones de la práctica y del trabajo profesional del profesor que se realizan acerca de los aspectos que considera el observador, son importantes en el proceso de desarrollo profesional del profesor. Estas notas se han registrado aparte porque conducen al análisis a realizar en el desarrollo de la investigación y no pretenden hacer interferencia con la toma de datos mediante los instrumentos descritos anteriormente.

La tabla 6.05 presenta un esquema de los instrumentos de recogida de información que se han empleado en esta investigación. Cada instrumento se presenta como parte de los anexos digitales.

\begin{tabular}{|c|c|c|c|c|}
\hline Tipo & Instrumento & Finalidad & Registro & Notación ${ }^{2}$ \\
\hline \multirow[t]{3}{*}{ Entrevistas } & $\begin{array}{l}\text { Entrevista } \\
\text { Inicial }\end{array}$ & $\begin{array}{l}\text { Hacer el primer } \\
\text { acercamiento } \\
\text { formal al } \\
\text { desarrollo del } \\
\text { profesor }\end{array}$ & $\begin{array}{l}\text { Grabación } \quad y \\
\text { transcripción }\end{array}$ & $\mathrm{El}$ \\
\hline & $\begin{array}{l}\text { Entrevistas } \\
\text { Intermedias }\end{array}$ & $\begin{array}{lr}\text { Realizar } & \text { una } \\
\text { evaluación } & \\
\text { intermedia } & \text { del } \\
\text { proceso } & \text { de } \\
\text { desarrollo a partir } \\
\text { de la } & \text { propia } \\
\text { visión } & \text { del } \\
\text { profesor } & \\
\text { observado } & \end{array}$ & $\begin{array}{l}\text { Grabación } \quad y \\
\text { transcripción }\end{array}$ & EM \\
\hline & Entrevista Final & $\begin{array}{lr}\text { Evaluar } & \text { el } \\
\text { proceso } & \text { de } \\
\text { desarrollo } & \end{array}$ & $\begin{array}{l}\text { Grabación } \quad y \\
\text { transcripción }\end{array}$ & $\mathrm{EF}$ \\
\hline
\end{tabular}

2 Por notación se entiende la forma en que se van a referenciar en los capítulos que siguen a continuación 


\begin{tabular}{|c|c|c|c|c|}
\hline & & $\begin{array}{ll}\text { durante } & \text { el } \\
\text { periodo } & \text { de } \\
\text { observación } & \end{array}$ & & \\
\hline & Charlas Previas & $\begin{array}{l}\text { Lograr un } \\
\text { acercamiento a } \\
\text { lo que el profesor } \\
\text { piensa hacer } \\
\text { justamente antes } \\
\text { del ejercicio de la } \\
\text { práctica }\end{array}$ & $\begin{array}{l}\text { Grabación y } \\
\text { transcripción }\end{array}$ & $\mathrm{CP}$ \\
\hline & $\begin{array}{l}\text { Declaraciones } \\
\text { Posteriores }\end{array}$ & $\begin{array}{l}\text { Realizar un } \\
\text { primer } \\
\text { acercamiento a } \\
\text { la reflexión sobre } \\
\text { el trabajo } \\
\text { realizado en la } \\
\text { práctica } \\
\text { manera de } \\
\text { inmediata a la } \\
\text { actividad en el } \\
\text { aula }\end{array}$ & $\begin{array}{l}\text { Grabaciones y } \\
\text { Transcripciones }\end{array}$ & $\mathrm{DP}$ \\
\hline Artefactos & Fichas del diario & $\begin{array}{l}\text { Recolectar } \\
\text { información } \\
\text { complementaria } \\
\text { sobre la práctica, } \\
\text { visión de la } \\
\text { misma y } \\
\text { desarrollo }\end{array}$ & $\begin{array}{l}\text { Producción } \\
\text { escrita del } \\
\text { profesor. }\end{array}$ & FD \\
\hline \multirow[t]{2}{*}{ Observación } & $\begin{array}{l}\text { Observación de } \\
\text { clase }\end{array}$ & $\begin{array}{l}\text { Recolectar } \\
\text { información } \\
\text { directa sobre la } \\
\text { práctica }\end{array}$ & $\begin{array}{l}\text { Grabaciones y } \\
\text { traslaciones }\end{array}$ & $\mathrm{OB}$ \\
\hline & $\begin{array}{l}\text { Declaraciones } \\
\text { Espontáneas y } \\
\text { Notas de } \\
\text { Observación }\end{array}$ & $\begin{array}{l}\text { Recolectar } \\
\text { información } \\
\text { sobre sus } \\
\text { concepciones, }\end{array}$ & $\begin{array}{l}\text { Grabación } \\
\text { traslación }\end{array}$ & $\begin{array}{l}\mathrm{DE} \\
\mathrm{NO}\end{array}$ \\
\hline
\end{tabular}




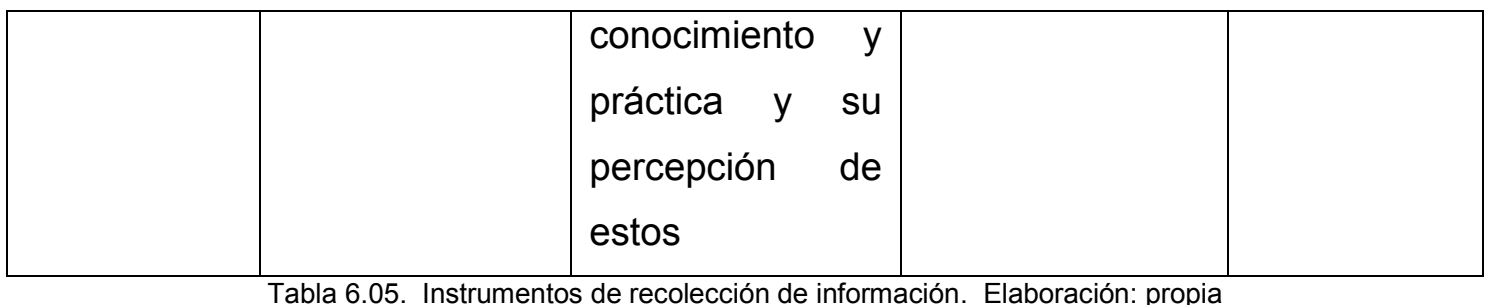

\subsection{Instrumentos de análisis de la información}

Seguido a los instrumentos de recolección de información, se presentan los instrumentos de análisis: análisis de las concepciones de los profesores respecto de la enseñanza y el aprendizaje de las matemáticas, del conocimiento profesional y del desarrollo profesional, teniendo en cuenta los referentes teóricos que previamente se han abordado y los objetivos y la metodología de esta investigación.

\subsubsection{Instrumento de análisis de las concepciones de los profesores respecto de la enseñanza y el aprendizaje de las matemáticas}

El análisis de las concepciones de los profesores se realiza en tres momentos. El primero de ello corresponde a la identificación de alguna tendencia de acuerdo con el tipo de metodología que utiliza y la forma en que dicha metodología está caracterizada. El segundo momento consiste en identificar las concepciones relacionadas con la metodología y evaluación, las matemáticas escolares, el aprendizaje, el papel del alumno y el papel del profesor en cada una de las tendencias descritas. Finalmente, el tercer momento, responde a unas preguntas generales acerca de las tendencias del primer momento y las concepciones identificadas en el segundo.

Para el análisis de las concepciones de los profesores respecto a la enseñanza y el aprendizaje de las matemáticas, se ha decido diseñar tablas de doble entrada de acuerdo con la necesidad de confrontar una determinada tendencia didáctica con las diferentes características de las concepciones.

A continuación, se presenta la tabla 6.06 correspondiente al primer momento, en el que se presenta cada una de las tendencias, su metodología y características:

\begin{tabular}{|l|l|l|}
\hline & Metodología & Características \\
\hline Tradicional & $\begin{array}{l}\text { Ejercitación } \\
\text { repetitiva }\end{array}$ & El docente da las pautas \\
\hline
\end{tabular}




\begin{tabular}{|c|c|c|}
\hline & & $\begin{array}{l}\text { Interesan los conceptos y reglas } \\
\text { Proceso de aprendizaje deductivo (regla- } \\
\text { aplicación) } \\
\text { El aprendizaje es un proceso individual }\end{array}$ \\
\hline Tecnológica & $\begin{array}{l}\text { Ejercitación } \\
\text { reproductiva }\end{array}$ & $\begin{array}{l}\text { El docente da las pautas poniendo énfasis } \\
\text { en que los alumnos comprendan } \\
\text { Interesan los conceptos y reglas, } \\
\text { procedimientos locales y lógica de la } \\
\text { asignatura } \\
\text { Procesos de aprendizaje inductivos } \\
\text { simulado (por el docente) y deductivos } \\
\text { El aprendizaje es un proceso individual }\end{array}$ \\
\hline Espontaneista & "Activismo" & $\begin{array}{l}\text { El docente propone las actividades, } \\
\text { promoviendo la participación de los } \\
\text { alumnos } \\
\text { Interesan actitudes y procedimientos } \\
\text { generales } \\
\text { Proceso de aprendizaje inductivo } \\
\text { El aprendizaje es un proceso social }\end{array}$ \\
\hline Investigativa & $\begin{array}{l}\text { resolución de } \\
\text { situaciones } \\
\text { problemáticas }\end{array}$ & $\begin{array}{l}\text { El docente propone investigaciones y } \\
\text { apoya la reflexión y el trabajo autónomo } \\
\text { del } \\
\text { alumno }\end{array}$ \\
\hline
\end{tabular}




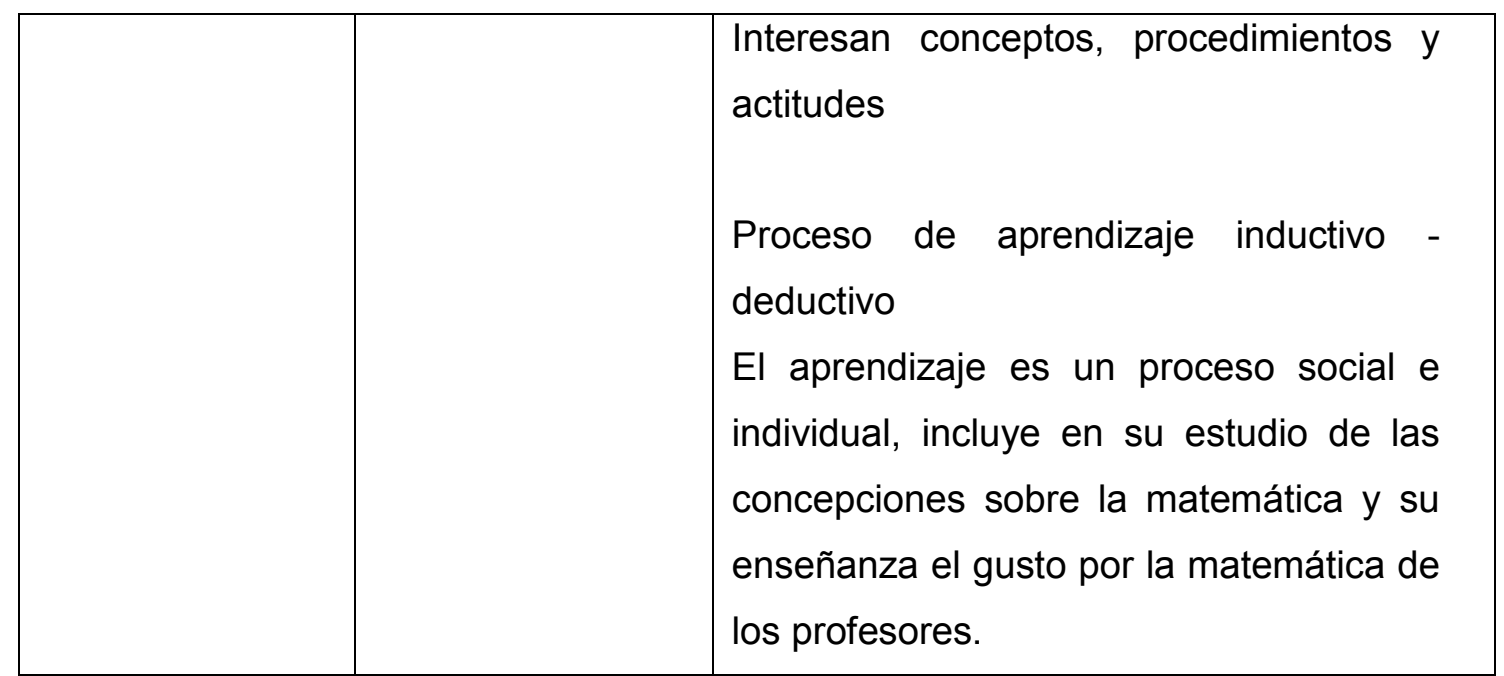

Tabla 6.06. Instrumento de caracterización de tendencias didácticas del profesor de matemáticas. Primer momento de análisis. Elaboración: propia

En las siguientes páginas se presentan los descriptores de cada uno de los elementos de las concepciones del profesor que pueden surgir en el análisis frente a la metodología, la concepción del aprendizaje, el papel del alumno y el papel del profesor correspondientes al segundo momento: 


\section{Metodología}

\begin{tabular}{|c|c|c|c|c|}
\hline & Tradicional & Tecnológica & Espontaneista & Investigativa \\
\hline 1 & $\begin{array}{l}\text { La actividad del aula } \\
\text { se caracteriza por la } \\
\text { repetición reiterada } \\
\text { de ejercicios tipo. }\end{array}$ & $\begin{array}{l}\text { La actividad del aula se } \\
\text { caracteriza por la repetición } \\
\text { de ejercicios que intentan } \\
\text { reproducir procesos lógicos } \\
\text { y, coherentemente, el } \\
\text { estudio de los errores por } \\
\text { parte de los alumnos. }\end{array}$ & $\begin{array}{l}\text { Los ejercicios son } \\
\text { sustituidos por una } \\
\text { actividad experimental } \\
\text { no reflexiva. } \\
\text { Hay cierta tendencia a } \\
\text { poner en juego métodos, } \\
\text { recursos, etc. que } \\
\text { parecen funcionar en } \\
\text { otras aulas }\end{array}$ & $\begin{array}{l}\text { Los alumnos se enfrentan } \\
\text { habitualmente a situaciones para las } \\
\text { que no poseen procesos de } \\
\text { resolución dados, estas son } \\
\text { situaciones problemáticas, ya sean } \\
\text { problemas o investigaciones, } \\
\text { frecuentemente contextualizadas en } \\
\text { problemáticas reales. }\end{array}$ \\
\hline
\end{tabular}




\begin{tabular}{|c|c|c|c|c|}
\hline & & & $\begin{array}{ll}\text { eventualmente, } & \text { un } \\
\text { conocimiento } & \text { no } \\
\text { organizado. } & \end{array}$ & \\
\hline 3 & $\begin{array}{l}\text { La principal fuente } \\
\text { de información para } \\
\text { el alumno la } \\
\text { constituyen el } \\
\text { docente y el libro de } \\
\text { texto. }\end{array}$ & $\begin{array}{l}\text { El libro de texto se ve } \\
\text { ampliado por otros } \\
\text { materiales donde se } \\
\text { encuentra el "conocimiento } \\
\text { establecido" } \\
\text { Se mantiene el papel del } \\
\text { docente como principal } \\
\text { fuente de información. }\end{array}$ & \multicolumn{2}{|c|}{$\begin{array}{l}\text { La información que se moviliza en el aula puede provenir del } \\
\text { docente, de los alumnos, de otras personas que intervengan, de } \\
\text { situaciones cotidianas... }\end{array}$} \\
\hline 4 & \multicolumn{2}{|c|}{$\begin{array}{l}\text { El docente "enseña" para un alumno ficticio que se } \\
\text { identifica con el alumno "medio" del grupo-clase, } \\
\text { homogeneizando el grupo. } \\
\text { No se realiza diferenciación individual en el proceso } \\
\text { de enseñanza. }\end{array}$} & $\begin{array}{l}\text { La actividad que se } \\
\text { genera en el aula } \\
\text { permite que cada } \\
\text { alumno la realice según } \\
\text { sus posibilidades, } \\
\text { contando con la ayuda } \\
\text { de sus compañeros. } \\
\text { Se atiende } \\
\text { implícitamente no }\end{array}$ & $\begin{array}{l}\text { Se atiende explícitamente a la } \\
\text { diferenciación individual mediante el } \\
\text { planteamiento de actividades que } \\
\text { permiten el trabajo en distintos } \\
\text { niveles y con actividades específicas } \\
\text { para cada necesidad. }\end{array}$ \\
\hline
\end{tabular}




\begin{tabular}{|c|c|c|c|c|}
\hline & & & $\begin{array}{l}\text { planificado a la } \\
\text { diferenciación individual }\end{array}$ & \\
\hline 5 & $\begin{array}{l}\text { No se usan } \\
\text { materiales } \\
\text { manipulativos. }\end{array}$ & $\begin{array}{l}\text { Se usan materiales } \\
\text { manipulativos para reforzar, } \\
\text { explicar o dar utilidad a la } \\
\text { teoría, de manera aislada }\end{array}$ & $\begin{array}{l}\text { Se usan asiduamente } \\
\text { materiales variados } \\
\text { sobre todo para motivar } \\
\text { a los alumnos y facilitar } \\
\text { su comunicación. Es } \\
\text { fundamental que éstos } \\
\text { los manipulen. }\end{array}$ & $\begin{array}{l}\text { Se usan materiales variados como } \\
\text { apoyo a y detonante de la } \\
\text { investigación matemática del } \\
\text { alumno, también para apoyar el paso } \\
\text { del pensamiento concreto al } \\
\text { abstracto }\end{array}$ \\
\hline 6 & 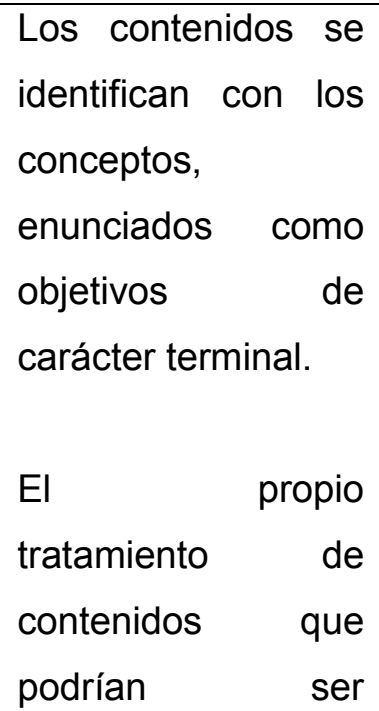 & $\begin{array}{l}\text { Se persiguen objetivos } \\
\text { terminales y funcionales, } \\
\text { poniéndose más énfasis en } \\
\text { objetivos procedimentales } \\
\text { locales }\end{array}$ & $\begin{array}{l}\text { Los objetivos sólo } \\
\text { definen un marco } \\
\text { genérico de actuación } \\
\text { de carácter orientativo y } \\
\text { están sujetos a } \\
\text { eventuales } \\
\text { modificaciones en } \\
\text { cuanto al grado de } \\
\text { consecución. }\end{array}$ & $\begin{array}{l}\text { Los objetivos marcan claramente las } \\
\text { intenciones educativas, pero están } \\
\text { sujetos a reformulaciones bien } \\
\text { fundamentadas }\end{array}$ \\
\hline
\end{tabular}




\begin{tabular}{|c|c|c|c|c|}
\hline & $\begin{array}{l}\text { procedimentales los } \\
\text { convierte en } \\
\text { conceptuales. }\end{array}$ & & & \\
\hline 7 & $\begin{array}{l}\text { El docente sigue } \\
\text { una programación } \\
\text { prescrita de } \\
\text { antemano, externa a } \\
\text { él y rígida, sin } \\
\text { plantearse } \\
\text { relaciones entre las } \\
\text { unidades }\end{array}$ & $\begin{array}{l}\text { Para el docente ra } \\
\text { programación es un } \\
\text { documento cerrado, que } \\
\text { elabora previamente en } \\
\text { función de sus } \\
\text { conocimientos de la materia } \\
\text { escolar, de sus alumnos, de } \\
\text { su experiencia previa en la } \\
\text { enseñanza de esos } \\
\text { contenidos. }\end{array}$ & $\begin{array}{l}\text { La programación es un } \\
\text { documento vivo que, por } \\
\text { basarse en los intereses } \\
\text { que, en cada momento, } \\
\text { manifiestan los alumnos } \\
\text { y en la negociación con } \\
\text { ellos, no dispone de una } \\
\text { organización inicial. }\end{array}$ & $\begin{array}{l}\text { El docente dispone de una propuesta } \\
\text { organizativa de los elementos del } \\
\text { programa, pero no está vinculado a } \\
\text { un recorrido concreto. } \\
\text { Existe una trama que vincula y } \\
\text { organiza el conocimiento por la que } \\
\text { el docente se mueve dependiendo de } \\
\text { los intereses y el nivel de los } \\
\text { alumnos. }\end{array}$ \\
\hline
\end{tabular}

Tabla 6.07. Instrumento de caracterización de metodología del profesor de matemáticas. Segundo momento de análisis 


\section{Evaluación}

\begin{tabular}{|c|c|c|c|c|}
\hline 8 & Para calificar. & $\begin{array}{l}\text { Para calificar a los alumnos y } \\
\text { medir la consecución de los } \\
\text { objetivos prefijados. }\end{array}$ & $\begin{array}{l}\text { Para comprobar el interés } \\
\text { de los alumnos y mejorar la } \\
\text { dinámica del aula. }\end{array}$ & $\begin{array}{l}\text { Para valorar la evolución de las ideas de } \\
\text { los alumnos y mejorar los procesos de } \\
\text { enseñanza y de aprendizaje. }\end{array}$ \\
\hline 9 & $\begin{array}{l}\text { Centrada en } \\
\text { 'reproducir' los } \\
\text { contenidos } \\
\text { practicados, } \\
\text { principalmente los } \\
\text { algorítmicos y las } \\
\text { aplicaciones } \\
\text { mostradas.Atiende, } \\
\text { sobre todo al producto. }\end{array}$ & $\begin{array}{l}\text { Centrada en la medición } \\
\text { detallada de los aprendizajes. } \\
\text { Atiende al producto, pero } \\
\text { intenta medir la consecución de } \\
\text { los objetivos prefijados. }\end{array}$ & $\begin{array}{lrr}\text { Centrada en } & \text { los } \\
\text { procedimientos y en las } \\
\text { actitudes. Atiende } & \text { al } \\
\text { proceso, aunque no de } \\
\text { forma sistemática. }\end{array}$ & $\begin{array}{l}\text { Centrada en la evolución del } \\
\text { conocimiento del alumno, la actuación } \\
\text { del profesor y el desarrollo del proyecto } \\
\text { y de los procesos. Se reconsideran los } \\
\text { diversos aspectos metodológicos a } \\
\text { partir de las conclusiones. }\end{array}$ \\
\hline
\end{tabular}




\begin{tabular}{|l|l|l|l|l|l|}
\hline 10 & $\begin{array}{l}\text { Realizada mediante } \\
\text { exámenes escritos. }\end{array}$ & $\begin{array}{l}\text { Realizada mediante exámenes } \\
\text { y plantillas específicas de } \\
\text { observación. }\end{array}$ & $\begin{array}{l}\text { Realizada mediante la } \\
\text { observación directa del } \\
\text { trabajo de los grupos de } \\
\text { alumnos y su participación } \\
\text { éstos y en asambleas. }\end{array}$ & $\begin{array}{l}\text { Realizada } \\
\text { Instrumentos de seguimiento: } \\
\text { producciones de los alumnos, diario del } \\
\text { profesor, observaciones de varios tipos, } \\
\text { etc. }\end{array}$ \\
\hline 11 & Al final del proceso. & Al inicio y final del proceso. & Realizada periódicamente. & Realizada de forma continua. \\
\hline 12 & El profesor. & El profesor y/o los alumnos. & El profesor y los alumnos. & El profesor y los alumnos. \\
\hline
\end{tabular}

Tabla 6.08. Instrumento de caracterización de evaluación del profesor de matemáticas. Segundo momento de análisis 


\section{Concepción de las Matemáticas Escolares}

\begin{tabular}{|c|c|c|c|c|}
\hline & Tradicional & Tecnológica & Espontaneista & Investigativa \\
\hline 13 & $\begin{array}{l}\text { La asignatura está } \\
\text { orientada, } \\
\text { exclusivamente, } \\
\text { hacia la } \\
\text { adquisición de } \\
\text { conceptos y reglas }\end{array}$ & $\begin{array}{l}\text { Interesan tanto los conceptos } \\
\text { y reglas como los procesos } \\
\text { lógicos que los sustentan }\end{array}$ & $\begin{array}{l}\text { No interesan tanto los } \\
\text { conceptos como los } \\
\text { procedimientos y el } \\
\text { fomento de actitudes } \\
\text { positivas hacia el trabajo } \\
\text { escolar y como } \\
\text { ciudadano. }\end{array}$ & $\begin{array}{l}\text { Interesan tanto la adquisición de } \\
\text { conceptos, como el desarrollo de } \\
\text { procedimientos y el fomento de } \\
\text { actitudes positivas hacia la propia } \\
\text { materia, el trabajo escolar en general } \\
\text { y como ciudadano, siendo la materia } \\
\text { y el trabajo escolar los que } \\
\text { determinan el peso específico de } \\
\text { cada una de las componentes } \\
\text { citadas. }\end{array}$ \\
\hline 14 & $\begin{array}{l}\text { Se identifica con cor } \\
\text { No se suelen consid } \\
\text { se hace consiste en } \\
\text { No se establecen re }\end{array}$ & $\begin{array}{l}\text { nidos matemáticos escolares. } \\
\text { ar contenidos geométricos y si } \\
\text { listado de nombres. } \\
\text { iones entre los contenidos. }\end{array}$ & $\begin{array}{l}\text { Las matemáticas } \\
\text { inmersas en la } \\
\text { problemática real son el } \\
\text { único referente de los } \\
\text { conocimientos } \\
\text { movilizar en el aula. }\end{array}$ & $\begin{array}{l}\text { Las matemáticas escolares parten a } \\
\text { partir de la etnomatemática de los } \\
\text { alumnos y recoge las necesidades } \\
\text { socio-políticas, culturales de ellos } \\
\text { El conocimiento matemático se } \\
\text { construye a partir de un carácter más } \\
\text { formal de acuerdo a la edad de los } \\
\text { estudiantes, el cual proviene del }\end{array}$ \\
\hline
\end{tabular}




\begin{tabular}{|c|c|c|c|c|}
\hline & & & & $\begin{array}{l}\text { análisis de lo concreto. } \\
\text { Los contenidos matemáticos } \\
\text { escolares se consideran tanto los } \\
\text { numéricos propios de la etapa, como } \\
\text { los geométricos, la medida, el } \\
\text { tratamiento de la información y la } \\
\text { resolución de problemas, destacando } \\
\text { este último. }\end{array}$ \\
\hline 15 & $\begin{array}{l}\text { Las matemáticas } \\
\text { conciben acabadas }\end{array}$ & colares son exactas y se & $\begin{array}{l}\text { Se potencian la } \\
\text { estimación y la } \\
\text { aproximación, ligadas a } \\
\text { contextos reales, y se } \\
\text { concibe en construcción. } \\
\text { Se construye en el } \\
\text { propio contexto escolar } \\
\text { por parte de los alumnos }\end{array}$ & $\begin{array}{l}\text { Las matemáticas escolares muestran } \\
\text { su doble perspectiva de } \\
\text { exactitud/aproximación dependiendo } \\
\text { del contexto y se concibe en } \\
\text { construcción. }\end{array}$ \\
\hline 16 & $\begin{array}{l}\text { La finalidad de la } \\
\text { asignatura } \\
\text { poner }\end{array}$ & $\begin{array}{l}\text { La asignatura ha de tener un } \\
\text { carácter práctico que permita } \\
\text { su aplicación utilitaria en la }\end{array}$ & $\begin{array}{l}\text { La asignatura posee un } \\
\text { carácter formativo, con } \\
\text { objeto de servir de }\end{array}$ & $\begin{array}{l}\text { La finalidad última de la asignatura es } \\
\text { favorecer el desarrollo de una forma } \\
\text { de pensamiento matemático que }\end{array}$ \\
\hline
\end{tabular}




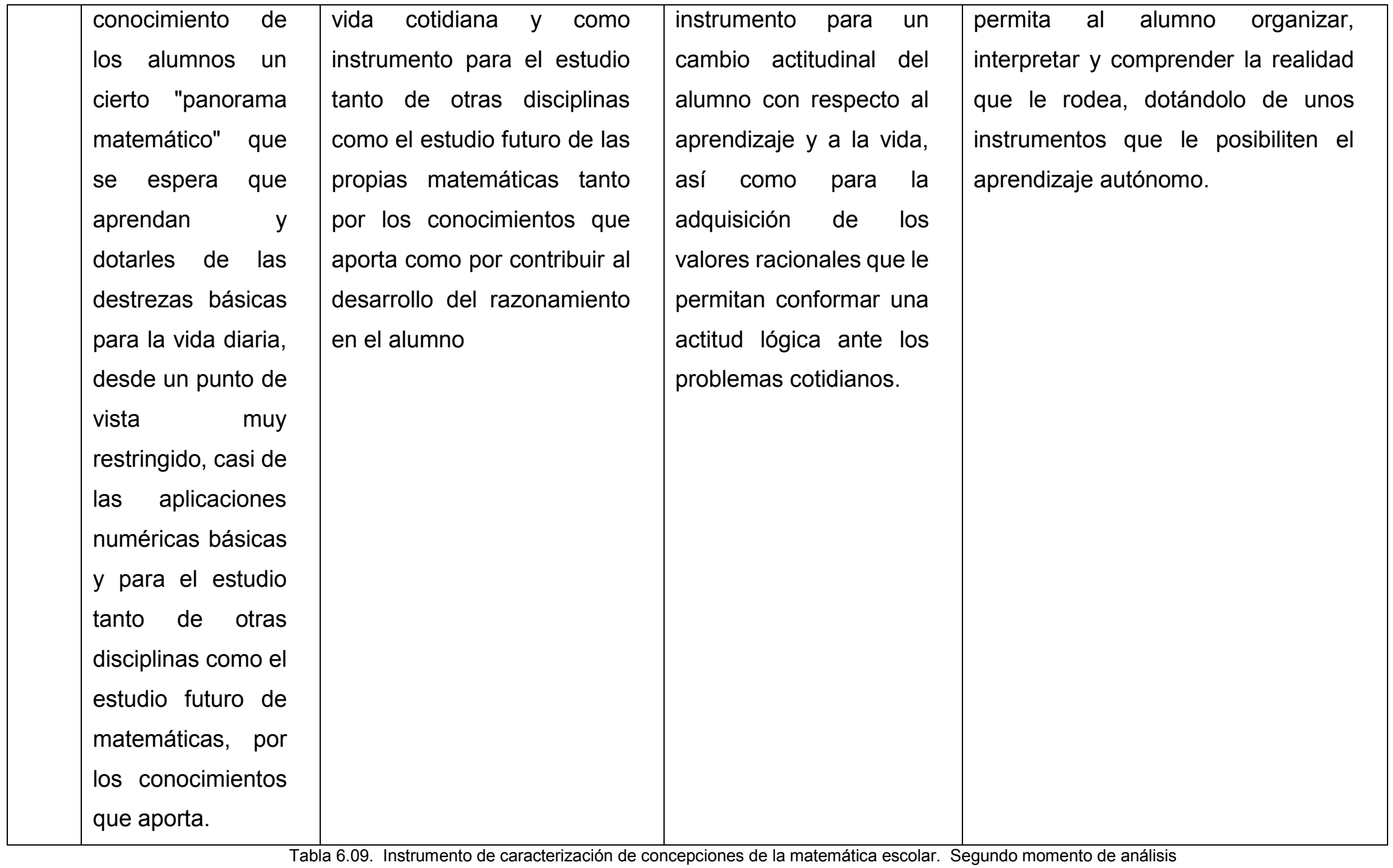




\section{Concepción del aprendizaje}

\begin{tabular}{|c|c|c|c|c|}
\hline & Tradicional & Tecnológica & Espontaneista & Investigativa \\
\hline 17 & $\begin{array}{l}\text { Se presupone que el } \\
\text { aprendizaje se } \\
\text { realiza, utilizando la } \\
\text { memoria como } \\
\text { principal recurso, } \\
\text { por superposición } \\
\text { de unidades de } \\
\text { información }\end{array}$ & $\begin{array}{l}\text { El aprendizaje se sigue } \\
\text { concibiendo } \\
\text { memorístico, } \\
\text { organizándose } \\
\text { internamente según la } \\
\text { lógica estructural de la } \\
\text { materia'". }\end{array}$ & $\begin{array}{l}\text { Se aprende cuando el } \\
\text { objeto de aprendizaje, } \\
\text { que surge } \\
\text { aleatoriamente del } \\
\begin{array}{l}\text { contexto, posee un } \\
\text { significado para el } \\
\text { alumno. }\end{array}\end{array}$ & $\begin{array}{l}\text { Los objetos de aprendizaje no sólo } \\
\text { tienen significado, sino también la } \\
\text { capacidad de ser aplicados en } \\
\text { contextos diferentes de donde fueron } \\
\text { aprendidos, adquiriendo así un } \\
\text { carácter móvil a través de una malla } \\
\text { conceptual. }\end{array}$ \\
\hline 18 & $\begin{array}{l}\text { El único aprendizaje } \\
\text { efectivo y correcto } \\
\text { es el que proviene } \\
\text { de un proceso } \\
\text { deductivo. }\end{array}$ & $\begin{array}{l}\text { Aunque el aprendizaje } \\
\text { pueda comenzar por la } \\
\text { observación de un proceso } \\
\text { inductivo, el verdadero } \\
\text { aprendizaje ha de apoyarse } \\
\text { en un proceso deductivo. }\end{array}$ & $\begin{array}{l}\text { El aprendizaje se } \\
\text { produce a partir de la } \\
\text { participación activa del } \\
\text { alumno en procesos } \\
\text { inductivos. }\end{array}$ & $\begin{array}{l}\text { El aprendizaje comienza, } \\
\text { normalmente, por la observación de } \\
\text { regularidades que permiten aflorar } \\
\text { una conjetura; pero a ésta ha de } \\
\text { seguir una comprobación razonable } \\
\text { y, en la medida de lo posible, una } \\
\text { generalización adecuada }\end{array}$ \\
\hline 19 & $\begin{array}{l}\text { El alumno se hace } \\
\text { con los } \\
\text { conocimientos por el } \\
\text { simple hecho de que }\end{array}$ & $\begin{array}{l}\text { Para aprender, al alumno le } \\
\text { basta entender, asimilar el } \\
\text { conocimiento que proviene } \\
\text { del exterior. }\end{array}$ & $\begin{array}{l}\text { El aprendizaje se } \\
\text { produce, de manera } \\
\text { espontánea, cuando el } \\
\text { alumno está inmerso en }\end{array}$ & $\begin{array}{l}\text { El aprendizaje se produce a través de } \\
\text { investigaciones que han sido } \\
\text { planificadas por el docente. Además, }\end{array}$ \\
\hline
\end{tabular}




\begin{tabular}{|c|c|c|c|c|}
\hline & $\begin{array}{l}\text { el docente se los } \\
\text { presente. }\end{array}$ & & $\begin{array}{lr}\text { situaciones } & \text { que } \\
\text { propician } & \text { el } \\
\text { descubrimiento } & \end{array}$ & $\begin{array}{l}\text { para que se produzca aprendizaje } \\
\text { éste debe institucionalizarse. }\end{array}$ \\
\hline 20 & $\begin{array}{l}\text { El docente desea } \\
\text { que el alumno } \\
\text { explicite ro lo } \\
\text { aprendido con la } \\
\text { expresión usada por } \\
\text { él. No le interesa la } \\
\text { idea sino la } \\
\text { mecánica. De ahí } \\
\text { que no conceda } \\
\text { especial } \\
\text { importancia a que el } \\
\text { alumno argumente } \\
\text { sus conclusiones. }\end{array}$ & $\begin{array}{l}\text { Es importante que el } \\
\text { alumno explicite la } \\
\text { comprensión de los } \\
\text { contenidos (se trata de una } \\
\text { verbalización para } \\
\text { comprobar que se está } \\
\text { produciendo el aprendizaje } \\
\text { deseado). La expresión de } \\
\text { lo aprendido, con las } \\
\text { palabras del alumno, } \\
\text { muestra el resultado del } \\
\text { aprendizaje. }\end{array}$ & $\begin{array}{l}\text { Es importante que el } \\
\text { alumno comunique (más } \\
\text { que argumente de un } \\
\text { modo más o menos } \\
\text { justificado) } \\
\text { conclusiones. }\end{array}$ & $\begin{array}{l}\text { La expresión de lo que aprende por } \\
\text { parte del alumno es una parte } \\
\text { importante del propio proceso de } \\
\text { aprendizaje. Es importante, además, } \\
\text { que el alumno argumente sus } \\
\text { conclusiones. }\end{array}$ \\
\hline 21 & \multicolumn{2}{|c|}{$\begin{array}{l}\text { El alumno interactúa con la materia y el docente, } \\
\text { siendo el último el intermediario entre ésta y el } \\
\text { alumno. La interacción que se produce entre el } \\
\text { profesor y el alumno no es equilibrada, siendo más } \\
\text { fuerte el flujo en la dirección profesores alumno que } \\
\text { la inversa. }\end{array}$} & $\begin{array}{l}\text { El alumno interactúa con } \\
\text { la materia, el docente y } \\
\text { sus compañeros, pero el } \\
\text { énfasis se coloca en la } \\
\text { interacción con los }\end{array}$ & $\begin{array}{l}\text { Los principales elementos del } \\
\text { entorno de aprendizaje interactúan } \\
\text { entre sí (el alumno interactúa con la } \\
\text { materia, el docente y sus } \\
\text { compañeros) de manera equilibrada. }\end{array}$ \\
\hline
\end{tabular}




\begin{tabular}{|c|c|c|c|c|}
\hline & & & $\begin{array}{lll}\text { compañeros } & \text { y } & \text { el } \\
\text { docente. } & & \end{array}$ & \\
\hline 22 & \multicolumn{2}{|c|}{$\begin{array}{l}\text { La única forma de agrupamiento que permite un } \\
\text { verdadero aprendizaje es el trabajo individual. }\end{array}$} & $\begin{array}{l}\text { La forma ideal de } \\
\text { agrupamiento que } \\
\text { propicia el aprendizaje } \\
\text { es el trabajo en grupo, } \\
\text { con sus } \\
\text { correspondientes } \\
\text { debates. }\end{array}$ & $\begin{array}{l}\text { La forma de agrupamiento } \\
\text { aconsejable para la producción de } \\
\text { aprendizaje depende de la actividad } \\
\text { a desarrollar. }\end{array}$ \\
\hline 23 & $\begin{array}{l}\text { La estructura de la } \\
\text { propia asignatura, } \\
\text { plasmada en la } \\
\text { programación, es el } \\
\text { dinamizador ideal } \\
\text { del aprendizaje. }\end{array}$ & \begin{tabular}{llr} 
El dinamizador & ideal del \\
aprendizaje & es & la lógica \\
subyacente & a & los \\
contenidos & \multicolumn{2}{c}{ matemáticos } \\
escolares. & \multicolumn{2}{c}{}
\end{tabular} & $\begin{array}{l}\text { El motor del aprendizaje } \\
\text { son los intereses de los } \\
\text { alumnos. }\end{array}$ & $\begin{array}{l}\text { El dinamizador ideal del aprendizaje } \\
\text { es el equilibrio entre los intereses y } \\
\text { estructura mental de los alumnos y } \\
\text { los de las matemáticas. }\end{array}$ \\
\hline 24 & \multicolumn{2}{|c|}{$\begin{array}{l}\text { La forma como aprende el alumno es inalterable y } \\
\text { justifica en gran medida en los resultados }\end{array}$} & \multirow{2}{*}{\multicolumn{2}{|c|}{ La forma como aprende el alumno puede ser modificada }} \\
\hline 25 & $\begin{array}{l}\text { La actitud del } \\
\text { alumno hacia el } \\
\text { aprendizaje no se } \\
\text { transforma. }\end{array}$ & $\begin{array}{l}\text { En la actitud del alumno } \\
\text { hacia el aprendizaje hay } \\
\text { aspectos que pueden sufrir } \\
\text { cambios. }\end{array}$ & & \\
\hline
\end{tabular}




\section{Papel del alumno}

\begin{tabular}{|c|c|c|c|c|}
\hline & Tradicional & Tecnológica & Espontaneista & Investigativa \\
\hline 26 & \multicolumn{2}{|c|}{$\begin{array}{l}\text { El alumno no tiene que ver con el diseño de las } \\
\text { actividades programadas para el trabajo en aula ni } \\
\text { con la planeación de clase ni con el diseño didáctico }\end{array}$} & $\begin{array}{l}\text { El alumno hace parte } \\
\text { indirecta de la selección } \\
\text { y secuenciación de } \\
\text { contenidos y objetivos, a } \\
\text { través de la negociación } \\
\text { de intereses, y en el } \\
\text { diseño didáctico, a } \\
\text { través de } \\
\text { intervenciones en el } \\
\text { quehacer del aula. }\end{array}$ & $\begin{array}{l}\text { El alumno hace parte directa e } \\
\text { indirectamente en el diseño didáctico } \\
\text { a partir de su actitud y predisposición } \\
\text { para aprender por sí mismo }\end{array}$ \\
\hline 27 & $\begin{array}{l}\text { En los casos en } \\
\text { que exista una } \\
\text { "buena } \\
\text { enseñanza", la } \\
\text { responsabilidad de } \\
\text { los resultados del } \\
\text { aprendizaje, que } \\
\text { dependen del } \\
\text { grado de sumisión, }\end{array}$ & $\begin{array}{l}\text { Cuando los procesos de } \\
\text { enseñanza se realizan en un } \\
\text { contexto adecuado, la } \\
\text { responsabilidad } \\
\text { aprendizaje recae en el } \\
\text { alumno. }\end{array}$ & $\begin{array}{l}\text { La motivación } \\
\text { proveniente de la propia } \\
\text { acción es la clave de los } \\
\text { buenos resultados del } \\
\text { aprendizaje. }\end{array}$ & $\begin{array}{l}\text { Para que se dé aprendizaje es } \\
\text { necesario que el alumno otorgue } \\
\text { significado a lo que aprende, siendo } \\
\text { consciente de su propio proceso de } \\
\text { aprendizaje. } \\
\text { La responsabilidad del aprendizaje } \\
\text { recae en la marcha del proceso } \\
\text { completo. }\end{array}$ \\
\hline
\end{tabular}




\begin{tabular}{|c|c|c|c|c|}
\hline & $\begin{array}{l}\text { es exclusiva del } \\
\text { alumno. }\end{array}$ & & & \\
\hline 28 & $\begin{array}{l}\text { El alumno escucha } \\
\text { la explicación del } \\
\text { docente para } \\
\text { poder repetir } \\
\text { posteriormente el } \\
\text { proceso explicado. }\end{array}$ & $\begin{array}{l}\text { El alumno, al enfrentarse a } \\
\text { cada una de sus tareas } \\
\text { educativas, reproduce el } \\
\text { proceso lógico mostrado por } \\
\text { el docente, imitando así su } \\
\text { estilo cognitivo. }\end{array}$ & $\begin{array}{l}\text { El alumno pasa de } \\
\text { actividad en actividad, } \\
\text { participando } \\
\text { intensamente en cada } \\
\text { una de ellas. }\end{array}$ & $\begin{array}{l}\text { La actividad del alumno está } \\
\text { organizada, interna o externamente, } \\
\text { hacia la búsqueda de respuestas a } \\
\text { determinados interrogantes. }\end{array}$ \\
\hline 29 & \multicolumn{2}{|c|}{$\begin{array}{l}\text { Al ser el docente el que proporciona la clave para la } \\
\text { repetición/reproducción posterior, es fundamental la } \\
\text { atención a éste, es decir la fuente de información } \\
\text { fundamental. }\end{array}$} & $\begin{array}{l}\text { La actividad del alumno } \\
\text { no incluye un tiempo } \\
\text { para la reflexión sobre } \\
\text { su propia acción. }\end{array}$ & $\begin{array}{l}\text { El alumno toma conciencia de qué } \\
\text { hace y para qué lo hace. }\end{array}$ \\
\hline 30 & $\begin{array}{l}\text { El alumno no se } \\
\text { plantea procesar la } \\
\text { información que } \\
\text { proviene del } \\
\text { docente, ni en } \\
\text { forma ni en fondo. }\end{array}$ & $\begin{array}{l}\text { La confianza del alumno en } \\
\text { lo expuesto por el docente, } \\
\text { inducida por la técnica } \\
\text { empleada, le impide } \\
\text { cuestionarse sobre el fondo } \\
\text { del contenido. }\end{array}$ & $\begin{array}{l}\text { El ambiente dinámico } \\
\text { que se propicia en la } \\
\text { clase, permite que el } \\
\text { alumno comunique sus } \\
\text { experiencias } \\
\text { sentimientos con el } \\
\text { docente y los demás } \\
\text { compañeros. }\end{array}$ & $\begin{array}{l}\text { El alumno mantiene una actitud crítica } \\
\text { ante las informaciones que se } \\
\text { movilizan en el aula. }\end{array}$ \\
\hline
\end{tabular}

Tabla 6.11. Instrumento de caracterización del papel del alumno. Segundo momento de análisis 


\section{Papel del docente}

\begin{tabular}{|c|c|c|c|c|}
\hline & Tradicional & Tecnológica & Espontaneista & Investigativa \\
\hline 31 & $\begin{array}{l}\text { El docente } \\
\text { transmite } \\
\text { verbalmente los } \\
\text { contenidos de } \\
\text { aprendizaje, } \\
\text { mediante } \\
\text { explicación de lo } \\
\text { reflejado en el } \\
\text { libro de texto, } \\
\text { realizando una } \\
\text { reproducción } \\
\text { literal de éste. } \\
\text { Actúa como un } \\
\text { especialista en el } \\
\text { contenido. }\end{array}$ & $\begin{array}{l}\text { El docente organiza los } \\
\text { contenidos de aprendizaje, } \\
\text { los cuales transmite } \\
\text { mediante exposición, } \\
\text { utilizando estrategias } \\
\text { organizativas expositivas que } \\
\text { procuran ser atractivas. } \\
\text { Actúa como un técnico del } \\
\text { contenido y del diseño } \\
\text { didáctico. }\end{array}$ & $\begin{array}{l}\text { Por su marcado carácter } \\
\text { humanista y especialista } \\
\text { en dinámica de grupos, } \\
\text { induce al alumno a } \\
\text { participar en las } \\
\text { actividades } \\
\text { promueve, analizando } \\
\text { las reacciones y } \\
\text { respuestas a sus } \\
\text { propuestas. }\end{array}$ & $\begin{array}{l}\text { El docente provoca la curiosidad del } \\
\text { alumno conduciendo su investigación } \\
\text { hacia la consecución de } \\
\text { aprendizajes. Su carácter de } \\
\text { experimentador interactivo del } \\
\text { contenido y de los métodos le obliga } \\
\text { a analizar los procesos en el contexto } \\
\text { del aula (investigación -acción). }\end{array}$ \\
\hline 32 & $\begin{array}{l}\text { El docente (y/o el } \\
\text { libro de texto) es el } \\
\text { que valida las } \\
\text { ideas que se } \\
\text { movilizan en el }\end{array}$ & $\begin{array}{l}\text { El docente es el que valida } \\
\text { las ideas que se movilizan en } \\
\text { el aula, planteando } \\
\text { interrogantes a los alumnos } \\
\text { cuyas respuestas llevan a la }\end{array}$ & $\begin{array}{l}\text { La información que se } \\
\text { moviliza en el aula es } \\
\text { validada por el grupo } \\
\text { (grupo-clase o pequeños } \\
\text { grupos de trabajo). En }\end{array}$ & $\begin{array}{l}\text { La información que se moviliza en el } \\
\text { aula es validada por el grupo, por el } \\
\text { docente o por el propio alumno. En } \\
\text { cualquier caso, se potencia la } \\
\text { reflexión de los alumnos y el }\end{array}$ \\
\hline
\end{tabular}




\begin{tabular}{|c|c|c|c|}
\hline $\begin{array}{l}\text { aula, corrigiendo a } \\
\text { los alumnos en } \\
\text { caso de errores y } \\
\text { aportando él } \\
\text { mismo la } \\
\text { información } \\
\text { correcta. }\end{array}$ & $\begin{array}{l}\text { "auto corrección" (en verdad } \\
\text { es una corrección } \\
\text { enmascarada del docente). }\end{array}$ & $\begin{array}{l}\text { ocasiones se sustituye el } \\
\text { papel de la corrección, } \\
\text { pero no se potencia que } \\
\text { los alumnos "separen a } \\
\text { reflexionar" sobre sus } \\
\text { ideas ni que desarrollen } \\
\text { estrategias de } \\
\text { autovalidación delas } \\
\text { mismas' }\end{array}$ & $\begin{array}{l}\text { desarrollo de estrategias para su } \\
\text { autocorrección, propiciándose que } \\
\text { los estudiantes asuman } \\
\text { responsabilidad a la hora de juzgar la } \\
\text { adecuación de sus ideas. }\end{array}$ \\
\hline
\end{tabular}

Tabla 6.12. Instrumento de caracterización del papel del profesor. Segundo momento de análisis 
Finalmente, la tabla correspondiente al tercer momento del análisis:

\begin{tabular}{|c|c|c|c|c|c|}
\hline \multicolumn{2}{|c|}{ Categoría/Tendencias } & \multirow{2}{*}{$\begin{array}{l}\text { Tradicional } \\
\text { Ejercitación } \\
\text { repetitiva }\end{array}$} & \multirow{2}{*}{$\begin{array}{l}\text { Tecnológica } \\
\text { Ejercitación } \\
\text { reproductiva } \\
\text { (procedimientos } \\
\text { lógicos) }\end{array}$} & Espontaneista & \multirow{2}{*}{$\begin{array}{l}\text { Investigativa } \\
\text { Resolución de situaciones } \\
\text { problemáticas }\end{array}$} \\
\hline \multirow{6}{*}{ 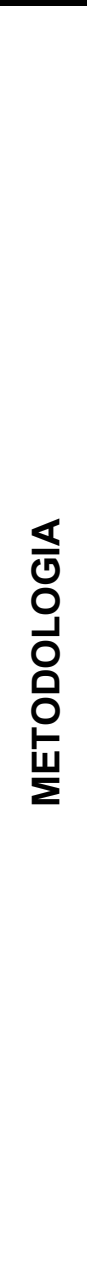 } & Praxis & & & $\begin{array}{l}\text { Experimentación } \\
\text { (énfasis en el } \\
\text { método) }\end{array}$ & \\
\hline & & $\begin{array}{l}\text { Exposición } \\
\text { magistral }\end{array}$ & Exposición inductiva & $\begin{array}{l}\text { Descubrimiento } \\
\text { aleatorio, } \\
\text { manipulación de } \\
\text { modelos }\end{array}$ & Investigación planificada \\
\hline & $\begin{array}{l}\text { Fuentes de } \\
\text { Información }\end{array}$ & $\begin{array}{l}\text { Docente y libro } \\
\text { de texto (únicos } \\
\text { referentes) }\end{array}$ & $\begin{array}{l}\text { Docente y material } \\
\text { especializado }\end{array}$ & Diversas & Diversas \\
\hline & $\begin{array}{l}\text { Diferenciación } \\
\text { individual }\end{array}$ & No se realiza & No se realiza & Atención implícita & Atención explícita \\
\hline & Objetivos & $\begin{array}{l}\text { Conceptuales de } \\
\text { carácter terminal }\end{array}$ & $\begin{array}{l}\text { Terminales } \\
\text { operativos } \\
\text { (procedimentales) }\end{array}$ & $\begin{array}{l}\text { Flexibles } \\
\text { orientativos }\end{array}$ & Flexibles y revisables \\
\hline & Programación & $\begin{array}{l}\text { Oficial, } \\
\text { prescriptiva, }\end{array}$ & $\begin{array}{l}\text { Secuencial, } \\
\text { estructurada } \\
\text { cerrada }\end{array}$ & $\begin{array}{l}\text { Aleatoria, } \\
\text { contenidos } \\
\text { negociados }\end{array}$ & $\begin{array}{ll}\text { Redes } & \text { conceptuales } \\
\text { organizadas } & \end{array}$ \\
\hline
\end{tabular}




\begin{tabular}{|c|c|c|c|c|c|}
\hline & & $\begin{array}{l}\text { rígida (unidades } \\
\text { aisladas) }\end{array}$ & & & \\
\hline \multirow{4}{*}{ 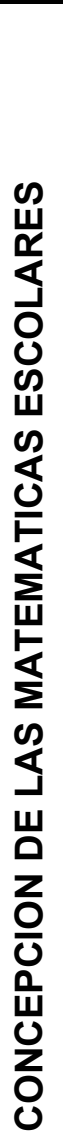 } & Orientación & $\begin{array}{l}\text { Énfasis } \\
\text { conceptual }\end{array}$ & $\begin{array}{l}\text { Énfasis conceptual y } \\
\text { procedimental local }\end{array}$ & $\begin{array}{l}\text { Énfasis } \\
\text { procedimental y } \\
\text { actitudinal }\end{array}$ & $\begin{array}{l}\text { Procedimientos, conceptos } \\
\text { y actitudes }\end{array}$ \\
\hline & $\begin{array}{l}\text { ¿Cuál es su } \\
\text { contenido? }\end{array}$ & $\begin{array}{l}\text { Aritmética, } \\
\text { énfasis } \\
\text { operatorio }\end{array}$ & $\begin{array}{l}\text { Aritmética, énfasis } \\
\text { operatorio }\end{array}$ & $\begin{array}{lr}\text { Matemáticas } & \text { que } \\
\text { emanan de la } \\
\text { problemática real } \\
\text { del entorno }\end{array}$ & $\begin{array}{l}\text { Síntesis de las matemáticas } \\
\text { formales y matemáticas } \\
\text { cotidianas. Importancia de } \\
\text { la resolución de problemas } \\
\text { como contenido }\end{array}$ \\
\hline & ¿Cómo es? & $\begin{array}{l}\text { Exacta } \quad y \\
\text { acabada }\end{array}$ & Exacta y acabada & $\begin{array}{l}\text { Inexacta y en } \\
\text { construcción }\end{array}$ & $\begin{array}{l}\text { Doble perspectiva exacta } \\
\text { inexacta en función del } \\
\text { contexto. En construcción }\end{array}$ \\
\hline & Finalidad & $\begin{array}{l}\text { Informativa } \\
\text { utilitaria } \\
\text { instrumental } \\
\text { (conceptual) }\end{array}$ & $\begin{array}{l}\text { Informativa, utilitaria e } \\
\text { instrumental } \\
\text { (razonamiento) }\end{array}$ & $\begin{array}{l}\text { Formativa con } \\
\text { valores racionales y } \\
\text { actitudes }\end{array}$ & $\begin{array}{l}\text { Formativa, aprender a } \\
\text { aprender }\end{array}$ \\
\hline
\end{tabular}




\begin{tabular}{|c|c|c|c|c|c|}
\hline \multirow{5}{*}{ 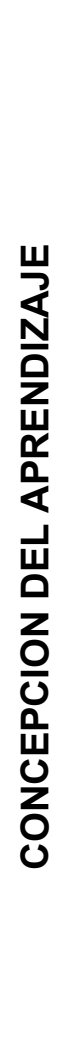 } & Aprendizaje & $\begin{array}{l}\text { Memorístico } \\
\text { acumulativo }\end{array}$ & $\begin{array}{l}\text { Memorístico } \\
\text { secuencial }\end{array}$ & $\begin{array}{l}\text { Significativo } \\
\text { aleatorio }\end{array}$ & $\begin{array}{l}\text { Significativo relevante } \\
\text { mediante redes semánticas }\end{array}$ \\
\hline & Tipo y forma & Deductiva & $\begin{array}{l}\text { Inductivos simulados } \\
\text { y deductivos }\end{array}$ & Inductivo & Inducción - deducción \\
\hline & Procesos & Por apropiación & Por asimilación & $\begin{array}{l}\text { Por construcción } \\
\text { espontánea }\end{array}$ & $\begin{array}{l}\text { Por construcción dirigida. } \\
\text { Institucionalización del } \\
\text { aprendizaje }\end{array}$ \\
\hline & $\begin{array}{l}\text { Importancia } \\
\text { argumentación }\end{array}$ & No se enfatiza & $\begin{array}{lll}\text { Importancia } & \text { de } & \text { la } \\
\text { explicitación } & \text { de } & \text { la } \\
\text { comprensión } & & \text { del } \\
\text { contenido } & & \\
& & \end{array}$ & $\begin{array}{l}\text { Importancia de la } \\
\text { comunicación, ideas }\end{array}$ & $\begin{array}{l}\text { Importancia de la } \\
\text { argumentación mediante } \\
\text { conclusiones como medio y } \\
\text { fin }\end{array}$ \\
\hline & Interacción & $\begin{array}{l}\text { El profesor le da } \\
\text { las matemáticas } \\
\text { a los alumnos }\end{array}$ & $\begin{array}{l}\text { El profesor le brinda } \\
\text { las matemáticas a los } \\
\text { alumnos }\end{array}$ & $\begin{array}{ll}\text { El profesor } \\
\text { interactúa con los } \\
\text { estudiantes } & \text { por } \\
\text { medio de las } \\
\text { matemáticas }\end{array}$ & $\begin{array}{l}\text { Las matemáticas, los } \\
\text { alumnos y el profesor } \\
\text { interactúan entre sí }\end{array}$ \\
\hline
\end{tabular}




\begin{tabular}{|c|c|c|c|c|c|}
\hline & $\begin{array}{l}\text { Tipo de } \\
\text { agrupamiento }\end{array}$ & $\begin{array}{l}\text { Trabajo } \\
\text { individual }\end{array}$ & Trabajo individual & $\begin{array}{l}\text { Trabajo en grupo y } \\
\text { debates }\end{array}$ & $\begin{array}{l}\text { Diversidad de } \\
\text { agrupamientos y puestas en } \\
\text { común }\end{array}$ \\
\hline & Dinamizador & $\begin{array}{l}\text { Estructura de la } \\
\text { asignatura por } \\
\text { programación }\end{array}$ & $\begin{array}{l}\text { Logística de la } \\
\text { disciplina inferida de } \\
\text { la materia escolar }\end{array}$ & $\begin{array}{l}\text { Intereses del grupo } \\
\text { de alumnos }\end{array}$ & $\begin{array}{l}\text { Intereses de los alumnos y } \\
\text { la disciplina }\end{array}$ \\
\hline & Aptitud & Predeterminada & Predeterminada & Transformable & Transformable \\
\hline & Actitud & Predeterminada & $\begin{array}{l}\text { Parcialmente } \\
\text { transformable }\end{array}$ & Transformable & Transformable \\
\hline 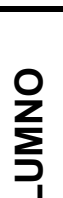 & $\begin{array}{l}\text { Participación en } \\
\text { diseño didáctico }\end{array}$ & No participa & No participa & $\begin{array}{l}\text { Indirectamente a } \\
\text { través de sus } \\
\text { reacciones }\end{array}$ & $\begin{array}{ll}\text { Participa directa } & 0 \\
\text { indirectamente } & \end{array}$ \\
\hline 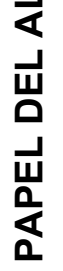 & $\begin{array}{l}\text { Clave de } \\
\text { transferencia de } \\
\text { enseñanza y } \\
\text { aprendizaje }\end{array}$ & $\begin{array}{l}\text { Unión } \\
\text { responsable, } \\
\text { sumisión }\end{array}$ & $\begin{array}{l}\text { Responsable } \\
\text { principal, motivación } \\
\text { por el contexto }\end{array}$ & $\begin{array}{l}\text { Motivación por la } \\
\text { acción }\end{array}$ & $\begin{array}{l}\text { El proceso, motivación por } \\
\text { los significados }\end{array}$ \\
\hline
\end{tabular}




\begin{tabular}{|c|c|c|c|c|c|}
\hline & ¿Qué hace? & $\begin{array}{l}\text { Escucha y repite } \\
\text { Atiende } \\
\text { Acepta }\end{array}$ & $\begin{array}{l}\text { Reproduce e imita } \\
\text { Atiende } \\
\text { Cree }\end{array}$ & $\begin{array}{l}\text { Actúa } \\
\text { Juega } \\
\text { Dialoga }\end{array}$ & $\begin{array}{l}\text { Investiga } \\
\text { Reflexiona } \\
\text { Cuestiona }\end{array}$ \\
\hline \multirow{5}{*}{ 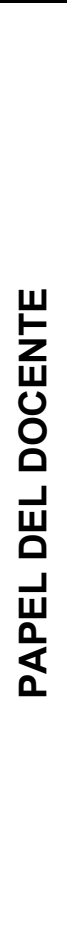 } & ¿Qué hace? & $\begin{array}{l}\text { Transmite } \\
\text { verbalmente }\end{array}$ & $\begin{array}{l}\text { Transmite por } \\
\text { procesos } \\
\text { tecnológicos }\end{array}$ & Induce & Provoca \\
\hline & ¿Cómo hace? & Explica & Expone & Promueve & Conduce \\
\hline & ¿Qué hace? & Reproduce & Organiza & $\begin{array}{l}\text { Analiza reacciones } \\
\text { y respuestas a sus } \\
\text { propuestas }\end{array}$ & $\begin{array}{l}\text { Investiga en y sobre la } \\
\text { acción }\end{array}$ \\
\hline & Actúa como & $\begin{array}{l}\text { Especialista en el } \\
\text { contenido }\end{array}$ & $\begin{array}{l}\text { Técnico del contenido } \\
\text { y del diseño didáctico }\end{array}$ & $\begin{array}{l}\text { Humanista, } \\
\text { especialista en } \\
\text { grupo }\end{array}$ & $\begin{array}{l}\text { Experimentador, interactivo } \\
\text { del contenido y los métodos }\end{array}$ \\
\hline & $\begin{array}{l}\text { Validación de la } \\
\text { información }\end{array}$ & $\begin{array}{l}\text { Valida el docente } \\
\text { aportando } \\
\text { información } \\
\text { explícitamente }\end{array}$ & $\begin{array}{l}\text { Valida el docente } \\
\text { aportando } \\
\text { información } \\
\text { implícitamente }\end{array}$ & $\begin{array}{l}\text { Valida el grupo, el } \\
\text { alumno sin que se } \\
\text { potencie toma de } \\
\text { conciencia }\end{array}$ & $\begin{array}{l}\text { Se potencia el desarrollo de } \\
\text { elementos } \\
\text { autoevaluación }\end{array}$ \\
\hline
\end{tabular}

Tabla 6.13. Instrumento de caracterización de metodología del profesor de matemáticas. Tercer momento de análisis 


\subsubsection{Categorías del Conocimiento Especializado del Profesor de Matemáticas}

En este apartado se detallan las categorías del conocimiento especializado del profesor de matemáticas a partir de preguntas concretas que permiten identificar cuáles son los conocimientos, concepciones, actitudes y capacidades propios de su quehacer tanto en la práctica como en las actividades fuera del aula. Las respuestas a estas preguntas se obtienen a partir del análisis de la información recolectada.

\begin{tabular}{|c|c|}
\hline Conocimientos & $\begin{array}{l}\text { ¿Cuál es el Conocimiento Matemático que pone que pone } \\
\text { de manifiesto el profesor? } \\
\text { ¿Cómo es el conocimiento del tema que se observa en la } \\
\text { investigación? ¿Cómo es el conocimiento de la estructura } \\
\text { matemática del tema específico? ¿Cómo es el conocimiento } \\
\text { de la práctica del tema? } \\
\text { ¿Cuál es el Conocimiento Didáctico del Contenido } \\
\text { Matemático que pone de manifiesto? } \\
\text { ¿Cuál es el conocimiento didáctico del contenido en } \\
\text { matemáticas para el aprendizaje de los estudiantes que } \\
\text { requiere en la enseñanza? } \\
\text { ¿De qué manera el conocimiento didáctico del contenido } \\
\text { promueve y facilita el aprendizaje de las matemáticas? } \\
\text { ¿Cuál es el conocimiento del currículo de matemáticas por } \\
\text { parte del profesor? } \\
\text { ¿Qué conocimiento del contexto escolar tiene el profesor? } \\
\text { ¿Qué otros conocimientos ponen de manifiesto? }\end{array}$ \\
\hline Concepciones & $\begin{array}{l}\text { ¿Cuáles son las concepciones sobre las matemáticas? } \\
\text { ¿Cuáles sobre las matemáticas escolares? } \\
\text { ¿Cuáles sobre la enseñanza? } \\
\text { ¿Cuáles Sobre el aprendizaje? } \\
\text { ¿Sobre la enseñanza de las matemáticas? } \\
\text { ¿Sobre el aprendizaje de las matemáticas? } \\
\text { ¿Sobre el mundo?, referido a la cosmovisión del profesor } \\
\text { Otras concepciones }\end{array}$ \\
\hline Actitudes & $\begin{array}{l}\text { ¿Cómo son sus actitudes hacia las matemáticas? } \\
\text { ¿Hacia la enseñanza? } \\
\text { ¿Hacia la enseñanza de las matemáticas? }\end{array}$ \\
\hline
\end{tabular}




\begin{tabular}{|c|c|}
\hline & $\begin{array}{l}\text { ¿Hacia los estudiantes? } \\
\text { ¿Hacia las características personales de los estudiantes? } \\
\text { ¿Hacia sí mismo? } \\
\text { Otras actitudes }\end{array}$ \\
\hline Capacidades & $\begin{array}{l}\text { Habilidad para reflexionar } \\
\text { Capacidad para la autocrítica } \\
\text { Capacidad para compartir ideas } \\
\text { Capacidad para respetar las ideas de los demás } \\
\text { Habilidad para trabajar en grupo } \\
\text { Capacidad para tomar decisiones y responsabilizarse de } \\
\text { ellas } \\
\text { Capacidad para comunicar sus propias ideas sobre } \\
\text { matemáticas } \\
\text { Habilidad para distinguir el modo idiosincrásico de } \\
\text { pensamiento que posee cada alumno } \\
\text { Destreza para diferenciar las tareas dependiendo del nivel } \\
\text { de los alumnos } \\
\text { Destreza para diseñar materiales de acuerdo con objetivos } \\
\text { previamente determinados } \\
\text { Destreza para organizar el currículo } \\
\text { Habilidad para analizar críticamente materiales publicados } \\
\text { Destreza a la hora de abordar problemas (pedagógicos y } \\
\text { propios de las matemáticas } \\
\text { Habilidad para orientar a los alumnos } \\
\text { Otras capacidades }\end{array}$ \\
\hline
\end{tabular}

Tabla 6.14. Instrumento de caracterización del conocimiento especializado del profesor de matemáticas

Los datos se obtienen a través de los instrumentos de recolección de la información en la forma como se describe en la tabla 6.15, e inmediatamente inicia un proceso de preanálisis y posterior análisis siguiendo los instrumentos de análisis de la información, tal como se muestra en la tabla 6.16: 


\begin{tabular}{|c|c|c|c|c|}
\hline \multicolumn{5}{|c|}{ Recolección de la información } \\
\hline \multirow{8}{*}{$\begin{array}{c}\text { Entrevista } \\
\text { Inicial [EN01] }\end{array}$} & $\begin{array}{c}\text { Trabajo de } \\
\text { Aula }\end{array}$ & \multirow{8}{*}{$\begin{array}{c}\text { Entrevista } \\
\text { intermedia } \\
\text { [EN02] }\end{array}$} & $\begin{array}{c}\text { Trabajo de } \\
\text { Aula }\end{array}$ & \multirow{8}{*}{$\begin{array}{c}\text { Entrevista } \\
\text { Final } \\
\text { [EN03] }\end{array}$} \\
\hline & $\begin{array}{c}\text { Charlas Previas } \\
{[\mathrm{CP}]}\end{array}$ & & $\begin{array}{c}\text { Charlas Previas } \\
{[\mathrm{CP}]}\end{array}$ & \\
\hline & Observación [OB] & & Observación [OB] & \\
\hline & $\begin{array}{c}\text { Notas de } \\
\text { Observación [NO] }\end{array}$ & & $\begin{array}{c}\text { Notas de } \\
\text { Observación [NO] }\end{array}$ & \\
\hline & $\begin{array}{c}\text { Declaraciones } \\
\text { Espontáneas [DE] }\end{array}$ & & $\begin{array}{c}\text { Declaraciones } \\
\text { Espontáneas [DE] }\end{array}$ & \\
\hline & Declaraciones & & Declaraciones & \\
\hline & Posteriores [DP] & & Posteriores [DP] & \\
\hline & $\begin{array}{c}\text { Fichas de diario } \\
\text { [FD] }\end{array}$ & & $\begin{array}{c}\text { Fichas de diario } \\
\text { [FD] }\end{array}$ & \\
\hline
\end{tabular}

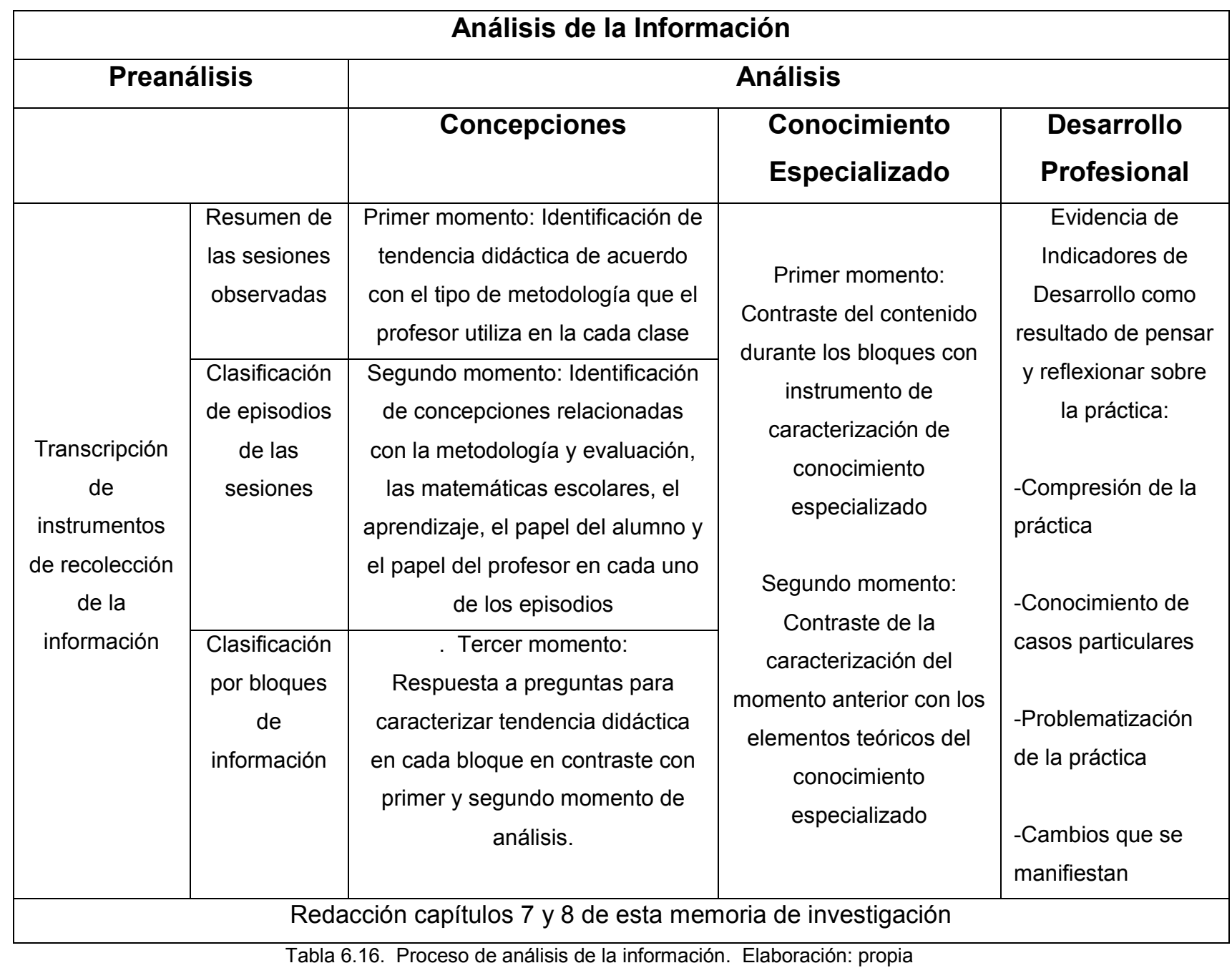




\section{CONTEXTUALIZACIÓN DEL TRABAJO DE CAMPO}

El trabajo de campo se ha realizado a partir de la observación de Lucho, profesor vinculado al Instituto Pedagógico Nacional IPN, unidad académico administrativa de la Universidad Pedagógica Nacional UPN en la ciudad de Bogotá D.C.

La elección del Instituto Pedagógico Nacional como institución educativa en la cual ejecutar el proceso de observación se debe a la disposición de las directivas de esta entidad para realizar trabajo investigativo y de formación docente, los horarios en los que se pudo llevar a cabo y el carácter público que se asimila a las condiciones iniciales propuestas al iniciar la investigación y la posibilidad de interpolar la misma en diferentes contextos, en especial el argentino. Lucho está vinculado como profesor del área de matemáticas del IPN.

La elección de Lucho corresponde a que cumple la condición propuesta para la investigación como profesor de grado décimo (análogo al cuarto año de secundaria de la Ciudad Autónoma de Buenos Aires) y la disposición para permitir la entrada al aula de clase de un observador y de un colega que le permita realizar un análisis sobre su labor profesional.

\subsection{Instituto Pedagógico Nacional}

El IPN, es una unidad académico administrativa de la UPN, fundado el 9 de marzo de 1927 a partir de la segunda misión alemana encabezada por la profesora Francisca Radke con el fin de formar a las mujeres docentes del país. Como resultado de su misión pedagógica, en 1955 se crea la Universidad Pedagógica Nacional, que en sus primeros años se dedicó a la formación de profesoras. La UPN, en su carácter de Universidad Nacional, tiene como misión la formación de profesores en Colombia y la construcción del proyecto pedagógico del país. El 10 de mayo de 2018, por decreto presidencial, el IPN fue declarado patrimonio histórico y cultural de la nación.

EI IPN, como dependencia de la Universidad, es un colegio estatal que forma a niños, niñas y jóvenes desde el jardín hasta el secundario. También es el principal centro de prácticas de las diferentes carreras de la UPN y esto permite que los estudiantes del Instituto estén acostumbrados a la presencia de uno o varios profesores en el aula de clase. 
La educación en instituciones educativas en Colombia está diferenciada en Educación Básica Primaria, Educación Básica Secundaria, Educación Media Vocacional. La primaria, comprende los años o grados primero a quinto, empezando el ciclo con niños de seis años, la secundaria, dividida en educación básica que va de sexto a noveno y la media correspondiente a los grados décimo y once. Al finalizar el grado once, los estudiantes obtienen el título de bachiller; para el caso específico del IPN, los alumnos pueden elegir diferentes énfasis: matemáticas, ciencias sociales, ciencias naturales y artísticas.

\begin{tabular}{|c|c|c|c|c|}
\hline $\begin{array}{l}\text { Se ingresa } \\
\text { al sistema } \\
\text { a partir } \\
\text { de los } 6 \\
\text { años }\end{array}$ & $\begin{array}{c}\text { Educación } \\
\text { Básica } \\
\text { Primaria } \\
\text { Grados } 1^{\circ} \\
\text { a } 5^{\circ}\end{array}$ & $\begin{array}{l}\text { Educación } \\
\text { básica } \\
\text { secundaria } \\
\text { Grados } 6^{\circ} \\
\text { a } 9^{\circ}\end{array}$ & $\begin{array}{c}\text { Educación } \\
\text { media } \\
\text { académica } \\
\text { o técnica } \\
\text { Grados } \\
10^{\circ} \text { y } 11^{\circ}\end{array}$ & $\begin{array}{l}\text { Es opcional } \\
\text { profundizar en } \\
\text { un área técnica } \\
\text { o un énfasis } \\
\text { como } \\
\text { matemáticas, } \\
\text { artes, ciencias o } \\
\text { humanidades }\end{array}$ \\
\hline
\end{tabular}

Gráfico 7.01. Sistema de educación primaria y secundaria en Colombia. . Fuente: propia

Al igual que la mayoría de los colegios del país, el IPN agrupa a los docentes por nivel y área de tal forma que se puedan consolidar los procesos de enseñanza y aprendizaje de manera más homogénea. Así, el área de matemáticas vincula a los profesores de primaria y secundaria que la enseñan. En la institución educativa en mención el área de matemáticas está conformada por un equipo de diecisiete profesores de matemáticas, de los cuales Lucho hace forma parte.

Por sus características particulares y en su condición de colegio público, el IPN admite estudiantes de todos los niveles económicos. El colegio está ubicado sobre la Calle 127 con Carrera 9 en la ciudad de Bogotá, una zona de la ciudad cercana a viviendas de todos los niveles sociales, muy similar a como ocurre con algunas escuelas públicas de la ciudad de Buenos Aires. Por otro lado, los niños y niñas que se educan en el IPN provienen no solamente de los sectores cercanos, también de diferentes barrios de la capital colombiana, superando recorridos de más de media hora en auto o colectivo.

\subsection{Lucho}

Lucho, como se ha decidido nombrar al profesor centro de esta investigación es un Licenciado en Matemáticas de la UPN, en el momento de iniciar el acompañamiento, cuenta con cinco años de experiencia profesional en dos colegios de la ciudad de Bogotá, entre ellos el IPN. En su formación docente siempre ha estado cercano a la 
UPN, siendo sus primeros pasos en esta Facultad cuando siendo estudiante de colegio pertenecía al Club de Matemáticas del Departamento de Matemáticas de dicha universidad. Para el segundo año de observación Lucho ingresó al programa de Especialización en Educación Matemática de la misma Universidad.

Luego de su formación inicial trabaja en un colegio del sector privado y accede a la plaza que ocupa como profesor ocasional a partir de necesidades inmediatas del IPN mientras se realiza un concurso docente para cubrir los puestos requeridos. Asegura dedicar parte de su horario extraescolar a preparar sus tareas y reflexionar sobre su profesión. Para la preparación de sus clases suele recurrir a distintos materiales y fuentes. Está comprometido con su mejora como profesor. Una de las cuestiones que destaca de las características profesionales que debe tener el docente es pensar que nada está acabado; esto es, siempre se puede aprender más.

Respecto de las matemáticas, siente especial atracción por la materia. En su etapa escolar recuerda que no tuvo problemas con las matemáticas mecánicas, recuerda positivamente su paso por el Club de Matemáticas donde se acercó a la Universidad Pedagógica, donde conoció matemáticas no mecánicas.

\subsection{Descripción general del proceso de observación}

El proceso inicia con una carta de acercamiento al director de la institución y al coordinador académico quienes dan su aval para el desarrollo de la observación y su ejecución fue informada en el área de matemáticas del IPN. Siempre se hace mención que la observación será no participante y no tiene el carácter de dar un juicio de valor acerca de la labor profesional de Lucho.

Después de la aceptación por parte de todos los entes institucionales, se pacta con Lucho una cita para la primera entrevista y se coordinan las fechas del periodo de observación, se le pregunta si estaría dispuesto a llenar el formato de las fichas de diario y compartir algunos de los documentos internos empleados para la planificación de las actividades en aula. En principio se pactan ocho sesiones de observación cuyo tema principal serán las expresiones algebraicas y resolución de ecuaciones e inecuaciones resolución de inecuaciones, tanto lineales y no lineales como con módulo.

Para la octava sesión de observación Lucho manifestó interés en el acompañamiento de la aplicación de un conjunto de actividades adicionales que planificó como 
complemento de la enseñanza del tema en cuestión. Entre Lucho y el investigador se pactó que se realizarían dos sesiones de observación adicional en el año 2015 y algunas más para el año 2016 si así lo permitía Lucho. Finalmente se realizaron catorce observaciones, diez en el año 2015 y cuatro en el año 2016. 


\section{TERCERA PARTE: TRABAJO DE CAMPO Y ANÁLISIS}

En esta parte se presentan los resultados obtenidos a partir del trabajo de campo. Las memorias de investigación relatan al lector cada una de las sesiones de clase observadas y su posterior análisis a la luz de los instrumentos de análisis presentados en el capítulo 6 además de otros resultados que surgieron fuera de los límites propuestos en el marco teórico.

\section{LA PRÁCTICA DE LUCHO}

En este apartado se describe de manera detallada cómo es la práctica de Lucho a partir de la descripción de las generalidades de las clases observadas y la implementación de los instrumentos de recolección de información. Para esta descripción se utiliza el formato 'episodios de las sesiones' que consiste en caracterizar los principales momentos de la clase y que se le ha solicitado a Lucho en el formato de Fichas de Diario y posteriormente se lleva a cabo el análisis de la práctica a la luz de los instrumentos elaborados previamente.

Este capítulo está separado en dos grandes secciones. La primera comprendida en los numerales 8.1 a 8.3 corresponden a la descripción y análisis de las sesiones observadas a Lucho. La segunda, numerales 8.4 a 8.6 responden al análisis general de tres aspectos relevantes que han surgido en el marco teórico: El conocimiento especializado, la reflexión y las concepciones de Lucho.

La primera sección de este capítulo introduce tres momentos de observación que se han determinado a partir de la lectura de las sesiones observadas y la mirada de la práctica de Lucho a partir de los instrumentos descritos en el Capítulo 7: un primer bloque, que son las 7 primeras sesiones que corresponderían al estado inicial de la práctica de Lucho, un segundo bloque en el que se resaltan algunos cambios con relación al estado inicial de la práctica de Lucho debido a la transformación que se evidencia al contrastar el quehacer de Lucho y los instrumentos de análisis un tercer bloque correspondiente a la observación de la práctica de Lucho un año después coincidiendo institución y grados asignados. 


\subsection{Bloque I. Primer momento de observación}

La descripción cada uno de los bloques se realiza haciendo la descripción de las sesiones observadas, posteriormente se describen las concepciones identificadas, el conocimiento especializado y apuntes acerca de la reflexión de Lucho.

\subsubsection{Sesiones observadas}

En este bloque se observan un total de siete sesiones en las que Lucho abarca suma y resta de expresiones algebraicas y solución de ecuaciones e inecuaciones con una incógnita.

\subsubsection{Sesión 01: Suma y resta de expresiones algebraicas racionales}

Es la primera sesión de clase observada luego de la entrevista inicial. Ya los estudiantes están avisados de la presencia del investigador en el aula de clase. Por el contexto institucional del IPN, los estudiantes ya están acostumbrados a la presencia de uno o varios profesores en el salón. De todas maneras, se lleva a cabo la presentación formal del profesor invitado al aula de clase, aclarando la observación no participante durante las siguientes sesiones de clase.

El investigador se presenta a los estudiantes y es esta la única vez que habla con ellos, luego Lucho hace algunas aclaraciones sobre talleres anteriores, calificaciones y la necesidad de realizar una actividad evaluativa en la siguiente sesión. A partir de este momento se da el inicio de la clase la cual se divide en momentos: el primero de ellos la explicación de la suma y resta de expresiones algebraicas racionales y el segundo momento, trabajo individual a partir de una lista de ejercicios propuestos por Lucho y el tercer momento, de finalización de clase, aclarando lo que vendría en sesiones posteriores.

La explicación del tema de la sesión la realiza a partir de cuatro ejemplos que escribe en el pizarrón y en el que detalla los posibles casos que los estudiantes se encontrarían en la lista de ejercicios que les propone para el segundo momento. Los cuatro ejemplos y la forma como los solucionó en el pizarrón tal como se muestran en la tabla 8.01: 


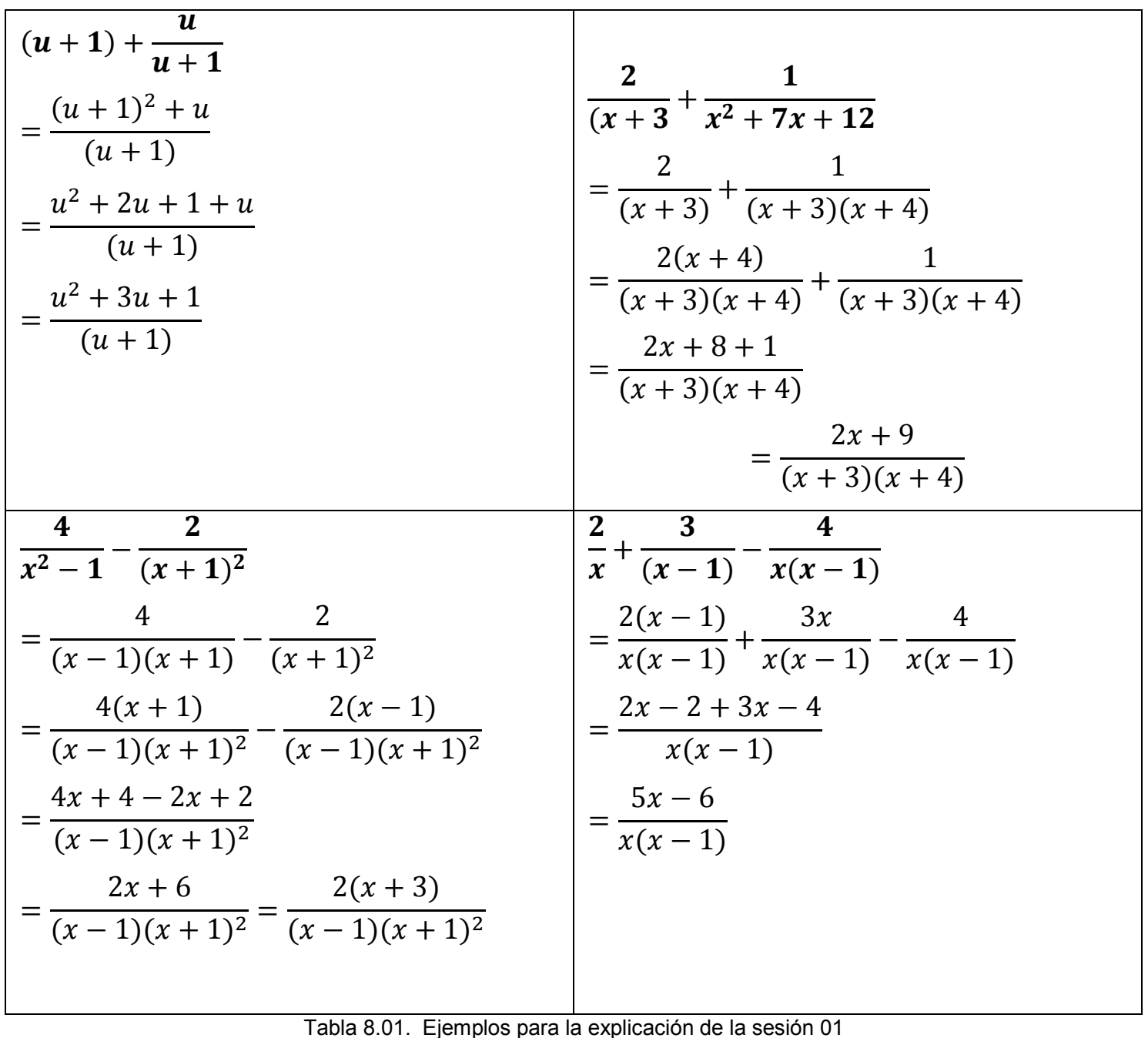

Finalizada la parte de explicación, Lucho procede a indicar cuáles serían los ejercicios por realizar, avisa que el trabajo es individual, aunque pueden conformar grupos de máximo tres personas para apoyarse: 


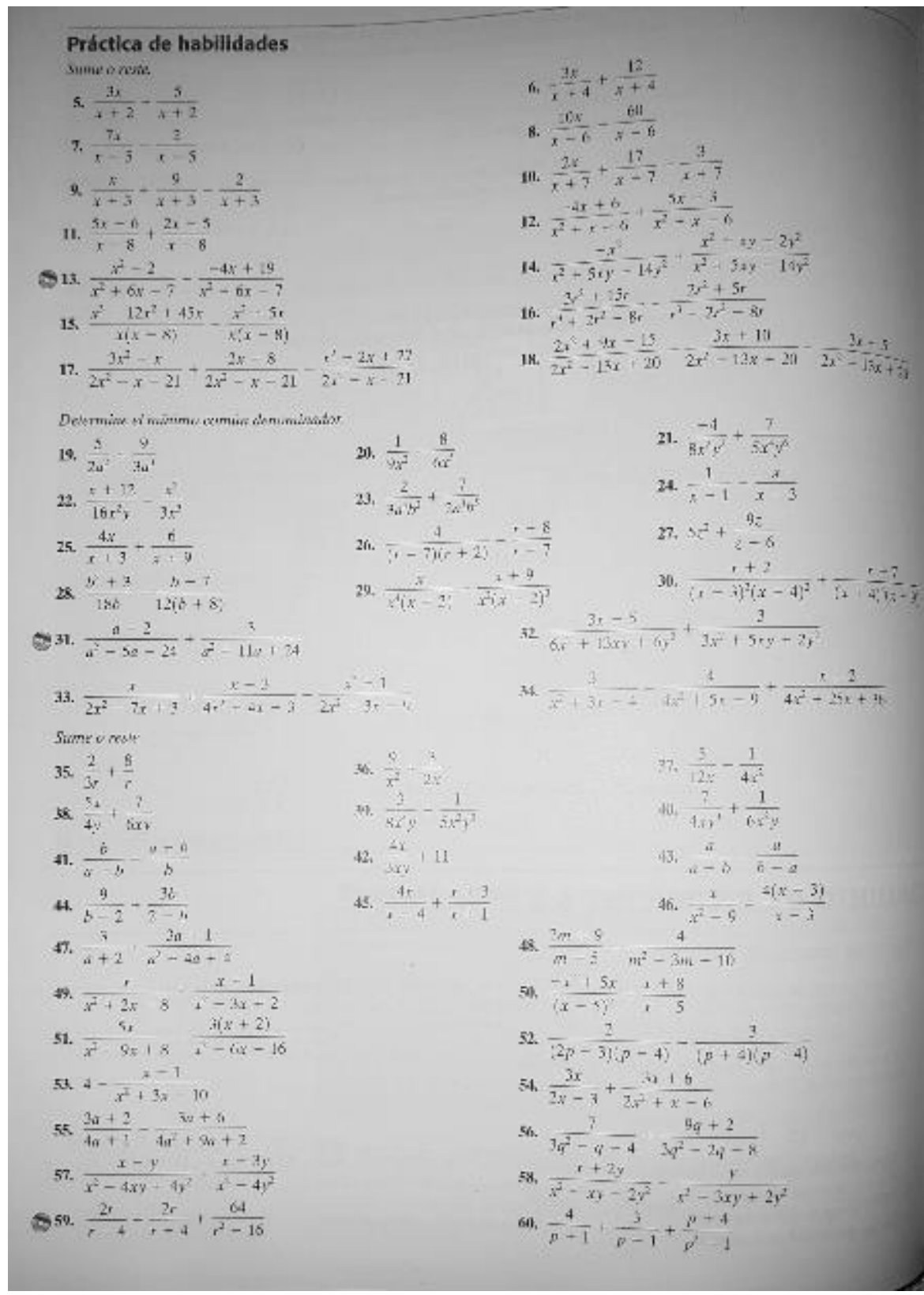

Imagen 8.01 Ejercicios de la primera sesión de observación [OB01.149]

\begin{tabular}{lll}
\hline \hline OB01.150 & Est & Profe, ¿nos podemos hacer en grupo? \\
\hline OB01.151 & Lucho & $\begin{array}{l}\text { Solamente para compartir libro, en grupos de máximo } 3 \\
\text { personas y se apoyan en lo que necesiten }\end{array}$ \\
\hline OB01.152 & Estudiante & Gracias Profe \\
\hline
\end{tabular}

Esta parte de trabajo individual se divide en dos partes, la primera sin el apoyo de Lucho para la solución de los ejercicios y la segunda, mediante una supervisión constante del trabajo de los estudiantes ya que Lucho observa que los estudiantes no están siguiendo la instrucción [NO01.035, DE01.036]. 
Cuando se acerca la hora de finalización de clase, Lucho pide a los estudiantes que se organicen para escuchar la metodología de la actividad evaluativa que se llevará a cabo en la próxima sesión [NO01.046]. Los estudiantes piden que aplace el examen, pero Lucho justifica que ese es el único curso al que no le ha hecho quíz (pequeña prueba escrita) [NO01.047] y que debe hacerlo para tener un registro de notas y de evaluación del curso y para no tener que poner más temas que evaluar en fechas posteriores [NO01.048]:

\begin{tabular}{|c|c|c|}
\hline OB01.407 & Lucho & $\begin{array}{l}\text { Por favor organícense para saber cómo va a ser la siguiente } \\
\text { sesión }\end{array}$ \\
\hline OB01.408 & Com & $\begin{array}{l}\text { Los estudiantes se organizan en filas aunque tardan en } \\
\text { hacerlo }\end{array}$ \\
\hline OB01.409 & Lucho & $\begin{array}{l}\text { Tengo que hacer quíz porque en este salón no se ha hecho } \\
\text { por los tiempos, pero debo hacerlo }\end{array}$ \\
\hline OB01.410 & Estudiante & No profe \\
\hline OB01.411 & Lucho & $\begin{array}{l}\text { Si, debo tener registro de notas y evaluación porque de lo } \\
\text { contrario se acumulan temas y va a ser más complicado para } \\
\text { ustedes. De por sí, ya es más complicado. }\end{array}$ \\
\hline
\end{tabular}

Al finalizar la clase, en las declaraciones posteriores, Lucho comenta que se había sentido nervioso al principio por la presencia del observador, recordando que dicha presencia tiene el fin de apoyarlo en su proceso de crecimiento docente [DP01.013]. Reconoce también que en algunos momentos y por la ubicación que toma el investigador en el aula, se olvida de su presencia y puede explicar más fácilmente el tema [DP01.014].

Por otro lado, considera que logró lo que pretendía en clase y opina que si los estudiantes estudian lo básico van a poder aprobar el examen; aunque sabe que este curso la tiene más difícil porque a diferencia de los otros décimos y por las cualidades de este curso, no ha podido hacer quices semanales [DP01.019, DP01.020]. Lucho está tranquilo frente al aprendizaje de los estudiantes a tan solo unos días de su primera actividad evaluativa [NO01.049]. 
El resumen de la sesión según la tabla por episodios es la siguiente:

\begin{tabular}{|c|c|c|c|}
\hline Episodio & Objetivo & Contenido & Actividad \\
\hline Ep 01.1 & $\begin{array}{l}\text { Explicar a los } \\
\text { estudiantes la forma } \\
\text { de solucionar sumas y } \\
\text { restas de expresiones } \\
\text { algebraicas racionales }\end{array}$ & $\begin{array}{l}\text { Suma y resta de } \\
\text { expresiones } \\
\text { algebraicas racionales }\end{array}$ & $\begin{array}{l}\text { Explicación en el } \\
\text { pizarrón }\end{array}$ \\
\hline Ep 01.2 & $\begin{array}{l}\text { Resolver sumas y } \\
\text { restas de expresiones } \\
\text { algebraicas racionales }\end{array}$ & $\begin{array}{l}\text { Suma y resta de } \\
\text { expresiones } \\
\text { algebraicas racionales }\end{array}$ & $\begin{array}{l}\text { Ejercicios del libro } \\
\text { de texto }\end{array}$ \\
\hline Ep 01.3 & $\begin{array}{l}\text { Comentar el desarrollo } \\
\text { de la siguiente sesión }\end{array}$ & $\begin{array}{l}\text { Aspectos a tener en } \\
\text { cuenta en la actividad } \\
\text { evaluativa }\end{array}$ & $\begin{array}{l}\text { Diálogo con los } \\
\text { estudiantes acerca } \\
\text { del procedimiento } \\
\text { de la actividad } \\
\text { evaluativa }\end{array}$ \\
\hline
\end{tabular}

Tabla 8.02. Resumen por episodios sesión 01

En el episodio 01.1 Lucho explica a los estudiantes la forma de realizar sumas y restas entre expresiones algebraicas. Para ello ha elegido ejemplos directamente del libro de texto y realiza la explicación correspondiente tal como se observa en la tabla 8.01. En dicha explicación toma cuatro ejemplos y les explica la técnica para desarrollar de acuerdo con los posibles casos. A medida que Lucho escribe en el pizarrón va explicando el paso a paso. En el primer ejemplo [OB01.052 a OB01.076]:

\begin{tabular}{|c|c|c|}
\hline Lucho: & $(u+1)+\frac{u}{u+1}$ & $\begin{array}{l}\text { Primero, esta expresión que } \\
\text { encerré entre paréntesis se debe } \\
\text { sumar con esta fracción. } \\
\text { Entonces, ¿qué haría? }\end{array}$ \\
\hline Estudiantes & \multicolumn{2}{|c|}{ Se le coloca denominador y se hace carita feliz } \\
\hline Lucho & \multicolumn{2}{|c|}{$\begin{array}{l}\text { Denominador uno y podríamos hacer carita feliz con este ejemplo. } \\
\text { Entonces, multiplico }\end{array}$} \\
\hline Lucho & $(u+1)+\frac{u}{u+1}$ & $\begin{array}{l}\text { U más 1, por u más 1. U más uno } \\
\text { al cuadrado. Denominador sería } \\
\text { mínimo común múltiplo entre uno } \\
\text { y u más } 1 \text {. Que sería u más } 1 \text {. }\end{array}$ \\
\hline
\end{tabular}




\begin{tabular}{|c|c|c|}
\hline Estudiantes & \multicolumn{2}{|l|}{ Arriba } \\
\hline \multirow[t]{4}{*}{ Lucho } & \multicolumn{2}{|l|}{ Ahora, 1 por $U, U$. } \\
\hline & \multicolumn{2}{|c|}{ Como es suma sumaría... listo } \\
\hline & \multicolumn{2}{|l|}{ Carita feliz o suma en cruz } \\
\hline & \multicolumn{2}{|c|}{ U más 1 por U más 1 daría $U$ al cuadrado más dos $U$ más 1 al cuadrado } \\
\hline Estudiantes & \multicolumn{2}{|l|}{ Sobre } \\
\hline Lucho & \multicolumn{2}{|l|}{ Y denominador común } \\
\hline Estudiantes & \multicolumn{2}{|c|}{ No, no es el mínimo común múltiplo. Es la multiplicación } \\
\hline Lucho & \multicolumn{2}{|c|}{ En este caso también sirve la multiplicación entre las dos fracciones. } \\
\hline Lucho & \multirow{11}{*}{$=\frac{u^{2}+2 u+1+u}{(u+1)}$} & $\begin{array}{l}\text { Ok, entonces, resolvemos el } \\
\text { segundo caso, resolver el } \\
\text { producto notable de U más } 1 \text { al } \\
\text { cuadrado. }\end{array}$ \\
\hline Estudiantes & & Dos U \\
\hline Lucho & & $U$ al cuadrado \\
\hline Lucho & & $\begin{array}{l}\text { La regla es, el primero al } \\
\text { cuadrado, más dos veces el } \\
\text { primero por el segundo dos } u \text {, por } \\
\text { el segundo al cuadrado, } 1 \text { al } \\
\text { cuadrado }\end{array}$ \\
\hline Estudiantes & & $\begin{array}{l}\text { No, es dos por u al cuadrado más } \\
1 \text { al cuadrado }\end{array}$ \\
\hline Lucho & & Eso se resuelve \\
\hline Estudiantes & & $\begin{array}{l}\text { No, u al cuadrado más uno al } \\
\text { cuadrado }\end{array}$ \\
\hline Lucho & & $\begin{array}{l}\text { Si, u más } 1 \text { por u más } 1 \text {, u más } 1 \\
\text { al cuadrado y se aplica la regla }\end{array}$ \\
\hline Estudiantes & & Por qué no lo haces con números \\
\hline Lucho & & $\begin{array}{llr}\text { No porque estoy con letras } \\
\text { algebraicas, } & & \text { fracciones } \\
\text { algebraicas } & & \\
\end{array}$ \\
\hline Lucho & & $\begin{array}{l}\text { Resuelvo fracción } \\
\text { algebraica. } \\
\text { Recuerde la regla, el primero al } \\
\text { cuadrado más dos veces el } \\
\text { primero por el segundo más el } \\
\text { segundo al cuadrado. }\end{array}$ \\
\hline Estudiantes & \multicolumn{2}{|l|}{ Está bien } \\
\hline Lucho & Ahora más $U$ que es este más $U$ que está ahí. & e está ahí. \\
\hline
\end{tabular}




\begin{tabular}{l|l|l}
\hline \hline \multicolumn{3}{l}{ Y ahora que hago } \\
\hline Estudiantes & Queda u a la dos más tres u más unos \\
\hline Lucho & \multicolumn{1}{c}{$\begin{array}{l}u^{2}+2 u+1+u \\
\end{array}$} & $\begin{array}{l}\text { Entonces, aquí hacemos la suma } \\
\text { de términos semejantes. } U\end{array}$ \\
& cuadrado más dos u más $u$, tres $u$, \\
& Tabla 8.03. Explicación del primer ejemplo de la tabla 8.01 [OB01.052 a OB01.076]
\end{tabular}

Los estudiantes se dedican plenamente a prestar atención y a escribir en sus cuadernos; algunos de ellos realizan comentarios entre sí acerca de lo que se está realizando, llevan a cabo micro explicaciones en los grupos cercanos, aunque algunos, definitivamente no están prestando atención a la actividad en curso [NO01.009, NO01.015]. Lucho es el conferencista principal y resuelve las preguntas de los alumnos a medida que va escribiendo en el pizarrón, se ayuda del libro de texto y de algunos apuntes personales principalmente.

En el episodio 01.2 Lucho da una lista de ejercicios para que los estudiantes resuelvan y ellos deberán aplicar las técnicas explicadas en el episodio anterior (Tabla 8.01) y sus conocimientos previos para llegar a la respuesta. Lucho ha dado la instrucción de realizar la actividad en grupos de cuatro estudiantes. Ellos ahora se disponen a llevar a cabo la actividad [NO01.038]. Las preguntas que surjan a medida que desarrollan los ejercicios las resuelven entre todos los miembros del grupo, si no encuentran respuestas la consultan con el profesor. Algunas de las preguntas que hacen los estudiantes son las siguientes:

\begin{tabular}{ll}
\hline \hline [OB01.321] Estudiante: & $\begin{array}{l}\text { En el caso de este ejercicio (refiriéndose al ejercicio 18) ¿se } \\
\text { deben factorizar los denominadores? }\end{array}$ \\
\hline
\end{tabular}
Los estudiantes se refieren al ejercicio 18:

[OB01.322] Comentario:

$$
\frac{2 x^{2}+9 x-15}{2 x^{2}-13 x+20}-\frac{3 x+10}{2 x^{2}-13 x+20}-\frac{3 x-5}{2 x^{2}-13 x+20}
$$

Fíjate cuál es el denominador en todas. Analiza si es necesario

[OB01.323] Lucho: o si se puede factorizar y con base a ello resuelve. ¿Tienen igual o diferente denominador?

\begin{tabular}{lll}
\hline [OB01.324] & Estudiante: & El mismo \\
\hline [OB01.325] & Lucho: & ¿Entonces? \\
\hline
\end{tabular}




\begin{tabular}{|c|c|c|}
\hline [OB01.327] & Estudiante: & En el caso de este ejercicio, ¿cómo hacemos? \\
\hline [OB01.328] & Lucho: & ¿Cuál? \\
\hline [OB01.329] & Estudiante: & $\begin{array}{l}\text { Este: } \\
\qquad \frac{x+12}{16 x^{2} y}-\frac{x^{2}}{3 x^{3}}\end{array}$ \\
\hline [OB01.330] & Estudiante: & No hay factores comunes en el denominador \\
\hline [OB01.331] & Lucho: & $\begin{array}{l}\text { Fíjense que en el denominador del primer término está } \\
\text { dieciséis, equis al cuadrado y ye. En el del segundo término } \\
\text { está tres y equis al cubo. ¿mínimo común múltiplo entre } 16 \text { y } \\
3 \text { ? }\end{array}$ \\
\hline [OB01.332] & Estudiante: & Cuarenta y ocho \\
\hline [OB01.333] & Lucho: & ¿Entonces? \\
\hline [OB01.334] & Estudiante: & $\begin{array}{l}\text { En el primer término se multiplica por tres y en el segundo por } \\
\text { dieciséis }\end{array}$ \\
\hline [OB01.335] & Lucho: & Y el de equis al cuadrado y equis al cubo \\
\hline [OB01.336] & Estudiante: & $\begin{array}{l}\text { Equis al cubo y se multiplica por equis en el primer término y } \\
\text { por nada en el segundo }\end{array}$ \\
\hline [OB01.337] & Lucho: & ¿Si entienden? \\
\hline [OB01.338] & Estudiante: & Si \\
\hline [OB01.339] & Lucho: & Entonces les toca a ustedes solitos \\
\hline
\end{tabular}

En algunos casos la respuesta del docente no es comprendida [NO01.040]. En algunos grupos uno de los estudiantes realiza la actividad, otros hacen cosas que incluso no tienen que ver con la clase de matemáticas; en otros grupos se reparten los ejercicios a realizar para intentar lograr realizarlos en el menor tiempo posible.

En el episodio 01.3 Lucho retoma ejercicios que se complicaron para la mayoría de los estudiantes y los resuelve en colaboración con los mismos alumnos, por ejemplo, el ejercicio 54:

$$
\frac{3 x}{2 x-3}+\frac{3 x+6}{2 x^{2}+x-6}
$$

\begin{tabular}{ll|l|l}
\hline \hline [OB01.387] & Est: & \multicolumn{2}{c}{ ¿Profe, cómo se resuelve el ejercicio 54? } \\
\hline [OB01.388] & Comentario: & \multicolumn{1}{c}{ Ante la reiterada pregunta, hace la explicación en el tablero } \\
\hline [OB01.389] & Lucho: & $\frac{3 x}{2 x-3}+\frac{3 x+6}{2 x^{2}+x-6}$ & $\begin{array}{l}\text { Este ejercicio se resuelve } \\
\text { factorizando primero el }\end{array}$ \\
\hline \hline
\end{tabular}




\begin{tabular}{|c|c|c|c|}
\hline & & & $\begin{array}{l}\text { denominador del segundo } \\
\text { término. Esto es un caso de } \\
\text { factorización, ¿recuerdan } \\
\text { cuál? }\end{array}$ \\
\hline [OB01.390] & Estudiante: & \multicolumn{2}{|c|}{$\begin{array}{l}\text { Si. Como dos no es cuadrado perfecto, se multiplica y divide } \\
\text { por dos y luego se buscan dos números que multiplicados den } \\
\text { menos doce y sumados den uno. }\end{array}$} \\
\hline & & \multicolumn{2}{|c|}{ Nota: Lo escribe en el tablero así: } \\
\hline [OB01.391] & Comentario & $\frac{3 x+6}{2 x^{2}+x-}$ & $=\frac{3 x+6}{\frac{4 x^{2}+x \cdot 2-12}{2}}$ \\
\hline [OB01.392] & Lucho: & \multicolumn{2}{|l|}{ ¿Si entienden? } \\
\hline [OB01.393] & Estudiante: & \multicolumn{2}{|l|}{ Si } \\
\hline [OB01.394] & Lucho: & \multicolumn{2}{|l|}{ ¿Cuáles son esos números? } \\
\hline [OB01.395] & Estudiante: & \multicolumn{2}{|l|}{ Cuatro y menos tres } \\
\hline [OB01.396] & Lucho: & $\begin{aligned} & \frac{3 x+6}{2 x^{2}+x-6} \\
= & \frac{3(x+2)}{\frac{(2 x+4)(2 x-3)}{2}}\end{aligned}$ & ¿Si entienden? \\
\hline [OB01.397] & Estudiante: & \multicolumn{2}{|l|}{ Si } \\
\hline [OB01.398] & Lucho: & $\begin{aligned} & \frac{3 x+6}{2 x^{2}+x-6} \\
= & \frac{3(x+2)}{(x+2)(2 x-3)} \\
& \frac{3 x+6}{2 x^{2}+x-6} \\
= & \frac{3}{(2 x-3)}\end{aligned}$ & $\begin{array}{l}\text { Ahora simplifico y me queda } \\
\text { esto: }\end{array}$ \\
\hline [OB01.399] & Lucho & \multicolumn{2}{|c|}{ La expresión inicial es: $\frac{3 x}{2 x-3}+\frac{3 x+6}{2 x^{2}+x-6}=\frac{3 x}{2 x-3}+\frac{3}{2 x-3}$} \\
\hline [OB01.400] & Estudiante & \multicolumn{2}{|l|}{ Ahora es más fácil } \\
\hline
\end{tabular}

Finalmente Lucho explica la dinámica de la siguiente clase en la que llevará a cabo la primera actividad evaluativa del año:

Aunque se mantiene la distribución de los asientos en pequeños grupos se hace una explicación en gran grupo. Los estudiantes vuelven a tomar el papel de receptores. Nuevamente hay comentarios entre ellos y surgen murmullos en particular a lo referido en la actividad evaluativa [NO01.045]. 
La tabla 8.04 sintetiza cada uno de los episodios de esta sesión:

\begin{tabular}{|l|l|}
\hline \multicolumn{2}{|c|}{ Episodio 01.1 } \\
\hline Papel del profesor & Papel del estudiante \\
\hline $\begin{array}{l}\text { Conferencista principal } \\
\text { Resolutor de preguntas acerca de su } \\
\text { propia explicación }\end{array}$ & Receptor de la información \\
\hline Recursos & Clima del Aula \\
\hline $\begin{array}{l}\text { Pizarrón y marcadores } \\
\text { Apuntes personales } \\
\text { Libro de texto }\end{array}$ & $\begin{array}{l}\text { Trabajo en gran grupo } \\
\text { Comentarios acerca de la explicación } \\
\text { Incertidumbre con relación a ciertos } \\
\text { momentos de la explicación }\end{array}$ \\
\hline
\end{tabular}

\begin{tabular}{|c|c|}
\hline \multicolumn{2}{|c|}{ Episodio 01.2} \\
\hline Papel del profesor & Papel del estudiante \\
\hline $\begin{array}{l}\text { Observador del trabajo de los } \\
\text { estudiantes } \\
\text { Resolutor de preguntas acerca de los } \\
\text { ejercicios propuestos }\end{array}$ & Resolutor de ejercicios \\
\hline Recursos & Clima del Aula \\
\hline $\begin{array}{l}\text { Apuntes personales, notas del } \\
\text { pizarrón } \\
\text { Libro de texto }\end{array}$ & $\begin{array}{l}\text { Trabajo individual en pequeños grupos } \\
\text { Comentarios acerca de la explicación } \\
\text { Incertidumbre con la forma de resolver } \\
\text { algunos ejercicios }\end{array}$ \\
\hline
\end{tabular}

\begin{tabular}{|l|l|}
\hline \multicolumn{2}{|c|}{ Episodio 01.3 } \\
\hline Papel del profesor & Papel del estudiante \\
\hline $\begin{array}{l}\text { Conferencista principal } \\
\text { Resolutor de preguntas acerca de su } \\
\text { propia explicación }\end{array}$ & Receptor de la información \\
\hline Recursos & Clima del Aula \\
\hline Pizarrón y marcadores & $\begin{array}{l}\text { Comentarios acerca de la explicación } \\
\text { Apuntes personales }\end{array}$ \\
& $\begin{array}{l}\text { Incertidumbre con relación a la actividad de la } \\
\text { siguiente clase }\end{array}$ \\
\hline
\end{tabular}

Al inicio de la sesión Lucho ha afirmado que la clase del día "tiene que ver con suma y resta de expresiones algebraicas racionales, para ello en primer momento voy a 
presentar ejemplos de cómo se suman y restan expresiones racionales y luego vamos a hacer algunos ejercicios en clase para que los estudiantes practiquen" [CP01.009]. AI final "espera que comprendan bien los ejemplos y que se pongan a hacer los ejercicios porque si no, no les va a ir bien en el quiz que toca hacer la próxima clase" [DP01.017]. Esto es, quería explicar con algunos ejemplos cómo realizar sumas y restas entre expresiones algebraicas racionales y les brindó a los estudiantes un conjunto de ejemplos que con su uso se pueden convertir en técnicas de tal forma que las puedan mecanizar y así tener buenos resultados en el examen.

\subsubsection{Sesión 02: Actividad evaluativa}

Antes de la actividad evaluativa correspondiente a la segunda sesión observada, Lucho comenta en la charla previa que no está tan seguro de los posibles resultados; afirma no haber preguntado en la prueba algo que no haya explicado o que los estudiantes pudieran hacer con los ejercicios que han realizado [CP02.022]; reconoce que puede haber ejercicios que ellos no entiendan, aunque calcula que algunos estudiantes van a poder realizar toda la prueba [CP02.028].

La sesión de clase inicia con la organización de los estudiantes por filas mirando a un lado y luego de casi de diez minutos puede verificar lista de asistentes y dar las instrucciones para el desarrollo de la actividad ya que el orden y disposición de los estudiantes así lo permitió [NO02.003, NO02.004, NO02.005]. Lucho no permite el uso de los celulares, el diálogo entre compañeros, el uso de lápiz para el desarrollo de la prueba, ni ningún tipo de ayuda [NO02.007, NO02.008, NO02.009]. La actividad se realiza en silencio y de forma individual. Los ejercicios propuestos son los siguientes: 


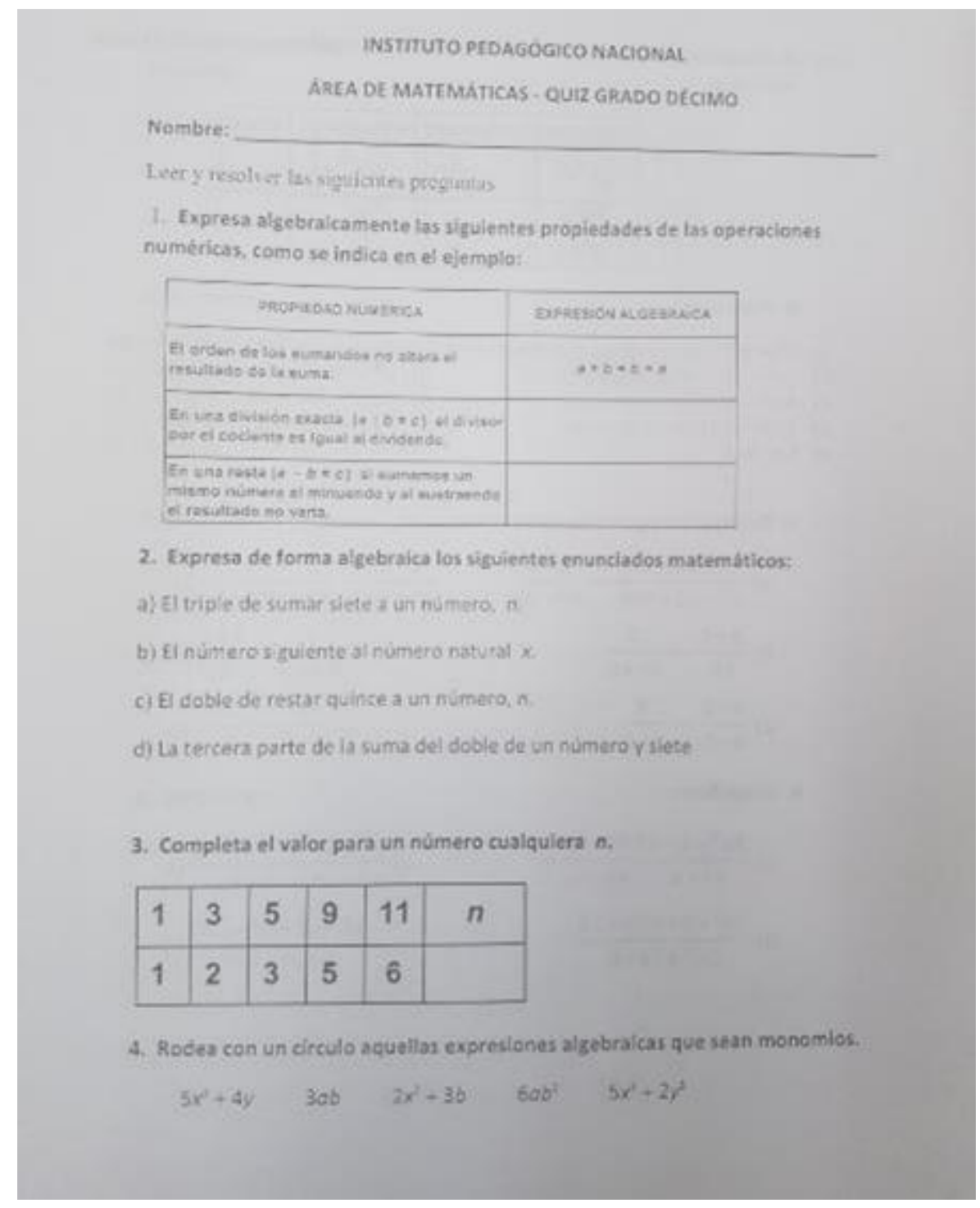

Imagen 8.02. Actividad evaluativa sesión 2 hoja 1 


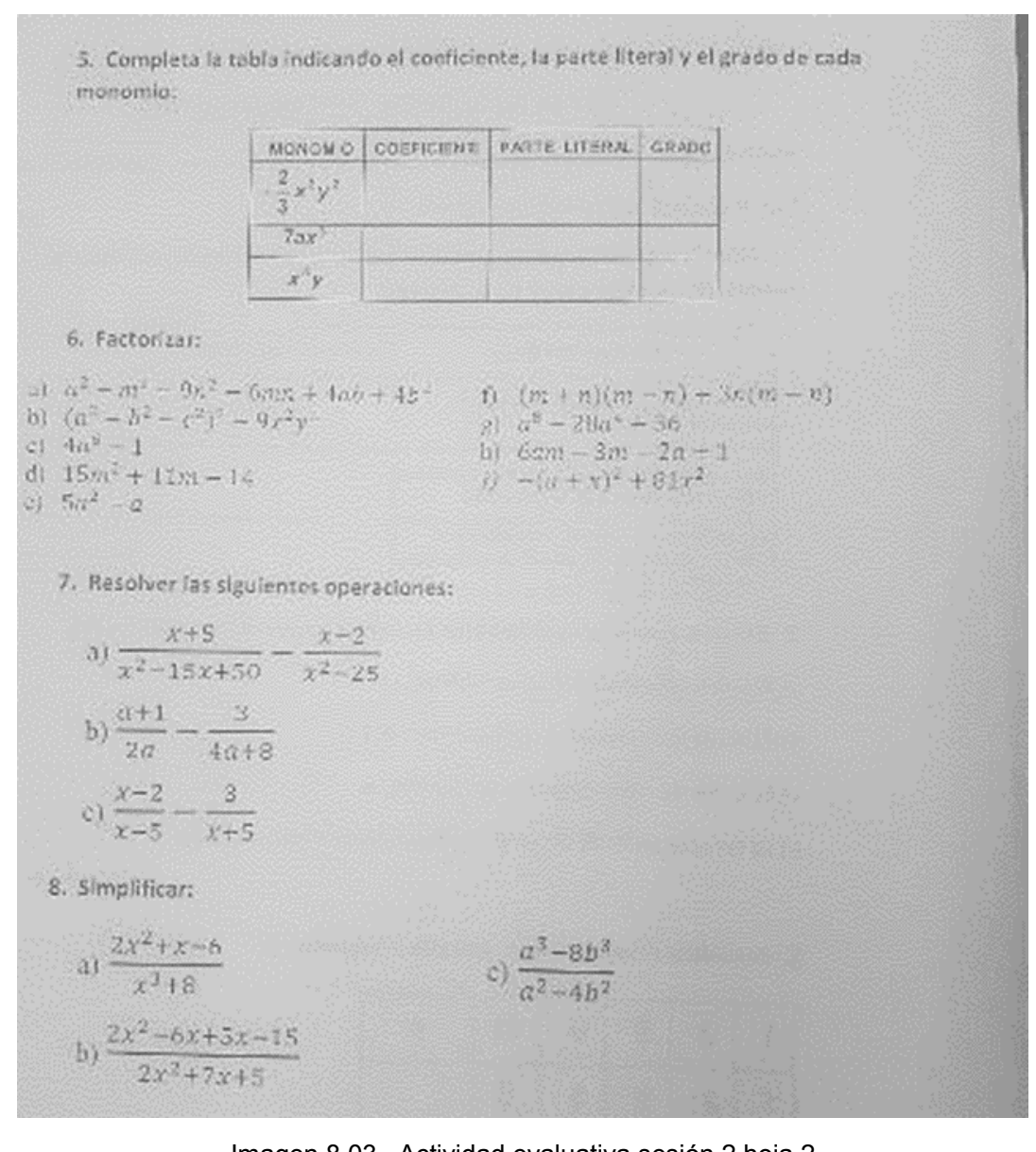

Imagen 8.03. Actividad evaluativa sesión 2 hoja 2

Los estudiantes inician el desarrollo de la prueba y Lucho se queda en su puesto mirando cómo desarrollan la actividad. La prueba tiene ocho ejercicios que involucran el conjunto de números reales, simplificación de expresiones algebraicas, operaciones expresiones algebraicas, factorización; temas que los estudiantes de décimo grado (equivalente cuarto año de secundaria para la ciudad de Buenos Aires) deberían manejar bien ya que son temas correspondientes a octavo y noveno grado (análogos del segundo y tercer año de secundaria para la ciudad de Buenos Aires). Los ejercicios corresponden al estilo del libro, en particular con los del final de las secciones que en clases anteriores indicó a los estudiantes realizar en el cuaderno [NO02.011, NO02.012].

Lucho, prevé en este momento que los resultados de los estudiantes no van a ser los mejores [DE02.013]:

\begin{tabular}{lll}
\hline \hline [OB02.082] & Lucho: & $\begin{array}{l}\text { Parece ser que no les va a ir bien, creo que les voy a permitir } \\
\text { sacar el cuaderno durante media hora }\end{array}$ \\
\hline [OB02.083] & Comentario: & Dirige la mirada al observador de la clase \\
\hline \hline
\end{tabular}


Evitando peores resultados, permite que los estudiantes saquen el cuaderno durante media hora [DE02.014, OB02.083, OB02.089]. La condición de seguir trabajando de manera individual y sin diálogo entre el compañero prevalece.

Dada la demora inicial, Lucho permite que la evaluación sea entregada diez minutos luego de la finalización de la clase [NO02.018, NO02.019]. Algunos estudiantes entregan la prueba sin contestar la mayoría de los ejercicios [NO02.021], otros se quedan hasta el final tratando de resolverla en su totalidad [NO02.022].

En las declaraciones posteriores, Lucho reconoce que los resultados de la prueba serán desastrosos y que por ello prefiere hacer verificaciones semanales para evitar que se acumulen temas [DP02.013]; no obstante, es consciente que los temas evaluados ya deberían ser manejados por los estudiantes [DP02.022]. Sabe también que debe avanzar con la temática correspondiente y planteada en el plan de estudios y que más adelante podrá reforzar adecuadamente el tema evaluado [DP02.023].

La tabla 8.05 corresponde a la descripción de los episodios de la sesión:

\begin{tabular}{|c|c|c|c|}
\hline Episodio & Objetivo & Contenido & Actividad \\
\hline Ep 02.1 & $\begin{array}{l}\text { Evaluar el aprendizaje } \\
\text { de los estudiantes con } \\
\text { relación a los } \\
\text { contenidos enseñados } \\
\text { durante la primera } \\
\text { parte del año escolar }\end{array}$ & $\begin{array}{l}\text { Números Reales } \\
\text { Factorización de } \\
\text { expresiones algebraicas } \\
\text { Suma y resta de } \\
\text { expresiones algebraicas } \\
\text { polinómicas y racionales }\end{array}$ & $\begin{array}{l}\text { Actividad } \\
\text { evaluativa, primera } \\
\text { parte }\end{array}$ \\
\hline Ep 02.2 & $\begin{array}{l}\text { Evaluar el aprendizaje } \\
\text { de los estudiantes con } \\
\text { relación a los } \\
\text { contenidos enseñados } \\
\text { durante la primera } \\
\text { parte del año escolar }\end{array}$ & $\begin{array}{l}\text { Números Reales } \\
\text { Factorización de } \\
\text { expresiones algebraicas } \\
\text { Suma y resta de } \\
\text { expresiones algebraicas } \\
\text { polinómicas y racionales }\end{array}$ & $\begin{array}{l}\text { Actividad } \\
\text { evaluativa, primera } \\
\text { parte }\end{array}$ \\
\hline
\end{tabular}

\begin{tabular}{|l|l|}
\hline \multicolumn{2}{|c|}{ Episodio 02.1 } \\
\hline Papel del profesor & Papel del estudiante \\
\hline Evaluador & Resolutor de la evaluación \\
\hline
\end{tabular}




\begin{tabular}{|l|l|}
\hline $\begin{array}{l}\text { Resolutor de preguntas acerca de las } \\
\text { consignas de la actividad }\end{array}$ & \\
\hline Recursos & Clima del Aula \\
\hline $\begin{array}{l}\text { Lápiz y papel } \\
\text { Hoja de evaluación }\end{array}$ & $\begin{array}{l}\text { Trabajo en silencio } \\
\text { Molestia por la dificultad del ejercicio } \\
\text { Pregunta constante al profesor }\end{array}$ \\
\hline
\end{tabular}

\begin{tabular}{|l|l|}
\hline \multicolumn{2}{|c|}{ Episodio 02.2 } \\
\hline Papel del profesor & Papel del estudiante \\
\hline $\begin{array}{l}\text { Observador del trabajo de los } \\
\text { estudiantes } \\
\text { Resolutor de preguntas acerca de las } \\
\text { preguntas de la evaluación }\end{array}$ & Resolutor de ejercicios \\
\hline Recursos & Clima del Aula \\
\hline $\begin{array}{l}\text { Apuntes personales } \\
\text { Lápiz y papel } \\
\text { Actividad evaluativa }\end{array}$ & $\begin{array}{l}\text { Trabajo individual } \\
\text { Incertidumbre con la forma de resolver } \\
\text { algunos ejercicios } \\
\text { Optimismo de parte de todos por permitir } \\
\text { sacar el cuaderno de apuntes }\end{array}$ \\
\hline
\end{tabular}

\subsubsection{Sesión 03: Retroalimentación de la actividad evaluativa}

En la charla previa de esta sesión, Lucho comenta que en efecto los resultados de la actividad evaluativa no fueron los mejores porque las calificaciones fueron bajas [CP03.006]; no obstante, el hecho que los estudiantes hubiesen podido sacar el cuaderno durante algún tiempo de la actividad permitió que los resultados no fueran tan malos [CP03.012, refiriéndose a la calificación de los estudiantes]. Comenta también que es necesario hacer la retroalimentación de la evaluación, por lo que piensa postergar la explicación de la solución de ecuaciones para la siguiente sesión.

La clase inicia con unas palabras de Lucho acerca de la actividad evaluativa, en esta, Lucho hace énfasis en el hecho que lo que se preguntó fue explicado en clase y que los temas en cuestión hacen parte del plan de estudios de octavo y noveno: conjunto de números reales, simplificación de expresiones algebraicas, operaciones expresiones algebraicas, factorización y de la forma de calificar [OB03.011, NO03.008]: 


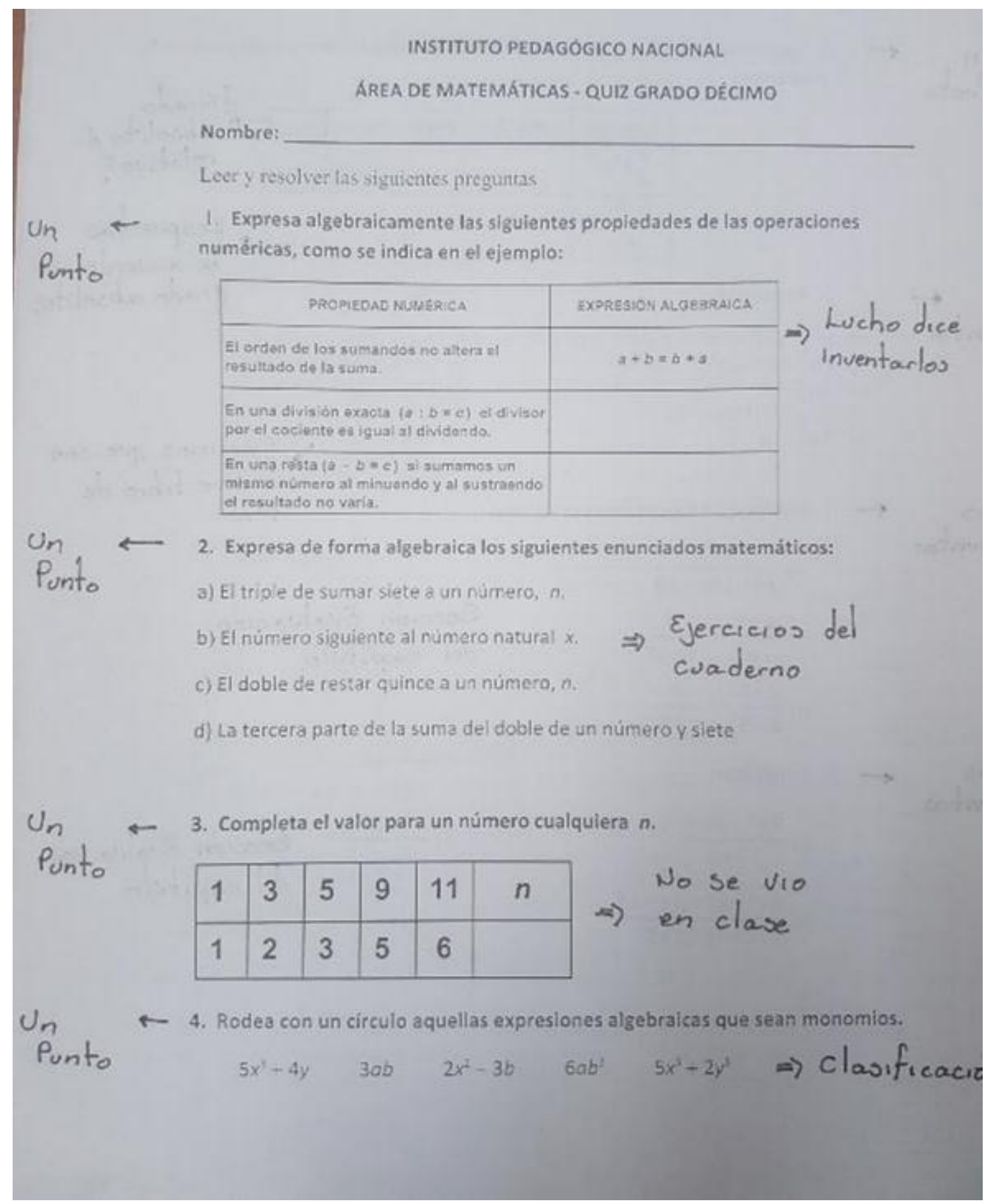

Imagen 8.04. Actividad evaluativa, puntaje asignado, hoja 1 


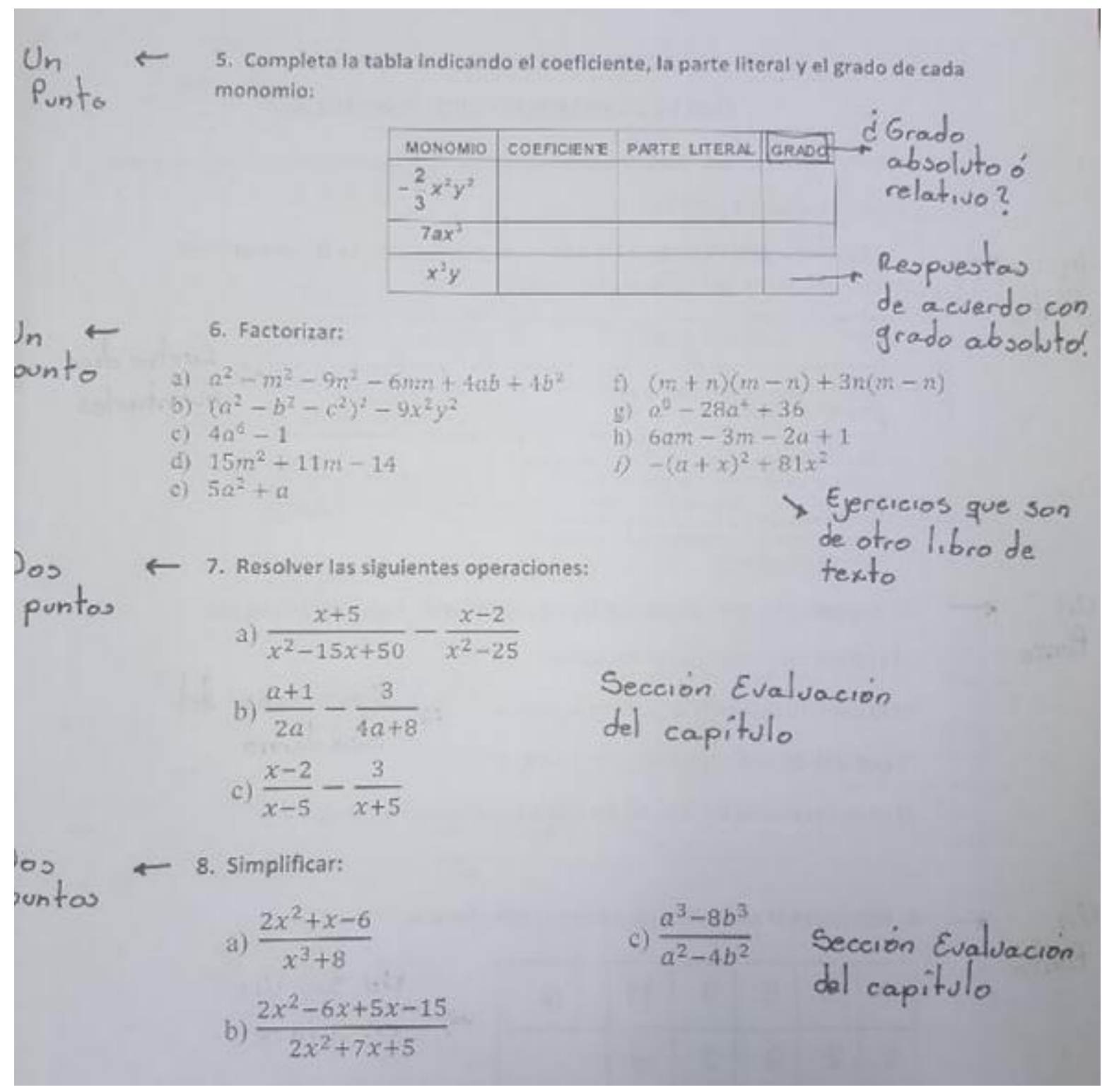

Imagen 8.05. Actividad evaluativa, puntaje asignado, hoja 2

También, manifiesta a los alumnos que la intensión no es ponerles mala nota, pero si exigir que tengan unos conocimientos básicos fuertes [DE03.014].

Posteriormente, Lucho inicia con el desarrollo de la prueba. La dinámica de esta actividad va alternada entre la explicación del profesor, la explicación de algún estudiante en el pizarrón y el trabajo individual de los estudiantes. Para el desarrollo de ejercicios que tienen literales, Lucho recibe los primeros cinco cuadernos con el fin de sumar puntos positivos válidos en la calificación de la actividad.

En la declaración posterior, Lucho comenta que los estudiantes se dieron cuenta que los ejercicios no eran tan difíciles y que los habrían podido resolver bien si hubiesen estudiado un poco [DP03.010]; reconoce que quizás debió preguntar tan solo siete u 
ocho de los que estaban [DP03.016], aunque sabe que, por el pronto ingreso a la Facultad, este tipo de actividades los va cultivando en sus hábitos de estudio [DP03.017, DP03.018]. Para la siguiente sesión iniciará con la explicación de ecuaciones lineales [DP03.024].

La tabla 8.06 describe los episodios de esta sesión:

\begin{tabular}{|c|c|c|c|}
\hline Episodio & Objetivo & Contenido & Actividad \\
\hline Ep 03.1 & $\begin{array}{l}\text { Corregir de manera } \\
\text { grupal el desarrollo de } \\
\text { la actividad evaluativa } \\
\text { de la sesión anterior }\end{array}$ & $\begin{array}{l}\text { Números Reales } \\
\text { Factorización de } \\
\text { expresiones algebraicas } \\
\text { Suma y resta de } \\
\text { expresiones algebraicas } \\
\text { polinómicas } \\
\text { racionales }\end{array}$ & $\begin{array}{l}\text { Explicación en el } \\
\text { pizarrón }\end{array}$ \\
\hline Ep 03.2 & $\begin{array}{l}\text { Corregir el desarrollo } \\
\text { de la actividad } \\
\text { evaluativa a partir de la } \\
\text { interacción de los } \\
\text { estudiantes del curso }\end{array}$ & $\begin{array}{l}\text { Números Reales } \\
\text { Factorización de } \\
\text { expresiones algebraicas } \\
\text { Suma y resta de } \\
\text { expresiones algebraicas } \\
\text { polinómicas } \\
\text { racionales }\end{array}$ & $\begin{array}{l}\text { Explicación en el } \\
\text { pizarrón } \\
\text { Desarrollo } \\
\text { individual }\end{array}$ \\
\hline
\end{tabular}

\section{Episodio 03.1}

\begin{tabular}{|l|l|}
\hline Papel del profesor & Papel del estudiante \\
\hline $\begin{array}{l}\text { Propositor de la reflexión acerca de } \\
\text { Conferencista principal } \\
\text { Resolutor de preguntas acerca de las } \\
\text { consignas de la actividad }\end{array}$ & \\
\hline Recursos & \\
\hline $\begin{array}{l}\text { Pizarrón y marcador } \\
\text { Hoja de evaluación }\end{array}$ & Clima del Aula \\
Notas de evaluación & Reflexión personal y grupal \\
\hline
\end{tabular}




\begin{tabular}{|c|c|}
\hline \multicolumn{2}{|c|}{ Episodio 03.2} \\
\hline Papel del profesor & Papel del estudiante \\
\hline $\begin{array}{l}\text { Explicación de la actividad } \\
\text { Director de la clase } \\
\text { Propositor del trabajo individual }\end{array}$ & $\begin{array}{l}\text { Resolutor de ejercicios propuestos } \\
\text { Participante de la explicación }\end{array}$ \\
\hline Recursos & Clima del Aula \\
\hline Apuntes personales del profesor & Trabajo individual y espíritu de competencia \\
\hline $\begin{array}{l}\text { Apuntes personales de los } \\
\text { estudiantes } \\
\text { Lápiz y papel } \\
\text { Actividad evaluativa }\end{array}$ & $\begin{array}{l}\text { Optimismo en relación a la manera de } \\
\text { desarrollar la actividad }\end{array}$ \\
\hline
\end{tabular}

\subsubsection{Sesión 04: Solución de ecuaciones lineales}

En la charla previa de la sesión 04, Lucho comenta que va a recordar el método para resolver ecuaciones lineales para así poder introducir a los estudiantes a la resolución de inecuaciones lineales y no lineales [CP04.008] así como la de inecuaciones expresadas con módulo [CP04.009]. El profesor espera que los estudiantes recuerden el método para resolver ecuaciones y así facilitar la explicación de las desigualdades [CP04.013].

La clase inicia con el llamado a lista y con la explicación de cuatro ejemplos [NO04.004], los cuales escribe en el pizarrón y comenta lo que los estudiantes deberán realizar. Los ejercicios que Lucho explica son los siguientes: 


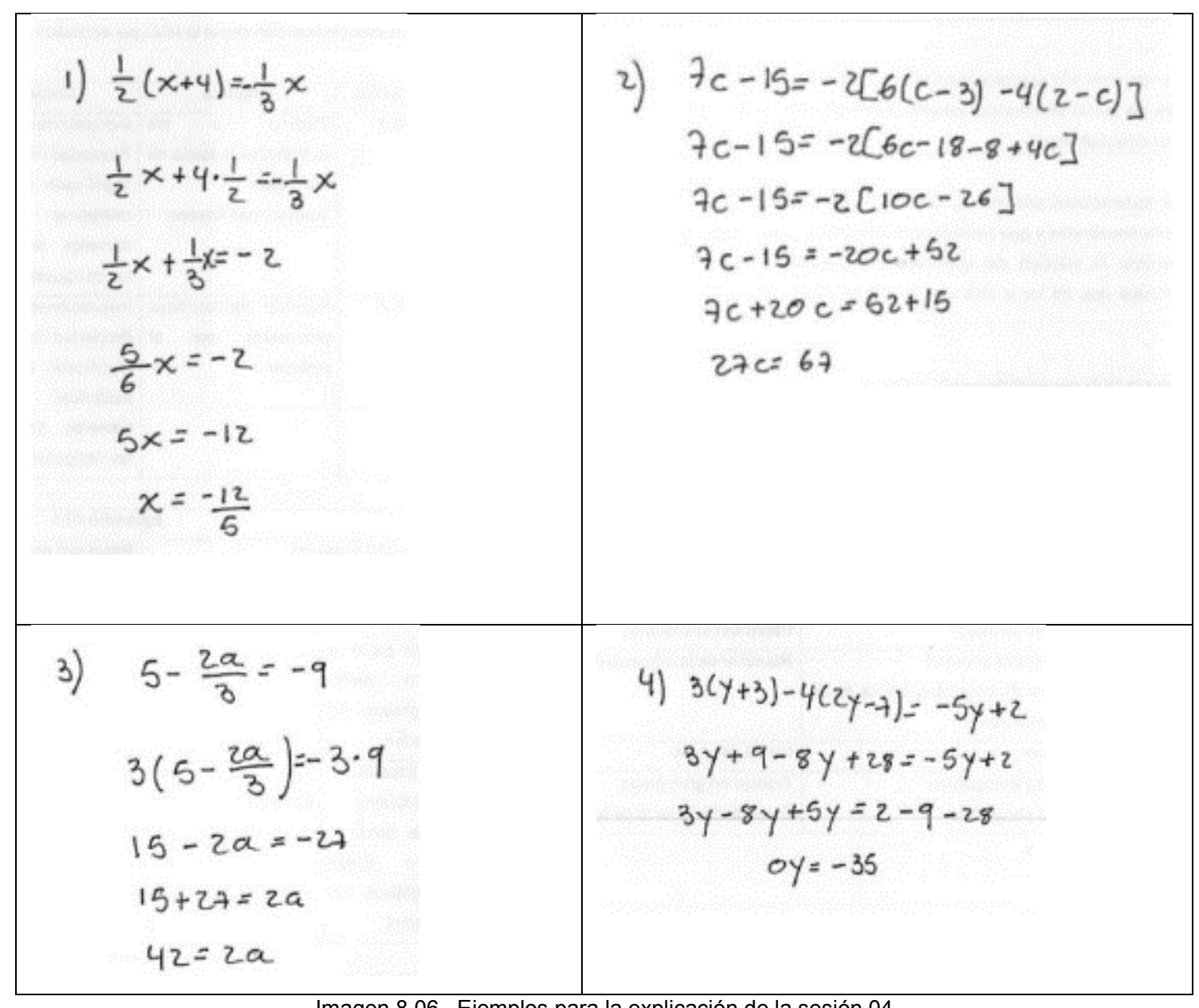

Imagen 8.06. Ejemplos para la explicación de la sesión 04

Finalizada la parte de explicación, Lucho indica cuáles son los ejercicios del libro y permite que el trabajo sea en grupos de tres estudiantes [NO04.007]: 
5ección 2.1 Resplución de ecuaciones lineales
67. $-6(z-1)--5(z+2)$
6ik. $7(x-1)=3(x+2)$
(19.) $-3(1-5)-2(1-5)$
70. $+(2 x-4)--2(x+3)$
71. $3 x+4(2-x)-4 x+5$
72. $f(3,-\eta)-8(y+1)$
73. $2-(x+5)-4 x-8$
74. $4 x-2(3 x-7)-2 x-6$
76. $5 x+2(x-4)-8 x+12$
77. $-3(y-1)+2 y-4(y-3)$
79. $6-(n+3)=3 n+5-2 n$
80. $8-3(2 a-4)-5+3 \pi-4 k$
82. $-2(3 w+6)-(4 x-3)=21$
8.3. $-4(3-4 x)-2(x-1)-12 x$
35. $5(a+3)-a--(4 a-6)+1$
86. $3(2 x-4)+3(x+1)-9$
75. $n-(n+4)-4(s-1)+2 p$
78. 5 r $-13-4$ ir $-3(r+5)-16$
H. $4(2 x-2)-3(x+7)--4$
H4, $-4(2 z-6)--3(z-4)+8$
8s. $3[6-\langle h+2)]-6-4(-h+7)$
90. $-z-6 z 13-4 \quad[6-z-(3-2 z)]$
6) $89.2[3 x-(4 x-6) \mid-5(x-6)$
92. $3\{[(x-2)+4 x]-(x-3)\}=4-(x-12)$
94. $-3(6-4 x)-4-|5 x-[6 x-(4 x-(3 x-2))]|$
91. $4 \mid 2-[3(r+1)-2(c+1)]-2$
93. $|4(d+3)-5| 3 d-2(2 d+7)|-8|=-15 d-6$

Resuelva cada ccaación, Si sa respuesta no ev un entero, déjela cono una fracrib́n.
95. $\frac{s}{4}=-16$
96. $\frac{15 c+3}{9}-2$
97. $\frac{4 x-2}{3}--6$
9R. $\frac{1}{2}(6 r-10)=7$
99. $\frac{7}{4} t+\frac{7}{B} t-39$
1110. $\frac{1}{4}(x-2)-\frac{1}{3}(2 x+6)$
101. $\frac{1}{2}(x-2)-\frac{1}{3}(x+2)$
102. $\frac{1}{2} x+2-\frac{1}{8} x-1$
1113. $4-\frac{3}{4} a=7$
104. $x-2=\frac{3}{4}(x+4)$
Q105. $\frac{1}{2}=\frac{1}{5} x-\frac{1}{4}$
1116. $\frac{1}{3} x+\frac{5}{6}=2 x$
107. $\frac{1}{4}(x+3)=\frac{1}{3}(x-2)+1$
108. $\frac{5}{6} m-\frac{5}{12}-\frac{7}{8} m+\frac{2}{3}$

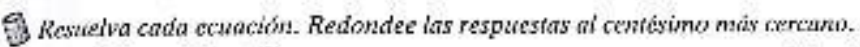
109. $0.4 n+4.7=5.1 n$
110. $0.2(x-30)=1.6 x$
111. $4.7 x-3.6(x-1)-4.9$
112. $6.1 p-4.5(3-2 p)=15.7$
113. $5(z+3.41)--7.89(2 z-4)-5.67$
114. $0.05(2000+2 x)-0.04(2500-6 x)$
115. $0.6(500-2.4 x)-3.6(2 x-4000)$
116. $0.42 x-x=5.1(x+3)$
117. $1000(7.34 q+14.78)=100(3.91-4.21 q)$
118. $0.6(14 x-8000\}--0.4\{20 x+12,600)+20.6 x$

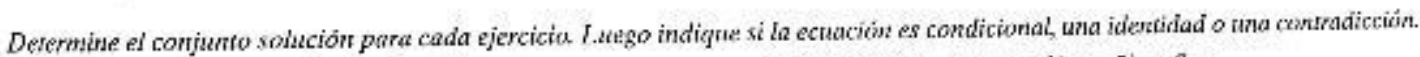
119. $3(y+3)-4(2 y-7)=-5 y+2$
120. $9 x+12-8 x=-6(x-2)+7 x$
121. $4(2 x-3)+15=6(x-4)+12 x-21$
122. $-5(c+3)+4(c-2)=2(c+2)$
123. $4-\left(\frac{2}{3} x-2\right)=2\left(-\frac{1}{3} x+1\right)$
124. $7-\left(\frac{1}{2} x+4\right)=3\left(-\frac{1}{6} x+2\right)$
8125. $6(x-1)=-3(2-x)+3 x$
126. $0.6(z+5)-0.5(z+2)=0.1(z-23)$
127. $0.8 z-0.3(z+10)=0.5(z+1)$
128. $4(2-3 x)=-[6 x-(8-6 x)]$

\section{Resolución de problemas}

129. Densidad poblacional La densidad poblacional de Estados Unidos ha aumentado de manera constante desde 2000. Lil densidad poblacional de Estados Unidos puede estimurse por medio de la ecuación

$$
P=0.82 t+78.5
$$

donde $P$ es la densidad poblacional, medido en personas por millas cuadradas, $y$ t es el número de añus desde 2000 .
Utilice $\mathrm{r}=1$ para $2001, \mathrm{r}=2$ para 2002 , y asi sucssivame1 Si la densidad de población cuntinúa en aumento a la actual,

a) determine la densidad poblacional de Estados Uni en 2008 .

b) ¿durante qué año la densidad población dc Esta Unidos alcanzará 100 personas por milla cuadrada?

Imagen 8.07. Ejercicios del libro, sesión 04 
Informa que al final de la clase recogerá aleatoriamente el cuaderno de uno de los tres integrantes de cada grupo. Al igual que la primera sesión de observación, este episodio se divide en dos partes, la primera sin el apoyo de él para la solución de los ejercicios y la segunda, mediante una vigilancia constante del trabajo de los estudiantes ya que Lucho observa que los estudiantes no están siguiendo la instrucción.

Al finalizar la clase, en las declaraciones posteriores, Lucho comenta que observó que algunos estudiantes no habían trabajado en clase [DP04.009] y que no se nota mucho interés de una parte del grupo [DP04.014]. Manifiesta también, que hay algunos estudiantes que comprenden bien el desarrollo de la actividad propuesta [DP04.017] y considera que logró lo que pretendía en clase, considerando que si los estudiantes estudian lo básico van a poder comprender bien el desarrollo de las inecuaciones [DP04.019, DP04.20].

El resumen de la sesión por episodios se describe en la tabla 8.07:

\begin{tabular}{|c|c|c|c|}
\hline Episodio & Objetivo & Contenido & Actividad \\
\hline Ep 04.1 & $\begin{array}{l}\text { Explicar a los } \\
\text { estudiantes la forma } \\
\text { de solucionar } \\
\text { ecuaciones lineales. }\end{array}$ & $\begin{array}{l}\text { Ecuaciones lineales de } \\
\text { primer grado } \\
\text { Ecuaciones racionales }\end{array}$ & $\begin{array}{l}\text { Explicación en el } \\
\text { pizarrón }\end{array}$ \\
\hline Ep 04.2 & $\begin{array}{l}\text { Resolver ecuaciones } \\
\text { propuestas por el } \\
\text { profesor }\end{array}$ & $\begin{array}{l}\text { Suma y resta de } \\
\text { expresiones algebraicas } \\
\text { racionales }\end{array}$ & $\begin{array}{l}\text { Ejercicios del libro } \\
\text { de texto }\end{array}$ \\
\hline
\end{tabular}

\begin{tabular}{|l|l|}
\hline \multicolumn{2}{|c|}{ Episodio 04.1 } \\
\hline Papel del profesor & Papel del estudiante \\
\hline $\begin{array}{l}\text { Conferencista principal } \\
\text { Resolutor de preguntas acerca de su } \\
\text { propia explicación }\end{array}$ & Receptor de la información \\
\hline Recursos & Clima del Aula \\
\hline $\begin{array}{l}\text { Pizarrón y marcadores } \\
\text { Apuntes personales } \\
\text { Libro de texto }\end{array}$ & $\begin{array}{l}\text { Trabajo en gran grupo } \\
\text { Comentarios acerca de la explicación } \\
\text { Incertidumbre con relación a ciertos } \\
\text { momentos de la explicación }\end{array}$ \\
\hline
\end{tabular}




\begin{tabular}{|c|c|}
\hline \multicolumn{2}{|c|}{ Episodio 04.2} \\
\hline Papel del profesor & Papel del estudiante \\
\hline $\begin{array}{l}\text { Observador del trabajo de los } \\
\text { estudiantes } \\
\text { Resolutor de preguntas acerca de los } \\
\text { ejercicios propuestos }\end{array}$ & Resolutor de ejercicios \\
\hline Recursos & Clima del Aula \\
\hline $\begin{array}{l}\text { Apuntes personales, notas del } \\
\text { pizarrón } \\
\text { Libro de texto }\end{array}$ & $\begin{array}{l}\text { Trabajo individual en pequeños grupos } \\
\text { Comentarios acerca de la explicación } \\
\text { Incertidumbre con la forma de resolver } \\
\text { algunos ejercicios }\end{array}$ \\
\hline
\end{tabular}

\subsubsection{Sesión 05: Un imprevisto en la práctica docente}

En la charla previa a esta sesión, Lucho considera que puede explicar la forma en que se van a solucionar las inecuaciones lineales y para ello tiene como premisa el hecho que las inecuaciones se solucionan de la misma manera excepto que cuando se pasa a multiplicar o dividir un número negativo, el símbolo de la desigualdad cambia [CP05.009].

Esta sesión coincide con el cumpleaños del colegio y por esta razón, la mayoría de los estudiantes se encuentra ausente [NO05.001]. Cuando Lucho pregunta por los alumnos que no están, le informan que tienen permiso de coordinación de convivencia para los respectivos ensayos y decoración para el cumpleaños del colegio. Ante la situación presentada y verificando con la respectiva coordinación, Lucho considera que no es pertinente hacer la explicación de las inecuaciones:

[NO05.004]: Lucho se acerca al observador y le comenta que no es pertinente hacer una nueva explicación si la mayoría de los estudiantes no está y decide que pueden avanzar en el desarrollo de los ejercicios propuestos en la sesión anterior

Lucho le indica a los estudiantes que pueden trabajar en grupo, aunque cada uno en su cuaderno [OB05.037], los ejercicios que se propusieron en la anterior sesión y pide que se le informe a los alumnos que no están que se tienen que adelantar y presentar los ejercicios en la siguiente sesión [OB05.030]. 
Para esta clase, el trabajo se realiza en pequeños grupos y Lucho resuelve dudas sobre los ejercicios que los alumnos tienen que desarrollar [NO05.011].

Al finalizar la sesión, Lucho les informa que la próxima clase realizará la explicación de un tema nuevo y solicita que asistan la mayoría de los estudiantes[OB05.175]. En la declaración posterior, Lucho comenta que las actividades como el cumpleaños del colegio están buenísimas, pero deberían ser informadas con antelación para una mejor preparación de clase; igual considera que la planeación para esta sesión se traslada a la siguiente [DP05.010, DP05.012].

La tabla 8.08 corresponde a la quinta sesión es la siguiente:

\begin{tabular}{|l|l|l|l|}
\hline Episodio & \multicolumn{1}{|c|}{ Objetivo } & \multicolumn{1}{c|}{ Contenido } & \multicolumn{1}{c|}{ Actividad } \\
\hline Ep 05.1 & $\begin{array}{l}\text { Resolver ecuaciones } \\
\text { propuestas por el } \\
\text { profesor }\end{array}$ & $\begin{array}{l}\text { Suma y resta de } \\
\text { expresiones algebraicas } \\
\text { racionales }\end{array}$ & $\begin{array}{l}\text { Ejercicios del libro } \\
\text { de texto }\end{array}$ \\
\hline
\end{tabular}

\begin{tabular}{|c|c|}
\hline \multicolumn{2}{|c|}{ Episodio 05.1} \\
\hline Papel del profesor & Papel del estudiante \\
\hline $\begin{array}{l}\text { Observador del trabajo de los } \\
\text { estudiantes } \\
\text { Resolutor de preguntas acerca de los } \\
\text { ejercicios propuestos }\end{array}$ & Resolutor de ejercicios \\
\hline Recursos & Clima del Aula \\
\hline $\begin{array}{l}\text { Apuntes personales, notas del } \\
\text { pizarrón. } \\
\text { Libro de texto }\end{array}$ & $\begin{array}{l}\text { Trabajo individual en pequeños grupos } \\
\text { Comentarios acerca de la explicación } \\
\text { Incertidumbre con la forma de resolver } \\
\text { algunos ejercicios }\end{array}$ \\
\hline
\end{tabular}

Tabla 8.08. Episodios sesión 05

\subsubsection{Sesión 06: Solución de inecuaciones lineales}

En la charla previa a esta sesión, Lucho comenta nuevamente que en el quehacer docente siempre se está expuesto a imprevistos tales como los sucedidos en la clase anterior y que a pesar de la falta de coordinación en la comunicación, el profesor se debe adaptar a dichas situaciones [CP06.013]. Nuevamente considera que puede explicar la forma en que se van a solucionar las inecuaciones lineales y para ello tiene 
como premisa el hecho que las inecuaciones se solucionan de la misma manera excepto que cuando se pasa a multiplicar o dividir un número negativo, el símbolo de la desigualdad cambia [CP06.017].

La clase inicia recordando a los estudiantes del curso que durante el desarrollo de la misma revisará el cuaderno de los estudiantes ausentes de la sesión anterior [OB06.018]. Luego escribe en el pizarrón los signos < > y le pregunta a los estudiantes su significado [OB06.027].

Luego pregunta qué significa la expresión $x<3$, a la vez que los estudiantes comentan que el profesor se está refiriendo a los números que son menores que tres [OB06.035 a OB06.040].

\begin{tabular}{ll|l|l}
\hline \hline [OB06.035] & Lucho: & \multicolumn{1}{c}{$x<3$} & Qué significa esto? \\
\hline [OB06.036] & Estudiante: & Que equis es menor que tres \\
\hline [OB06.037] & Estudiante: & Que hay un número que es más pequeño que tres \\
\hline [OB06.038] & Estudiante: & Son los valores que son menores que tres \\
\hline [OB06.039] & Lucho: & En efecto es cualquier valor que sea más pequeño que tres \\
\hline [OB06.040] & Lucho: & Eso es único o hay muchos valores
\end{tabular}

Lucho comenta a los estudiantes que las inecuaciones se resuelven de manera similar que las ecuaciones [OB06.074] y les presenta tres ejemplos que son los siguientes:

\begin{tabular}{|l|c|}
\hline 1) $x-9>-6$ & $\frac{6(x-2)}{5}<\frac{10(2-x)}{3}$ \\
$x>-6+9$ & $6(x-2) \cdot 3<5 \cdot 10(2-x)$ \\
$x>3$ & $18(x-2)<50(2-x)$ \\
Solución: $(3 ; \infty)$ & $18 x-36<100-50 x$ \\
& $18 x+50 x<100+36$ \\
& $68 x<136$ \\
& $x<\frac{136}{68}$ \\
& $x<2$ \\
& Solucion: $(-\infty ; 2)$ \\
\hline
\end{tabular}




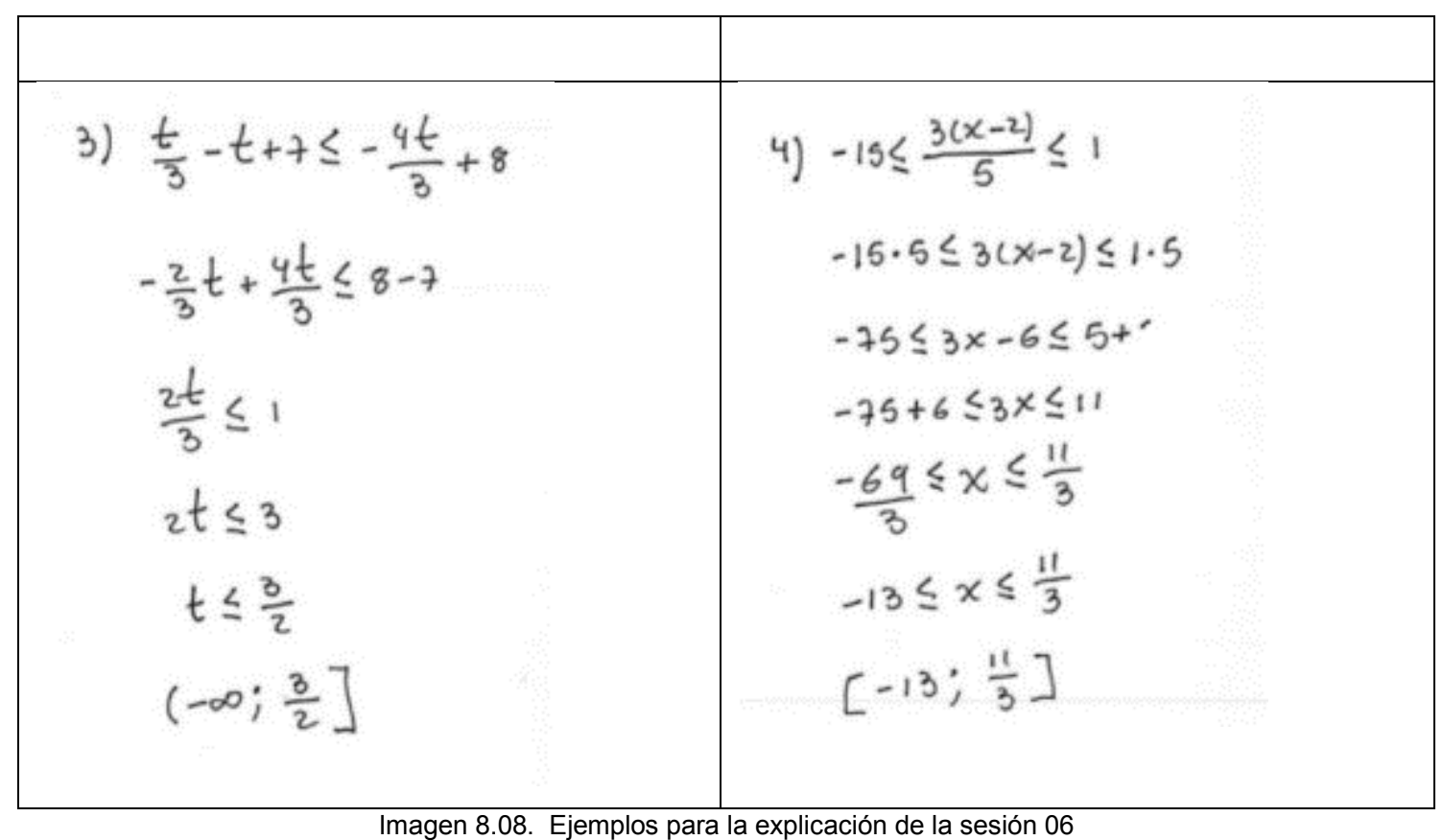

Es importante anotar que Lucho hace tres recomendaciones importantes para el desarrollo de las inecuaciones: aplicar propiedad distributiva si es necesario, poner los términos que tienen la variable a la derecha, despejar la variable teniendo en cuenta que si se pasa a multiplicar o dividir números negativos se cambia el símbolo de la inecuación [NO06.015, NO06.016, NO06.017].

Finalizada la parte de explicación, Lucho procede a indicar cuáles serían los ejercicios por realizar: múltiplos de tres de la página 121 del libro de texto [NO06.022], avisa que el trabajo es individual, aunque pueden conformar grupos de máximo tres personas para apoyarse [OB06.226]. 
Sección 2.5 Resolución de uesigualdades lineales

Resadivo cada desigualdad y grafiquer la solucién en la recta namírica.
15. $x-9>-6$
16. $2 x+3>4$
18. $12 b-5 \leq \$ b+7$
19, $4.7 x-5.48=11.44$
17. $3-x<-4$
21. $4(x+2) \leq 4 x+8$
22. $15.3>3(a-1.4)$
24. $-6(d+2)<-9 d+3(d-1)$
25. $2 y-6 y+8 \leq 2(-2 y+9)$
20. $1.4 x+2.2<2.6 x-01.2$
23. $5 b-6=3(b+3)+2 b$
26. $\frac{y}{2}+\frac{4}{5}=3$
Rosuekra cada desizualdad y dé la sohución en noración de intervalo.
27. $4+\frac{4 x}{3}<6$
28. $4-3 x<5+2 x+17$
29. $\frac{n-5}{3}-v>-3(v-1)$
30. $\frac{h}{2}-\frac{5}{6}<\frac{7}{8}+h$
31. $\frac{t}{3}-t+7 \leq-\frac{4 l}{3}+8$
32. $\frac{6(x-2)}{5}>\frac{10(2-x)}{3}$

63. $-3 x+1<3[(x+2)-2 x]-1$

34. $4[x-(3 x-2)]>3(x+5)-15$

Resuelva cada desigualdad y de la spihución en notación de intervalo.
35. $-2 \leq t+3<4$
36. $-7<p-6 \leq-5$
37. $-15 \leq-3 z \leq 12$
38. $-16<5-3 n=13$
Q39. $4 \leq 2 x-4<7$
40. $-12<3 x-5 \leq-1$
41. $14 \leq 2-3 g<15$
42. $\frac{1}{2}<3 x+4<13$

Resuelva cada desigualdad y proporcione ef conjunto solución.
43. $5 \leq \frac{3 x+1}{2}<11$
44. $\frac{3}{5}<\frac{-x-5}{3}<2$
45. $-6 \leq-3(2 x-4)<12$
46. $-6<\frac{4-3 x}{2}<\frac{2}{3}$
47. $0 \leq \frac{3(u-4)}{7} \leq 1$
48. $-15<\frac{3(x-2)}{5} \leq 0$

Resuelva cada desigualdad e indique el conjunto solución.
49. $c \leq 1$ y $c>-3$
50. $d>00 d \leqslant 8$
51. $x<2 y x>4$
52. $w \leq-1 \circ w>6$
(2) $53+1<3 y x+1>-4$
54. $5 x-3 \leq 70-2 x+5<-3$

Resuelva cada desigualdad e indique el conjunto solución.
55. $2 s+3<70-3 s+4 \leq-17$
56. $4 a+7 \geq 9 \mathrm{y}-3 a+4 \leq-17$
57. $4 x-5 \geq 5$ y $3 x-7 \leq-1$
58. $5-3 x<-3$ y $5 x-3>10$
59. $4-r<-203 r-1<-1$
60. $-x+3<0 \circ 2 x-5 \geq 3$
61. $2 k+5>-1 \mathrm{y} 7-3 k \leq 7$
62. $2 q-11 \leq-7 \circ 2-3 q<11$

Imagen 8.09. Ejercicios del libro de texto para la sesión 06

De la misma forma que la sesión anterior, Lucho avisa que va a recoger el cuaderno de alguno de los grupos para constatar el desarrollo de estos [OB06.226]. El trabajo individual, se divide en dos partes, la primera sin el apoyo de Lucho para la solución de los ejercicios y la segunda, mediante una vigilancia constante del trabajo de los estudiantes ya que Lucho observa que los estudiantes no están siguiendo la instrucción de solución de las desigualdades [DE06.023, NO06.024].

Al finalizar la clase, en las declaraciones posteriores, Lucho comenta que el hecho de haber explicado la solución de ecuaciones y que tuvieran más tiempo para solucionar los ejercicios les permitió encontrar la solución del ejercicio [DP06.014]. Piensa continuar con la explicación, aunque ya reconoce que no va a alcanzar a explicar desigualdades con módulo [DP06.018]. 
El resumen de la sesión según la tabla por episodios es la siguiente:

\begin{tabular}{|c|c|c|c|}
\hline Episodio & Objetivo & Contenido & Actividad \\
\hline Ep 06.1 & $\begin{array}{llr}\text { Explicar } & \text { a } & \text { los } \\
\text { estudiantes la forma } & \text { solucionar } \\
\text { de } & \text { ineales. }\end{array}$ & $\begin{array}{l}\text { Inecuaciones lineales } \\
\text { Propiedad distributiva } \\
\text { Significado de pasar a } \\
\text { multiplicar o dividir } \\
\text { números negativos en } \\
\text { las desigualdades }\end{array}$ & $\begin{array}{l}\text { Explicación en el } \\
\text { pizarrón }\end{array}$ \\
\hline Ep 06.2 & $\begin{array}{l}\text { Resolver inecuaciones } \\
\text { propuestas por el } \\
\text { profesor }\end{array}$ & $\begin{array}{l}\text { Inecuaciones lineales } \\
\text { Propiedad distributiva } \\
\text { Significado de pasar a } \\
\text { multiplicar o dividir } \\
\text { números negativos en } \\
\text { las desigualdades }\end{array}$ & $\begin{array}{l}\text { Ejercicios del libro } \\
\text { de texto }\end{array}$ \\
\hline
\end{tabular}

\begin{tabular}{|l|l|}
\hline \multicolumn{2}{|c|}{ Episodio 06.1 } \\
\hline Papel del profesor & Papel del estudiante \\
\hline $\begin{array}{l}\text { Conferencista principal } \\
\text { Resolutor de preguntas acerca de su } \\
\text { propia explicación }\end{array}$ & Receptor de la información \\
\hline Recursos & Clima del Aula \\
\hline $\begin{array}{l}\text { Pizarrón y marcadores } \\
\text { Apuntes personales } \\
\text { Libro de texto }\end{array}$ & $\begin{array}{l}\text { Trabajo en gran grupo } \\
\text { Comentarios acerca de la explicación } \\
\text { Incertidumbre con relación a ciertos } \\
\text { momentos de la explicación }\end{array}$ \\
\hline
\end{tabular}

\begin{tabular}{|l|l|}
\hline \multicolumn{2}{|c|}{ Episodio 06.2 } \\
\hline Papel del profesor & Papel del estudiante \\
\hline $\begin{array}{l}\text { Observador del trabajo de los } \\
\text { estudiantes }\end{array}$ & Resolutor de ejercicios \\
$\begin{array}{l}\text { Resolutor de preguntas acerca de los } \\
\text { ejercicios propuestos }\end{array}$ & \\
\hline Recursos & Clima del Aula \\
\hline
\end{tabular}




\begin{tabular}{|l|l|l|}
\hline $\begin{array}{l}\text { Apuntes personales, notas del } \\
\text { pizarrón } \\
\text { Libro de texto }\end{array}$ & $\begin{array}{l}\text { Trabajo individual en pequeños grupos } \\
\text { Comentarios acerca de la explicación } \\
\text { Incertidumbre con la forma de resolver } \\
\text { algunos ejercicios }\end{array}$ \\
\hline
\end{tabular}

\subsubsection{Sesión 07: Solución de inecuaciones no lineales}

En la charla previa a esta sesión, Lucho comenta que no va a alcanzar a realizar la explicación de desigualdades con valor absoluto (módulo) ya que debe realizar la actividad de heteroevaluación con los estudiantes [CP07.008]. También afirma que la explicación la va a realizar a partir de los casos de factorización y la "regla de los signos" [CP07.011]. Espera que los estudiantes no tengan problema con la solución planteada puesto que ya tienen las suficientes bases para el desarrollo de las actividades propuestas [CP07.015].

La clase inicia recordando a los estudiantes el método de resolución de las inecuaciones y que para el caso de la sesión, se va a recurrir al uso de temas que se han explicado en las últimas semanas. Lucho comenta que se trata de inecuaciones que no son lineales y que se hará uso de los casos de factoreo y de suma y resta de expresiones algebraicas racionales [OB07.010]. A continuación, presenta los ejemplos:

\begin{tabular}{|c|c|c|}
\hline 1) & $\frac{x-3}{x+2} \leqslant 0$ & 2) $\frac{5}{x+4} \geqslant-1$ \\
\hline & $\begin{array}{l}\text { Negativo } \\
\pm-\end{array}$ & $\frac{5}{x+4}+1 \geqslant 0$ \\
\hline & $\doteqdot-$ & $\frac{5}{x+4}+\frac{x+4}{x+4} \geqslant 0$ \\
\hline I) & $x-3 \geqslant 0$ y $x+2<0$ & $a_{a}$ \\
\hline & $x \geqslant 3 \quad$ y $x<-2$ & $\frac{x+4}{x+4} \geqslant 0$ \\
\hline & $H(H)_{-2}$ [iththt & Positivo \\
\hline & Imposible & $\pm \Rightarrow+\quad=\Rightarrow+$. \\
\hline II) & $x-3 \leq 0$ y $x+2>0$ & \\
\hline
\end{tabular}




\begin{tabular}{|c|c|}
\hline & $\begin{array}{l}x+9 \geqslant 0 \text { y } x+4>0 \\
x \geqslant-9 \text { y } x>-4 \\
x>-4 \\
(-4 ; \infty) \\
x+9 \leqslant 0 \text { y } x+4<0 \\
x \leqslant-9 \text { y } x \leqslant-4 \\
x \leqslant-9 \\
(-\infty ;-9] \\
\text { Solución: }\end{array}$ \\
\hline 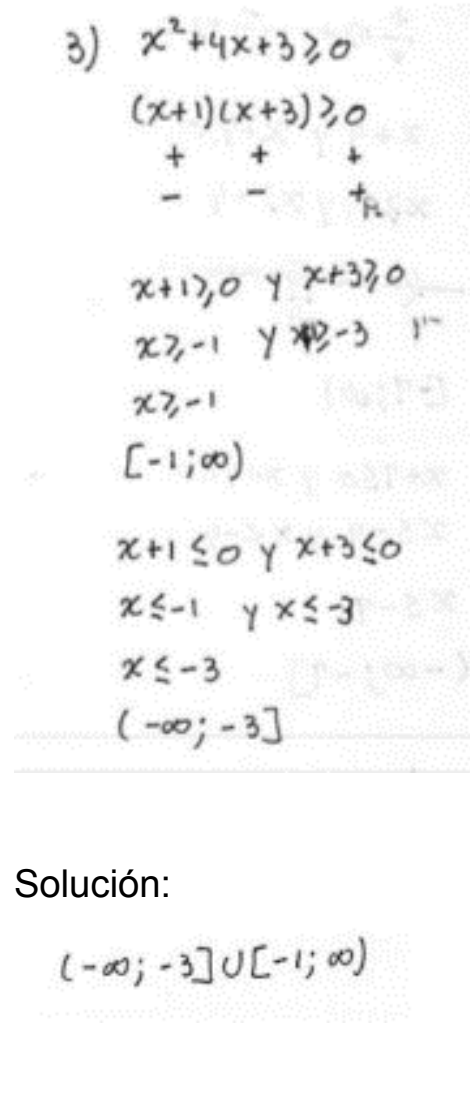 & 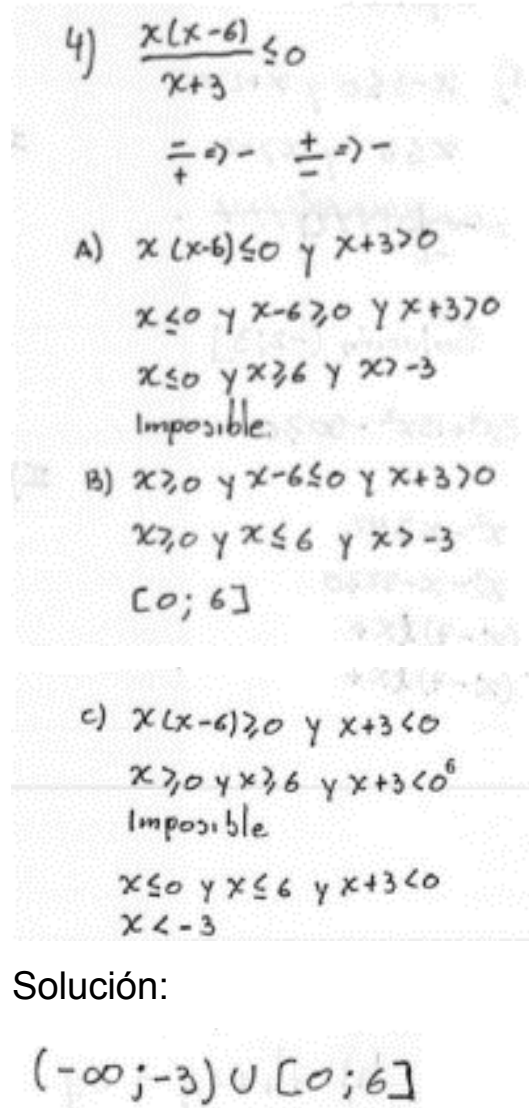 \\
\hline
\end{tabular}

Imagen 8.10. Ejemplos para la explicación de la sesión 07

Es importante anotar que Lucho hace las mismas recomendaciones para el desarrollo de las inecuaciones [NO07.008]: aplicar propiedad distributiva o factoreo si es necesario, poner los términos que tienen la variable a la derecha, despejar la variable teniendo en cuenta que si se pasa a multiplicar o dividir números negativos se cambia el símbolo de 
la inecuación [OB07.131]. Les hace énfasis en el uso de la unión y de la intersección y caracteriza la representación del intervalo solución [DE07.009]

Finalizada la parte de explicación, Lucho procede a indicar cuáles serían los ejercicios a realizar: del 43 al 60 de la página 580 del libro de texto [OB07.129]:
Resuelva cada desigualdad y proporcione la solucion en notación constructiva de conjuntos.
43. $\frac{x+2}{x-4}>0$
46. $\frac{x-1}{x+5} \leq 0$
49. $\frac{a-9}{a+5}<0$
52. $\frac{2 d-6}{d-1}<0$
55. $\frac{5 a+10}{3 a-1} \geq 0$
58. $\frac{k+3}{k} \geq 0$
44. $\frac{x+2}{x-4}=0$
47. $\frac{x+3}{x-2} \geq 0$
50. $\frac{b+7}{b+1}=0$
53. $\frac{3 y+6}{y+4}=0$
56. $\frac{x+4}{x-4}=0$
59. $\frac{3 x+8}{x-2} \leq 0$
45. $\frac{x-1}{x+5}<0$
48. $\frac{x-4}{x+6}>0$
5. $\frac{c-10}{c-4}>0$
54. $\frac{4 z-8}{z-9} \geq 0$
57. $\frac{3 x+4}{2 x-1}<0$
60. $\frac{4 x-2}{2 x-8}>0$

Imagen 8.11. Ejercicios libro de texto sesión 07

Lucho permite que el trabajo sea en grupos de máximo tres [OB07.133] y deja un tiempo para que los estudiantes hagan solos los ejercicios y luego explica las dudas que surjan.

Al finalizar la clase, en las declaraciones posteriores, Lucho comenta que los resultados de la heteroevaluación no van a ser los mejores y que debe haber un cambio en los procedimientos de la enseñanza [DP07.003]. Con respecto a los estudiantes considera que depende mucho la actitud hacia la clase el hecho que ellos puedan aprender [DP07.005].

El resumen de la sesión por episodios se presenta en la tabla 8.10:

\begin{tabular}{|c|c|c|c|}
\hline Episodio & Objetivo & Contenido & Actividad \\
\hline Ep 07.1 & $\begin{array}{llr}\text { Explicar a } & \text { los } \\
\text { estudiantes } & \text { la } & \text { forma } \\
\text { de solucionar } \\
\text { inecuaciones } & \text { no } \\
\text { lineales. } & & \end{array}$ & $\begin{array}{l}\text { Inecuaciones no } \\
\text { lineales } \\
\text { Propiedad distributiva } \\
\text { Significado de pasar a } \\
\text { multiplicar o dividir } \\
\text { números negativos en } \\
\text { las desigualdades }\end{array}$ & $\begin{array}{l}\text { Explicación en el } \\
\text { pizarrón }\end{array}$ \\
\hline
\end{tabular}




\begin{tabular}{|c|c|c|c|}
\hline Ep 07.2 & $\begin{array}{l}\text { Resolver inecuaciones } \\
\text { propuestas por el } \\
\text { profesor }\end{array}$ & $\begin{array}{l}\text { Inecuaciones no } \\
\text { lineales } \\
\text { Propiedad distributiva } \\
\text { Significado de pasar a } \\
\text { multiplicar o dividir } \\
\text { números negativos en } \\
\text { las desigualdades }\end{array}$ & $\begin{array}{l}\text { Ejercicios del libro } \\
\text { de texto }\end{array}$ \\
\hline
\end{tabular}

\begin{tabular}{|l|l|}
\hline \multicolumn{2}{|c|}{ Episodio 07.1 } \\
\hline Papel del profesor & Papel del estudiante \\
\hline $\begin{array}{l}\text { Conferencista principal } \\
\text { Resolutor de preguntas acerca de su } \\
\text { propia explicación }\end{array}$ & Receptor de la información \\
\hline Recursos & Clima del Aula \\
\hline $\begin{array}{l}\text { Pizarrón y marcadores } \\
\text { Apuntes personales } \\
\text { Libro de texto }\end{array}$ & $\begin{array}{l}\text { Trabajo en gran grupo } \\
\text { Comentarios acerca de la explicación } \\
\end{array}$ \\
Incertidumbre con relación a ciertos \\
momentos de la explicación
\end{tabular}

\begin{tabular}{|c|c|}
\hline \multicolumn{2}{|c|}{ Episodio 07.2} \\
\hline Papel del profesor & Papel del estudiante \\
\hline $\begin{array}{l}\text { Observador del trabajo de los } \\
\text { estudiantes } \\
\text { Resolutor de preguntas acerca de los } \\
\text { ejercicios propuestos }\end{array}$ & Resolutor de ejercicios \\
\hline Recursos & Clima del Aula \\
\hline $\begin{array}{l}\text { Apuntes personales, notas del } \\
\text { pizarrón } \\
\text { Libro de texto }\end{array}$ & $\begin{array}{l}\text { Trabajo individual en pequeños grupos } \\
\text { Comentarios acerca de la explicación } \\
\text { Incertidumbre con la forma de resolver } \\
\text { algunos ejercicios }\end{array}$ \\
\hline
\end{tabular}

Observadas las sesiones de clase bajo la mirada de los instrumentos de análisis se entiende que es necesario hacer un corte para describir las concepciones identificadas, el conocimiento especializado que se caracteriza y el estado actual de la reflexión por parte de Lucho. 


\subsubsection{Concepciones identificadas en este bloque}

Terminada la primera etapa de observación de la práctica y con base en los instrumentos propuestos en el Capítulo 7 es posible caracterizar algunos de los posicionamientos que posee Lucho a partir del análisis de su práctica y las opiniones implícitas y explícitas de enseñanza y aprendizaje de las matemáticas. Esta caracterización será importante ya que permite identificar las transformaciones que se dan a lo largo de la práctica de Lucho a medida que se realiza el acompañamiento.

La metodología está caracterizada por la repetición de ejercicios tipo, la explicación del docente está dada de manera constante por la presentación del libro de texto como técnica habitual:
[FD01.05]: Recursos: Apuntes personales, notas del pizarrón. Libro de texto
[FD01.07]: Recursos: Apuntes personales, notas del pizarrón. Libro de texto [FD01.09]: Recursos: Apuntes personales, notas del pizarrón. Libro de texto [FD04.04]: Recursos: Pizarrón y marcadores, notas del pizarrón. Libro de texto. [FD04.06]: Recursos: Apuntes personales, notas del pizarrón. Libro de texto. [FD05.03]: Recursos: Apuntes personales, notas del pizarrón. Libro de texto [FD06.04]: Recursos: Pizarrón y marcadores, notas del pizarrón. Libro de texto [FD06.06]: Recursos: Apuntes personales, notas del pizarrón. Libro de texto [FD07.04]: Recursos: Apuntes personales, notas del pizarrón. Libro de texto [FD07.06]: Recursos: Apuntes personales, notas del pizarrón. Libro de texto

La principal fuente de información para el alumno la constituyen el docente y el libro de texto. De acuerdo con los recursos descritos en las fichas de diario, Lucho no realiza diferenciación individual en el proceso de enseñanza, no emplea materiales manipulativos.

Persigue objetivos terminales y funcionales, pone más énfasis en objetivos procedimentales locales:

\section{Objetivos planteados:}

[FD01.01]: Explicar a los estudiantes la forma de solucionar sumas y restas de expresiones algebraicas racionales

[FD01.02]: Resolver sumas y restas de expresiones algebraicas racionales [FD03.01]: Corregir de manera grupal el desarrollo de la actividad evaluativa de la sesión anterior 
[FD03.02]: Corregir el desarrollo de la actividad evaluativa a partir de la interacción de los estudiantes del curso

[FD04.01]: Explicar a los estudiantes la forma de solucionar ecuaciones lineales.

[FD04.02]: Resolver ecuaciones propuestas por el profesor

[FD05.01]: Resolver ecuaciones propuestas por el profesor

[FD06.01]: Explicar a los estudiantes la forma de solucionar inecuaciones lineales.

[FD06.02]: Resolver inecuaciones propuestas por el profesor

[FD07.01]: Explicar a los estudiantes la forma de solucionar inecuaciones no lineales.

[FD07.02]: Resolver inecuaciones propuestas por el profesor

Dichos objetivos se deben quizás a que Lucho sigue una programación prescrita de antemano, externa a él y rígida [EN01.123].

La evaluación está centrada para calificar, para medir la consecución de los objetivos prefijados. Lucho la lleva a cabo con el fin de 'reproducir' los contenidos practicados, principalmente los algorítmicos y las aplicaciones mostradas en clase: [EN03.139 a EN03.141]. La evaluación atiende sobre todo al producto y es realizada mediante exámenes escritos al final del proceso, orientada y dirigida directamente por Lucho.

Con relación a las concepciones sobre las matemáticas escolares, se observa que Lucho orienta la asignatura exclusivamente hacia la adquisición de conceptos y reglas [FD01.13, CP03.009, DP05.015]. De esta manera, las matemáticas escolares coinciden con la que se muestra básicamente en el libro de texto.

Lo anterior coincide con las concepciones del aprendizaje que se identifican en este bloque: Lucho presupone que el aprendizaje se realiza, utilizando la memoria como principal recurso, por superposición de unidades de información [DP01.022]. El alumno se hace con los conocimientos por el simple hecho de que el docente se los presente y por ello se evalúa al finalizar la explicación de un determinado tema [DP01.025].

Para aprender, al alumno le basta entender, asimilar el conocimiento que proviene del exterior [EN01.103], Lucho quiere que los estudiantes expliciten lo aprendido con la expresión usada por él [NO03.026]. No le interesa la idea sino la mecánica, de ahí la explicación al inicio de la clase y luego el trabajo de ejercitación [NO03.011]. El alumno interactúa con las matemáticas realizando los ejercicios propuestos [NO05.014]. La interacción que se produce entre el profesor y el alumno no es equilibrada, siendo más fuerte el flujo en la dirección profesor a estudiante que la inversa, evidenciado 
esto en la explicación permanente por parte de Lucho en cada una de las actividades propuestas [NO03.020].

La estructura de la propia asignatura, plasmada en la programación, es el dinamizador ideal del aprendizaje, pero Lucho resalta que la forma de agrupamiento puede cambiar si en la actitud del alumno hacia el aprendizaje se detectan aspectos que pueden sufrir cambios [DP06.012, DP07.020].

Así, el papel del alumno está perfilado únicamente como el de aprendiz. El alumno no tiene que ver con el diseño de las actividades programadas para el trabajo en aula ni con la planeación de clase ni con el diseño didáctico [EN01.130, NO07.015]

Entonces, el papel del docente se ve limitado a un ejercicio de trasmisión verbal de los contenidos de aprendizaje, mediante explicación de lo reflejado en el libro de texto, realizando una reproducción literal de éste. Actúa como un especialista en el contenido, aunque es el libro de texto el que valida las ideas que se movilizan en el aula, corrigiendo a los alumnos en caso de errores y aportando él mismo la información correcta [OB04.192, OB05.061, OB05.063].

Respecto de la enseñanza y el aprendizaje de las matemáticas, se puede caracterizar una concepción tradicional en la manera como realiza las clases. Lo primero que hace Lucho en las clases es dar las pautas de cómo se resuelven los ejercicios, esto se evidencia en las sesiones 1, 4, 6 y 7 [OB01.051 a OB01.200; OB04.021 a OB04.100; OB06.018 a OB06.212; OB07.012 a OB07.121]: las clases están caracterizadas en su momento inicial cuando presenta el ejemplo para el desarrollo de la clase intentando que los estudiantes se interesen por los conceptos y reglas para el desarrollo de los ejercicios que considera deben resolver; así, Lucho intenta que el aprendizaje de sus alumnos sea mediante un proceso deductivo en el que a partir de la regla, se lleve a cabo una aplicación determinada [DE07.016].

El aprendizaje se convierte en un proceso individual donde cada uno tiene que responder de manera propia sobre sus aprendizajes en el momento de la "evaluación" [DE06.027].

En los casos en que exista una "buena enseñanza", la responsabilidad de los resultados del aprendizaje, que dependen del grado de sumisión, es exclusiva del alumno, en particular el alumno escucha la explicación del docente para poder repetir 
posteriormente el proceso explicado, reproduciendo el proceso lógico mostrado por el docente, imitando así su estilo cognitivo [DP02.025, DP03.011, DP04.027]. Al ser Lucho quien proporciona la clave para la repetición/reproducción posterior, es fundamental la atención a éste, es decir la fuente de información fundamental [DE06.029].

\subsubsection{Conocimiento Especializado en este bloque}

\section{Con relación al conocimiento}

Lucho pone de manifiesto el conocimiento de los temas suma y resta de expresiones algebraicas y solución de ecuaciones e inecuaciones de primer grado con una variable. Se observa principalmente que, Lucho resuelve los ejercicios previamente [NO07.007] y no tiene problemas conceptuales a la hora de resolverlos en la clase con los estudiantes. El conocimiento del tema observado se vincula principalmente a la resolución de enunciados y ejercicios que son más avanzados a los que propone en clase; esto es, Lucho se ha preparado para resolver ejercicios a partir de las teorías para la solución matemática de dichos temas [EN02.189, EN02.190].

En el caso de Lucho, el conocimiento de tema se vincula directamente con la estructura matemática puesto que permite dar orientaciones a los estudiantes acerca de lo que pueden aprender en otros contextos y en carreras universitarias [DE06.030]; Lucho manifiesta desarrollar este tipo de conocimiento en cuanto a su preparación para el ingreso a una carrera de especialización ya que en esta requiere de de una visión general para la aplicación de un campo particular de las matemáticas: en este caso, las relaciones de la teoría de campos y grupos con las estructuras algebraicas [EN02.228].

Respecto al conocimiento de la práctica, éste parece estar limitado a la enunciación de ejercicios [NO06.019; FD01 a FD07] y la explicación de estos; esta limitación puede estar determinada por dos aspectos: una la falta de espacios institucionales para realizar las clases de matemáticas en otro espacio [EN02.215], otra por una posible carencia de Lucho acerca de cómo presentar el tema ante los estudiantes [EN02.217]. Así, el conocimiento de las características del aprendizaje de las matemáticas que Lucho pone en evidencia muestra una situación paradójica: en un primer momento Lucho habla de la importancia de la resolución de problemas para el aprendizaje de las matemáticas [EN01.093], pero en su práctica no lo realiza [DP04.029, EN02.056, EN02.057], quizás debido a las expectativas de aprendizaje que tienen los estudiantes a los cuales orienta 
[DE07.017]. Lucho identifica las motivaciones de los estudiantes más avanzados [DP04.015] pero no profundiza en ellos debido al temor de que ellos avancen más sin permitir el aprendizaje de los estudiantes que están menos motivados [DP04.019].

Finalmente, el conocimiento de los estándares de aprendizaje de las matemáticas de Lucho se adapta a los requerimientos de orden nacional (Lineamientos, Estándares Básicos propuestos por el Ministerio de Educación) y de orden local (plan de área de matemáticas de la Institución) y su labor de enseñanza va en procura de lograr el manejo temático de los temas por parte de sus estudiantes. Lucho maneja el contexto institucional de acuerdo con las necesidades de los estudiantes y de la profundización que realizan en el respectivo grado de enseñanza en el que se encuentran, propuesta en general por el área de matemáticas de la institución y tiene un manejo de grupo coherente con los acuerdos que internamente se manejan en la institución:

[N007.019]: Las planeaciones de Lucho están sustentadas por el documento del área de matemáticas del Colegio, las temáticas salen de esa planeación aprobada por el equipo de área, aunque las decisiones de puesta en práctica dependen de cada docente

Universidad Pedagógiça Nacional Instituio Pedagógiao Nacional

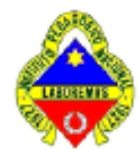

\section{METAS COMPETENCIAS Y DESEMPEÑOS 2015 MATEMÁTICAS \\ PLANEACIÓN POR SEMESTRE GRADO DÉCIMO}

\begin{tabular}{|c|c|c|c|}
\hline \multicolumn{2}{|r|}{ Área : Matemáticas } & Asignatura : Precálculo & 1001,1003 Y 1004/I Semestre \\
\hline \multicolumn{4}{|c|}{ Meta: Analizar y resolver situaciones en diversos contextos, incluido el análisis estadístico de datos, que se pueden modelar por medio de funciones. } \\
\hline \multicolumn{4}{|c|}{$\begin{array}{l}\text { Competencias: } \\
\text { - Comparar y contrastar las propiedades de los números (naturales, enteros, racionales y reales) y las de sus relaciones y operaciones para construir, } \\
\text { manejar y utilizar apropiadamente los distintos sistemas numéricos. } \\
\text { - Establecer relaciones y diferencias entre diferentes notaciones de números reales para decidir sobre su uso en una situación dada. } \\
\text { - Interpretar y comparar resultados de estudios con información estadística provenientes de medios de comunicación. } \\
\text { - Riseñar experimentos aleatorios (de las ciencias fisicas, naturales o sociales) para estudiar un problema o pregunta. } \\
\text { aleatorio, muestreo con remplazo). }\end{array}$} \\
\hline \multicolumn{4}{|c|}{$\begin{array}{l}\text { Desempeño actitudinal: } \\
\text { Asumo con responsabilidad y compromiso las labores académicas, el cuidado del medio ambiente y la sana convivencia. }\end{array}$} \\
\hline CORTE & CONTENIDO & ACTIVIDADES POR & DESEMPEÑOS \\
\hline I & $\begin{array}{l}\text { - Propiedades de los números reales } \\
\text { - Conjunto e intervalos. } \\
\text { - Valor absoluto y distancia. } \\
\text { - Exponentes enteros } \\
\text { - Radicales } \\
\text { - Exponentes Racionales } \\
\text { - Productos especiales y } \\
\text { factorización } \\
\text { - Expresiones Fraccionarias }\end{array}$ & $\begin{array}{l}\text { En el transcurso del corte las actividades que } \\
\text { se tendrán en cuanta para evaluar el proceso } \\
\text { del estudiante se relacionan con: Tareas, } \\
\text { talleres, quiz, trabajos, participación o } \\
\text { tablero. }\end{array}$ & $\begin{array}{l}\text { 1. Formulo y resuelvo problemas en los que } \\
\text { utilizo el conjunto de los números reales y sus } \\
\text { diferentes formas de representación. } \\
\text { Recomendaciones: } \\
\text { - Identifique las propiedades y relaciones de los } \\
\text { números reales. }\end{array}$ \\
\hline
\end{tabular}




\section{Con relación a sus actitudes}

Lucho es un profesor que está dispuesto a aprender porque siente que su quehacer es contradictorio [DP01.010], lo evidencia así en la Entrevista Inicial (donde favorece el aprendizaje de las matemáticas a través de la resolución de problemas) y su práctica (constituida por una tendencia tradicional), en particular sus declaraciones posteriores.

Respecto a sus estudiantes, Lucho es un profesor que cree que ellos están destinados a un éxito o un fracaso hacia el aprendizaje de las matemáticas: Fracaso porque a la mayoría no les interesa a su edad y por sus motivaciones propias [DE06.031, DE06.33] y éxito porque a los pocos que les gusta les va a facilitar [DE06.032]. Comprende bien que la línea de profundización elegida (Humanidades) hace que ellos no se sientan cercanos a las matemáticas, pero potencia el hecho que haya buenos estudiantes en su grupo [DE07.018]. Bien puede ser que ellos tengan mucho o poco interés por el aprendizaje de las matemáticas, Lucho considera que es importante que los estudiantes aprendan ya sea para aplicaciones en la universidad o las pruebas estandarizadas: En cualquier carrera univesitaria les van a pedir matemáticas, ya sea en algún curso específico o en pruebas saber [DE06.030].

\subsubsection{Acerca de la reflexión de Lucho}

En el primer momento de observación no se evidencia ejercicio reflexivo por parte de Lucho. Con relación a la primera sesión y la entrevista inicial se nota un panorama de contradicción: en la primera sesión se nota una tendencia tradicional [NO01.050] a lo largo de la Entrevista Inicial se menciona un quehacer docente a lo largo del desarrollo de la resolución de problemas [EN01.082, EN01.083].

Las charlas previas, las declaraciones posteriores y las fichas de diario le conceden la oportunidad de generarse preguntas acerca de su práctica. La primera sesión no deja entrever un ejercicio reflexivo, ni en la ficha de diario [FD01.10, FD01.11, FD01.12] ni en las declaraciones posteriores [DP01.001 a DP01.029], pero a medida que se va reiterando el ejercicio van apareciendo enunciados que lo acercan a la reflexión. De la observación continua y la propuesta de mejora que escribe en las fichas de diario se obtiene que a medida que avanza el proceso de observación y acompañamiento se pregunta acerca de cómo acercar a los estudiantes hacia una comprensión de las matemáticas: 


\section{Propuesta de mejora en Fichas de diario:}

[FD01.10]: Las dificultades que he encontrado en esta sesión han sido referentes al tiempo.

[FD01.11]: No es que no confíe en que lo que estoy haciendo sea o no sea. Soy consciente de que debo tener muchos errores, pero haciendo se aprende.

[FD01.12]: Hay diferencias con relación a lo que esperaba de los estudiantes y lo que ellos han hecho. Esto ha generado dificultades que deben ser mejoradas por lo pronto [FD02.07]: Hay que plantear distintas metodologías para el diseño de la evaluación porque los estudiantes no llegaron a los resultados esperados.

[FD03.07]: Es necesario hacer actividades que sean más dinámicas con relación a lo propuesto en las clases anteriores

[FD03.08]: Se destaca la inquietud de los estudiantes frente a su proceso de enseñanza, pero hay que buscar elementos que los movilicen más.

[FD03.09]: Debo pensar en elementos para que los estudiantes superen dificultades con relación a las definiciones de abstracción de características fundamentales e impredecibles.

[FD04.07]: Búsqueda de alternativas para sacar a los estudiantes de la dificultad de los alumnos hacia lo particular y la solución sin generalizar

[FD05.04]: Es importante movilizar a todos los estudiantes para que realicen los ejercicios propuestos

[FD06.07]: Determinar estrategias para que los niños solucionen ecuaciones e inecuaciones

[FD07.07]: Como profesor no estoy movilizando a los estudiantes y la metodología no es adecuada para el desarrollo de las actividades propuestas. Es urgente un cambio de parte mía

Entonces, la generación de estas inquietudes y en particular de [FD07.07] surge una ruptura en la práctica de Lucho, la cual incide en el desarrollo de las clases con el grupo observado y las rutinas adoptadas en el aula de clase tienen un cambio que permiten al investigador identificar un posible cambio de conducta en el quehacer profesional de Lucho.

\subsection{Bloque II. Segundo momento de observación}

Luego de la séptima sesión, lucho se empieza a dar cuenta que hay elementos de la clase que no están funcionando, en particular la propuesta de mejora de dicha sesión [DP07.028]. Al preguntársele posteriormente si había notado esa necesidad de cambio afirma que si, pero por alguna razón la había obviado [EN03.096], y quizá el ejercicio de 
observación y de tratar de mostrar una clase que evolucionara lo hizo cambiar de estrategia [EN03.097] en la misma acción y es aquí donde se da el primer corte en la práctica observada de Lucho, conllevando a la iniciación de un segundo bloque en el que se manifiestan cambios con relación a lo atendido hasta el momento y que se describen a continuación.

\subsubsection{Sesiones observadas}

En este bloque se observan tres sesiones, que corresponden a un momento de refuerzo de los temas estudiados en el primer bloque con modificación de algunas actividades.

\subsubsection{Sesión 08: Heteroevaluación y propuesta de mejora}

Se acerca la mitad del primer semestre y por instrucciones institucionales hay que hacer la heteroevaluación del primer corte:

[N008.002]: El sistema de Evaluación Institucional indica que las calificaciones parciales de los estudiantes de grado décimo tienen un componente denominado heteroevaluación en la que mediante una conversación entre cada estudiante y el docente se otorga una calificación acerca del proceso individual de cada alumno.

En la charla previa, Lucho reconoce el trabajo del grupo, en particular el hecho de ser del énfasis de humanidades hace que su gusto e interés hacia las matemáticas no sea mayor, aunque para algunos las matemáticas se pueden volver una herramienta potente de acuerdo con el contexto que se emplee [CP08.010].

La actividad de esta sesión se divide en dos partes, la primera consiste en dialogar con cada estudiante acerca del proceso realizado durante la primera parte del año y generar consciencia de cada uno [CP08.007]. Lucho permite que los estudiantes trabajen en el desarrollo de otras actividades [NO08.006] ya que los estudiantes le han solicitado el espacio para no quedar atrasados en otras materias. Que estén mal en matemáticas ya es suficiente escarnio para ponerse a estudiar en las otras áreas [DE08.008].

Algunos estudiantes aprovechan esta actividad para hacer una retroalimentación seria de su papel como alumnos y para hacer comentarios acerca del proceso de enseñanza por parte del profesor [NO08.009]. Lucho recibe con buen gesto los comentarios que le 
realizan y llega a acuerdos con los estudiantes que considera se han esforzado por aprender y aportar a la clase de matemáticas [DP08.021]. Con los estudiantes que no tienen buen comportamiento en clase ni actitud para con la materia Lucho tiene un trato más frío y no negocia la calificación de la heteroevaluación [NO08.010, NO08.011].

Cuando termina la heteroevaluación, que pudo realizar porque en un bloque anterior tuvo una sustitución [OB08.001], Lucho indica a los estudiantes que se reúnan en grupos de tres estudiantes para desarrollar una actividad [OB08.188, OB08.190]. A medida que cada grupo realice lo propuesto, permitirá que realicen otro ejercicio [NO08.015]. Condiciona a los estudiantes a modificar su heteroevaluación positiva o negativamente de acuerdo con los resultados finales de la actividad propuesta [OB08.192].

La primera hoja que entrega es la siguiente:

\section{TAREA 1}

Responda a continuación las siguientes preguntas. Trate de contestar de manera crítica y con la seriedad que corresponde:

¿Para qué sirven las ecuaciones y las inecuaciones?

¿Qué situaciones reales se pueden resolver mediante ecuaciones?

Imagen 8.13. Tarea 01 Sesión 08

Lucho les dice que tienen diez minutos y les recuerda el condicionamiento que tiene el buen desarrollo de la actividad con relación a la calificación que se está negociando [OB08.200]. Pasado el tiempo, el profesor interrumpe para socializar lo que los estudiantes han escrito y complementa lo que les ha dicho con ejemplos como el lanzamiento de un balón de fútbol, la caída de alguien que se tira haciendo puenting, el conocimiento de la presión atmosférica (que permite saber la altura a la que se encuentra un avión un globo o un excursionista que escala una montaña), la comparación del gasto total invertido en un vehículo diesel y uno de nafta. [OB08.217, OB08.218, OB08.219, OB08.220].

Seguido a ello les pide que los que no han puesto ejemplos propongan alguno diferente, provocando, en palabras de Lucho, la creatividad de los estudiantes al tener bases para responder las preguntas: 
Lucho se ha acercado al observador para decir textualmente:

[OB08.225] Com espero que desarrollen creatividad a la hora de contestar esta pregunta.

Algunos minutos más adelante les entrega la siguiente hoja y una pelotita de ping pon:

\section{TAREA 2}

¿Cuál de las siguientes gráficas representa la altura de un ping pon cuando se lanza al aire con relación al tiempo transcurrido?
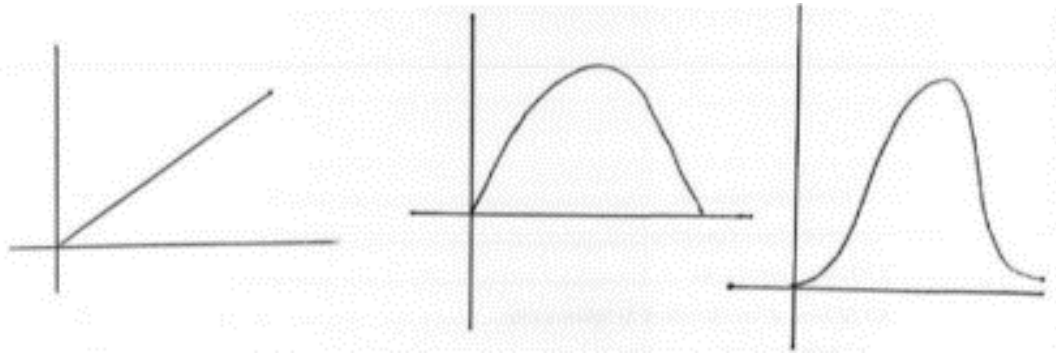

¿Cuál de las siguientes gráficas representa la altura de un ping pon cuando se lanza al piso con relación al tiempo transcurrido?
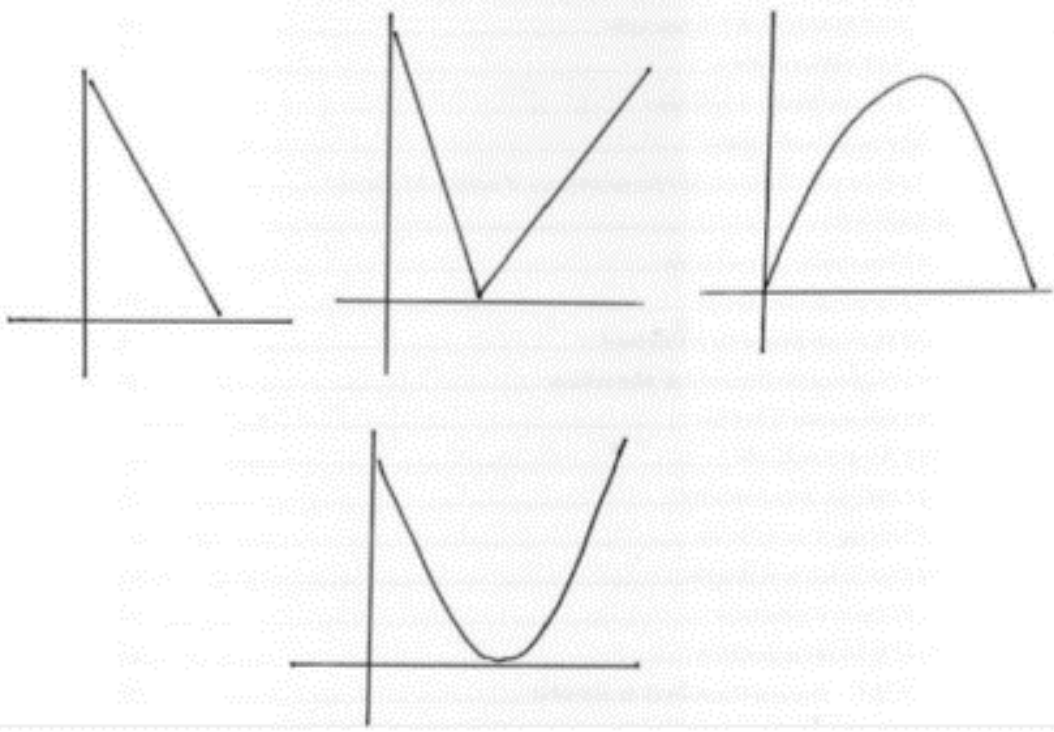

Lance el ping pon al aire y luego al piso y compare las respuestas obtenidas.

Vuelva a lanzar el ping pon al piso y con ayuda de su celular determine el tiempo del recorrido. ¿Cuánto dura el recorrido? ¿A qué altura lo lanzó? ¿En qué momento llegó al piso el ping pon? 
Pasados unos minutos luego de que les entrega la hoja a todos, les pide nuevamente silencio y les hace una explicación sobre algunas aplicaciones de las ecuaciones, les hace reflexionar que con ayuda de un modelo matemático se puede determinar la altura exacta del ping pong si se conoce la ecuación de su lanzamiento con relación al tiempo [OB08.248, OB08.249]. Al finalizar la explicación, Lucho reclama las hojas y les entrega una última hoja:

\section{TAREA 3}

Responda las siguientes preguntas e indique si se trata de una ecuación o de una inecuación:

Las edades de un padre y su hijo difieren 27 años, ¿a qué edad tendrá el padre el doble de la edad del hijo?

Las edades de un padre y su hijo difieren 27 años, ¿entre qué edades tendrá el padre más del doble de la edad del hijo?

¿Cuántos metros de tela metálica se necesitan para vallar una parcela cuadrada cuya área sea de $36 \mathrm{~m}^{2}$ ?

¿Cuántos metros de tela metálica se necesitan para vallar una parcela cuadrada cuya área sea, al menos, de $36 \mathrm{~m}^{2}$ ?

Imagen 8.15. Tarea 3 Sesión 08

Después de un rato, Lucho le pide a un estudiante que comente los resultados:

\begin{tabular}{lll}
\hline \hline [OB08.272] & Estudiante: & $\begin{array}{l}\text { La primera es una ecuación. Es lógico que cuando tenga el hijo } \\
\text { tenga } 27 \text { años, el padre va a tener } 27 \text { años más }\end{array}$ \\
\hline [OB08.273] & Estudiante: & $\begin{array}{l}\text { La segunda es una ecuación. El padre tendrá más del doble de } \\
\text { edad entre los } 27 \text { años y los } 54 \text { años }\end{array}$ \\
\hline [OB08.274] & Estudiante: & $\begin{array}{l}\text { El tercero se puede expresar como cuatro equis igual a cuatro } \\
\text { veces la raíz de treinta y seis, es una ecuación }\end{array}$ \\
\hline [OB08.275] & Estudiante: & El último es una inecuación \\
\hline
\end{tabular}


Finalmente, hace entrega de una hoja a cada estudiante para el desarrollo de la tarea para la casa:

\section{TAREA}

Complete la siguiente tabla transformando cada expresión con los distintos sistemas de representación:

\begin{tabular}{|l|l|l|}
\hline $\begin{array}{l}\text { Representación } \\
\text { Simbólica }\end{array}$ & Representación Gráfica & Representación verbal \\
\hline $2 x^{3}-5 x+3=0$ & & \\
\hline & & \\
\hline & & $\begin{array}{c}\text { El triple de un número al } \\
\text { cuadrado menos su quinta } \\
\text { parte es 6 }\end{array}$ \\
\hline
\end{tabular}

Imagen 8.16. Tarea para la casa Sesión 08

La clase termina con dos comentarios generales por parte de Lucho, el primero indicando qué estudiantes van perdiendo (alrededor del 50\%) y cuáles van en aceptable (alrededor del $40 \%$ ) y les pide mucho interés para las siguientes sesiones porque seguramente pueden recuperar si manifiestan interés por la clase [OB08.283]. El segundo comentario lo inicia preguntando las actividades realizadas durante la clase y recapitula lo que ha propuesto en cada una de las cuatro tareas propuestas [OB08.285, OB08.286, OB08.287, OB08.288, OB08.289, OB08.290].

En la declaración posterior, Lucho comenta que si bien son muchos los estudiantes que están perdiendo, hay que reconocer que en matemáticas esto es un suceso normal [DP08.015]. Dice que el trabajo planeado para la actividad del día está dedicado a bajar la pérdida realizada en la actividad de heteroevaluación [DP08.019]. Ha introducido un elemento nuevo en el desarrollo de su práctica que es el hecho de mencionar las representaciones tanto para las ecuaciones como para las inecuaciones y ha logrado un proceso de reflexión con los estudiantes acerca de lo aprendido y acerca del proceso realizado durante las clases anteriores. Sobre la siguiente sesión dice que ha replanteado el seguir explicando y que necesita hacer una retroalimentación del proceso realizado [DP08.033]. 
La tabla 8.11 sintetiza los episodios de esta sesión:

\begin{tabular}{|c|c|c|c|}
\hline Episodio & Objetivo & Contenido & Actividad \\
\hline Ep 08.1 & $\begin{array}{l}\text { Realizar el proceso de } \\
\text { heteroevaluación de } \\
\text { los estudiantes de } \\
\text { décimo. }\end{array}$ & $\begin{array}{l}\text { Actitud del estudiante } \\
\text { frente a la clase de } \\
\text { matemáticas } \\
\text { Revisión reflexiva de } \\
\text { los contenidos } \\
\text { aprendidos durante la } \\
\text { primera parte del año } \\
\text { escolar }\end{array}$ & $\begin{array}{lll}\text { Dialogo con el } \\
\text { profesor }\end{array}$ \\
\hline Ep 08.2 & $\begin{array}{l}\text { Generar reflexión } \\
\text { acerca del significado } \\
\text { de las ecuaciones e } \\
\text { inecuaciones }\end{array}$ & $\begin{array}{l}\text { Ecuaciones } \\
\text { Inecuaciones }\end{array}$ & $\begin{array}{l}\text { Tarea } 1 \\
\text { Reflexión acerca } \\
\text { de la utilidad de las } \\
\text { ecuaciones e } \\
\text { inecuaciones }\end{array}$ \\
\hline Ep 08.3 & $\begin{array}{l}\text { Modelar algunas } \\
\text { situaciones con ayuda } \\
\text { de las ecuaciones }\end{array}$ & Ecuaciones & $\begin{array}{l}\text { Tarea } 2 \\
\text { Uso de las } \\
\text { ecuaciones para } \\
\text { modelar algunas } \\
\text { situaciones }\end{array}$ \\
\hline Ep 08.4 & $\begin{array}{l}\text { Diferenciación entre } \\
\text { las ecuaciones y las } \\
\text { inecuaciones }\end{array}$ & $\begin{array}{l}\text { Ecuaciones } \\
\text { Inecuaciones } \\
\text { Significado de las } \\
\text { ecuaciones } \\
\text { inecuaciones }\end{array}$ & $\begin{array}{lr}\text { Tarea 3 } \\
\text { Diferenciación del } \\
\text { uso cotidiano de } \\
\text { ecuaciones } \\
\text { inecuaciones }\end{array}$ \\
\hline Ep 08.5 & $\begin{array}{l}\text { Reconocer en los } \\
\text { estudiantes el uso de } \\
\text { las representaciones } \\
\text { de las ecuaciones }\end{array}$ & $\begin{array}{l}\text { Ecuaciones } \\
\text { Inecuaciones } \\
\text { Significado de las } \\
\text { ecuaciones } \\
\text { inecuaciones }\end{array}$ & $\begin{array}{l}\text { Tarea 4, para la } \\
\text { casa } \\
\text { Representación de } \\
\text { las ecuaciones e } \\
\text { inecuaciones }\end{array}$ \\
\hline
\end{tabular}

\section{Episodio 08.1}

\begin{tabular}{|l|l|}
\hline Papel del profesor & Papel del estudiante \\
\hline $\begin{array}{l}\text { Cuestionador y reflexivo del } \\
\text { aprendizaje de los estudiantes }\end{array}$ & $\begin{array}{l}\text { Reflexión y crítico de su quehacer } \\
\text { Analista de su propio aprendizaje }\end{array}$ \\
\hline
\end{tabular}




\begin{tabular}{|l|l|}
\hline Recursos & Clima del Aula \\
\hline Calificaciones & $\begin{array}{l}\text { Trabajo individual } \\
\text { Diálogo entre estudiantes y profesor } \\
\text { Rescate de valores con relación al proceso de } \\
\text { enseñanza y aprendizaje }\end{array}$ \\
\hline
\end{tabular}

\begin{tabular}{|c|c|}
\hline \multicolumn{2}{|c|}{ Episodio 08.2} \\
\hline Papel del profesor & Papel del estudiante \\
\hline $\begin{array}{l}\text { Orientador pasivo de la actividad } \\
\text { permitiendo que sean los estudiantes } \\
\text { los que propongan el desarrollo de la } \\
\text { actividad } \\
\text { Generador de reflexión a partir de } \\
\text { alguna idea básica }\end{array}$ & $\begin{array}{l}\text { Reflexivo frente a la utilidad de las ecuaciones } \\
\text { y las inecuaciones } \\
\text { Resolutor de la situación }\end{array}$ \\
\hline Recursos & Clima del Aula \\
\hline $\begin{array}{l}\text { Tarea propuesta } \\
\text { Anotaciones } \\
\text { Libro de texto }\end{array}$ & $\begin{array}{l}\text { Trabajo en grupo } \\
\text { Interés por el desarrollo de la actividad }\end{array}$ \\
\hline
\end{tabular}

\begin{tabular}{|l|l|}
\hline \multicolumn{2}{|c|}{ Episodio 08.3 } \\
\hline Papel del profesor & Papel del estudiante \\
\hline $\begin{array}{l}\text { Orientador pasivo de la actividad } \\
\text { permitiendo que sean los estudiantes } \\
\text { los que propongan el desarrollo de la } \\
\text { actividad }\end{array}$ & $\begin{array}{l}\text { Reflexivo frente a la utilidad de las ecuaciones } \\
\text { Resolutor de la situación a partir de } \\
\text { Generador de reflexión a partir de } \\
\text { alguna idea básica }\end{array}$ \\
\hline Recursos & \\
\hline $\begin{array}{l}\text { Tarea propuesta } \\
\text { Anotaciones } \\
\text { Libro de texto }\end{array}$ & Trabajo en grupo \\
\hline
\end{tabular}

\begin{tabular}{|l|l|}
\hline \multicolumn{2}{|c|}{ Episodio 08.4 } \\
\hline Papel del profesor & Papel del estudiante \\
\hline Orientador pasivo de la actividad & Reflexivo frente a la utilidad de las ecuaciones \\
permitiendo que sean los estudiantes & y las inecuaciones \\
\hline
\end{tabular}




\begin{tabular}{|l|l|}
\hline $\begin{array}{l}\text { los que propongan el desarrollo de la } \\
\text { actividad } \\
\begin{array}{l}\text { Generador de reflexión a partir de } \\
\text { alguna idea básica }\end{array}\end{array}$ & $\begin{array}{l}\text { Resolutor de la situación a partir de } \\
\text { cuestionamientos del trabajo en grupo }\end{array}$ \\
\hline Recursos & Clima del Aula \\
\hline $\begin{array}{l}\text { Tarea propuesta } \\
\text { Anotaciones }\end{array}$ & $\begin{array}{l}\text { Trabajo en grupo } \\
\text { Libro de texto }\end{array}$ \\
\hline
\end{tabular}

\begin{tabular}{|c|c|}
\hline \multicolumn{2}{|c|}{ Episodio 08.5} \\
\hline Papel del profesor & Papel del estudiante \\
\hline $\begin{array}{l}\text { Orientador pasivo de la actividad } \\
\text { permitiendo que sean los estudiantes } \\
\text { los que propongan el desarrollo de la } \\
\text { actividad } \\
\text { Asesor del uso de las } \\
\text { representaciones de las ecuaciones } \\
\text { e inecuaciones }\end{array}$ & $\begin{array}{l}\text { Reflexivo frente a la utilidad de las ecuaciones } \\
\text { y las inecuaciones } \\
\text { Propositor de formas de representación de } \\
\text { ecuaciones e inecuaciones } \\
\text { Resolutor de la situación a partir de } \\
\text { cuestionamientos del trabajo en grupo }\end{array}$ \\
\hline Recursos & Clima del Aula \\
\hline $\begin{array}{l}\text { Tarea propuesta } \\
\text { Anotaciones } \\
\text { Libro de texto }\end{array}$ & $\begin{array}{l}\text { Trabajo en grupo } \\
\text { Interés por el desarrollo de la actividad }\end{array}$ \\
\hline
\end{tabular}

\subsubsection{Sesión 09: Una propuesta alterna}

La sesión inicia con el llamado de lista y la corrección de la tarea de la sesión anterior, para ello Lucho elige un estudiante para que exponga en el pizarrón los resultados de la tarea [OB09.017]. Repite el ejercicio con dos estudiantes más y luego pregunta si están de acuerdo con las resoluciones planteadas, se corrigen errores y se procede al desarrollo de la sesión [NO09.006, NO09.007].

Luego de ello, pide que se hagan grupos de tres estudiantes y les entrega ejercicios con enunciados que permiten modelar ecuaciones de primer y segundo grado tanto polinómicas como racionales [NO09.008]. Los enunciados de estos problemas son los siguientes: 
Planeacióa de un arenero Betsy Nixon está planeando construir un arenero rectangular para su hija. Cuenta con 38 pies de madera para utilizar en los lados. Si el largo del arenero será de 11 pies, ¿cuál será el ancho?

Volumen de concreto en una entrada de automóvil Anthony Palmiotto, está instalando concreto para una entrada de cochera, será de 15 pies de largo por 10 pies de ancho y 6 pulgadas de profundidad.

a) Determine el volumen del concreto necesario en pies cúbicos.

b) Si 1 yarda cúbica $=27$ pies cúbicos, ¿cuíntas yardas cúbicas de concreto se necesitan?

c) Si el concreto cuesta $\$ 35$ por yarda cúbica, ¿cuál es el costo del conereto? El concreto debe comprarse en yardas cúbicas completas

Capacidad de una cubeta Sandra Hakanson tiene una cubeta en la que desea mezclar detergente. Las dimensiones de la cubeta se muestran en la figura.

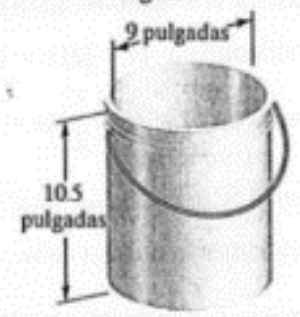

a) Determine la capacidad de la cubeta en pulgadas cúbicas.

b) Si 231 pulgadas cúbicas $=1$ galón, ¿cuál es la capacidad de la cubeta en galones?

c) Si las instrucciones en la botella de detergente dicen que agregue 1 onza por galón de agua, ¿cuánto detergente debe añadir Sandra a la cubeta llena de agua?

Alfombra La longitud de una alfombra persa es 3 pies mayor que el doble de su ancho. Determine la longitud y el ancho de la alfombra, si su área mide 65 pies cuadrados.

Lanzamiento de una pelota José Ramirez lanza una pelota hacia arriba desde lo alto de un edificio. La distancia, $d$ de la pelota respecto del piso en cualquier instante, $t$, es $d=-16 r^{2}+80 c+96 . \_$Cuánto tardará la pelota en chocar contra el piso?
Área de un helipuerto Un helipuerto en Raleigh, Carolina del Norte, tiene dos círculos concéntricos como se muestra en la figura.

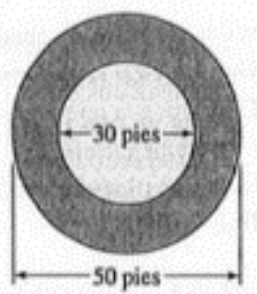

Determine el área de la región roja en la figura.
Contenedores para helado La companifa de helados de Gil y Lori vende helados en dos contenedores, un bote cilindrico y una caja rectangular como se muestra en la figura. $\angle \mathrm{A}$ cuál contenedor le cabe más helado y cuál es la diferencia de volúmenes?

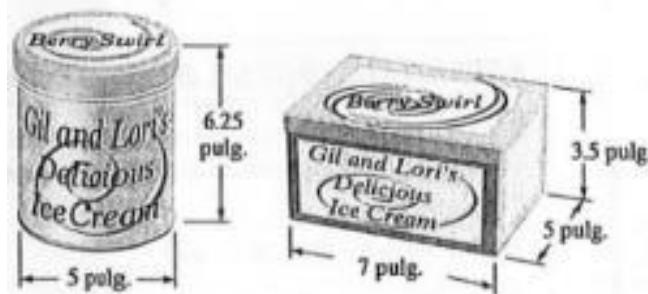

Utilidad Una compañía que produce esculturas de madera obtiene una utilidad semanal de acuerdo con la función $f(x)=-1.4 x^{2}+56 x-70$, donde $x$ es el número de esculturas que fabrica y vende cada semana.

a) Determine el número de esculturas que la compania debe vender cada semana para maximizar su utilidad. b) ¿Cuál es la utilidad semanal máxima?

Venta de escobas Un negocio vende $n$ escobas, $n \leq 32$, a un precio de $(10-0.1 n)$ dolares cada una. $\measuredangle$ Cuántas escobas debe vender para tener un ingreso de $\$ 160$ ?

Imagen 8.17. Tarea 1 Sesión 09

Luego, pide a los estudiantes que comenten la forma en que pueden abordar los problemas [OB09.053], da un tiempo para que solucionen los problemas; posteriormente van pasando a realizar la respectiva solución, discutiendo entre ellos si los procedimientos eran los adecuados.

En la segunda parte de la actividad, Lucho les pregunta nuevamente a los estudiantes en sus respectivos grupos que contesten para qué sirven las inecuaciones y que recuerden situaciones reales que permiten su uso [NO09.009, NO09.010, OB09.209]. 
Cuando la sesión va finalizando, Lucho les hace entrega de la tarea que tiene dos partes:

\section{Tarea Obligatoria}

Resuelva las siguientes ecuaciones racionales:

$$
\begin{aligned}
& \frac{x+2}{x}+\frac{x}{x+2}=3 \\
& \frac{2 x}{2 x}=3 x \\
& \frac{x-3}{7 x-3}-\frac{3}{x+3}=\frac{x}{x-2} \\
& \frac{x-1}{x-2}=\frac{x}{x-2}
\end{aligned}
$$

De un posible enunciado cuya resolución se modela con la ecuación: $2(3 x-2) x=2$

Complete la siguiente tabla:

\begin{tabular}{|c|c|c|}
\hline Intervalos / Regiones & Conjunto & Gráfico \\
\hline$(-5,4]$ & & \\
\hline & $\{x \in R / x \geq 2\}$ & \\
\hline & & \\
\hline
\end{tabular}

\section{Tarea Voluntaria}

Dos de los lados de un rectángulo son el triple que los otros dos. Si la superficie del rectángulo es de $75 \mathrm{~m}^{2}$. ¿Cuáles son sus dimensiones?

Construya la inecuación que lo modeliza, resuélvala analítica y gráficamente.

Dos hermanos se llevan seis años. Durante cierto período de sus vidas, la edad del mayor excede en más de tres años al doble de la del menor. ¿Cuál es dicho período?

Imagen 8.18. Tarea obligatoria y tarea voluntaria Sesión 09

En las declaraciones posteriores, Lucho maneja la alegría del desarrollo de las actividades realizadas por los estudiantes [DP09.018]; considera que el trabajo de las 
dos horas de clase del día de hoy ha podido complementar de manera significativa lo elaborado hasta antes de la heteroevaluación [DP09.019].

La tabla 8.12 propone la descripción de los episodios:

\begin{tabular}{|l|l|l|l|}
\hline Episodio & \multicolumn{1}{|c|}{ Objetivo } & \multicolumn{1}{|c|}{ Contenido } & \multicolumn{1}{|c|}{ Actividad } \\
\hline Ep 09.1 & $\begin{array}{l}\text { Recapitular la } \\
\text { actividad realizada en } \\
\text { la sesión anterior y el } \\
\text { desarrollo de la tarea }\end{array}$ & $\begin{array}{l}\text { Ecuaciones } \\
\text { inecuaciones } \\
\text { estudiantes }\end{array}$ \\
\hline Ep 09.2 & $\begin{array}{l}\text { Generar reflexión } \\
\text { acerca del uso del } \\
\text { lenguaje para modelar } \\
\text { ecuaciones }\end{array}$ & $\begin{array}{l}\text { Ecuaciones } \\
\text { permiten modelizar } \\
\text { ecuaciones }\end{array}$ \\
\hline
\end{tabular}

\begin{tabular}{|c|c|}
\hline \multicolumn{2}{|c|}{ Episodio 09.1} \\
\hline Papel del profesor & Papel del estudiante \\
\hline Organizador de la actividad & $\begin{array}{l}\text { Propositor frente a la actividad desarrollada } \\
\text { Ponente del desarrollo de sus ideas }\end{array}$ \\
\hline Recursos & Clima del Aula \\
\hline $\begin{array}{l}\text { Ejercicios de la clase anterior } \\
\text { Propuesta de los estudiantes } \\
\text { Libro de texto } \\
\text { Desarrollo de la tarea }\end{array}$ & $\begin{array}{l}\text { Trabajo de exposición individual en gran } \\
\text { grupo } \\
\text { Al ser otra dinámica para el desarrollo de la } \\
\text { clase hay un ambiente de tranquilidad }\end{array}$ \\
\hline
\end{tabular}

\begin{tabular}{|l|l|}
\hline \multicolumn{2}{|c|}{ Episodio 09.2} \\
\hline Papel del profesor & Papel del estudiante \\
\hline $\begin{array}{l}\text { Director de la actividad a partir de las } \\
\text { pautas }\end{array}$ & $\begin{array}{l}\text { Búsqueda hacia su propio conocimiento a } \\
\text { partir de elementos de clases anteriores }\end{array}$ \\
\hline Recursos & Clima del Aula \\
\hline $\begin{array}{l}\text { Actividad propuesta por Lucho de texto } \\
\text { Cuaderno de apuntes }\end{array}$ & $\begin{array}{l}\text { Trabajo en pequeños grupos } \\
\text { Cordialidad entre compañeros } \\
\text { Trabajo colaborativo }\end{array}$ \\
\hline
\end{tabular}




\subsubsection{Sesión 10: Una propuesta alterna II}

Los estudiantes se reúnen en la sala de sistemas para la primera hora de clase:

[DE10.003]: Esta clase tendrá dos momentos. Uno en la primera hora de clase en la que podrá usar la sala de informática y la segunda hora en el aula de clase.

En la sala de informática, Lucho les indica a los estudiantes las condiciones para el trabajo en la sala y les recuerda que de su comportamiento dependerá que vuelvan a tener clase en esta aula [OB10.014] y les entrega una hoja con un manual de uso del programa GrafEq. Seguido a ello, les indica verbalmente la manera de elaborar gráficas con el programa [OB10.023]. Lucho indica y recuerda a los estudiantes que el programa sirve únicamente para representar gráficas más no para resolver ecuaciones [OB10.028].

A partir de las instrucciones que Lucho da, los estudiantes corrigen los ejercicios que tenían como tarea de la sesión anterior y luego, propone algunas situaciones para que sean resueltas por los estudiantes:

\begin{tabular}{ll}
\hline \hline OB10.061 Lucho & $\begin{array}{l}\text { Las edades de un padre y su hijo difieren 27 años, ¿entre qué } \\
\text { edades tendrá el padre más del doble de la edad del hijo? }\end{array}$ \\
\hline \hline OB10.082 Lucho & $\begin{array}{l}\text { Una fábrica paga a casa agente comercial un euro por articulo } \\
\text { vendido más una cantidad fija de mil euros, otra fábrica de la } \\
\text { cuatrocientos fijos. ¿cuántos artículos debe vender un agente } \\
\text { comercial de la competencia para ganar más dinero que el } \\
\text { primero? }\end{array}$ \\
\hline \hline
\end{tabular}

Esta aplicación es muy sencilla de utilizar ya que basta con introducir una inecuación con dos incógnitas, para que el programa muestre la región del plano solución. En el anexo 02 se encuentra el manual que Lucho hizo entrega a los estudiantes para el manejo del programa. Cabe destacar que en el caso de que lo que se pretenda resolver sea una inecuación con una incógnita, el proceso a seguir pasa por representar su inecuación con dos incógnitas asociada y, a continuación, estudiar el corte de esta región con el eje de abscisas y así determinar el intervalo solución; lo que permite 
aumentar parcialmente el nivel de complejidad y, por tanto, potenciar las capacidades cognitivas de los alumnos.

Las situaciones son resueltas por los estudiantes, algunos de los cuales comentan sus resultados en gran grupo, describiendo el proceso realizado en la solución [OB10.070, OB10.087]

La segunda parte de la actividad comienza cuando Lucho permite el acceso a internet, y los invita a ingresar a los enlaces:

http://proyectodescartes.org/EDAD/materiales_didacticos/EDAD_4eso_ecuaciones_e_i necuaciones-JS-apli/index.htm

https://proyectodescartes.org/EDAD/materiales_didacticos/EDAD_4eso_inecuacionesJS-LOMCE/index.htm[OB10.093] ${ }^{3}$

y les pide realizar las actividades que se proponen con ayuda de sus apuntes, el libro y el programa GrafEq [OB10.094]. La instrucción que Lucho da se remite a la realización de los ejercicios tanto en el cuaderno como con la ayuda de los programas de computador. Los estudiantes responden positivamente la actividad.

Al terminar el tiempo permitido para el uso de la sala, Lucho indica a los estudiantes que regresen al salón [OB10.108]. Ellos están involucrados en la actividad a tal punto que Lucho tiene que quitar el internet de la sala [OB10.116] y como consecuencia de esta acción los alumnos regresan al salón. En el aula, Lucho pregunta acerca del desarrollo de la clase [OB10.122] y luego explica que la evaluación de este tema será a partir de una socialización de cada uno de los grupos de trabajo de las últimas tres sesiones donde comentarán lo realizado y lo expuesto [OB10.134, OB10.135].

En las declaraciones posteriores, Lucho comenta que está contento con el desarrollo de la actividad porque no esperaba que los estudiantes desarrollaran la segunda parte con el programa GrafEq [DP10.006], lo que indica que los estudiantes ya tienen una mejor comprensión del tema desarrollado [DP10.016].

\footnotetext{
${ }^{3}$ A fecha 20 de marzo de 2019 el enlace se encontraba aún activo
} 
La tabla correspondiente a la sesión es la tabla 8.13:

\begin{tabular}{|c|c|c|c|}
\hline Episodio & Objetivo & Contenido & Actividad \\
\hline Ep 10.1 & $\begin{array}{lr}\text { Realizar } & \text { las } \\
\text { representaciones } & \text { y } \\
\text { modelizaciones con } \\
\text { uso de applets en } \\
\text { software educativo }\end{array}$ & $\begin{array}{l}\text { Inecuaciones } \\
\text { lineales }\end{array}$ & $\begin{array}{l}\text { Modelización de } \\
\text { situaciones en } \\
\text { software educativo }\end{array}$ \\
\hline Ep 10.2 & $\begin{array}{lrr}\text { Invitar a } & \text { los } \\
\text { estudiantes a modelar } \\
\text { otro tipo } & \text { de } \\
\text { inecuaciones } & \text { con } \\
\text { ayuda de } & \text { software } \\
\text { educativo } & \end{array}$ & $\begin{array}{ll}\text { Inecuaciones con dos } \\
\text { variables } & \\
\text { Sistemas } & \text { de } \\
\text { inecuaciones } & \\
\end{array}$ & $\begin{array}{l}\text { Desarrollar la } \\
\text { actividad } \\
\text { propuesta por } \\
\text { Lucho mediante el } \\
\text { uso de software } \\
\text { educativo }\end{array}$ \\
\hline
\end{tabular}

\begin{tabular}{|l|l|}
\hline \multicolumn{2}{|c|}{ Episodio 10.1 } \\
\hline Papel del profesor & Papel del estudiante \\
\hline $\begin{array}{l}\text { Orientador del uso del software } \\
\text { educativo }\end{array}$ & $\begin{array}{l}\text { Desarrollador de la actividad a partir del } \\
\text { conocimiento ya establecido }\end{array}$ \\
\hline Recursos & Clima del Aula \\
\hline $\begin{array}{l}\text { Aplicación Descartes } \\
\text { Cuaderno de apuntes }\end{array}$ & $\begin{array}{l}\text { Motivación por salir del espacio cotidiano } \\
\text { Aplicación de conocimientos establecidos }\end{array}$ \\
\hline
\end{tabular}

\begin{tabular}{|l|l|}
\hline \multicolumn{2}{|c|}{ Episodio 10.2 } \\
\hline Papel del profesor & Papel del estudiante \\
\hline $\begin{array}{l}\text { Orientador del uso del software } \\
\text { educativo }\end{array}$ & $\begin{array}{l}\text { Desarrollador de la actividad a partir del } \\
\text { conocimiento ya establecido. } \\
\text { Investigador de la nueva situación planteada } \\
\text { por Lucho que no corresponde a temáticas } \\
\text { abordadas por el profesor en sesiones } \\
\text { anteriores }\end{array}$ \\
\hline Recursos & $\begin{array}{l}\text { Clima del Aula } \\
\text { Cuadicación Descartes de apuntes }\end{array}$ \\
\hline
\end{tabular}




\begin{tabular}{|l|l|}
\hline & $\begin{array}{l}\text { Reflexión sobre conocimiento establecido en } \\
\text { su formación académica }\end{array}$ \\
\hline
\end{tabular}

Tabla 8.13. Episodios sesión 10

En este punto termina el ciclo de observaciones del primer año. Se ha convenido dialogar a lo largo del tiempo para ayudar a Lucho a desarrollar la planeación de una serie de clases que replanteen el desarrollo de los procesos de enseñanza que de observaron durante el primer y segundo momento de observación.

\subsubsection{Concepciones identificadas en este bloque}

Terminada la segunda etapa de observación de la práctica y de manera similar que con el primer bloque y los instrumentos propuestos en el Capítulo 7 es posible caracterizar algunos de los posicionamientos que posee Lucho a partir del análisis de su práctica y las opiniones implícitas y explícitas de enseñanza y aprendizaje de las matemáticas a lo largo de las sesiones 8, 9 y 10. Esta caracterización denota algunas transformaciones que se dan a lo largo de la práctica de Lucho a medida que se realiza el acompañamiento y se clasifican en un segundo bloque porque se logran unas caracterizaciones diferentes a las observadas en las primeras siete sesiones que permiten interpretar e identificar su proceso de Desarrollo Profesional.

La metodología aún está caracterizada por la repetición de ejercicios tipo, aunque la explicación del docente ya no está dada únicamente por la presentación directa de los contenidos, aunque el libro de texto sigue siendo un recurso notable:

\footnotetext{
[FD08.07]: Recursos: Calificaciones - Diálogo entre estudiantes y profesor

[FD08.09]: Recursos: Tarea propuesta. Anotaciones. Libro de texto.

[FD08.11]: Recursos: Tarea propuesta. Anotaciones. Libro de texto.

[FD09.04]: Recursos: Ejercicios de la clase anterior. Propuesta de los estudiantes.

Libro de texto. Desarrollo de la tarea.

[FD10.04]: Recursos: Aplicación GrafEq. Cuaderno de Apuntes.

[FD10.06]: Recursos: Aplicación Descartes. Cuaderno de Apuntes.
}

Así, la principal fuente de información para el alumno ya no la constituyen el docente y el libro de texto; de acuerdo con los recursos descritos en las fichas de diario, Lucho inicia un proceso de transformación de la metodología en la que se sale del libro de texto y propone actividades adicionales. Entre la sesión 9 y 10 ya tiene en cuenta la propuesta de los estudiantes [OB09.227, OB09.228, OB10.052] y se acerca a ellos 
identificando los errores propios [OB10.054]. Ya se percibe el empleo de otro material tal como las tareas y las plataformas GrafEq y Descartes [NO09.023, N010.005] y, aunque no realiza diferenciación individual en el proceso de enseñanza, ya distingue de diferente manera el trabajo en grupos y se involucra en una transformación de su práctica en la que inicia de manera paulatina la utilización de materiales manipulativos [NO08.018, NO10.015].

Lucho expone los contenidos pero no en su fase final, sino simulando su proceso de construcción, apoyado en estrategias expositivas, uso de ejemplos, cuestiones a los alumnos, uso de material para ejemplificar; de esta manera, al proponer tareas [OB08.199, OB08.217, OB08.231, OB09.029, OB09.036, OB09.042, OB09.209, OB09.222, OB10.051, OB10.078].

El libro de texto se ve ampliado por otros materiales donde se encuentra el conocimiento establecido en las primeras sesiones de observación: Lucho no se separa de su rol como principal fuente de información de sus estudiantes [DP10.043, DP10.044].

De esta manera, persigue objetivos terminales y funcionales, aún pone más énfasis en objetivos procedimentales locales:

\section{Objetivos planteados:}

[FD08.01]: Realizar el proceso de heteroevaluación de los estudiantes de décimo. [FD08.02]: Generar reflexión acerca del significado de las ecuaciones e inecuaciones [FD08.03]: Modelar algunas situaciones con ayuda de las ecuaciones [FD08.04]: Diferenciación entre las ecuaciones y las inecuaciones [FD08.05]: Reconocer en los estudiantes el uso de las representaciones de las ecuaciones.

[FD09.01]: Recapitular la actividad realizada en la sesión anterior y el desarrollo de la tarea.

[FD09.02]: Generar reflexión acerca del uso del lenguaje para modelar ecuaciones. [FD10.01]: Realizar las representaciones y modelizaciones con uso de applets en software educativo.

[FD10.02]: Invitar a los estudiantes a modelar otro tipo de inecuaciones con ayuda de software educativo. Reconocer los distintos tipos de ecuaciones e inecuaciones. Modelizar procesos que involucren ecuaciones e inecuaciones. Interpretar y reconocer los conjuntos solución de ecuaciones e inecuaciones. Trabajar con sus distintas formas de expresión. Resolver los distintos tipos de ecuaciones e inecuaciones. Explicar y justificar el procedimiento seguido al resolver y representar ecuaciones e 
inecuaciones. Resolver analítica y gráficamente los distintos tipos de inecuaciones. Reconocer situaciones del entorno que se puedan resolver mediante el uso de ecuaciones e inecuaciones.

Resolver inecuaciones propuestas por el profesor.

Dichos objetivos conllevan a Lucho a utilizar material manipulativo para reforzar, explicar o dar utilidad a la teoría [CP09.006].

La evaluación está centrada para calificar, para medir la consecución de los objetivos prefijados y también la medición detallada de los aprendizajes. De sus reflexiones en las primeras sesiones tiene presente que debe identificar los procesos de aprendizaje individual y las actividades propuestas en este segundo bloque lo conllevan a 'reproducir' los contenidos practicados, principalmente los algorítmicos y las aplicaciones mostradas en clase [DP10.050, DP10.051]. La evaluación atiende sobre todo al producto y es realizada mediante el desarrollo de las tareas propuestas en cada una de las sesiones, aún es orientada y dirigida directamente por Lucho [DP10.042].

Con relación a las concepciones sobre las matemáticas escolares, se observa que Lucho sigue orientando la asignatura exclusivamente hacia la adquisición de conceptos y reglas. De esta manera, las matemáticas escolares coinciden con la que se muestra en el libro de texto aunque ya hay algunas otras actividades que salen de este contexto.

El desarrollo de las sesiones de este bloque reflejan que Lucho intenta acercarse a un carácter práctico que permita su aplicación utilitaria en la vida cotidiana y como instrumento para el estudio tanto de otras disciplinas como el estudio futuro de las propias matemáticas tanto por los conocimientos que aporta como por contribuir al desarrollo del razonamiento en el estudiante y esto lo hace acercándose a algunas situaciones que pueden ser simuladas en las tareas que propone en las sesiones 8 y 9 y por medio de la utilización de Software Educativo en la sesión 10.

Con relación a las concepciones del aprendizaje que se identifican en este bloque: Lucho presupone que el aprendizaje se realiza, utilizando la memoria como principal recurso, por superposición de unidades de información en el que el alumno se hace con los conocimientos por un proceso de simulación de un proceso deductivo a partir del desarrollo de las tareas que se proponen en las sesiones 8,9 y 10. 
Para aprender, el alumno debe entender y asimilar el conocimiento que proviene de esa deducción [EN03.123], Lucho aún busca que los estudiantes expliciten su aprendizaje en términos de las expresiones que él utiliza [NO10.014].

Si bien la sesión no se conforma de una explicación al inicio de la clase y luego el trabajo de ejercitación, y ya no se apoye directamente del libro de texto y dentro del aula cotidiana [NO08.024, NO09.020, NO10.024, NO10.025], todavía focaliza el aprendizaje de los estudiantes en la mecanización de los ejercicios propuestos. El alumno interactúa con las matemáticas realizando los ejercicios propuestos y con el uso de algún software educativo [OB08, OB09, OB10, NO09.021].

La interacción que se produce entre el profesor y el alumno aún es desequilibrada, siendo más fuerte el flujo en la dirección profesor a estudiante que la inversa, evidenciado esto en la explicación permanente por parte de Lucho en cada una de las actividades propuestas [NO10.027, NO10.028].

La estructura de la propia asignatura, plasmada en la programación, es el dinamizador ideal del aprendizaje, pero Lucho resalta que las tareas y la mediación con software educativo puede cambiar si en la actitud del alumno hacia el aprendizaje se detectan aspectos que pueden sufrir cambios [DP10.019].

En el segundo bloque, el papel del alumno aún se perfila únicamente como el de aprendiz. El alumno no tiene que ver con el diseño de las actividades programadas para el trabajo en aula ni con la planeación de clase ni con el diseño didáctico; no obstante, al enfrentarse a cada una de sus tareas educativas, reproduce el proceso lógico mostrado por el docente, imitando así su estilo cognitivo [NO09.014, NO10.032].

Entonces, el papel del docente se caracteriza por una organización de los contenidos de aprendizaje, los cuales transmite mediante exposición, utilizando estrategias organizativas expositivas que procuran ser atractivas: diseño de tareas, programación con software educativo, entre otros: Actúa como un técnico del contenido y del diseño didáctico. Así, actúa como un especialista en el contenido, aunque es el libro de texto el que valida las ideas que se movilizan en el aula, corrigiendo a los alumnos en caso de errores y aportando él mismo la información correcta [NO10.033].

Respecto de la enseñanza y el aprendizaje de las matemáticas, se puede caracterizar una concepción tradicional en la manera como realiza las clases. Las clases se 
caracterizan por el desarrollo de actividades diseñadas previamente por Lucho, las cuales, a partir de los saberes previos de los estudiantes y la explicación realizada en el primer bloque, van a ser resueltas.

Lucho espera que los estudiantes se interesen por los conceptos, reglas e instrumentos para el desarrollo de los ejercicios que considera deben resolver; e intenta que el aprendizaje de sus alumnos sea mediante un proceso deductivo en el que a partir de la regla, se lleve a cabo una aplicación determinada.

El aprendizaje se convierte en un proceso individual donde cada uno tiene que responder de manera propia sobre sus aprendizajes en el momento de la "evaluación".

\subsubsection{Conocimiento Especializado en este bloque}

A lo largo del segundo bloque se pueden distinguir algunos aspectos acerca del conocimiento especializado que no se observaron durante las primeras siete sesiones. Con relación al conocimiento de la práctica, se sale del contexto del libro de texto como fuente única y la explicación surge a partir de situaciones en las que empieza a formar parte el estudiante, tales como las tareas propuestas para las tres sesiones del bloque, el uso del software de la sesión 10 , la solución y validación que plantean los estudiantes en la sesión 9 y 10.

Con relación al conocimiento de las características del aprendizaje de las matemáticas, Lucho manifiesta entender tiene responsabilidad en el aprendizaje de los estudiantes [DP10.026] y que el cambio de su práctica le permite identificar cómo es el aprendizaje de los estudiantes de manera coherente [DP10.027, DP10.028].

Entonces, el cambio en el conocimiento especializado de Lucho para este bloque recae directamente en sus actitudes:

\section{Con relación a sus actitudes}

A través de las propuestas de mejora que Lucho presenta en las fichas de diario del primer bloque, Lucho constituye una serie de actividades con las cuales pretende afianzar el conocimiento de los estudiantes. En las declaraciones posteriores de la sesión 10, Lucho afirma que el cambio de la estructura de las clases se debe a su 
preocupación por el estado de aprendizaje de los estudiantes [DP10.024] y que su interés personal y profesional es que ellos aprendan [DP10.025].

Afirma que está intentando acercarse a una enseñanza de las matemáticas por medio de la resolución de problemas y por ello debe iniciar con actividades en las que los acerque a dichos problemas [DP10.028]. Esto último acerca a Lucho a algunos procesos de reflexión que lo llevan a establecer cambios en su práctica como manifestación de su desarrollo profesional en coherencia con lo planteado en el marco teórico de esta investigación.

\subsubsection{Acerca de la reflexión de Lucho}

En el segundo momento de observación se percibe la apropiación explícita del ejercicio reflexivo por parte de Lucho. Se nota un acercamiento a lo realizado en este bloque con lo mencionado en la entrevista inicial.

En las declaraciones posteriores y las fichas de diario se empiezan a distinguir elementos que se pueden considerar reflexivos:

[DP08.033]: He replanteado el seguir explicando, necesito hacer una retroalimentación del proceso realizado para que los estudiantes comprendan

[DP09.021]: Creo que he logrado hacer que los estudiantes se indaguen un poco acerca de los temas que se están viendo, aunque debo seguir buscando elementos que hagan de esta acción una constante.

[DP10.011]: Lograron un proceso de visualización de cosas que sabían pero no podían aplicar.

[DP10.028]: Si quiero acercarme a la enseñanza de las matemáticas por medio de resolución de problemas, un primer paso es proponer actividades que los acerquen, que me permita identificar la manera como los estudiantes aprenden mejor [FD08.16]: Es necesario presentar a los estudiantes algunas alternativas y hacer pensar a los estudiantes si la situación planteada es válida.

[FD08.17]: La valoración por parte del alumno de sus aprendizajes y experiencias debe ser objetivo de aprendizaje. Hay que plantear distintas metodologías para el diseño de la evaluación porque los estudiantes no llegaron a los resultados esperados.

[FD09.07]: Debo cuestionar a los estudiantes acerca de lo que están haciendo en su actividad grupal e individual.

[FD10.07]: Participación activa y responsable en el proceso de enseñanza-aprendizaje 
[FD10.08]: Relacionar los contenidos a aprender con otros $u$ otras experiencias sirve de ayuda ante las dificultades que surgen

[FD10.09]: Esta forma de trabajar obliga a usar contenidos ya trabajados para conseguir otros nuevos, es decir, los construidos se hacen funcionales

Entonces, Lucho se empieza a dar cuenta que hay elementos de la clase que no están acordes a sus intereses como docente [FD10.10], considera que la movilización de los estudiantes hacia contenidos que sean funcionales es necesaria. Al preguntársele posteriormente si había notado esa necesidad de cambio afirma que si, pero por alguna razón la había obviado [EN03.33], y quizá el ejercicio de observación y de tratar de mostrar una clase que evolucionara lo hizo cambiar de estrategia [EN03.035] en la misma acción y es aquí donde un año después surge un tercer momento en la práctica observada de Lucho.

\subsection{Bloque III. Tercer momento de observación}

Ha pasado casi un año desde la última observación de la práctica de Lucho, en el que él identificó la necesidad de cambio de algunas estrategias dentro del aula. La continuidad de Lucho en el IPN como docente de grado décimo permitirá identificar cómo es su práctica en un contexto que tiene condiciones similares a las del primer y segundo bloque: misma institución, misma carga académica y mismo marco legal. Las sesiones para observar serán en el grado décimo con énfasis en humanidades y en temas similares a los del año anterior, para así continuar la observación del proceso de desarrollo profesional de Lucho.

\subsubsection{Sesiones observadas}

En este bloque se observan cuatro sesiones que corresponden, de manera análoga, con los contenidos que se estudiaron durante el bloque I y II.

\subsubsection{Sesión 11: De los números reales a expresiones algebraicas racionales. Suma, resta y multiplicación}

En la charla previa a esta sesión, Lucho comenta que trabajará un par de actividades en los estudiantes repasarán en el contexto de los números reales la utilización de expresiones algebraicas racionales [CP11.006] y si bien son temas similares a los del año anterior, espera abordar el trabajo en aula de manera distinta [CP11.015] 
La sesión inicia con la presentación del profesor investigador [OB11.026], al igual que el año anterior Lucho comenta que el papel del observador es simplemente eso, observador y que él no tiene incidencia alguna en el desarrollo de la clase [OB11.030]. Ahora Lucho ya no llama a lista, tiene una hoja con los nombres de los estudiantes y la hace rotar por cada uno de los puestos para que cada uno firme en la fecha correspondiente [NO11.004]. Claro, se fija que la cantidad de firmas coincida con la cantidad de asistentes [NO11.006].

Luego de la presentación y de las indicaciones iniciales, Lucho les pide a los alumnos que por favor conformen grupos de cinco integrantes [OB11.035]. Como siempre, los estudiantes quieren no seguir las instrucciones y algún grupo pide que sean cuatro y otro que sean 6 (en total son 35 estudiantes y para esta observación no ha faltado ninguno) [OB11.038, OB11.039]. Lucho les insiste la importancia de seguir instrucciones y que esta vez no puede ser flexible frente a esa instrucción [OB11.041].

La actividad para realizar consiste en un concurso en el que los estudiantes van a determinar las respuestas a las siguientes preguntas, las cuales entrega a cada uno de los estudiantes [NO11.015]:

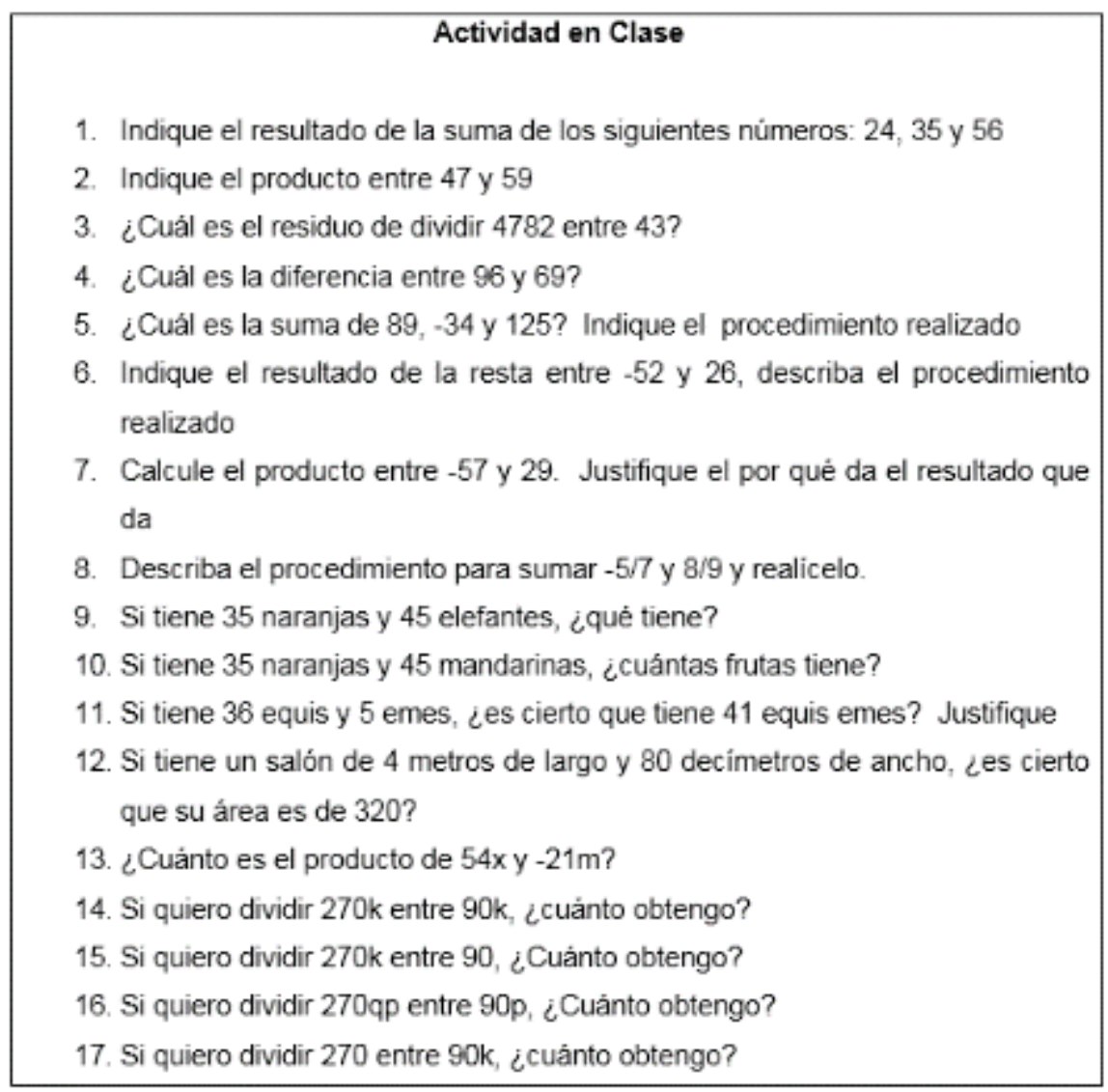


A medida que va realizando el concurso, Lucho hace las retroalimentaciones de las respuestas de cada grupo y va tomando en cuenta las participaciones de los estudiantes:

\begin{tabular}{lll}
\hline \hline [OB11.135] & Estudiante: & $\begin{array}{l}\text { Si quiero hacer la resta entre }-52 \text { y } 26 \text { tengo que hacer } 26 \\
\text { menos } 52\end{array}$ \\
\hline [OB11.136] & Lucho: & $\begin{array}{l}\text { Ten cuidado, porque es una resta. Si te piden hacer una } \\
\text { suma entre esos dos números ¿qué tienes que hacer? }\end{array}$ \\
\hline [OB11.137] & Estudiante: & Tengo que hacer menos 52 más 26 \\
\hline [OB11.138] & Lucho: & Y eso no es lo mismo que hacer 26 menos 52? \\
\hline [OB11.139] & Estudiante: & Si, entonces hay que hacer menos 52 menos 26 \\
\hline \hline
\end{tabular}

Luego de terminada la actividad en cuestión, Lucho procede a realizar la segunda parte de la actividad. Esta consiste en identificar áreas y perímetros de diferentes regiones. Para ello propone la siguiente actividad [OB11.305]:

\section{Actividad}

En grupos de tres personas hallar el área y el perimetro de las siguientes regiones trate de simplificar las respuestas de acuerdo con sus conocimientos previos:
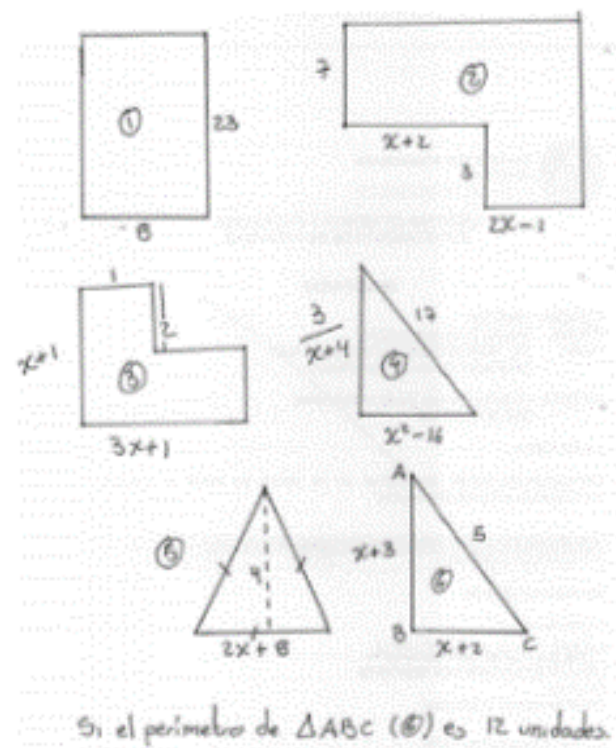

¿Cuanto vale $x$ ?

¿cuanto vale el perimetre? 
Lucho ha comentado la intención de la actividad: dado que ha realizado el concurso y seguramente ya han traído a su memoria algunos procedimientos, la idea es que ellos puedan hacer los productos y los cocientes notables, recordando así las propiedades de la multiplicación y las operaciones con expresiones algebraicas 011.308a].

Los estudiantes han realizado los ejercicios propuestos, algunos han realizado los productos y los cocientes. Otros los han dejado indicados:

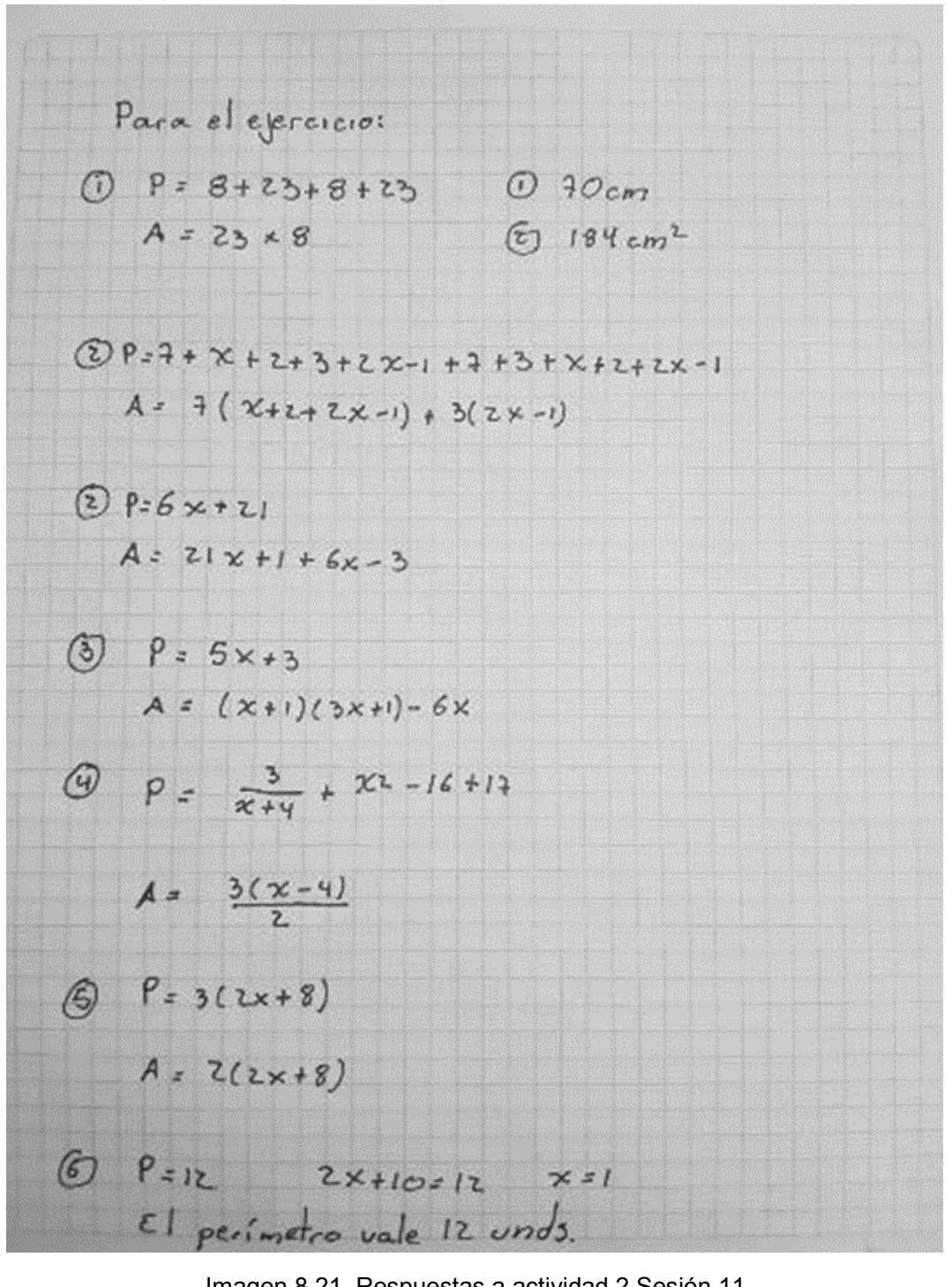

Imagen 8.21. Respuestas a actividad 2 Sesión 11

En los momentos finales de la clase Lucho escribe algunas respuestas de los estudiantes y les ha pedido que discutan acerca de quien los tenía bien:

\begin{tabular}{ll}
\hline [OB11.324] Estudiante: & $\begin{array}{l}\text { La respuesta no va en centímetros porque no se indica la } \\
\text { escala de medición }\end{array}$
\end{tabular}


Se puede uno imaginar que hay un rectángulo grande que

[OB11.333] Estudiante: mide 10 por tres equis menos uno y restarle el área del rectángulo que mide tres por equis más dos

\begin{tabular}{lll}
\hline [OB11.335] & Estudiante: & $\begin{array}{l}\text { También se puede hacer con dos rectángulos. Uno de siete } \\
\text { por tres equis menos uno y sumar el área del rectángulo que } \\
\text { mide tres por dos equis }\end{array}$ \\
\hline [OB11.348] & Estudiante: & $\begin{array}{l}\text { Se debe hacer la suma de tal forma que quede un } \\
\text { denominador y se puede dejar indicada o desarrollada }\end{array}$ \\
\hline [OB11.351] & Estudiante: & $\begin{array}{l}\text { El área se puede factorizar siempre y cuando el valor de equis } \\
\text { no sea menos cuatro }\end{array}$ \\
\hline [OB11.366] & Estudiante: & El área del triángulo es seis unidades cuadradas \\
\hline [OB11.367] & Estudiante: & $\begin{array}{l}\text { El mismo ejercicio dice que el perímetro es doce unidades sin } \\
\text { tener que resolver equis }\end{array}$ \\
\hline \hline
\end{tabular}

Lucho corrige las expresiones que no están correctas en los cuadernos de los estudiantes de acuerdo con la finalidad del ejercicio [NO11.026]. Al finalizar, Lucho les pide a los estudiantes que vayan averiguando la manera de solucionar ecuaciones de primer grado:

\begin{tabular}{ll}
\hline \hline & Les pido el favor que averigüen cómo resolver ecuaciones de \\
& primer grado porque seguramente lo van a necesitar en el \\
[OB11.381] Lucho: $\quad$ desarrollo de las siguientes clases. Estos son temas que ya se \\
\\
han estudiado previamente, incluso hoy los han estudiado, pero \\
no se pueden dejar de lado
\end{tabular}

Finaliza la sesión, la descripción por episodios se presenta en la tabla 8.14:

\begin{tabular}{|c|c|c|c|}
\hline Episodio & Objetivo & Contenido & Actividad \\
\hline Ep 11.1 & $\begin{array}{l}\text { Hacer un repaso de los } \\
\text { algoritmos de } \\
\text { operaciones básicas } \\
\text { con números reales }\end{array}$ & $\begin{array}{l}\text { Operaciones } \\
\text { números reales }\end{array}$ & $\begin{array}{l}\text { Concurso y } \\
\text { reflexión acerca del } \\
\text { desarrollo de los } \\
\text { algoritmos de las } \\
\text { operaciones } \\
\text { básicas con } \\
\text { números reales }\end{array}$ \\
\hline Ep 11.2 & $\begin{array}{lr}\text { Traer a la memoria } \\
\text { cercana } & \text { el } \\
\text { procedimiento } & \text { para }\end{array}$ & $\begin{array}{l}\text { Operaciones } \\
\text { expresiones } \\
\text { algebraicas }\end{array}$ & $\begin{array}{l}\text { Desarrollar } \\
\text { actividad } \\
\text { propuesta }\end{array}$ \\
\hline
\end{tabular}




\begin{tabular}{|l|l|l|}
\hline $\begin{array}{l}\text { desarrollar } \\
\text { operaciones con } \\
\text { expresiones } \\
\text { algebraicas }\end{array}$ & $\begin{array}{l}\text { buscando } \\
\text { alternativas de } \\
\text { respuesta a partir } \\
\text { de las opiniones y } \\
\text { del conocimiento } \\
\text { de los estudiantes. } \\
\text { Hacer una puesta } \\
\text { en común de los } \\
\text { resultados para } \\
\text { formalizar el } \\
\text { aprendizaje }\end{array}$ \\
\hline
\end{tabular}

\begin{tabular}{|l|l|}
\hline \multicolumn{2}{|c|}{ Episodio 11.1 } \\
\hline Papel del profesor & Papel del estudiante \\
\hline $\begin{array}{l}\text { Director del concurso, poca } \\
\text { participación, mediador entre el } \\
\text { conocimiento y los estudiantes }\end{array}$ & $\begin{array}{l}\text { Discusión entre ellos en grupo pequeño y en } \\
\text { gran grupo }\end{array}$ \\
\hline Recursos & Clima del Aula \\
\hline $\begin{array}{l}\text { Diseño de actividad previa } \\
\text { Conocimiento de los estudiantes } \\
\text { Hojas de papel }\end{array}$ & $\begin{array}{l}\text { Motivación por el desarrollo de una actividad } \\
\text { alterna para la clase de matemáticas, } \\
\text { facilitando la simulación del conocimiento } \\
\text { matemático } \\
\text { Aplicación de conocimientos establecidos }\end{array}$ \\
\hline
\end{tabular}

\begin{tabular}{|c|c|}
\hline \multicolumn{2}{|c|}{ Episodio 11.2} \\
\hline Papel del profesor & Papel del estudiante \\
\hline $\begin{array}{l}\text { Generador de preguntas para los } \\
\text { estudiantes. Mediador entre el } \\
\text { conocimiento y los estudiantes }\end{array}$ & $\begin{array}{l}\text { Desarrollador de la actividad a partir del } \\
\text { conocimiento ya establecido y de las } \\
\text { discusiones entre lo realizado por los otros. }\end{array}$ \\
\hline Recursos & Clima del Aula \\
\hline $\begin{array}{l}\text { Actividad diseñada } \\
\text { Cuaderno de apuntes } \\
\text { Libros de texto (por parte de los } \\
\text { estudiantes) }\end{array}$ & $\begin{array}{l}\text { Motivación por el desarrollo de una actividad } \\
\text { alterna para la clase de matemáticas } \\
\text { Aplicación de conocimientos establecidos }\end{array}$ \\
\hline
\end{tabular}




\subsubsection{Sesión 12: Del lenguaje usual al lenguaje algebraico}

La segunda sesión por observar en este bloque consistirá, según Lucho, en la realización de una serie de actividades en las que los estudiantes se acercarán al lenguaje algebraico por medio del lenguaje usual [CP12.006] de tal manera que encuentren un sentido a su uso [CP12.007].

La sesión inicia rotando la hoja de asistencia [NO12.004] y posteriormente una serie de preguntas rápidas por parte del profesor. Les pregunta, entre otras:

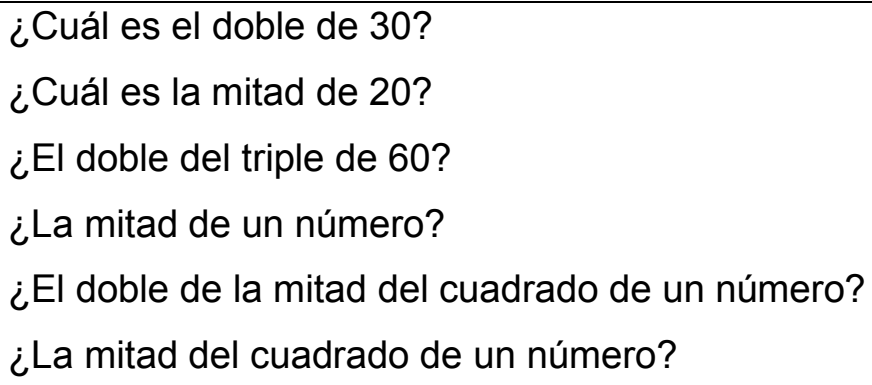

\begin{tabular}{lll}
\hline \hline [OB12.022] & Lucho: & María Camila, ¿cuál es el doble de 30? \\
\hline [OB12.023] & Estudiante: & Quince profe \\
\hline [OB12.024] & Lucho: & Así me gusta María Camila, enérgica, pero mejora la puntería \\
\hline [OB12.025] & Lucho: & Catalina, ¿cuál es el doble de treinta? \\
\hline [OB12.026] & Estudiante: & Sesenta \\
\hline
\end{tabular}

\begin{tabular}{lll}
\hline \hline [OB12.039] & Lucho: & Fernando, el doble de la mitad del cuadrado de un número \\
\hline [OB12.040] & Estudiante: & Pasito profe \\
\hline [OB12.041] & Lucho: & El doble de la mitad del cuadrado de un número \\
\hline \hline
\end{tabular}

Luego que termina la ronda, le entrega a cada estudiante un papel con una expresión algebraica y le pide que por favor la lea en voz alta.

\begin{tabular}{lll}
\hline \hline [OB12.071] & Lucho: & Haber, lee tu \\
\hline [OB12.072] & Estudiante: & $\begin{array}{l}\text { El triple del cuadrado de la mitad de un número aumentado } \\
\text { en tres }\end{array}$ \\
\hline [OB12.073] & Estudiante: & $\begin{array}{l}\text { El triple de la suma entre la mitad del cuadrado de un número } \\
y \text { tres }\end{array}$ \\
\hline
\end{tabular}


Se refieren a:

[OB12.074] Comentario

$3\left(\frac{x^{2}}{2}+3\right)$

Ojo, hay que tener cuidado, como lo leíste, suena a que dijiste esto:

[OB12.075] Lucho:

$3\left(\frac{x}{2}\right)^{2}+3$

\begin{tabular}{lll}
\hline [OB12.076] & Lucho: & Y mira que son distintos \\
\hline & Leen el siguiente:
\end{tabular}

[OB12.077] Comentario:

$\frac{2 x}{5}-6$

[OB12.078] Estudiante: La resta entre la quinta parte del doble de un número y seis

Terminada la lectura, Lucho les hace énfasis de "de" como conectivo de posesión y que es ese término el que da pista del orden de las expresiones [OB12.088].

Finalizada esta parte de la clase, Lucho entrega la siguiente actividad y pide a sus estudiantes que la desarrollen:

Eduardo, Carlos, Martín y Pedro deciden conformar una empresa de asesoría y venta de de computadores. Los aportes fueron de la siguiente manera: Carlos colocó 1/8 de capital, Pedro y Eduardo cada uno aporte el doble de lo de Carlos y el aporte de Martín es de $3 / 8$ del capital total.

En la primera reunión después de estar conformada la sociedad se acuerda destinar el $10 \%$ del capital para muebles y enseres necesarios para la empresa y un $15 \%$ para la compra de un vehículo.

1. En la segunda reunión se dan cuenta que es necesario para el funcionamiento inicial de la empresa dejar un capital en caja menor de tres millones.

a) Expresar cada una de las situaciones descritas en forma simbólica.

b) Si al final de estos gastos queda un capital de 57 millones, expresar dicha situación en forma de ecuación. 
c) Hallar el capital inicial

d) Teniendo en cuenta las condiciones anteriores y con un capital de 50 millones, calcular la cantidad que se destina para muebles y enseres, para compra de vehículo y la cantidad que queda disponible si se inicia la empresa con este capital.

2. La empresa decide invertir parte de sus utilidades en acciones y bonos. El contador determina que puede invertirse máximo 18 millones en cuan compañía de seguros que ofrece un interés anual simple del $12 \%$ en acciones, pero la empresa no desea invertir más del $40 \%$ de su capital disponible ya que la inversión presenta cierto riesgo. La misma compañía ofrece por bonos el $8 \%$ de interés. ¿Qué cantidad bajo estas condiciones se necesita invertir en bonos y acciones para que se pueda recibir en interés una cantidad mínimo de 1'620.000 anual?

3. Si otra empresa ofrece por los bonos intereses del 10\% y por acciones intereses del $12 \%$, pero sin ningún riesgo, y da un interés de $\$ 1^{\prime} 960.000$ anual, indicar la cantidad que se debe invertir en bonos y acciones.

4. Si la empresa desea una utilidad de cuatro millones, qué cantidad se debe invertir si se conservan las mismas tasas de interés.

5. Si usted fuera el encargado de esta empresa y tuviera que tomar una decisión, ¿cuál sería la mejor? ¿Por qué?

Imagen 8.23. Actividad 2 sesión 12

Antes de finalizar la sesión, Lucho hace debate con los estudiantes acerca de las respuestas de la situación. Con relación al primer ítem, no se ve problema alguno. El segundo ejercicio requiere un par de ecuaciones.

Para este ejercicio vamos a invertir dos cantidades de dinero que

[OB12.160] Lucho: Suman quince millones. El primer dinero da una ganancia de doce por ciento y el segundo de ocho por ciento. Pero el segundo dinero depende de lo que se utilice en el primer dinero

Resolviendo se tiene que lo mínimo a invertir en el primer dinero

[OB12.170] Lucho es diez coma cinco millones, así lo máximo del segundo será cuatro coma cinco. Miren que si equis es mayor o igual que diez coma cinco, eso lo ponemos en una recta numérica y ponemos 
el diez coma cinco acá y lo que es mayor a diez coma cinco a la derecha, como lo incluye, tenemos un corchete

Pone el siguiente gráfico:

[OB12.171]

Comentario

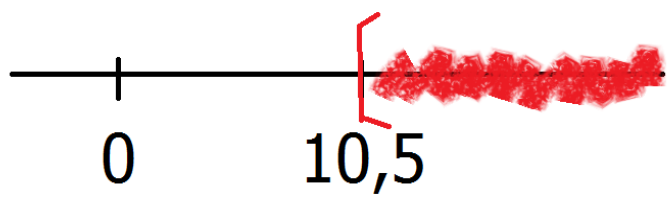

Para el tercer ejercicio, los estudiantes discuten si hay que invertir los 15 millones o los 18 millones. Lucho da la razón a un estudiante que al no haber riesgo, fijo va a haber ganancia y por tanto se debe resolver de la siguiente manera;

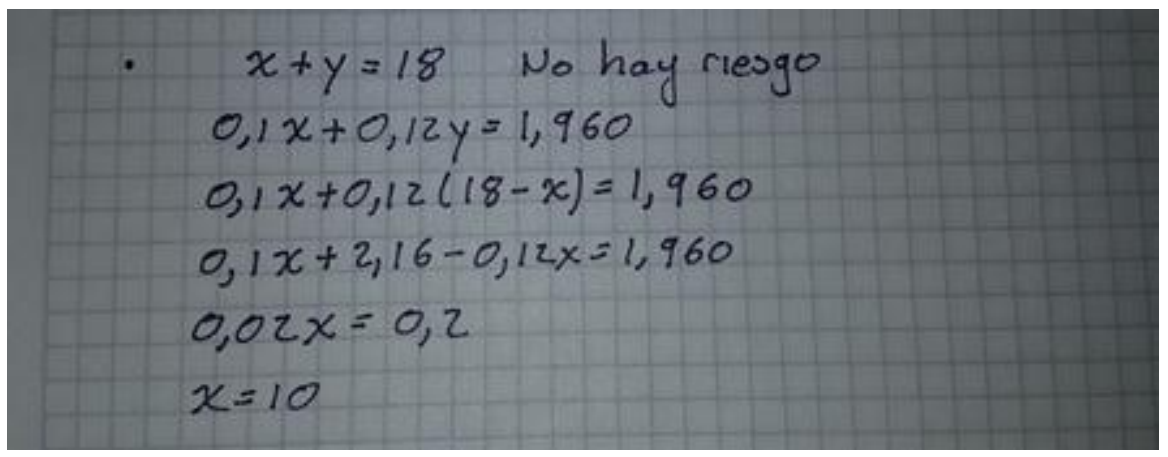

Imagen 8.24. Solución ejercicio 3 actividad 2 sesión 12

Para el cuarto ejercicio, todos los estudiantes coinciden que se hace igual que el tercero, pero no hay sentido porque la inversión es negativa.

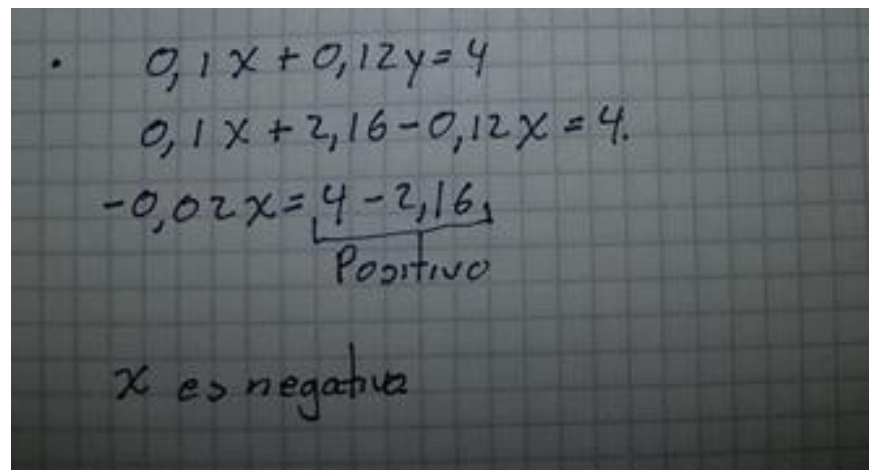

Imagen 8.25. Solución ejercicio 4 actividad 2 sesión 12

Concluyen los estudiantes que la segunda opción es la que más ganancia da porque fijo da un valor de un millón novecientos sesenta mil pesos. Un estudiante dice que es posible con la primera opción superar dicha ganancia, pero al comprobar observan que 
no es posible ganar lo mismo que en la segunda opción con la inversión de la primera opción. Lucho le permite seguir y el estudiante cae en cuenta que debería invertir 19 millones [OB12.206]

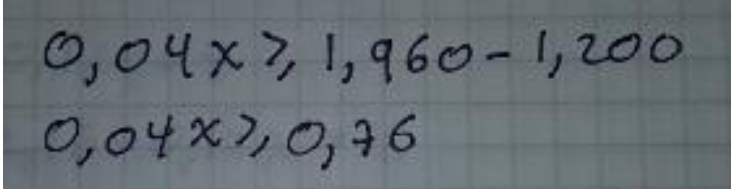

Imagen 8.26. Solución alternativa ejercicio 4 actividad 2 sesión 12

Cuando termina esta actividad, los estudiantes proponen a Lucho permitirles desarrollar algunos ejercicios libres para que él luego les dé el visto bueno.

La tabla 8.15 es la correspondiente a esta sesión:

\begin{tabular}{|c|c|c|c|}
\hline Episodio & Objetivo & Contenido & Actividad \\
\hline Ep 12.1 & $\begin{array}{l}\text { Traer a la memoria las } \\
\text { actividades acerca del } \\
\text { cambio de lenguaje en } \\
\text { el uso de expresiones } \\
\text { algebraicas }\end{array}$ & $\begin{array}{l}\text { Expresiones } \\
\text { algebraicas }\end{array}$ & $\begin{array}{lr}\text { Cuestionario } & y \\
\text { lectura } & \text { de } \\
\text { expresiones } & \\
\text { algebraicas } & \end{array}$ \\
\hline Ep 12.2 & $\begin{array}{lr}\text { Involucrar } & \text { en } \\
\text { situaciones } & \text { que } \\
\text { pueden ser reales para } \\
\text { el desarrollo de } \\
\text { habilidades } & \text { en } \\
\text { contenidos } & \\
\text { relacionados } & \text { con } \\
\text { expresiones } & \\
\text { algebraicas } & \end{array}$ & $\begin{array}{l}\text { Lenguaje usual } \\
\text { Expresiones } \\
\text { algebraicas } \\
\text { Interés simple } \\
\text { Ecuaciones de primer } \\
\text { grado }\end{array}$ & $\begin{array}{l}\text { Desarrollar la } \\
\text { actividad } \\
\text { propuesta } \\
\text { buscando } \\
\text { alternativas de } \\
\text { respuesta a partir } \\
\text { de las opiniones y } \\
\text { del conocimiento } \\
\text { de los estudiantes. } \\
\text { Hacer una puesta } \\
\text { en común de los } \\
\text { resultados para } \\
\text { formalizar aprendizaje }\end{array}$ \\
\hline
\end{tabular}




\begin{tabular}{|l|l|}
\hline \multicolumn{2}{|c|}{ Episodio 12.1 } \\
\hline Papel del profesor & Papel del estudiante \\
\hline Monitor de la actividad. Interrogador & $\begin{array}{l}\text { Resolutor de la situación respondiendo la } \\
\text { pregunta. }\end{array}$ \\
\hline Recursos & Clima del Aula \\
\hline $\begin{array}{l}\text { Actividad diseñada } \\
\text { Luaderno de apuntes } \\
\text { estudiantes) }\end{array}$ & $\begin{array}{l}\text { Atención por parte de los estudiantes para el } \\
\text { desarrollo de la actividad } \\
\text { Risas entre las respuestas que los estudiantes } \\
\text { dan parte de los }\end{array}$ \\
\hline
\end{tabular}

\begin{tabular}{|l|l|}
\hline \multicolumn{2}{|c|}{ Episodio 12.2 } \\
\hline Papel del profesor & Papel del estudiante \\
\hline Observador, resolutor de preguntas & $\begin{array}{l}\text { Investigador e interrogador a partir de la } \\
\text { situación dada }\end{array}$ \\
\hline Recursos & Clima del Aula \\
\hline $\begin{array}{l}\text { Actividad diseñada } \\
\text { Cuaderno de apuntes } \\
\text { estudiantes) }\end{array}$ & $\begin{array}{l}\text { Atención por parte de los estudiantes para el } \\
\text { desarrollo de la actividad }\end{array}$ \\
\hline
\end{tabular}

\subsubsection{Sesión 13: Ecuaciones e Inecuaciones lineales}

Ya con la introducción de las expresiones algebraicas, Lucho se propone a estudiar con los estudiantes la solución de ecuaciones e inecuaciones lineales [CP13.007]. La clase inicia con preguntas a los estudiantes para que ellos hagan referencia a situaciones cotidianas en las que perciban que hay cantidades que cambian. A partir de dichas situaciones, Lucho interroga si es posible hallar cantidades que se puedan relacionar, es decir por ejemplo, que una dependa de la otra. Al escuchar la opinión de los estudiantes, Lucho selecciona algunos ejemplos y los registra en el tablero:

\begin{tabular}{ll}
\hline \hline & Lucho escribe los siguientes ejemplos: \\
& La compra de una cantidad de fruta y el precio a pagar \\
& La cantidad de agua en un balde y el peso total \\
[OB13.058] Comentario & La temperatura de un cuerpo y el tiempo de refrigeración \\
& El radio de una circunferencia y su área \\
& La altura de un triángulo y el área \\
\hline \hline
\end{tabular}


La velocidad de un objeto y el tiempo que demora en avanzar cierta distancia

El área de una circunferencia de radio $r$ :

Posteriormente, Lucho caracteriza la forma en que cambian esas cantidades, esperando expresiones en las que estén involucradas tanto el sentido como la velocidad, cambia más rápido, aumenta, disminuye, entre otros:

Nótese cómo entre más fruta compre, más pague; o cómo entre más agua tenga más va a pesar el balde. Pero no así con la temperatura;

[OB13.076] Lucho: entre más tiempo esté refrigerado, menos caliente va a estar o entre más veloz sea un objeto, menos tiempo va a tardar en recorrer la distancia propuesta.

Luego de los ejemplos trabajados en el tablero, se queda con la situación de relación entre el radio y el área de un círculo y otra de la relación de altura y el área de un triángulo de base 5 :

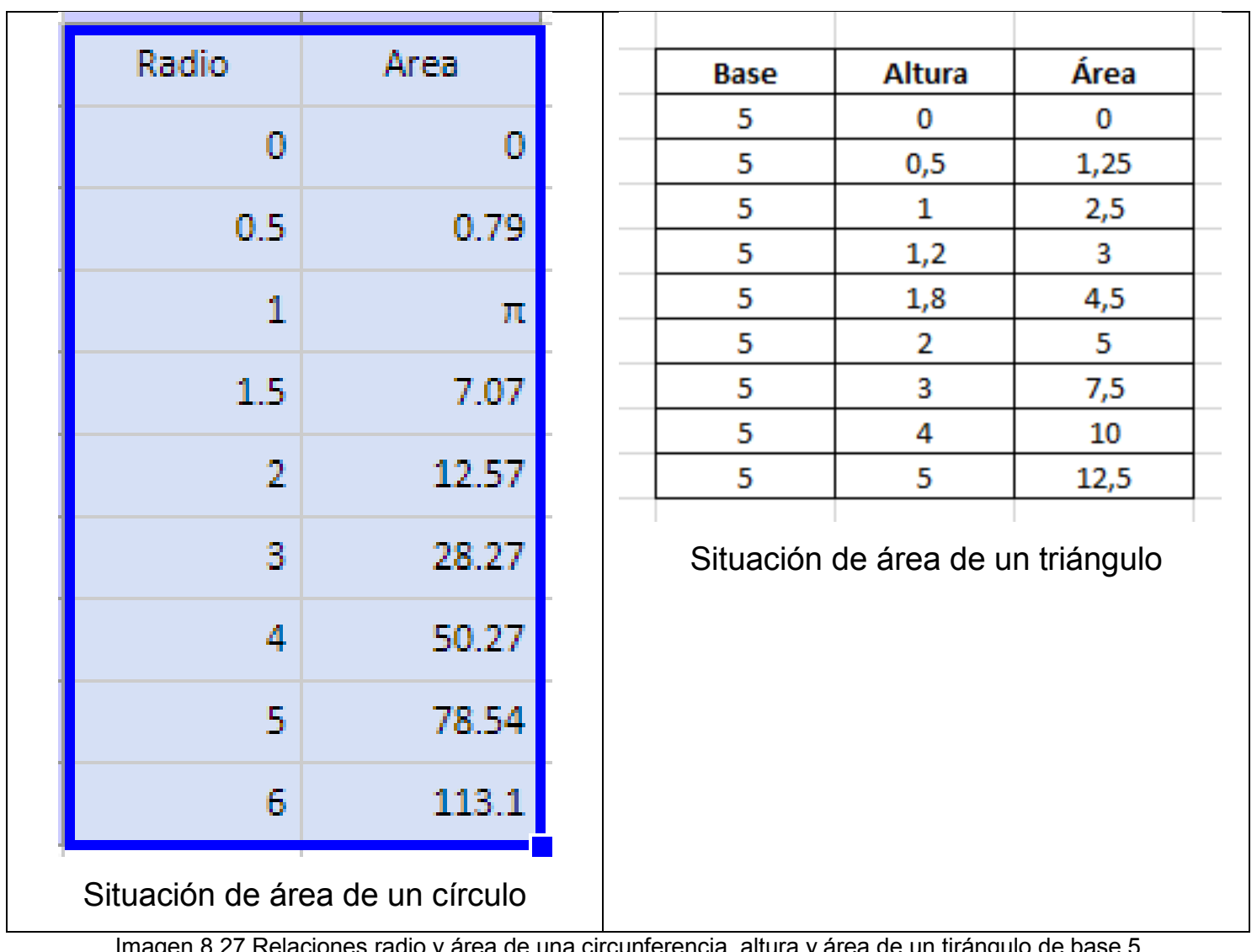

Imagen 8.27 Relaciones radio y área de una circunferencia, altura y área de un tirángulo de base 5 
Lucho incluye los datos en una tabla y con ayuda de los estudiantes, identifica las mismas características que se hablaron al principio de la clase: valores constantes y valores variables [OB13.096].

Lucho pregunta acerca de un valor específico que debe tomar el valor variable para que se obtenga un determinado valor:

\begin{tabular}{|c|c|c|}
\hline [OB13.098] & Lucho: & $\begin{array}{l}\text { ¿Cuánto debe medir el radio de la circunferencia para que el área } \\
\text { sea de } 49 \text { pi }\end{array}$ \\
\hline [OB13.111] & Lucho: & $\begin{array}{l}\text { ¿Cuánto debe medir la altura del tiángulo para que el área sea de } \\
20 ?\end{array}$ \\
\hline [OB13.121] & Lucho: & $\begin{array}{l}\text { ¿Cuánto debe medir el radio de la circunferencia para que el área } \\
\text { sea menor a } 300 \text { unidades cuadradas? }\end{array}$ \\
\hline [OB13.133] & Lucho: & $\begin{array}{l}\text { Una pelota ha sido lanzada al aire a una velocidad de } 25 \mathrm{~m} \text { por } \\
\text { segundo. ¿Al cabo de cuántos segundos se encontrará la pelota a } \\
20 \mathrm{~m} \text { de altura? Este problema se modela mediante la ecuación: } h \\
=v t-g t^{2} / 2 \text {. }\end{array}$ \\
\hline
\end{tabular}

Dadas estas situaciones, les pide a los estudiantes que recuerden el significado de los signos $<>$ y que indiquen cómo hacer los ejercicio del 3 al 9: 
Ejercicio 3: ¿Cuáles son los números cuyo triplo excede a su duplo en más de 20 ?

Ejercicio 4: ¿Cuál es el menor número entero múltiplo de 4, que satisface la siguiente inecuación:

$$
x+2<3 x+1 ? \text {. }
$$

Ejercicio 5: Si el lado de un cuadrado es mayor o igual que 7. ¿Qué se puede decir de su perimetro p?

Ejercicio 6: El perímetro de un cuadrado no supera el perimetro del rectángulo de la figura. ¿Qué se puede asegurar acerca de la superficie $S$ del cuadrado?

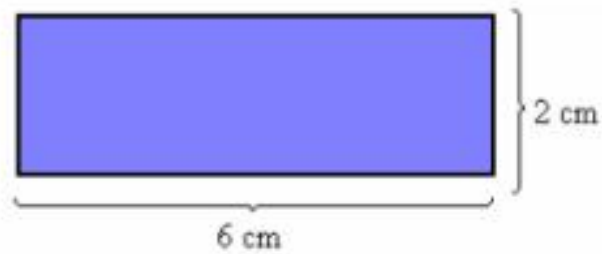

Ejercicio 7: Un padre y su hijo se llevan 22 años. Determinar en qué periodo de sus vidas, la edad del padre excede en más de 6 años al doble de la edad del hijo.

Eiercicio 8: Un coche se desplaza por una carretera a una velocidad comprendida entre $100 \mathrm{Km} / \mathrm{h}$ y $150 \mathrm{Km} / \mathrm{h}$. ¿Entre qué valores oscila la distancia del coche al punto de partida al cabo de 3 horas?

Ejercicio 9: Una fábrica paga a sus viajantes $\$ 10$ por articulo vendido más una cantidad fija de \$500.Otra fábrica de la competencia paga \$15 por artículo y \$300 fijas. ¿Cuántos artículos debe vender el viajante de la competencia para ganar más dinero que el primero?.

Imagen 8.28. Ejercicios sesión 13

Luego de la socialización de cómo plantear los ejercicios, los estudiantes se dan el permiso de desarrollarlos [OB13.192], un estudiante toma la vocería para preguntarle a los compañeros la manera en que los hicieron:

\begin{tabular}{lll}
\hline \hline [OB13.228] & Estudiante: & Compañeros, miren este problema \\
\hline [OB13.229] & Estudiante: & Pongamos atención \\
\hline & & $\begin{array}{l}\text { Tenemos tres peceras y cincuenta y seis peces. Los tamaños } \\
\text { de las peceras son pequeño, mediano y grande, siendo la } \\
\text { pequeña la mitad de la mediana y la grande el doble. Como }\end{array}$ \\
& & $\begin{array}{l}\text { no tenemos ninguna preferencia en cuanto al reparto de los } \\
\text { peces, decidimos que en cada una de ellas haya una cantidad } \\
\text { de peces proporcional al tamaño de cada pecera. ¿Cuántos } \\
\text { peces pondremos en cada pecera? }\end{array}$ \\
\hline [OB13.231] & Comentario & Pasa un rato mientras lo desarrollan \\
\hline
\end{tabular}




\begin{tabular}{|c|c|c|c|}
\hline [OB13.232] & Estudiante: & Yo creo que tengo la respue & \\
\hline [OB13.233] & Estudiante: & $p-m-g$ & Tenemos pe, eme y ge. \\
\hline [OB13.234] & Estudiante: & $p=\frac{1}{2} m$ & Pe es un medio de eme \\
\hline [OB13.235] & Estudiante: & $g=2 m$ & Y ge es el doble de eme \\
\hline [OB13.236] & Estudiante: & $\frac{1}{2} m+m+2 m=56$ & $\begin{array}{l}\text { Entonces, un medio de eme } \\
\text { más eme más dos eme es } \\
\text { igual a cincuenta y seis }\end{array}$ \\
\hline [OB13.237] & Estudiante: & $\frac{1}{2}+1+2=\frac{1}{2}+\frac{2}{2}+\frac{4}{2}=\frac{7}{2}$ & $\begin{array}{l}\text { Un medio más dos más uno } \\
\text { es lo mismo que un medio } \\
\text { más dos medios más cuatro } \\
\text { medios, ósea siete medios }\end{array}$ \\
\hline [OB13.238] & Estudiante: & $\frac{7}{2} m=56$ & $\begin{array}{l}\text { Siete medios de eme es igual } \\
\text { a cincuenta y seis }\end{array}$ \\
\hline [OB13.239] & Estudiante: & $7 m=112$ & $\begin{array}{l}\text { Siete eme es igual a ciento } \\
\text { doce }\end{array}$ \\
\hline [OB13.240] & Estudiante: & $m=16$ & Eme es igual a dieciséis \\
\hline [OB13.241] & Estudiante: & $\begin{aligned} g & =32 \\
m & =16 \\
p & =8\end{aligned}$ & $\begin{array}{l}\text { En la pecera grande van } \\
\text { treinta y dos, en la mediana } \\
\text { dieciséis, en la pequeña, ocho }\end{array}$ \\
\hline
\end{tabular}

La descripción por episodios es la siguiente:

\begin{tabular}{|c|c|c|c|}
\hline Episodio & Objetivo & Contenido & Actividad \\
\hline Ep 13.1 & $\begin{array}{l}\text { Modelar situaciones } \\
\text { de razones de cambio } \\
\text { para representar } \\
\text { situaciones de } \\
\text { ecuaciones lineales }\end{array}$ & $\begin{array}{l}\text { Razones y proporciones } \\
\text { Proporcionalidad directa } \\
\text { Ecuaciones lineales }\end{array}$ & $\begin{array}{l}\text { Cuestionamiento a } \\
\text { los estudiantes } \\
\text { acerca de la } \\
\text { nociones de } \\
\text { proporcionalidad } \\
\text { para abordar las } \\
\text { ecuaciones lineales }\end{array}$ \\
\hline Ep 13.2 & $\begin{array}{l}\text { Situaciones de } \\
\text { modelación de } \\
\text { ecuaciones lineales y } \\
\text { acercamiento a las } \\
\text { inecuaciones lineales }\end{array}$ & $\begin{array}{l}\text { Ecuaciones } \mathrm{e} \\
\text { inecuaciones lineales }\end{array}$ & $\begin{array}{lr}\text { Presentación de } \\
\text { situaciones de } \\
\text { modelación de } \\
\text { ecuaciones lineales }\end{array}$ \\
\hline
\end{tabular}




\begin{tabular}{|l|l|l|}
\hline $\mid$ & $\begin{array}{l}\text { a partir de razones } \\
\text { de cambio. al } \\
\text { Introducción de } \\
\text { concepto partir } \\
\text { inecuación a saberes } \\
\text { de los los } \\
\text { previos de los } \\
\text { estudiantes }\end{array}$ \\
\hline
\end{tabular}

\begin{tabular}{|l|l|}
\hline \multicolumn{2}{|c|}{ Episodio 13.1 } \\
\hline Papel del profesor & Papel del estudiante \\
\hline $\begin{array}{l}\text { Director de la actividad, moderador } \\
\text { de las participaciones de los } \\
\text { estudiantes, poca participación, } \\
\text { mediador entre el conocimiento y los } \\
\text { estudiantes }\end{array}$ & $\begin{array}{l}\text { Discusión entre ellos en gran grupo de } \\
\text { situaciones de ecuaciones lineales }\end{array}$ \\
\hline Recursos & Clima del Aula \\
\hline $\begin{array}{l}\text { Diseño de actividad previa } \\
\text { Conocimiento de los estudiantes } \\
\text { Hojas de papel }\end{array}$ & $\begin{array}{l}\text { Motivación por el desarrollo de una actividad } \\
\text { alterna para la clase de matemáticas }\end{array}$ \\
\hline
\end{tabular}

\begin{tabular}{|l|l|}
\hline \multicolumn{2}{|c|}{ Episodio 13.2 } \\
\hline Papel del profesor & Papel del estudiante \\
\hline $\begin{array}{l}\text { Generador de preguntas para los } \\
\text { estudiantes a partir de las preguntas } \\
\text { realizadas y de las modelaciones } \\
\text { presentadas. Mediador entre el } \\
\text { conocimiento y los estudiantes }\end{array}$ & $\begin{array}{l}\text { Desallador de la actividad a partir del } \\
\text { discusiones entre lo realizado por los otros. }\end{array}$ \\
\hline $\begin{array}{l}\text { Recursos } \\
\text { Cuctividad diseñada } \\
\text { Libros de texto (por parte de los } \\
\text { estudiantes) }\end{array}$ & Aplicación de conocimientos establecidos \\
\hline
\end{tabular}




\subsubsection{Sesión 14: Ecuaciones e inecuaciones no lineales}

La clase inicia invitando a los estudiantes a una actividad en el patio [OB14.001] y el paso de la hoja para el llamado de asistencia [OB14.007]. Para el desarrollo de esta sesión Lucho trae cuerdas de 120 centímetros. Arma grupos de dos personas y les pide seguir la instrucción:

\begin{tabular}{lll}
\hline \hline [OB14.017] & Lucho: & $\begin{array}{l}\text { Vamos a premiar con cinco décimas de la actividad evaluativa al } \\
\text { ganador de la siguiente actividad }\end{array}$ \\
\hline [OB14.018] & Lucho: & $\begin{array}{l}\text { Con la cuerda que les voy a entregar y sólo con la cuerda van a } \\
\text { armar un rectángulo de manera que tenga mayor área }\end{array}$ \\
\hline [OB14.019] & Lucho: & $\begin{array}{l}\text { Si un grupo puede llegar a justificar el por qué esa cantidad es la } \\
\text { mayor sin necesidad de medir tiene cinco décimas adicionales }\end{array}$ \\
\hline [OB14.020] & Lucho: & \begin{tabular}{l} 
Tienen quince minutos \\
\hline [OB14.021]
\end{tabular} \\
\hline \hline
\end{tabular}

Luego del desarrollo de la actividad, Lucho pide las medidas. Ningún grupo dio con la medida exacta. Les pide que por favor traten de reflexionar acerca de cómo es posible averiguar el dato solicitado [OB14.067].

Un grupo hace una explicación de la posible situación.

\begin{tabular}{lll}
\hline \hline [OB14.067] & Lucho: & $\begin{array}{l}\text { Tenemos un rectángulo de base equis y altura ye de } \\
\text { perímetro ciento veinte centímetros. Por tanto, tenemos que } \\
\text { encontrar el número que sea mayor en el producto equis ye, } \\
\text { pensemos cómo se puede solucionar la situación }\end{array}$ \\
\hline [OB14.068] & Estudiantes: & Ya profe \\
\hline [OB14.069] & Lucho: & Haber \\
\hline [OB14.070] & Estudiantes: & Equis más ye es sesenta \\
\hline [OB14.071] & Estudiantes: & Ciento veinte \\
\hline [OB14.072] & Estudiantes: & No, es sesenta, ancho y largo \\
\hline [OB14.073] & Estudiantes: & Bueno \\
\hline [OB14.074] & Estudiantes: & Equis por ye es el área \\
\hline [OB14.075] & Estudiantes: & $\begin{array}{l}\text { Entonces, equis por ye es igual que sesenta menos equis por } \\
\text { equis }\end{array}$ \\
\hline [OB14.076] & Comentario & Escribe: \\
\hline \hline
\end{tabular}




$$
x y=(60-x) x=\text { area }
$$

\begin{tabular}{lll}
\hline [OB14.077 & Estudiantes: & Equis por sesenta menos equis \\
\hline [OB14.078 & Estudiantes: & Es lo mismo \\
\hline [OB14.079 & Estudiantes: & Entonces sesenta equis menos equis al cuadrado es el área \\
\hline [OB14.080 & Estudiantes: & El área es cero cuando equis es cero o es sesenta \\
\hline [OB14.081 & Estudiantes: & Entonces, el mayor valor es cuando equis es treinta \\
\hline [OB14.082 & Lucho: & Es un buen modelo \\
\hline \hline
\end{tabular}

Luego, lucho les pide determinar la altura que se debe tener en cuenta para que entren mínimo quinientos centímetros cuadrados [OB14.085], y deja nuevamente que ellos exploren. Ya con la idea de la explicación de los compañeros, un par de grupos logran el desarrollo de la actividad:

\begin{tabular}{|c|c|c|c|}
\hline [OB14.096] & Estudiantes: & \multicolumn{2}{|c|}{$\begin{array}{l}\text { La altura por la base debe medir al menos quinientos } \\
\text { centímetros cuadrados }\end{array}$} \\
\hline [OB14.097] & Estudiantes: & \multicolumn{2}{|c|}{ Pero la altura más la base miden sesenta centímetros } \\
\hline [OB14.098] & Estudiantes: & \multicolumn{2}{|l|}{ Pensemos si fuese igual } \\
\hline [OB14.099] & Estudiantes: & \multicolumn{2}{|c|}{$\begin{array}{l}\text { Si la altura es ye, entonces la base es sesenta menos ye y se } \\
\text { iguala }\end{array}$} \\
\hline [OB14.100] & Estudiantes: & $y(60-y)=500$ & $\begin{array}{l}\text { Ye por sesenta menos ye es } \\
\text { quinientos }\end{array}$ \\
\hline [OB14.101] & Estudiantes: & $-y^{2}+60 y=500$ & $\begin{array}{l}\text { Menos ye cuadrado más } \\
\text { sesenta ye es igual a } \\
\text { quinientos }\end{array}$ \\
\hline [OB14.102] & Estudiantes: & $y^{2}-60 y+500=0$ & $\begin{array}{l}\text { Ye al cuadrado menos } \\
\text { sesenta ye más quinientos es } \\
\text { igual a cero }\end{array}$ \\
\hline [OB14.103] & Estudiantes: & \multicolumn{2}{|c|}{$\begin{array}{l}\text { Necesitamos buscar dos números que multiplicados den } \\
\text { quinientos y sumados den menos sesenta }\end{array}$} \\
\hline [OB14.104] & Estudiantes: & \multicolumn{2}{|c|}{ Esos números son menos cincuenta y diez } \\
\hline [OB14.105] & Estudiantes: & \multicolumn{2}{|c|}{ Probamos con cincuenta y diez y da cuatrocientos } \\
\hline [OB14.106] & Estudiantes: & \multicolumn{2}{|l|}{ Digo, quinientos } \\
\hline [OB14.107] & Estudiantes: & \multicolumn{2}{|c|}{$\begin{array}{l}\text { Probamos con cuarenta y nueve y once y vemos que } \\
\text { aumenta }\end{array}$} \\
\hline [OB14.108] & Estudiantes: & \multicolumn{2}{|c|}{ Pero no con cincuenta y uno y nueve } \\
\hline [OB14.109] & Estudiantes: & \multicolumn{2}{|c|}{$\begin{array}{l}\text { Vemos que el mayor valor de la altura es treinta y eso } \\
\text { conforma un cuadrado de novecientos centímetros cuadrados }\end{array}$} \\
\hline
\end{tabular}


Lucho asienta positivamente, pero recuerda que el valor válido es 10 y no menos cincuenta:

[OB14.110] Lucho Tengan cuidado que es cincuenta y no menos cincuenta

Finalmente, les pregunta, si la medida de la cuerda fueran $256 \mathrm{~cm}$ y quisiera lograr un área de por lo menos $4100 \mathrm{~cm}^{2}$, ¿de cuánto debe ser la medida del largo? [OB14.113] Los estudiantes llegan a las respuestas posibles con la lógica matemática, pero no aplicable al tamaño, ya que el área mayor es cuando el lado del rectángulo es de 64 centímetros y esta es de $4096 \mathrm{~cm}^{2}$.

\begin{tabular}{|c|c|c|c|}
\hline [OB14.133] & Estudiantes: & \multicolumn{2}{|c|}{$\begin{array}{l}\text { Esta diciendo que la cuerda mide doscientos cincuenta y seis } \\
\text { centímetros y la mitad es ciento veintiocho }\end{array}$} \\
\hline [OB14.134] & Estudiantes: & $y(128-y) \geq 4100$ & $\begin{array}{l}\text { El alto mide ye y el largo } \\
\text { ciento veintiocho menos } \\
\text { ye, por tanto y por ciento } \\
\text { veintiocho es mayor que } \\
\text { cuatro mil cien }\end{array}$ \\
\hline [OB14.135] & Estudiantes: & $-y^{2}+128 y \geq 4100$ & $\begin{array}{l}\text { Menos ye al cuadrado } \\
\text { más ciento veintiocho ye } \\
\text { es mayor o igual que } \\
\text { cuatro mil cien }\end{array}$ \\
\hline [OB14.136] & Estudiantes: & $y^{2}-128 y+4100 \leq 0$ & $\begin{array}{l}\text { Y ye al cuadrado menos } \\
\text { ciento veintiocho ye más } \\
\text { cuatro mil cien es menor } \\
\text { o igual que cero }\end{array}$ \\
\hline [OB14.137] & Estudiantes: & \multicolumn{2}{|l|}{ No será mayor que } \\
\hline [OB14.138] & Estudiantes: & \multicolumn{2}{|c|}{$\begin{array}{l}\text { No, fíjate que si paso el cuatro mil cien al otro lado pasa a } \\
\text { restar }\end{array}$} \\
\hline [OB14.139] & Estudiantes: & \multicolumn{2}{|c|}{$\begin{array}{l}\text { Yo paso menos ye al cuadrado más ciento veintiocho ye al } \\
\text { lado de cuatro mil cien }\end{array}$} \\
\hline [OB14.140] & Estudiantes: & \multicolumn{2}{|c|}{$\begin{array}{l}\text { Cero es mayor que todo eso, pero a mi me gusta más que ye } \\
\text { esté a la izquierda }\end{array}$} \\
\hline [OB14.141] & Estudiantes: & \multicolumn{2}{|c|}{$\begin{array}{l}\text { Puede ser también menos ye al cuadrado más ciento } \\
\text { veintiocho ye menos cuatro mil cien mayor o igual que cero }\end{array}$} \\
\hline [OB14.142] & Estudiantes: & \multicolumn{2}{|c|}{$\begin{array}{l}\text { Entonces, si multiplicamos por menos uno, cambiamos el } \\
\text { signo, cierto profe }\end{array}$} \\
\hline [OB14.143] & Lucho: & Así es & \\
\hline
\end{tabular}




\begin{tabular}{|c|c|c|c|}
\hline [OB14.144] & Estudiantes: & \multicolumn{2}{|c|}{ Profe, si fuera igual a cero, podemos aplicar cuadrática } \\
\hline [OB14.145] & Lucho: & Dele pues & \\
\hline [OB14.146] & Estudiantes: & $\frac{128 \pm \sqrt{128^{2}-4(1)(4100)}}{2}$ & $\begin{array}{l}\text { A es uno, be es menos } \\
\text { ciento veintiocho y ce es } \\
\text { cuatro mil cien }\end{array}$ \\
\hline [OB14.147] & Estudiantes: & $\frac{128 \pm \sqrt{128^{2}-16400}}{2}$ & $\begin{array}{l}\text { Cuánto es ciento } \\
\text { veintiocho al cuadrado? } \\
\text { Cuatro por uno, cuatro, } \\
\text { por cuatro mil cien es } \\
\text { dieciséis mil } \\
\text { cuatrocientos }\end{array}$ \\
\hline [OB14.148] & Estudiantes: & $\begin{array}{l}\text { Ciento veintiocho por ciento vei } \\
\text { trescientos ochenta y cuatro }\end{array}$ & no es dieciseismil \\
\hline [OB14.149] & Estudiantes: & Entonces lo de la raíz es negati & no se puede solucionar \\
\hline [OB14.150] & Estudiantes: & No se puede hacer un rectángu & \\
\hline [OB14.151] & Estudiantes: & Profe, entonces no se puede ha & \\
\hline [OB14.152] & Estudiantes: & $\begin{array}{l}\text { Profe, otra razón por la que no } \\
\text { parábola, si yo pongo zeta igual } \\
\text { ciento veintiocho ye, me da una } \\
\text { y cuyo vértice queda cuando ye }\end{array}$ & $\begin{array}{l}\text { es que esa es una } \\
\text { enos ye al cuadrado más } \\
\text { bola que abre hacia abajo } \\
\text { esenta y cuatro }\end{array}$ \\
\hline
\end{tabular}

Un estudiante pregunta qué pasaría si el problema se planteara buscando un área mayor o igual que mil novecientos ochenta [OB14.156], pero a la vez propone una solución [OB14.156 a OB14.166] que implica un valor positivo y otro negativo al mismo tiempo, por lo que Lucho le hace caer en cuenta que el caso es imposible [OB14.201].

Repite el ejercicio de búsqueda de estrategias con dos enunciados más, los cuales los estudiantes realizan sin la necesidad de que Lucho esté ordenando que lo hagan [OB14.211, OB14.228]:

\begin{tabular}{ll}
\hline \hline & Cuando dos espías amigos constrastan sus respectivas claves \\
[OB14.205] Lucho: $\quad \begin{array}{l}\text { numéricas de tres cifras, la suma de ambas ha de ser menor } \\
\text { que mil y su diferencia mayor que quinientos }\end{array}$
\end{tabular}

\begin{tabular}{ll}
\hline \hline [OB14.222] Lucho: & $\begin{array}{l}\text { Un empresario paga a un vendedor un sueldo fijo de novecientos } \\
\text { euros al mes más sesenta centavos por producto vendido. }\end{array}$ \\
\hline
\end{tabular}




\begin{tabular}{lll}
\hline \hline [OB14.223] & Lucho: & $\begin{array}{l}\text { Otro vendedor no tiene sueldo pero cobra uno coma ocho euros } \\
\text { por cada producto que logra vender }\end{array}$ \\
\hline OB14.224 & Lucho: & $\begin{array}{l}\text { ¿A partir de qué número de productos vendidos cobrará más el } \\
\text { segundo empleado? }\end{array}$ \\
\hline \hline
\end{tabular}

Al finalizar la actividad, Lucho recuerda a los estudiantes que la siguiente será la actividad evaluativa. Los estudiantes le piden nuevamente preparar algunos ejercicios entre ellos para el desarrollo de dicha actividad a lo que Lucho no pone problema alguno.

La tabla 8.17 es la respectiva para la sesión:

\begin{tabular}{|c|c|c|c|}
\hline Episodio & Objetivo & Contenido & Actividad \\
\hline Ep 14.1 & $\begin{array}{lr}\text { Involucrar a los } \\
\text { estudiantes con } & \text { el } \\
\text { estudio de las } \\
\text { desigualdades no } \\
\text { lineales a partir de las } \\
\text { ecuaciones } \\
\text { segundo grado }\end{array}$ & $\begin{array}{l}\text { Ecuaciones de segundo } \\
\text { grado. } \\
\text { Inecuaciones } \\
\text { lineales. } \\
\text { Productos notables } \\
\text { Fórmula cuadrática }\end{array}$ & $\begin{array}{lr}\text { Diseño de } & \text { un } \\
\text { rectángulo } & \text { que } \\
\text { tenga la mayor } \\
\text { área. } & \\
\text { Análisis } & \\
\text { matemático para } \\
\text { determinar } \\
\text { valores los } \\
\text { encontrar. }\end{array}$ \\
\hline Ep 14.2 & $\begin{array}{l}\text { Estudio de sistemas } \\
\text { de inecuaciones con } \\
\text { polinomios de } \\
\text { segundo grado }\end{array}$ & $\begin{array}{l}\text { Ecuaciones de segundo } \\
\text { grado. } \\
\text { Inecuaciones no } \\
\text { lineales. } \\
\text { Productos notables } \\
\text { Fórmula cuadrática }\end{array}$ & $\begin{array}{l}\text { Matematización de } \\
\text { la actividad anterior } \\
\text { que pueden ser } \\
\text { cotidianas en el } \\
\text { desarrollo r de } \\
\text { situaciones r en } \\
\text { contextos reales } \\
\text { por parte del } \\
\text { estudiante. }\end{array}$ \\
\hline
\end{tabular}

\begin{tabular}{|l|l|}
\hline \multicolumn{2}{|c|}{ Episodio 14.1 } \\
\hline Papel del profesor & Papel del estudiante \\
\hline Mediador entre el conocimiento y & Discusión entre ellos en grupo pequeño y en \\
lossaberes de estudiantes & $\begin{array}{l}\text { gran grupo para determinar los valores que } \\
\text { debe tener el rectángulo en mención }\end{array}$ \\
\hline
\end{tabular}




\begin{tabular}{|l|l|}
\hline & \\
\hline Recursos & Clima del Aula \\
\hline $\begin{array}{l}\text { Cartulinas de papel reciclado } \\
\text { Conocimiento de los estudiantes } \\
\text { Hojas de papel }\end{array}$ & Total inmersión en el desarrollo de la actividad \\
\hline
\end{tabular}

\begin{tabular}{|l|l|}
\hline \multicolumn{2}{|c|}{ Episodio 14.2 } \\
\hline Papel del profesor & Papel del estudiante \\
\hline $\begin{array}{l}\text { Generador de preguntas para los } \\
\text { estudiantes. Mediador entre el } \\
\text { conocimiento y los estudiantes }\end{array}$ & $\begin{array}{l}\text { Desarrollador de la actividad a partir del } \\
\text { conocimiento ya establecido y de las } \\
\text { discusiones entre lo realizado por los otros. }\end{array}$ \\
\hline Recursos & Clima del Aula \\
\hline $\begin{array}{l}\text { Actividad diseñada } \\
\text { Cuaderno de apuntes } \\
\text { Libros de texto (por parte de los } \\
\text { estudiantes) }\end{array}$ & $\begin{array}{l}\text { Motivación por el desarrollo de una actividad } \\
\text { alterna para la clase de matemáticas }\end{array}$ \\
\hline
\end{tabular}

El acompañamiento a las sesiones se da por finalizado en esta clase debido a que es posible identificar elementos propios de la práctica de Lucho en el nuevo año escolar que marcan una tendencia diferente a lo observado en el primer y segundo bloque.

\subsubsection{Concepciones identificadas en este bloque}

Se procede a caracterizar algunos de los posicionamientos que posee Lucho a partir del análisis de su práctica de manera similar a lo realizado en los bloques I y II.

La metodología está caracterizada por la puesta en marcha de métodos, recursos; de esta manera los ejercicios son sustituidos por una actividad experimental.

[FD11.04]: Recursos: Diseño de actividad previa. Conocimiento de los estudiantes. Hojas de papel

[FD11.06]: Recursos: Actividad diseñada. Cuaderno de apuntes. Libros de texto (por parte de los estudiantes). Tarea propuesta. Anotaciones. Libro de texto.

[FD12.04]: Recursos: Actividad diseñada. Cuaderno de apuntes. Libros de texto (por parte de los estudiantes). 
[FD14.05]: Recursos: Cuerdas. Conocimiento de los estudiantes. Hojas de papel. Material de estudio de los mismos estudiantes

Lucho propone actividades de manipulación de modelos propiciando, a menudo, el uso de materiales manipulativos, a través de los cuales se producirá, eventualmente, un conocimiento no organizado. Es importante tener en cuenta que las actividades que se generan en el aula permiten que cada alumno la realice según sus posibilidades, contando con la ayuda de sus compañeros y por ello Lucho acude al uso de materiales variados sobre todo para motivar a los alumnos y facilitar su comunicación:

\section{Objetivos planteados:}

[FD11.01]: Hacer un repaso de los algoritmos de operaciones básicas con números reales

[FD11.02]: Traer a la memoria cercana el procedimiento para desarrollar operaciones con expresiones algebraicas

[FD12.01]: Traer a la memoria las actividades acerca del cambio de lenguaje en el uso de expresiones algebraicas

[FD12.02]: Involucrar en situaciones que pueden ser reales para el desarrollo de habilidades en contenidos relacionados con expresiones algebraicas. Valorar los distintos puntos de vista como dar mayor riqueza de criterios

[FD13.01]: Modelar situaciones de razones de cambio para representar situaciones de ecuaciones lineales

[FD13.02]: Situaciones de modelación de ecuaciones lineales y acercamiento a las inecuaciones lineales

[FD14.01]: Involucrar a los estudiantes con el estudio de las desigualdades no lineales a partir de las ecuaciones de segundo grado.

[FD14.02]: Estudio de sistemas de inecuaciones con polinomios de segundo grado. [FD14.03]: Desarrollar la capacidad de deducción y observación. Desarrollar la capacidad de expresar sus propias deducciones y razonamientos con claridad, corrección y orden.

Los objetivos sólo definen un marco genérico de actuación de carácter orientativo y están sujetos a eventuales modificaciones en cuanto al grado de consecución. Los objetivos conllevan a Lucho a utilizar material manipulativo para reforzar, explicar o dar utilidad a la teoría, orientando a la vez que permite que los estudiantes logren procesos internos de desarrollo de pensamiento [Sesiones 11 a 14]. 
La evaluación está centrada para comprobar el interés de los alumnos y mejorar la dinámica del aula, para valorar la evolución de las ideas de los alumnos y mejorar los procesos de enseñanza y de aprendizaje cuando se logra iniciar procesos de matematización [EN03.143].

Con relación a las concepciones sobre las matemáticas escolares, se considera que a Lucho le interesa tanto la adquisición de conceptos, como el desarrollo de procedimientos y el fomento de actitudes positivas hacia la propia materia, el trabajo escolar en general y como ciudadano, siendo la materia y el trabajo escolar los que determinan el peso específico de cada una de las componentes citadas. Ahora se le ve más preocupado por la adquisición de conceptos y por el desarrollo de procedimientos y el fomento de actitudes positivas hacia las matemáticas, el trabajo escolar en general y como ciudadano; de esta manera, las matemáticas y el trabajo en aula son quienes determinan el peso específico de cada una de las componentes citadas.

Lo anterior coincide con las concepciones del aprendizaje que se identifican en este bloque: Lucho comprende que hay aprendizaje cuando el objeto, que surge del contexto, posee un significado para el alumno; es decir, el aprendizaje se produce a partir de la participación del alumno en procesos inductivos y de manera espontanea cuando se inmerge en situaciones que propician el descubrimiento.

El alumno interactúa con la materia, el docente y sus compañeros, pero el énfasis se coloca en la interacción con los compañeros y el docente.

Con relación al papel del alumno, éste hace parte indirecta de la selección y secuenciación de contenidos y objetivos, a través de la negociación de intereses en el diseño didáctico, y por medio de sus intervenciones en el quehacer del aula.

El alumno pasa de actividad en actividad, participando intensamente en cada una de ellas y esto se debe al ambiente dinámico que se propicia en la clase, y permite que el alumno comunique sus experiencias y sentimientos con el docente y los demás compañeros.

El papel del docente se caracteriza por la humanización y la especialización en la dinámica grupal. Lucho ahora induce al estudiante a participar en las actividades que promueve, analizando las reacciones y respuestas a sus propuestas. 
La información que se moviliza en el aula es validada por el grupo (grupo-clase o pequeños grupos de trabajo). En ocasiones se sustituye el papel de la corrección y se potencian estrategias de autovalidación que permiten al estudiante tomar consciencia del aprendizaje.

Respecto de la enseñanza y el aprendizaje de las matemáticas, se puede caracterizar una concepción espontaneista en la manera como realiza las clases. El docente propone las actividades, promueve la participación de los alumnos y al mismo tiempo le interesan las actitudes y los procedimientos generales.

Lucho lleva a cabo un proceso de enseñanza que propicia un aprendizaje inductivo que si bien no se acerca al modelo investigativo, si logra alejarse de la escuela tradicional que lleva a cabo en su aula durante el primer y segundo bloque. Lucho parece entender el aprendizaje como un proceso social en el que la interacción entre y con los estudiantes es fundamental en el proceso de formación.

\subsubsection{Conocimiento Especializado en este bloque}

A lo largo del tercer bloque se pueden distinguir algunos aspectos acerca del conocimiento especializado que complementan las ya caracterizadas durante el primer y segundo bloque: que no se observaron durante las primeras siete sesiones. Con relación al conocimiento de la temas, es posible identificar en Lucho la diversidad en formas de representación de ecuaciones e inecuaciones; ya es más frecuente el uso de representaciones tabulares y de representaciones gráficas en los momentos de observación, tal como ocurre en las sesiones 13 y 14.

Lo anterior se relaciona con el Conocimiento de la estructura matemática, en cuanto Lucho ahora estudia relaciones locales en el estudio de las ecuaciones, que intentan acercar al estudiante a una mejor compresión, por ejemplo, en la actividad de la cuerda y la relación con la ecuación planteada y la representación tabular empleada en [OB14.111].

El Conocimiento de la práctica, pareciera ser diferente en cuanto el contexto central ya no es el libro de texto y Lucho, intenta detectar el tipo de razonamiento que utilizan los estudiantes cuando les deja hacer los ejercicios que propone, las tareas y actividades, e incluso en los ejercicios que voluntariamente proponen los estudiantes. 
En cuanto al Conocimiento de la enseñanza de las matemáticas, Lucho pone en marcha diferentes estrategias como el uso de tareas que empleó en el segundo bloque, pero también el uso de material concreto, como las cuerdas de la sesión 14. Lucho se encuentra en búsqueda de estrategias que permitan la variedad en el proceso de enseñanza de las matemáticas [EN03.133].

De forma similar que en el bloque II, el conocimiento de las características del aprendizaje de las matemáticas, se caracteriza por la comprensión de Lucho acerca de la responsabilidad en el aprendizaje de los estudiantes sin que esto implique que el docente sea el centro de la actividad del aula [EN03.181], conocimiento que vincula al conocimiento de los estándares de aprendizaje de las matemáticas al considerar importante la revisión de contenidos en pro de una coherencia con las necesidades curriculares al plantear actividades que los estudiantes requieran [EN03.182].

\section{Con relación a sus actitudes}

En el tiempo entre los bloques II y III, Lucho constituye una serie de actividades que diferencia el desarrollo de su práctica en la búsqueda de estrategias que permitan afianzar el conocimiento de los estudiantes. En las declaraciones posteriores de la sesión 11, Lucho afirma que el cambio de la estructura de sus clases es consecuencia de la observación en el año anterior [DP11.003]. Lucho afirma que el cambio de la estructura de las clases debe ser constante y se debe a su preocupación por el estado de aprendizaje de los estudiantes [DP11.006].

Manifiesta estar intentando acercarse a una enseñanza de las matemáticas por medio de la resolución de problemas, aunque eso no siempre se dé, por lo que la actividad del alumno está organizada hacia la búsqueda de respuestas a interrogantes que lo lleven a los problemas [EN03.082]. Esto último acerca a Lucho a algunos procesos de reflexión que lo pueden acercar a un cambio en su práctica, a lo que en el marco teórico de esta investigación se ha denominado desarrollo profesional.

\subsubsection{Acerca de la reflexión de Lucho}

Con el desarrollo del tercer momento de observación, Lucho reflexiona a posteriori sobre lo acontecido en las sesiones realizadas desde la perspectiva de resolución de problemas. De este modo, analiza su práctica, la propia perspectiva (sus ventajas y 
limitaciones) y el aprendizaje de los contenidos matemáticos. El foco principal en el que centra su atención a lo largo de todas las fichas es el aprendizaje de sus alumnos. Así, valora constantemente respecto de las sesiones: cuáles son las dificultades que encuentran los alumnos (en relación con el modo de trabajo y con los contenidos concretos) y cuál es el grado de dificultad de la propia actividad, cuál es el papel del alumno y su motivación.

\footnotetext{
[FD11.07]: Expresar las ideas matemáticas y para expresarme haciendo uso de los signos y símbolos matemáticos para que los estudiantes aprendan

[FD11.08]: Es importante estar pensando siempre en cómo realizar adecuadamente el ejercicio de la enseñanza y tener en cuenta las construcciones de los estudiantes.

[FD13.07]: Identificar las características correspondientes a la solución de ecuaciones e inecuaciones a través de la situación planteada

[FD13.08]: Aunque pongo énfasis en lo procedimental y lo actitudinal, también me interesan los conceptos

[FD14.08]: Desarrollar la capacidad para imaginar mentalmente la situación descrita por los estudiantes

[FD14.09]: La capacidad para expresar y justificar su opinión y criticar las de los estudiantes, su capacidad para tomar decisiones razonables, para la autoreflexión
}

La reflexión sobre su propia actuación es menor, aunque logra hacer algunas consideraciones concretas sobre su grado de dirección y sobre dificultades propiciadas por su modo de intervenir [FD11.08]. La problematización de su actuación y las dificultades que en ella percibe es menor o no es su preocupación principal. No parece que no cuestione su actuación, lo que se aprecia es que su referente en este cuestionamiento es el aprendizaje del alumno, a quienes trata de mostrarse seguro.

Lucho piensa sobre la enseñanza, esta es la razón de los cambios observados con respecto al bloque I y II [EN03.039], hecho que implica que también piensa sobre cómo aprenden los estudiantes, en particular identifica ideas que los estudiantes no son capaces de utilizar [DP13.013], aunque se acerca a procesos de socialización en el aula [DP13.016] que coinciden con su reflexión acerca de estrategias que le permitan salir de rutinas establecidas implícitamente [DP11.015] coincidente con la proposición de actividades que acerquen a los estudiantes al aprendizaje de las matemáticas [DP11.017].

Finalizada la primera sección de este capítulo y descritas cada una de las catorce sesiones observadas en tres bloques se procede a describir el proceso de Desarrollo 
Profesional de Lucho. Dicho proceso se realiza a través del análisis de las Concepciones y de su Conocimiento Especializado a partir de los instrumentos establecidos en el marco teórico de esta investigación e interpretados por el autor de esta investigación.

\subsection{Concepciones de Lucho}

A partir de las caracterizaciones de Lucho en cada uno de los bloques correspondientes al periodo de observación, se han destacado en cada uno de los bloques acciones características que lo ubican en una tendencia didáctica en función de los instrumentos para el análisis.

Lo que sigue se ha extraído de la práctica de Lucho y sus declaraciones sobre ella, y la condensación de lo extraído en los análisis de los tres bloques observados además de las entrevistas realizadas.

\subsubsection{Metodología en el aula}

Con la puesta en práctica de la enseñanza de las ecuaciones e inecuaciones que involucran expresiones algebraicas racionales, Lucho muestra algunos cambios en la metodología: uno de ellos es atreverse a modificar el proceso de enseñanza iniciando con una metodología de explicación - desarrollo acercándose a una metodología con una perspectiva espontaneista a través del acercamiento a situaciones para la enseñanza de las matemáticas que se observa en los bloques I a III.

Lo anterior se justifica con el actuar de Lucho en los tres bloques de observación. En los momentos anteriores a la observación en el aula y durante el primer bloque de observación, la actividad de Lucho se caracteriza por la inducción, por parte suya de los contenidos [OB01 a OB07]. Durante el primer bloque de observación no hay actividades diseñadas explícitamente por Lucho para que los estudiantes construyan los contenidos [DP07.010]. El profesor pretende que los estudiantes realicen deducciones directas, descubran reglas a partir de la imitación de los ejercicios planteados como ejemplo [EN03.083, al preguntarle el por qué cambia la metodología de su clase].

En este bloque, el trabajo en gran grupo siempre se desarrolla al inicio de la clase. Lucho trata de mantener el orden y la disciplina mediante pautas de solicitud de palabra y un direccionamiento a la conclusión de la situación en la que se llegan a unos 
acuerdos, siendo Lucho quien orienta la consecución de los mismos [OB01.024, OB01.02, OB01.168, OB02.010, OB03.021, OB03.022, OB04.132, OB05.002, OB05.014, OB05.030, OB06,017, OB06.018, OB06.019, OB07.011, OB07.013].

En las sesiones de este bloque siempre se inicia la actividad en gran grupo para las explicaciones generales, el llamado a lista de asistentes, el seguimiento de instrucciones y la inicialización de la actividad.

El trabajo individual se realiza, luego de la explicación de los temas. Lucho considera que debe hacerse trabajo individual porque es una actividad de exploración en los estudiantes participan a partir de su propia realidad y propio contexto [DP05.016]. EI trabajo en grupo lo realiza en este bloque porque entiende y cree que los estudiantes no van a llegar a realizar lo que les ha solicitado [DP05.021]. Lucho Considera que el trabajo con pares, les puede dar a los estudiantes la oportunidad de comprender las explicaciones que ha realizado previamente [DP04.024, DE12.014]. En las sesiones antes de la heteroevaluación hace un intercambio constante entre el trabajo en grupo y el trabajo individual.

Lucho presenta inquietudes acerca de la metodología empleada en el aula de clase a partir de los resultados de la actividad evaluativa [DP03.006, DP03.020] y aunque decide seguir con las actividades planificadas, existe un momento de ruptura luego de la séptima sesión en la que Lucho prevé que tanto los resultados como los aprendizajes no son los esperados por él [DP07.003].

En las sesiones del segundo bloque, Lucho trata de incorporar la actividad explícita en la cual el estudiante indaga sobre los contenidos [DP09.021] y trata de hacer que la actividad del aula se aleje de la clase tradicional a partir de una propuesta que se acerca a la resolución de problemas [CP09.005, CP09.006], reconociendo que involucrarse en esta perspectiva es muy difícil porque no cuenta con elementos para desarrollarla a plenitud [EN02.058], aunque logrando el desarrollo de la actividad tal como lo esperaba [DP09.023].

En este bloque Lucho hace un trabajo en grupo, pero centrando la labor del aula en el conocimiento y los estudiantes [EN02.229]. Para Lucho, las agrupaciones ahora tienen el fin de exploración a partir de los saberes previos de los estudiantes [DP10.012]. 
En el tercer bloque de observación, la metodología observada es diferente; el profesor permite que los estudiantes exploren [DP12.005]; según Lucho, esto es algo que para los alumnos es difícil, por el hecho de que durante toda su formación en la escuela han sido guiados casi siempre [DP11.014, NO12.020], la disposición propia de ellos para la clase permite que tomen la iniciativa [NO11.021, NO12.021 DE13.018].

En la entrevista final, Lucho considera que ha fortalecido el trabajo en grupo, no en gran grupo: Ésa es una de las cosas que he cambiado. Depende del tipo de trabajo, es verdad, pero he abusado del trabajo en grupo en el que los estudiantes se reunían solamente para hacer ejercicios del libro [en las primeras observaciones]. Ahora reconozco que hace falta más trabajo individual. Vas encontrando dentro de cada actividad lo que sale bien [EN03.136].

Al finalizar el proceso de observación Lucho considera que la metodología de su clase se ha alejado del quehacer tradicional y se ha acercado más a la resolución de problemas, aunque reconoce que no necesariamente el desarrollo en aula se da bajo este ambiente, él mismo considera que, la actividad del alumno está organizada interna o externamente hacia la búsqueda de respuestas a determinados interrogantes [EN03.082]. Éste es un uno de los elementos que manifiesta ha mantenido en su práctica posterior, constituyendo una de las claves de su práctica en el aula, como explica en la entrevista final: ahora evito hacer una lista completa de ejercicios mecánicos del libro, sino que yo les planteo una actividad a partir de la cual, con sus conocimientos previos pueden llegar a establecer un determinado conocimiento; no obstante hay momentos en los que es necesario el mecanicismo para la aprehensión de un determinado algoritmo. [EN03.165].

Así, la metodología del primer bloque es caracterizada por la repetición de ejercicios tipo [OB01, OB03, OB04, OB05, OB06] y la explicación de manera constante por la presentación de ejemplos y ejercicios que son propios del libro de texto [OB01, OB03, OB04, OB05, OB06]. Los estudiantes realizan los ejercicios en grupo sin perseguir un fin específico que les permita el aprendizaje que el mismo docente pretende.

En el segundo bloque, si bien aún no se realiza alguna diferenciación individual en los procesos de enseñanza, Lucho distingue de manera distinta el trabajo en grupos [DP09.025, DP.10.030, DP10.031], permitiendo observar una trasformación de su práctica en la que de manera paulatina utiliza materiales manipulativos y software educativo [NO10.12, OB09.052, OB09.222, OB10.020, OB10.092] y expone los 
contenidos ya no en su fase final, sino que permite la simulación de construcción [DP10.032]; Lucho continúa promoviendo la repetición de ejercicios tipo y los ejemplos que construye son, en su mayoría, del libro de texto [NO08.024, EN02.212].

En el tercer bloque, la metodología se caracteriza por la puesta en marcha de otros recursos que en los dos bloques anteriores Lucho no utilizaba, como por ejemplo tareas dentro de las sesiones [OB11, OB12, OB13], el trabajo en grupo con un sentido de construcción del conocimiento [DP11.013, DP12.008, DP14.028] en el que propone actividades que sustituyen los ejercicios del libro de texto y simula construcción de conocimientos que los estudiantes aún no poseen [DP12.009, DP13.008].

\subsubsection{Evaluación}

Con relación a la evaluación, en la entrevista inicial Lucho comenta que la quiere entender como un proceso [EN01.144], hecho que se contrasta en la observación del primer bloque en la que se percibe que Lucho la centra en calificar, para medir la consecución de los objetivos prefijados [OB02, OB03]. En este bloque Lucho verifica los procesos de aprendizaje mediante la ejecución de la prueba escrita, hecho que manifiesta realizar siempre, incluso en otros cursos lo hace de manera semanal [DP02.011] y es por medio de esta que puede saber qué tanto aprenden los estudiantes [OB02.087], reproduciendo lo que se hace en clase, en particular el desarrollo de algoritmos [OB03.128].

En el segundo bloque se observa que Lucho aún emplea la evaluación con el propósito de reproducir ejercitaciones sobre los contenidos practicados y el desarrollo de algoritmos justificados [EN02.246], pero ahora atiende al producto y es realizada mediante el desarrollo de las tareas propuestas, evidenciado esto porque al final de las sesiones recoge los cuadernos y los califica entre sesiones [OB08.291, OB09.225, OB10.140].

En el tercer bloque la evaluación es realizada a partir de las motivaciones e intereses de los estudiantes, hecho que se evidencia cuando al finalizar las clases Lucho les pregunta acerca de los avances personales, grupales y estrategias realizadas [OB11.390, OB12.282, OB13.349, OB14.292]. Se observa coherencia entre las declaraciones iniciales sobre la evaluación y lo que ahora hace. En la entrevista final Lucho comenta que ahora hace un seguimiento individual, grupal y personal de los avances de los estudiantes [EN03.168]. 


\subsubsection{Matemáticas Escolares}

Con relación a la visión de las matemáticas escolares, en el primer bloque se observa que Lucho orienta la asignatura hacia la adquisición de conceptos y reglas, hecho que se observa en la explicación cotidiana de ejemplos a lo largo de las observaciones.

En el segundo bloque, Lucho orienta la asignatura exclusivamente hacia la adquisición de conceptos y reglas a partir de actividades que afiancen los conocimientos de las primeras siete sesiones [CP08.013]. Tanto en el bloque I como en el bloque II, las matemáticas escolares coinciden con las que se muestran en los libros de texto [EN02.088].

En el tercer bloque se nota un cambio en la visión de las matemáticas escolares por parte de Lucho, el cual se hace evidente cuando demuestra interés por la adquisición de conceptos y el desarrollo de procedimientos, además de actitudes positivas hacia la materia: "he analizado que las matemáticas que se enseñan deben estar rodeadas de conceptos, procedimientos e interés hacia los estudiantes [CP13.006] y esto está ligado al rol general de la escuela y el papel como ciudadano por parte de los estudiantes: "ustedes aprenden matemáticas en esta aula, pero no olviden que éstas tienen relación con toda su labor como estudiantes, con la escuela y como ciudadanos, en la vida cotidiana [OB14.195]; esto permite entender que Lucho se preocupa por tres elementos: desarrollo de competencias matemáticas, desarrollo de competencias ciudadanas, desarrollo del ser humano [EN03.197].

\subsubsection{Aprendizaje de las Matemáticas}

Lucho define el aprendizaje de las matemáticas escolares a partir de sus concepciones, en este sentido, en el primer bloque se observa que el aprendizaje se realiza utilizando la memoria [OB02]; así, el alumno se hace con los conocimientos por el simple hecho que el docente se los presente y por ello se evalúa al finalizar la explicación de un determinado tema: "pongan mucha atención porque lo que voy a explicar a continuación es importante y ustedes deben aprenderlo bien para que luego no estén preguntando en el examen cómo es que se hace" [OB01.168].

Esta condición se mantiene durante la observación del segundo bloque con una pequeña modificación: "para que el estudiante aprenda, no sólo se le debe explicar, debe entender y asimilar el conocimiento que viene de esa explicación" [DP08.027] por 
lo que Lucho recurre a la interacción con las matemáticas por medio de los ejercicios propuestos y el uso del software educativo que emplea en esta etapa [DP08.033].

Ya en el tercer bloque, Lucho manifiesta que el aprendizaje se da cuando el objeto matemático posee un significado para el alumno: he generado actividades para que el estudiante comprenda que este conocimiento es para sí, para que no sea yo quien repita siempre porque al fin de cuentas en esa repetición quien aprende soy yo y no el estudiante [CP11.019]. De esta manera se vuelve importante la participación activa del estudiante: "si el estudiante participa, se va a acercar más al aprendizaje y éste será espontáneo" [DP14.026], por lo que Lucho genera actividades que propician el descubrimiento [CP11.007].

\subsubsection{Papel del Alumno}

En el primer bloque, y desde el primer momento de observación, el papel del alumno es el de aprendiz. El estudiante repite las actividades que el profesor le propone en cada una de sus sesiones y no tiene que ver con el diseño de las actividades, la planeación de la clase o el diseño didáctico.

En el segundo bloque se observa un cambio en la postura del estudiante: ahora ya no repite de manera sistemática todo aquello que le proponen hacer. La interacción que se produce entre el profesor y el alumno es desequilibrada, siendo más fuerte el flujo en la dirección profesor a estudiante que la inversa, evidenciado esto en la explicación permanente por parte de Lucho en cada una de las actividades propuestas.

En el tercer bloque el estudiante hace parte indirecta de la selección y secuenciación de contenidos y objetivos, a través de la negociación de intereses, y en el diseño didáctico, a través de sus intervenciones en el quehacer del aula. Esto se evidencia cuando el estudiante pasa de actividad en actividad, participando intensamente en cada una de ellas y esto se debe al ambiente dinámico que se propicia en la clase.

El papel que adquiere progresivamente el alumno es el de criticar lo que se moviliza en el aula, dando sus argumentos, intercambiando sus ideas con sus compañeros, acordando con ellos. El alumno reflexiona, piensa, sopesa alternativas. A lo largo de la actividad, Lucho da importancia a la toma de conciencia por parte de alumno de lo que aprende, así considera que ahora los alumnos alumno toma conciencia de qué 
hacen y para qué lo hacen, comunican sus experiencias y sentimientos y mantienen una actitud crítica ante lo que pasa en el aula [DP12.011].

El aumento de la actitud crítica del alumno en el aula y de su autonomía es, además, uno de los aspectos que observa en los cambios propiciados en los estudiantes por su nuevo modo de trabajo, que valora positivamente y que encuentra ostensiblemente diferente respecto de su papel anterior: los estudiantes estaban muy dirigidos por lo que les decía, lo que yo les decía no veían otra cosa, mientras que ahora están escuchándome pero también están a la vez preguntándose si es posible tal cosa [EN02.209].

A posteriori, en las declaraciones sobre su práctica en la entrevista final, refleja mantener ese papel del alumno, destacando la consciencia de lo que aprende y su responsabilidad. Por otro lado, el alumno interviene en mayor medida en la propia marcha del proceso, pues sus aportes son consideradas más en la dirección del mismo. Además, Lucho hace explícito ante los alumnos esa toma en consideración de sus ideas y propuestas. Así declara que ha seguido ocurriendo tras el periodo de la actividad [EN03.149].

\subsubsection{Papel del Profesor}

En los bloques observados se identifica el papel de Lucho de la siguiente manera: en el primer bloque está limitado al desarrollo del ejercicio de trasmisión verbal de los contenidos de aprendizaje [OB01.056, OB03.048, OB05.049], en el que la actividad predominante es la explicación de ejemplos del libro de texto [NO01.23, NO04.56, EN02.210], esto se comprueba directamente con Lucho cuando se le pregunta de dónde salen los ejemplos que explica al inicio de cada sesión: "son ejercicios y ejemplos que vienen en el libro de texto y que permitirán que los estudiantes comprendan cómo desarrollar los ejercicios planteados" [EN02.212], por lo cual refleja lo que dice el libro de texto.

Lucho actúa como un mediador entre el conocimiento y lo que dice el libro de texto, está atento a revisar los errores de los estudiantes y constatarlos con el libro de texto: "si, mira - revisando el solucionario del libro - el ejercicio está resuelto como lo hemos resuelto nosotros en clase" [OB04.308]. 
En el segundo bloque, su rol cambia a organizador de contenidos de aprendizaje: "soy quien debe proponer una estructura mediada de los contenidos que deben aprender los estudiantes" [EN02.205, al preguntar por el cambio observado entre bloque I y bloque II], los cuales poseen unas estrategias organizativas tales como las tareas [FD08.02, FD08.03, FD08.04, FD08.05, FD09.02, FD10.01] y el uso de software educativo [FD10.04, FD10.06]. Así, su labor es de un especialista en el contenido que aún valida en el libro de texto el conocimiento [EN03.156].

En el tercer bloque se observan cambios con relación a la la dinámica grupal: "el trabajo en grupo y la formación del estudiante es fundamental ante el aprendizaje de las matemáticas, es importante que el estudiante participe en las actividades y decida qué matemáticas quiere aprender" [DP13.016]. Se observa que Lucho induce a los estudiantes a participar en las actividades que promueve: "es importante que participen para que se hagan cargo de su propio aprendizaje y lo involucren con sus necesidades personales" [OB12.211].

A lo largo del periodo de observación se comprende que Lucho deja de ser el centro de la actividad del aula y otorga dicho papel a los estudiantes [NO14.018, EN03.131]. papel del profesor se acerca a la organización y la conducción de dichos aportes. Tanto en el trabajo individual como en el trabajo en gran grupo, poco a poco va generando aportes por parte del alumno, su argumentación, su toma de conciencia de los procesos de razonamiento y argumentación, fuerza a que busquen nuevas soluciones y a que se expresen con precisión.

En el desarrollo de las últimas dos sesiones mantiene esas actuaciones, organizando, además, las intervenciones de los alumnos, incorporando sus aportaciones y reconduciendo la situación, completando, precisando, dirigiendo hacia los contenidos [OB13, OB14].

Se observan ocasiones en las que su intervención es mayor, aportando ayudas, corrigiendo de manera explícita, dirigiendo las construcciones conjuntas, a veces estableciéndose un diálogo casi exclusivamente entre él y los estudiantes que intervienen en ese momento, tomando el papel que otras veces atribuye al resto de sus compañeros: acordar, validar, criticar, argumentar [NO12.016].

Las concepciones se han modificado, Lucho ha variado su quehacer, partiendo de una tendencia tradicional y orientándose hacia una tendencia espontaneista. La tabla 8.18, 
que se presenta a continuación, resume cada una de las componentes estudiadas y los cambios presentados a lo largo de los tres bloques. En formato normal, se describen las características correspondientes a la tendencia tradicional, en formato subrayado las de la tendencia tecnológica y formato cursiva las de la tendencia espontaneista a fin de identificar visualmente los cambios que Lucho ha tenido a lo largo de la observación. 


\begin{tabular}{|c|c|c|c|c|}
\hline & & Bloque I & Bloque II & Bloque III \\
\hline & & Tradicional & Tradicional/Tecnológica & Espontaneista \\
\hline 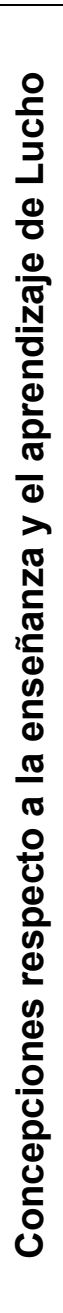 & Metodología & $\begin{array}{l}\text { Repetición de ejercicios tipo. } \\
\text { Explicación del docente está } \\
\text { dada de manera constante por } \\
\text { la presentación del libro de } \\
\text { texto. }\end{array}$ & 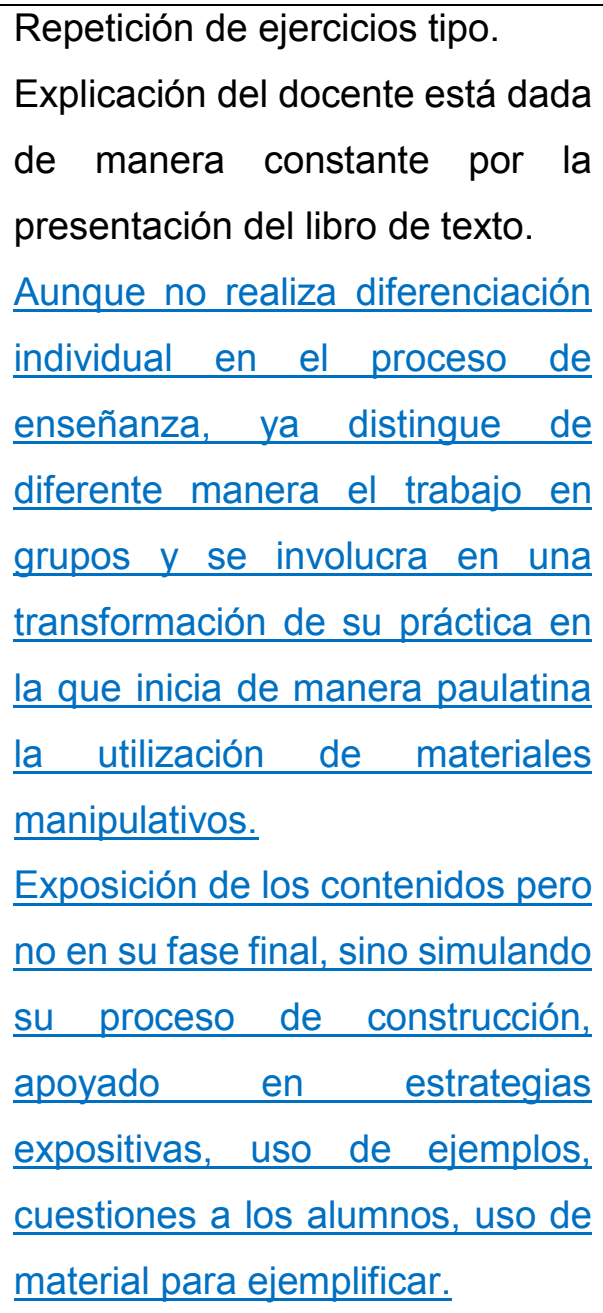 & $\begin{array}{l}\text { Caracterizada por la puesta en } \\
\text { marcha de métodos, recursos. } \\
\text { Los ejercicios son sustituidos } \\
\text { por una actividad experimental. } \\
\text { Propone actividades de } \\
\text { manipulación de modelos } \\
\text { propiciando, a menudo, el uso de } \\
\text { materiales manipulativos, a través } \\
\text { de los cuales se producirá, } \\
\text { eventualmente, un conocimiento } \\
\text { no organizado. }\end{array}$ \\
\hline
\end{tabular}




\begin{tabular}{|c|c|c|c|}
\hline Evaluación & $\begin{array}{l}\text { Centrada en calificar, para } \\
\text { medir la consecución de los } \\
\text { objetivos prefijados. } \\
\text { La lleva a cabo con el fin de } \\
\text { 'reproducir' los contenidos } \\
\text { practicados, principalmente los } \\
\text { algorítmicos y las aplicaciones } \\
\text { mostradas en clase } \\
\text { Atiende sobre todo al producto } \\
\text { y es realizada mediante } \\
\text { exámenes escritos al final del } \\
\text { proceso, orientada y dirigida } \\
\text { directamente por Lucho. }\end{array}$ & $\begin{array}{l}\text { Centrada en calificar, para medir } \\
\text { la consecución de los objetivos } \\
\text { prefijados. } \\
\text { La lleva a cabo con el fin de } \\
\text { 'reproducir' los contenidos } \\
\text { practicados, principalmente los } \\
\text { algorítmicos y las aplicaciones } \\
\text { mostradas en clase } \\
\text { Atiende sobre todo al producto y } \\
\underline{\text { es realizada mediante el }} \\
\underline{\text { desarrollo de las tareas }} \\
\underline{\text { propuestas en cada una de las }} \\
\underline{\text { sesiones, aún es orientada y }} \\
\text { dirigida directamente por Lucho. }\end{array}$ & $\begin{array}{l}\text { Centrada en comprobar el interés } \\
\text { de los alumnos y mejorar la } \\
\text { dinámica del aula, para valorar la } \\
\text { evolución de las ideas de los } \\
\text { alumnos y mejorar los procesos } \\
\text { de enseñanza y de aprendizaje } \\
\text { cuando se logra iniciar procesos } \\
\text { de matematización. }\end{array}$ \\
\hline $\begin{array}{l}\text { Matemáticas } \\
\text { Escolares }\end{array}$ & $\begin{array}{l}\text { Orienta la asignatura } \\
\text { exclusivamente hacia la } \\
\text { adquisición de conceptos y } \\
\text { reglas. }\end{array}$ & $\begin{array}{l}\text { Sigue orientando la asignatura } \\
\text { exclusivamente hacia la } \\
\text { adquisición de conceptos y reglas. } \\
\text { Las matemáticas escolares } \\
\text { coinciden con la que se muestran } \\
\text { en el libro de texto aunque ya hay } \\
\text { algunas otras actividades que } \\
\text { salen de este contexto. }\end{array}$ & $\begin{array}{l}\text { Interesa tanto la adquisición de } \\
\text { conceptos, como el desarrollo } \\
\text { de procedimientos y el fomento } \\
\text { de actitudes positivas hacia la } \\
\text { propia materia, el trabajo } \\
\text { escolar en general y como } \\
\text { ciudadano, siendo la materia y } \\
\text { el trabajo escolar los que }\end{array}$ \\
\hline
\end{tabular}




\begin{tabular}{|c|c|c|c|}
\hline & & & $\begin{array}{l}\text { determinan el peso específico } \\
\text { de cada una de las } \\
\text { componentes citadas. } \\
\text { Se preocupa más por la } \\
\text { adquisición de conceptos y por el } \\
\text { desarrollo de procedimientos y el } \\
\text { fomento de actitudes positivas } \\
\text { hacia las matemáticas, el trabajo } \\
\text { escolar en general y como } \\
\text { ciudadano. }\end{array}$ \\
\hline $\begin{array}{l}\text { Aprendizaje de } \\
\text { las Matemáticas }\end{array}$ & $\begin{array}{l}\text { El aprendizaje se realiza, } \\
\text { utilizando la memoria como } \\
\text { principal recurso, por } \\
\text { superposición de unidades de } \\
\text { información. } \\
\text { El alumno se hace con los } \\
\text { conocimientos por el simple } \\
\text { hecho de que el docente se los } \\
\text { presente y por ello se evalúa al } \\
\text { finalizar la explicación de un } \\
\text { determinado tema. }\end{array}$ & $\begin{array}{l}\text { El aprendizaje se realiza, } \\
\text { utilizando la memoria como } \\
\text { principal recurso, por } \\
\text { superposición de unidades de } \\
\text { información. } \\
\text { El alumno se hace con los } \\
\text { conocimientos por el simple hecho } \\
\text { de que el docente se los presente } \\
\text { y por ello se evalúa al finalizar la } \\
\text { explicación de un determinado } \\
\text { tema. }\end{array}$ & $\begin{array}{l}\text { Hay aprendizaje cuando el } \\
\text { objeto, que surge del contexto, } \\
\text { posee un significado para el } \\
\text { alumno; es decir, el aprendizaje } \\
\text { se produce a partir de la } \\
\text { participación activa del alumno } \\
\text { en procesos inductivos y de } \\
\text { manera espontanea } \\
\text { Se presentan en aula situaciones } \\
\text { que propician el descubrimiento. }\end{array}$ \\
\hline
\end{tabular}




\begin{tabular}{|c|c|c|c|}
\hline & & 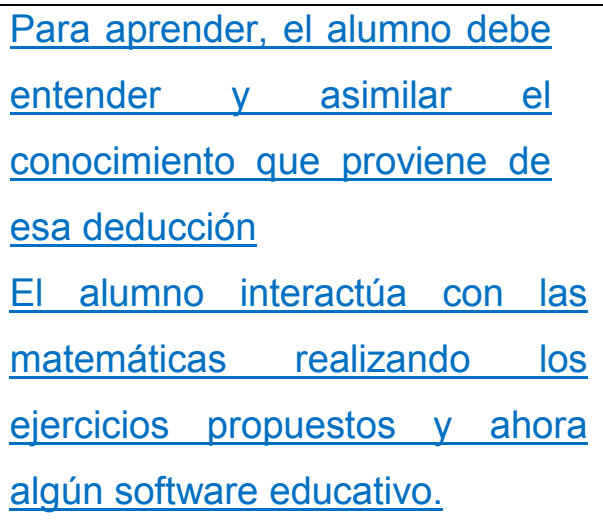 & \\
\hline $\begin{array}{l}\text { Papel del } \\
\text { alumno }\end{array}$ & $\begin{array}{l}\text { Perfilado únicamente como el } \\
\text { de aprendiz. } \\
\text { No tiene que ver con el diseño } \\
\text { de las actividades } \\
\text { programadas para el trabajo en } \\
\text { aula ni con la planeación de } \\
\text { clase ni con el diseño didáctico. }\end{array}$ & 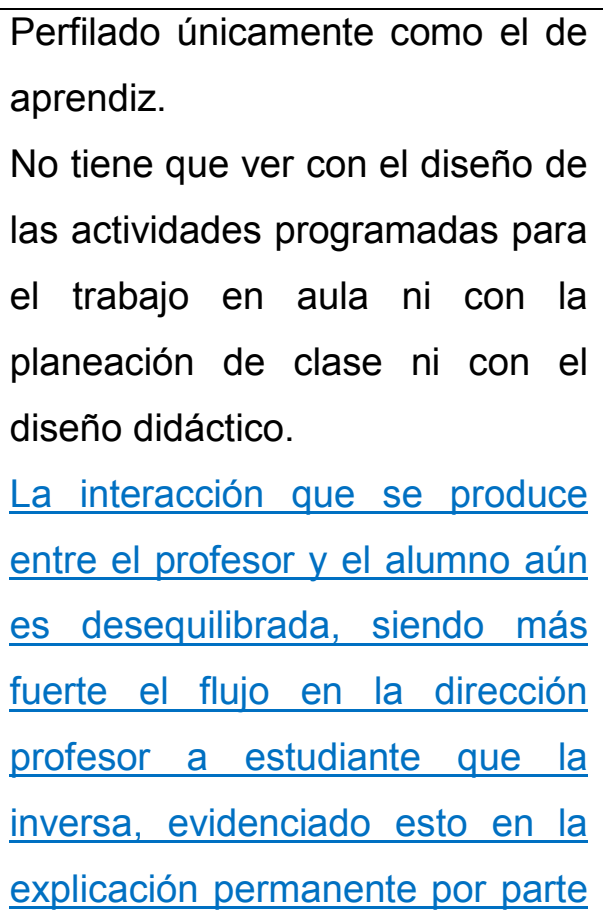 & $\begin{array}{l}\text { Hace parte indirecta de la } \\
\text { selección y secuenciación de } \\
\text { contenidos y objetivos, a través de } \\
\text { la negociación de intereses, y en } \\
\text { el diseño didáctico, a través de } \\
\text { sus intervenciones en el quehacer } \\
\text { del aula. } \\
\text { Pasa de actividad en actividad, } \\
\text { participando intensamente en } \\
\text { cada una de ellas y esto se debe } \\
\text { al ambiente dinámico que se } \\
\text { propicia en la clase. }\end{array}$ \\
\hline
\end{tabular}




\begin{tabular}{|c|c|c|c|}
\hline & & $\begin{array}{l}\text { de Lucho en cada una de las } \\
\text { actividades propuestas. }\end{array}$ & \\
\hline $\begin{array}{l}\text { Papel del } \\
\text { profesor }\end{array}$ & $\begin{array}{l}\text { Limitado al desarrollo del } \\
\text { ejercicio de trasmisión verbal } \\
\text { de los contenidos de } \\
\text { aprendizaje, mediante } \\
\text { explicación de lo reflejado en el } \\
\text { libro de texto, realizando una } \\
\text { reproducción literal de éste. } \\
\text { Actúa como un especialista en } \\
\text { el contenido, aunque es el libro } \\
\text { de texto el que valida las ideas } \\
\text { que se movilizan en el aula, } \\
\text { corrigiendo a los alumnos en } \\
\text { caso de errores y aportando él } \\
\text { mismo la información correcta. }\end{array}$ & 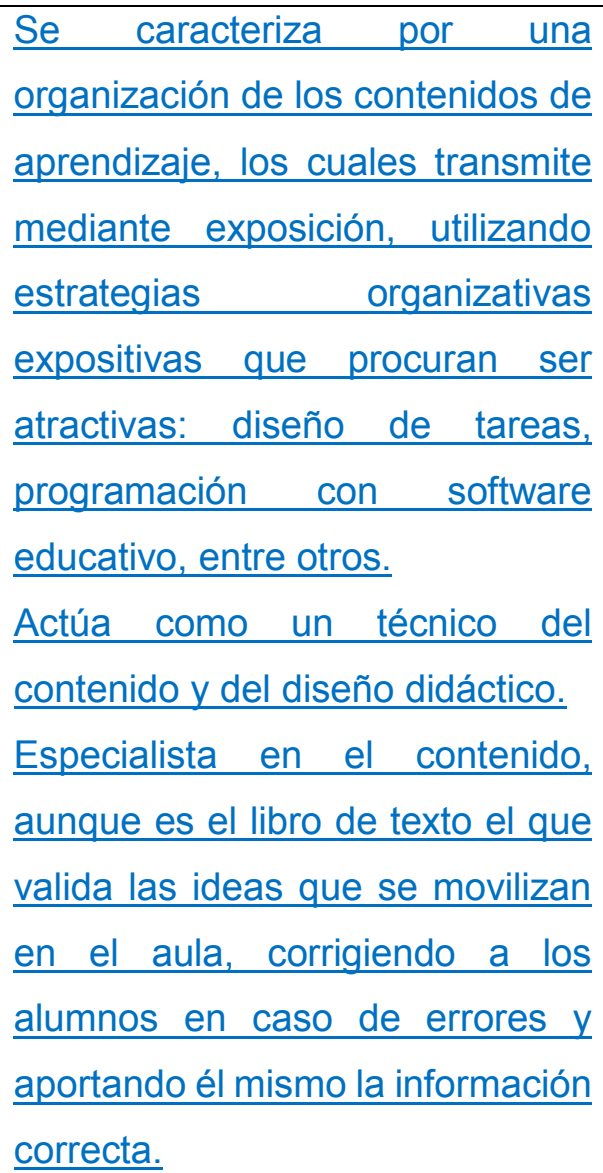 & $\begin{array}{l}\text { Humanización y la especialización } \\
\text { en la dinámica grupal. Lucho } \\
\text { ahora induce al estudiante a } \\
\text { participar en las actividades que } \\
\text { promueve, analizando las } \\
\text { reacciones y respuestas a sus } \\
\text { propuestas. }\end{array}$ \\
\hline
\end{tabular}




\subsection{Conocimiento Especializado de Lucho}

En este apartado se presentan algunos elementos de cada una de las componentes del Conocimiento Especializado de Lucho, los cuales se extraen a partir de los instrumentos de recolección y análisis de la información, complementando la información dada a lo largo de los tres bloques de observación.

\subsubsection{Conocimiento de Tema.}

En correspondencia con el marco teórico, esta componente del conocimiento especializado incluye aspectos de los conceptos que les permiten relacionarlos con contextos reales y aportar elementos epistemológicos ligados a las matemáticas que conllevan a la comprensión de diferentes significados que pueden atribuirse al contenido y los contextos en los que se sitúan. Para ello se tienen en cuenta los sistemas de representación y la fenomenología que Lucho domina en el tema ecuaciones e inecuaciones:

\subsubsection{Sistemas de Representación}

Para Lucho, las ecuaciones e inecuaciones se pueden representar:

En lenguaje analítico o simbólico, comprendido como es el sistema de representación más formal y al que más se suele recurrir ya que permite hacer todos los cálculos que se quieran a la ecuación o inecuación concreta, utilizando expresiones algebraicas [OB04.053]. Estas representaciones son empleadas por Lucho a lo largo del periodo de observación en cada una de las sesiones.

De manera gráfica. Es el método que recurre a la representación de "la forma" de las ecuaciones y el área de las inecuaciones, el cual es más visual y por tanto, más fácil de entender por los estudiantes [DP08.037]. Lucho las utiliza desde el segundo bloque de observación: 


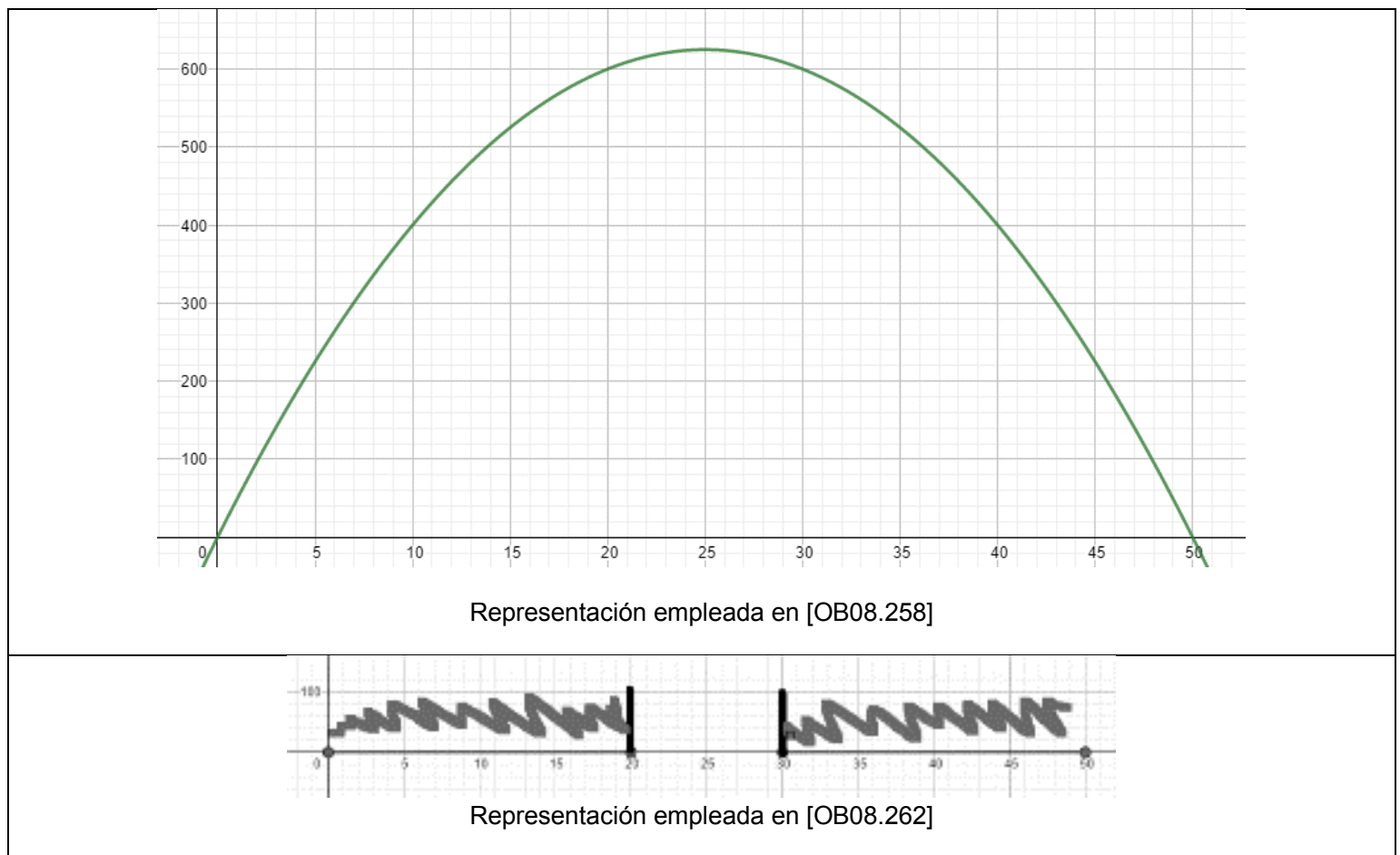

Imagen 8.29. Representación de ecuaciones e inecuaciones de manera gráfica utilizadas para la sesión 8 [OB08.258, OB08.262]

Por medio del lenguaje numérico, se representan las ecuaciones e inecuaciones mediante tablas de valores y mediante sistemas de aproximación como son Bolzano, Newton, Secante y Regula-falsi [DP13.011].

En particular, este va a ser el sistema de representación que menos usa Lucho, ya que tan sólo se refiere a él en el tercer bloque, como por ejemplo el utilizado en las sesión 14:

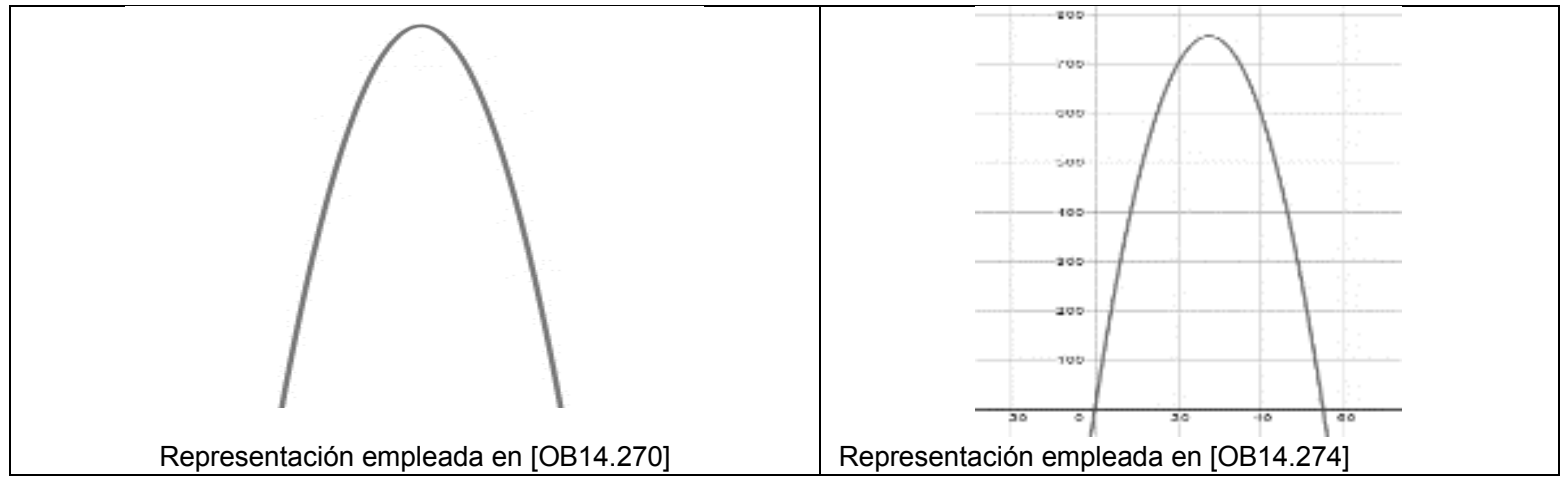




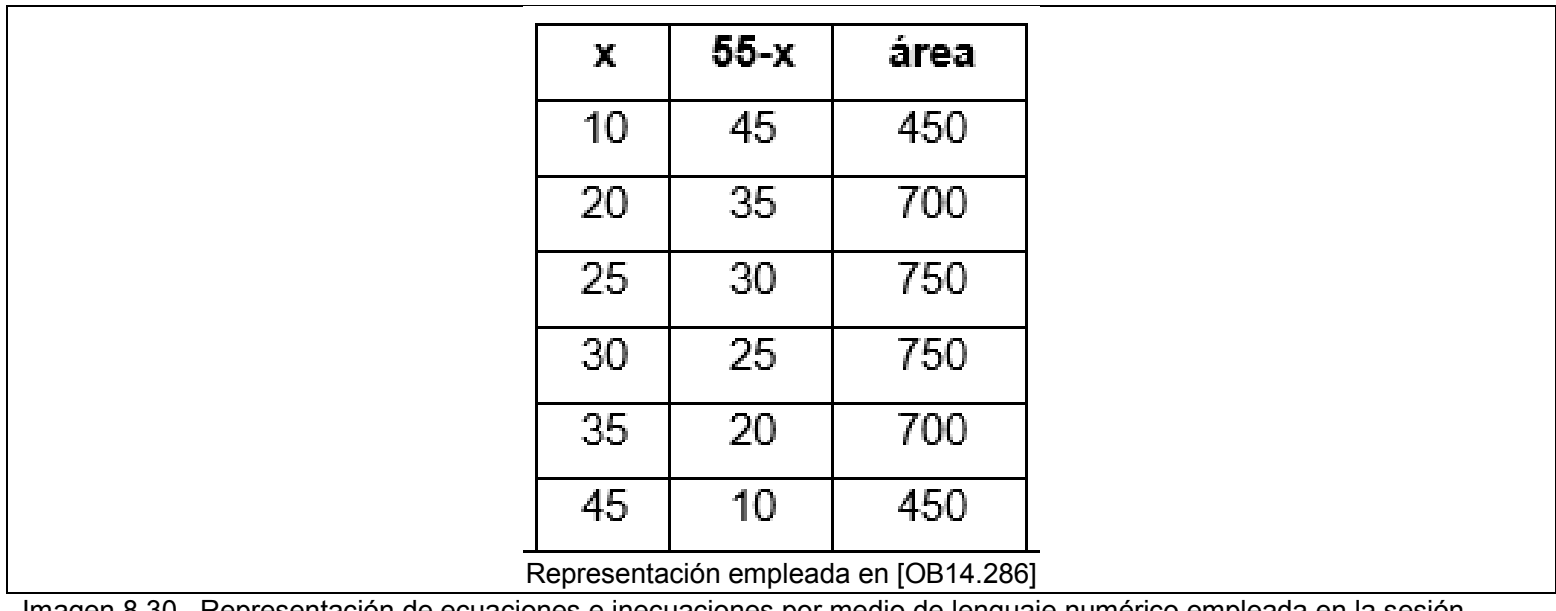

Imagen 8.30. Representación de ecuaciones e inecuaciones por medio de lenguaje numérico empleada en la sesión

14 [OB14.270, OB14.274, OB14.286]

En el tercer bloque se observa además que Lucho utiliza el sistema de representación verbal cuando se enuncia un problema o al leer una expresión simbólica; sin embargo, esta forma de representarlas no las utiliza para su resolución [OB11.004, OB12.022, OB12.025, OB12.028].

Las ecuaciones e inecuaciones son representadas por Lucho mediante las herramientas tecnológicas, representación que considera "una faceta muy importante de ellas, ya que con los diferentes softwares se puede tanto "escribirlas" como resolverlas" [EN02.230]. De entre los programas que se pueden utilizar, los applets de Descartes dan una buena aproximación en las clases de Lucho:

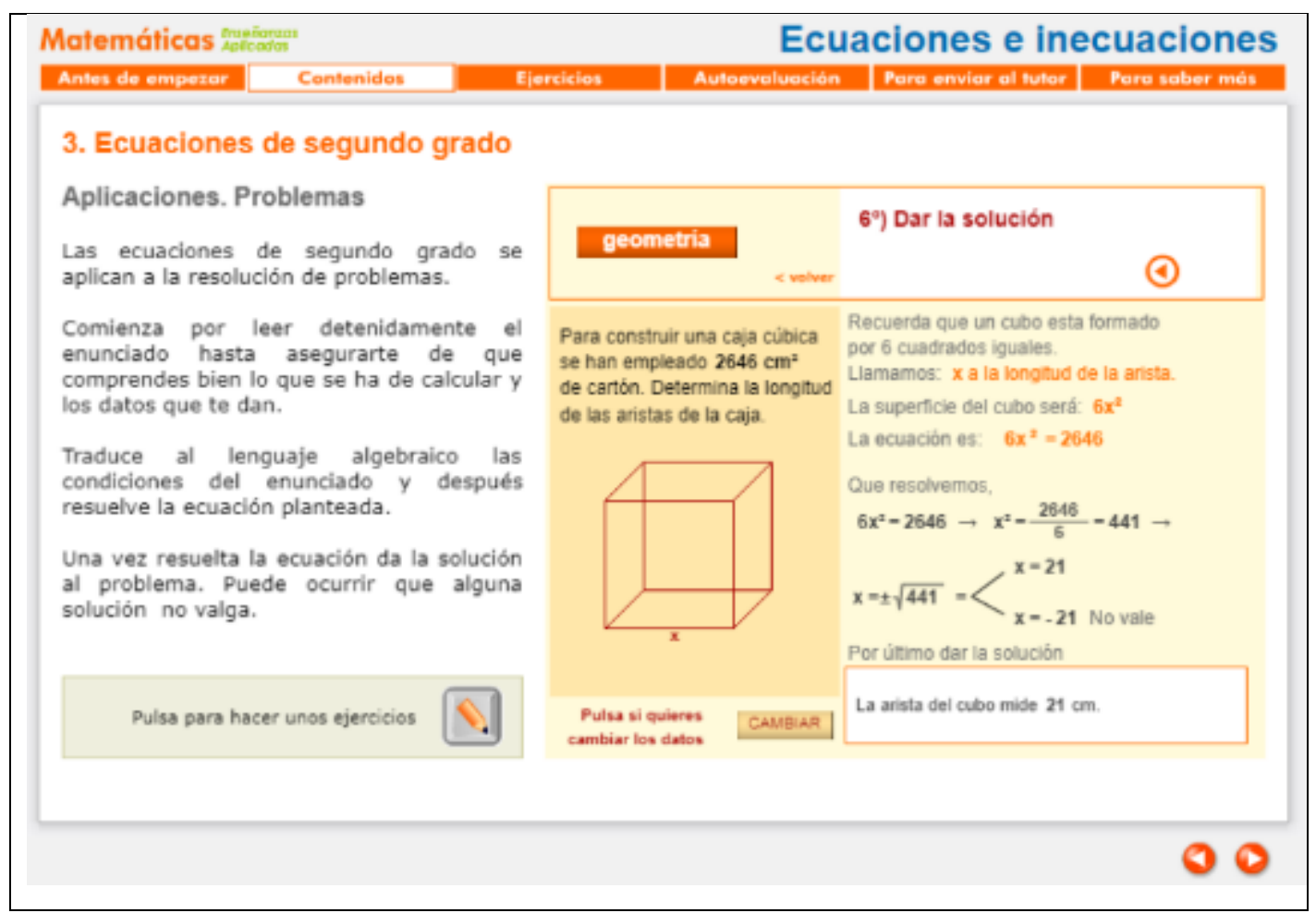




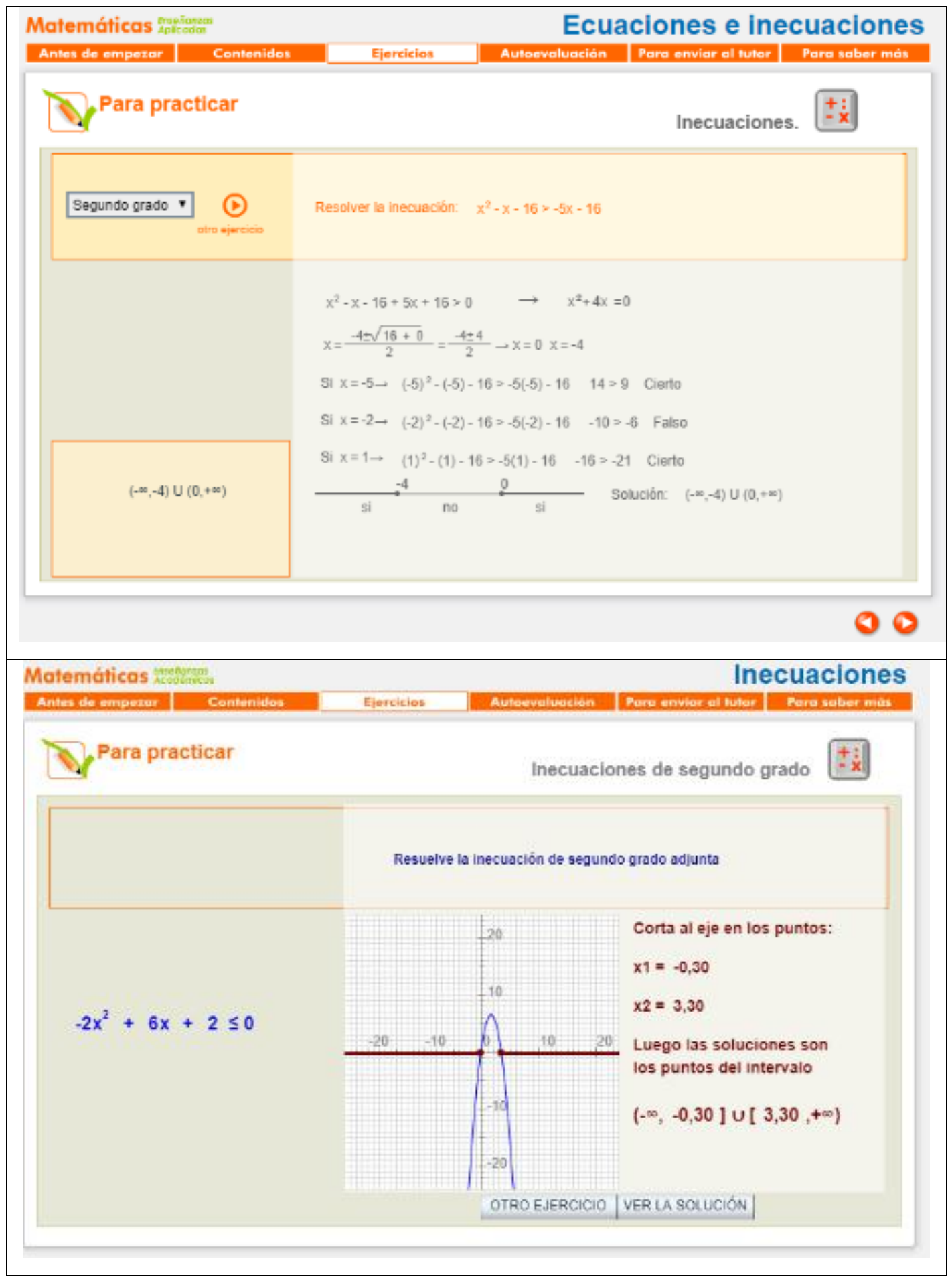

Imagen 8.31. Ecuaciones e inecuaciones representadas mediante herramientas tecnológicas, uso de la aplicación Descartes en el segundo bloque

\subsubsection{Fenomenología}

En el estudio de los fenómenos que responden al tema a tratar, Lucho distingue múltiples situaciones. Al preguntarle sobre la fenomenología, Lucho emplea una doble clasificación: "la que atiende a la naturaleza de las expresiones algebraicas que aparecen en las ecuaciones e inecuaciones (algebraicas y transcendentes)" [EN02.028] 
y la que toma como referencia la naturaleza de las magnitudes del problema, es decir, las asumidas como cantidades fijas o como cantidades variables [EN02.031].

Si se analiza la primera clasificación, empleada por Lucho a lo largo de los tres momentos de observación, y que hace referencia a la naturaleza de las expresiones algebraicas, se pueden identificar algunas situaciones a caracterizar tanto en las ecuaciones como en las inecuaciones:

Ecuaciones algebraicas: dichas ecuaciones se localizan en problemas de interpolación polinómica, problemas físicos como son los lanzamientos, los problemas gravitatorios y el movimiento, problemas numéricos como son los de edades, números consecutivos y repartos y problemas de perímetros, áreas y volúmenes. Para el caso de Lucho, las ecuaciones algebraicas se identifican durante el primer bloque de observación, pero su uso en situaciones, recién se observa en el segundo bloque [OB08, OB09, OB10], y en el tercer bloque, como por ejemplo en el problema físico que presenta en la sesión 13:

\begin{tabular}{|c|c|c|}
\hline \multirow[t]{2}{*}{ [OB13.133] } & Lucho & $\begin{array}{l}\text { Una pelota ha sido lanzada al aire a una velocidad de } \\
\text { veinticinco metros por segundo. ¿Al cabo de cuántos segundos } \\
\text { se encontrará la pelota a veinte metros de altura? Modelen el } \\
\text { problema con la ecuación }\end{array}$ \\
\hline & & $h=v t-\frac{g t^{2}}{2}$ \\
\hline
\end{tabular}

Inecuaciones: éstas se pueden encontrar en problemas de optimización de cantidades, de cálculo de edades, de contraseñas de seguridad, de volúmenes, áreas y perímetros, en problemas económicos y de sueldo variables entre otros. Lucho propone ejercicios de este tipo durante el desarrollo de los bloques I y II, pero se presentan de manera concreta en el tercer bloque, en especial en el desarrollo de la sesión 14:

Cuando dos espías amigos constrastan sus respectivas claves

OB14.205 Lucho numéricas de tres cifras, la suma de ambas ha de ser menor que mil y su diferencia mayor que quinientos

OB14.222 Lucho Un empresario paga a un vendedor un sueldo fijo de novecientos
euros al mes más sesenta centavos por producto vendido. 


\subsubsection{Conocimiento de la Estructura Matemática}

Tal como se ha descrito en el marco teórico, la estructura matemática abarca el conocimiento de las matemáticas desde la integración y la relación en estructuras amplias que pueden ir de lo local a lo universal (práctica matemática, tema, estructura matemática).

Lucho dividió el objeto matemático que aborda en las explicaciones en tres subtemas: igualdades, desigualdades y representación, los cuales están mediados por las propiedades y las operaciones de expresiones algebraicas.

Con relación a las igualdades, Lucho las distingue con las siguientes características:

Identidades: son igualdades que se verifican para cualquier valor real, entre las que se pueden englobar las igualdades notables. $x^{2}-1=(x+1)(x-1)$ [EN02.034].

Ecuaciones: expresiones en las que se busca dar solución a un valor o valores que cumplen determinadas condiciones, en las que se puede hacer una distinción atendiendo al número de incógnitas y a la naturaleza de las expresiones de sus miembros [EN02.035].

Así, Lucho diferencia entre:

Ecuaciones de primer grado: en las de una sola incógnita, la dificultad estará en el manejo de la jerarquía de las operaciones (paréntesis, denominadores, entre otros) [EN02.037].

Y en las de dos incógnitas, habrá que tener en cuenta que la solución se dará en forma de recta en el plano [EN02.038].

Ecuaciones de segundo grado: en las que se puede diferenciar entre ecuaciones completas e incompletas, teniendo en cuenta que con la fórmula general se pueden resolver los dos tipos a pesar de que las segundas tienen su método propio de resolución. En este tipo, también se tiene que considerar el estudio del número de soluciones a partir de la discriminante [EN02.042].

Ecuaciones de grado mayor que dos: dentro de esta categoría es especialmente importante la factorización, para la cual se abordará tanto el Algoritmo de Ruffini como 
el Teorema del Resto [EN02.043]. Se distinguen las ecuaciones bicuadradas, que se resolverán a través de un cambio de variable como las ecuaciones de segundo grado [EN02.045].

Ecuaciones racionales: para lo cual habrá que tener en cuenta el cálculo del mínimo común múltiplo de los denominadores [EN02.046].

Con respecto a las desigualdades, esto es, las inecuaciones, Lucho también atiende al número de incógnitas para su clasificación [EN02.047]. Él considera que para su resolución se recurren a las ecuaciones asociadas, por lo que la clasificación es la misma salvo en los tipos de soluciones que se obtienen, que será lo que se trata a continuación. Así, se localizan los siguientes tipos:

Inecuaciones con una incógnita: Referidas a las ecuaciones de primer, segundo, tercer o mayor grado y a las racionales. En estos casos, el resultado obtenido será un intervalo real que se puede expresar de manera gráfica, en forma de desigualdad o como un conjunto. Resaltar que, en el caso de inecuaciones con fracciones algebraicas, el procedimiento no se apoya tanto en la resolución de la ecuación asociada, sino que habrá que realizar la comprobación de signos del numerador y denominador [EN02.048].

Inecuaciones con dos incógnitas: donde habrá que tener en cuenta que la ecuación asociada define una curva en el plano y el tipo de desigualdad nos determinará la región solución [EN02.049].

Lucho es importante remarcar el vínculo entre las ecuaciones e inecuaciones y las funciones, ya que la representación de las funciones asociadas favorece notablemente la visualización por parte de los estudiantes de las soluciones [EN02.051].

\subsubsection{Conocimiento de la práctica matemática}

La práctica de Lucho se relaciona inicialmente con la enunciación de ejemplos y ejercicios a lo largo del primer bloque. Consecuencia de los resultados y del ejercicio de pensar sobre la práctica Lucho se sale del contexto del libro de texto como fuente única, iniciando un proceso en el que empiezan a figurar actividades tales como tareas y uso manipulativo de programas en la sesión 10. 
Al finalizar el proceso, la práctica de Lucho no se centra en el diálogo conocimiento libro de texto, sino que busca potenciar el razonamiento de los estudiantes, incluso con ejercicios que los mismos alumnos proponen.

\subsubsection{Conocimiento de las características del aprendizaje de las matemáticas}

En su quehacer profesional Lucho distingue cuatro elementos que caracterizan el aprendizaje de sus estudiantes: "dificultades, manejo deficiente de conceptos y procedimientos previos, asociaciones incorrectas y aplicación de reglas irrelevantes" [EN03.130].

Con relación a las dificultades, Lucho asegura que es posible que los estudiantes no distingan entre los distintos signos de desigualdad $(\leq, \geq,<,>)$, tengan dificultad para expresar algebraicamente un enunciado del lenguaje natural, no entiendan ni sepan leer el lenguaje matemático que se usa en la expresión, no reconozcan ecuaciones ni inecuaciones si la variable no es " $x$ " [EN01.135].

El manejo deficiente de conceptos y procedimientos previos se puede identificar a lo largo de las observaciones y en palabras de Lucho cuando "los estudiantes no cambian el símbolo de la desigualdad cuando se multiplica por un número negativo" [DP02.026], "se olvidan de comprobar las soluciones en las ecuaciones racionales" [DP08.029], "no entienden como solución un conjunto y tienen problemas al manejar expresiones infinitas tanto en intervalos como en la representación gráfica" [EN02.053].

En la entrevista final, Lucho comenta que los estudiantes realizan asociaciones incorrectas en el momento que no distinguen los intervalos solución en una inecuación, no diferencian el tipo de método de resolución de ecuaciones e inecuaciones y la dificultad para expresar un mismo conjunto solución en sus distintas formas [EN03.128].

Lucho, además comenta que los estudiantes llevan a cabo aplicación de reglas irrelevantes cuando no tienen en cuenta los denominadores en inecuaciones con fracciones algebraicas [DP14.030] y tienen confusión al interpretar la solución de un problema [DP14.031].

La principal oportunidad de aprendizaje que considera Lucho a lo largo del periodo de observación es la posibilidad de replantear de la explicación general, lo cual lo intenta a 
partir del desarrollo de las sesiones del segundo y se acerca más en el tercer bloque, logrando así potenciar estrategias para el dominio de los temas que está enseñando [EN02.238, EN03.192].

\subsubsection{Enseñanza de las matemáticas}

El conocimiento de la enseñanza de las matemáticas de Lucho durante el periodo observado está caracterizado, en sus propias palabras por dos elementos fundamentales: el uso del libro de texto y el aprovechamiento de las ideas de los estudiantes. En el acompañamiento realizado al aula de clase, se observa que el libro de texto es la herramienta principal para la enseñanza de las matemáticas durante los dos primeros bloques [OB01 a OB09] y el aprovechamiento de las ideas de los estudiantes una herramienta fundamental para la enseñanza durante el tercer bloque.

\subsubsection{Respecto del libro de texto:}

Al inicio de la observación, Lucho manifiesta que el inicio de su práctica docente la realiza adaptando propuestas concretas de libros de texto [EN01.094]. Su intervención en estos casos consiste en plantear el contenido para que los alumnos lo deduzcan y luego añadir otros objetivos y contenidos a los propuestos [EN01.095].

Para Lucho, el docente no se debe quedar en un texto [EN01.100], parece ser que inicialmente hay una contradicción entre lo que dice y lo que hace [OB01 a OB07]. Las sesiones observadas durante el desarrollo del primer bloque están apoyadas por los ejercicios de libro de texto [FD01, FD02, FD03, FD04, FD05, FD06, FD07], la caracterización de sus clases está orientada por lo que el libro de texto propone y las actividades para los estudiantes están dirigidas por lo planteado por el libro de texto [EN02.210].

En la planificación de la enseñanza de la solución de ecuaciones e inecuaciones del segundo bloque Lucho se aleja del libro de texto [OB02.217, OB02.218], pero decide usarlo al final "para reforzar lo enseñado durante cada una de estas tres sesiones de clase" [DP09.027]. Parece ser que se ha dado la oportunidad de alejarse del libro del texto y al preguntarle sobre esto, considera que esto es bueno porque tiene que revisar diferentes fuentes y se añaden otros contenidos a los de un libro de texto [DP09.028, EN02.221, EN03.167]. 
Al preguntarle sobre la ausencia del libro de texto para las actividades del tercer bloque, Lucho afirma que es un elemento que permite complementar y variar su actividad docente. Hay cosas que son buenas y otras que no vale la pena hacer [EN03.112]. El libro de texto permite que el profesor descanse un poco, pero no de cualquier forma [DE11.027], acercándose a lo que planteaba en [EN01.100] al afirmar que el docente no se debe quedar en el libro de texto.

No obstante, para Lucho, los libros de texto permiten hacer un desplazamiento en lo conceptual, en particular nombres, principios y definiciones, equilibrándose con el interés por los procedimientos [EN03.162].

Lucho no descarta el libro de texto, considera que "en el libro de texto se diseñan actividades alternativas, pero es el docente quien pone esta perspectiva" [EN03.158] y en algunos casos critica lo que propone el libro a tal manera de plantear sus propios ejemplos [DP10.036] que faciliten los procesos de aprendizaje y de enseñanza de las matemáticas.

Al final de la observación Lucho afirma que "el libro de texto sigue siendo el referente de qué enseñar respecto de un tema" [EN03.156]. Al preguntarle sobre la forma en que prepara la clase responde: elijo varios libros de texto y selecciono lo que considero le va a servir a los estudiantes sin respetar ni la secuenciación ni la temporalización que propone el libro [DP13.007, EN03.109]. El libro de texto, argumenta, "sirve como indicador de lo que marca la ley y le posibilita la coordinación obligada tanto con sus compañeros de grado como a nivel institucional y nacional" [EF03.157].

\subsubsection{Aprovechamiento de las ideas de los alumnos:}

Desde el inicio del acompañamiento, en particular la segunda sesión, se observa cómo Lucho introduce elementos en la acción a raíz de las dificultades que percibe en el aprendizaje de los alumnos [DP02.025]. Esto le lleva, a buscar ocasiones actividades alternativas o complementarias a las previstas como las propuestas en el bloque II.

Lucho está dispuesto a hacer acuerdos con los estudiantes y de mostrar unas matemáticas más activas [OB08.009], es una de las preocupaciones que tiene desde el inicio de la observación de Lucho [EN01.128] y la actividad en las últimas tres sesiones 
de clase le ha otorgado un elemento para mostrarle a los estudiantes que las matemáticas se pueden hacer más flexibles [DP14.035].

Si bien en el desarrollo de las sesiones se observaron ejercicios enlistados [OB01.149], en la segunda sesión Lucho desarrolla una propuesta en la que elabora tareas para desarrollar:

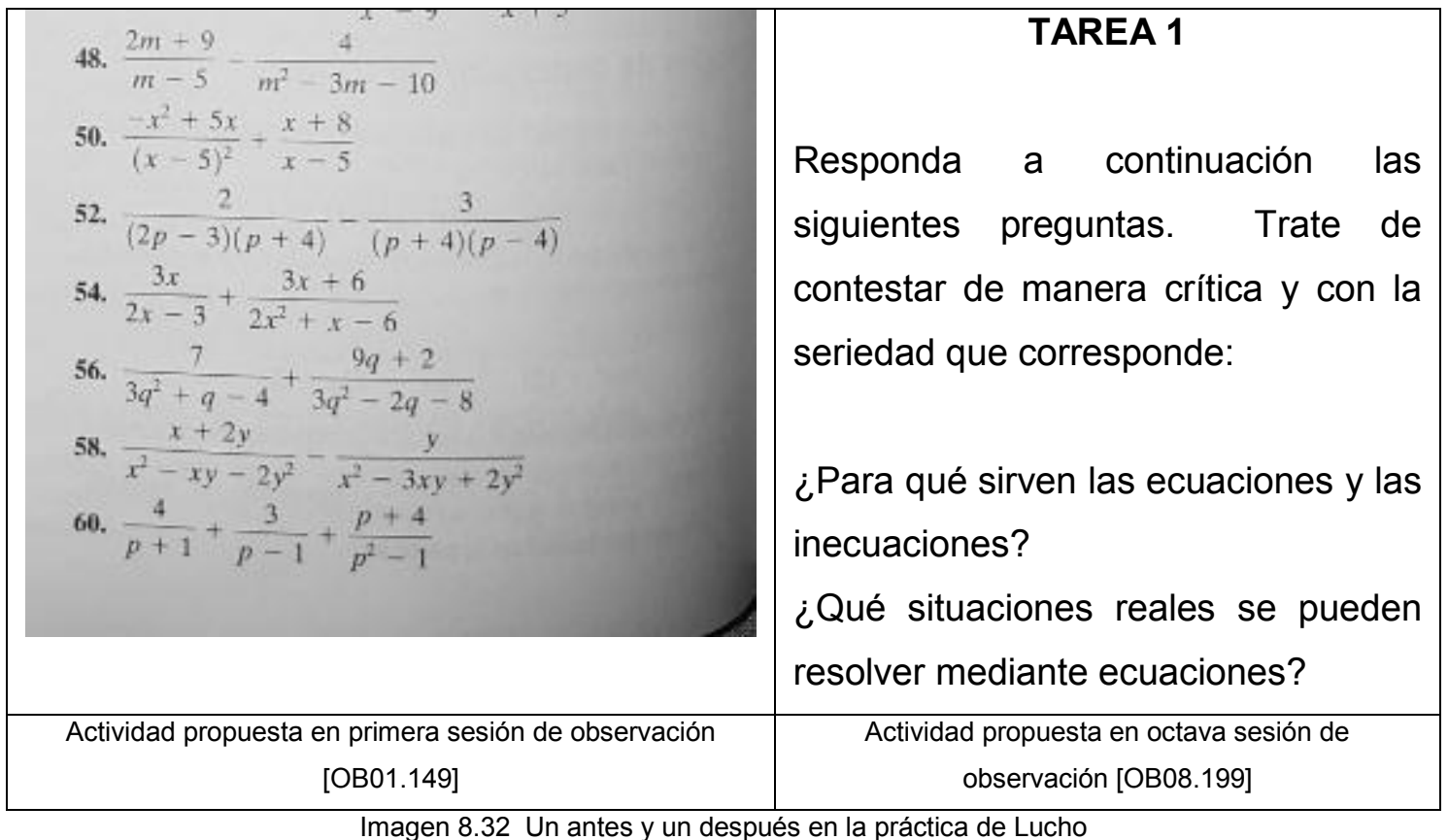

En el caso específico de la propuesta realizada, Lucho busca que sean los estudiantes quienes realicen conjeturas sobre lo que puede pasar en situaciones que involucren el uso de las ecuaciones y las inecuaciones [OB08.231, EN03.138].

\section{TAREA 2}

¿Cuál de las siguientes gráficas representa la altura de un ping pon cuando se lanza al aire con relación al tiempo transcurrido?
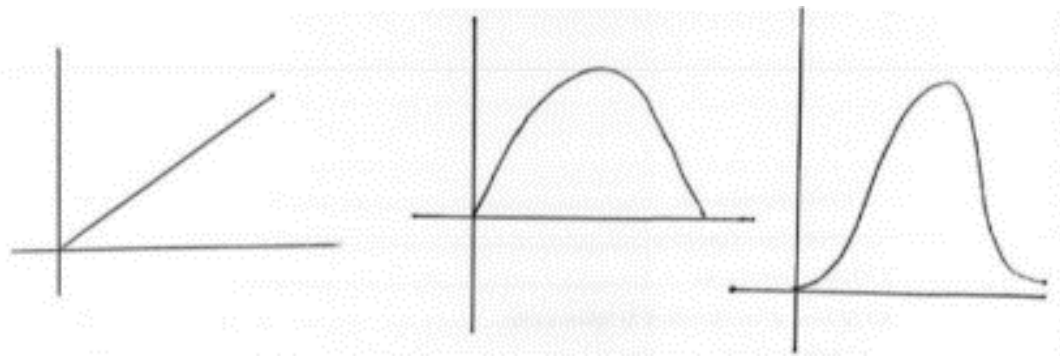

¿Cuál de las siguientes gráficas representa la altura de un ping pon cuando se lanza al piso con relación al tiempo transcurrido? 

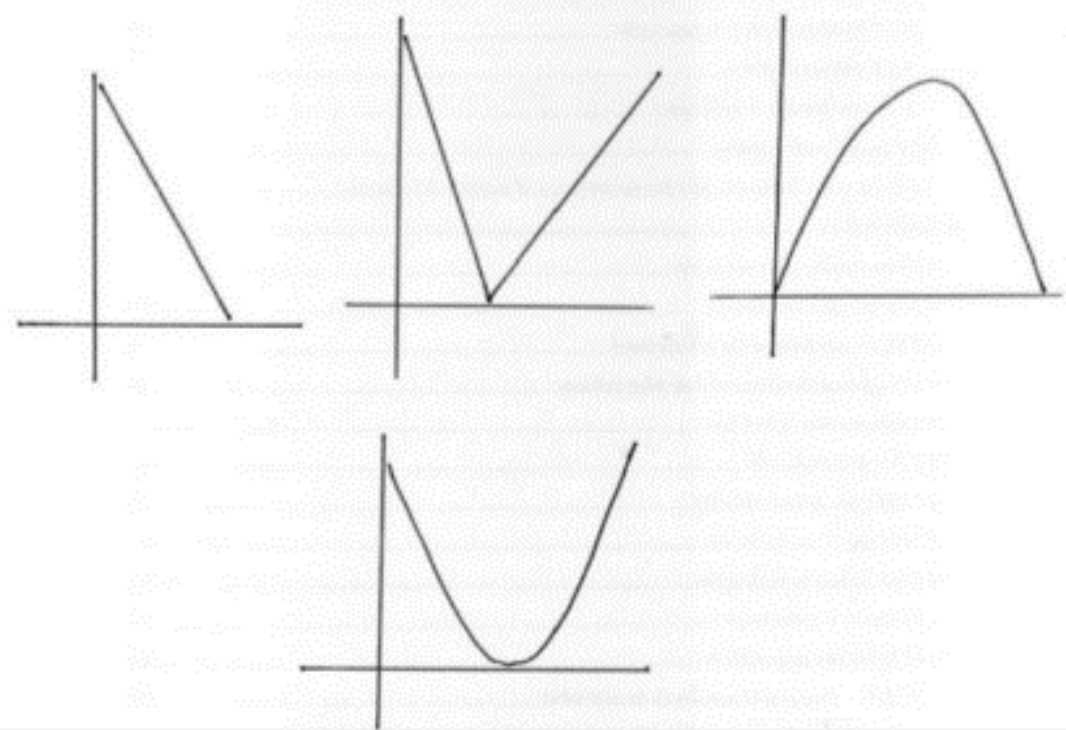

Lance el ping pon al aire y luego al piso y compare las respuestas obtenidas.

Vuelva a lanzar el ping pon al piso y con ayuda de su celular determine el tiempo del recorrido. ¿Cuánto dura el recorrido? ¿A qué altura lo lanzó? ¿En qué momento llegó al piso el ping pon?

¿Qué ocurre si se lanza el ping pon de distinta maneras? Pruébalo y discútelo con tus compañeros y tu profesor

Imagen 8.33 Actividad 2 sesión 8

Las ideas de los estudiantes son bien valoradas por Lucho, quien centra su reflexión sobre la forma como se procede [FD12.08, FD13.03]. El desarrollo de la actividad al final del proceso observado implica un número mayor de aportes de los estudiantes, permitiendo que se pueda proponer una actividad abierta a la indagación propia del estudiante [NO14.005].

\begin{tabular}{lll}
\hline \hline [OB14.017] & Lucho: & $\begin{array}{l}\text { Vamos a premiar con cinco décimas de la actividad evaluativa } \\
\text { al ganador de la siguiente actividad }\end{array}$ \\
\hline [OB14.018] & Lucho: & $\begin{array}{l}\text { Con la cuerda que les voy a entregar y sólo con la cuerda van a } \\
\text { armar un rectángulo de manera que tenga mayor área }\end{array}$ \\
\hline [OB14.019] & Lucho: & $\begin{array}{l}\text { Si un grupo puede llegar a justificar el por qué esa cantidad es } \\
\text { la mayor sin necesidad de medir tiene cinco décimas } \\
\text { adicionales }\end{array}$ \\
\hline [OB14.020] & Lucho: & Tienen quince minutos \\
\hline [OB14.021] & Lucho: & $\begin{array}{l}\text { Les pido que tengan nota del ancho, largo para tomar las } \\
\text { medidas }\end{array}$ \\
\hline \hline
\end{tabular}


Lucho considera importante la incorporación de las ideas de los alumnos, además, observa de modo más fluido el aprendizaje de los estudiantes [DP14.027], cree que permite mejor adaptación de lo previsto a lo que surge y percibe en el aula, mostrando de este modo una actuación más flexible [EN03.146].

\subsubsection{Estándares de aprendizaje de las matemáticas}

Las planeaciones de Lucho están sustentadas por el documento del área de matemáticas del Colegio, las temáticas salen de esa planeación aprobada por el equipo de área, aunque las decisiones de puesta en práctica dependen de cada docente [EN01.112, EN01.124].

Lucho comenta que para cada grado, cada docente propone una meta a cumplir durante el año escolar [EN01.117], un listado de competencias "que se corresponde con los estándares básicos del Ministerio de Educación" [EN01.118], un desempeño actitudinal que va en coherencia con lo planteado por el manual de convivencia del IPN [EN01.119] y el listado de contenidos por corte en el que "se describen los temas, las actividades por evaluar, y los desempeños" [EN01.120].

De esta manera el quehacer de Lucho en el aula se corresponde con los planteamientos institucionales (correspondencia con el documento de área), y los mínimos propuestos por el Ministerio de Educación. El apartado del documento de área con el que Lucho adapta las sesiones de clase observadas en los dos años corresponde a la gráfica que se presenta a continuación: 


\section{(ii) \\ Universidad Pedagógica Nacional \\ Instituto Pedagógic o Nacional \\ ÁREA DE MATEMÁTICAS \\ METAS, COMPETENCIAS Y DESEMPEÑOS 2016}

\begin{tabular}{|c|c|c|c|}
\hline \multirow{2}{*}{\multicolumn{2}{|c|}{$\begin{array}{l}\text { GRADO: DÉCIMO } \\
\text { DOCENTES: }\end{array}$}} & SECCIÓN: MEDIA & FECHA: ENERO 27 de 2016 \\
\hline & & ASIGNATURA: PRECÁLCULO & AREA: MATEMÁTICAS \\
\hline \multicolumn{4}{|c|}{$\begin{array}{l}\text { META ANUAL GRADO DÉCIMO: ANALIZAR Y RESOLVER SITUACIONES EN DIVERSOS CONTEXTOS, INCLUIDO EL } \\
\text { ANÁLISIS ESTADÍSTICO DE DATOS, QUE SE PUEDEN MODELAR POR MEDIO DE FUNCIONES. }\end{array}$} \\
\hline \multicolumn{4}{|c|}{\begin{tabular}{ll|l} 
NIVEL $1\left(1^{\circ}, 2^{\circ}\right.$ y & COMPETENCIAS \\
$\left.3^{\circ}\right)$
\end{tabular}} \\
\hline $\begin{array}{l}\text { PENSAMIENTO } \\
\text { NUMÉRICO }\end{array}$ & \multicolumn{3}{|c|}{$\begin{array}{l}\text { - Comparar y contrastar las propiedades de los números (naturales, enteros, racionales y reales) y las de sus relaciones } \\
\text { y operaciones para construir, manejar y utilizar apropiadamente los distintos sistemas numéricos. } \\
\text { - Establecer relaciones y diferencias entre diferentes notaciones de números reales para decidir sobre su uso en una } \\
\text { situación dada. }\end{array}$} \\
\hline $\begin{array}{l}\text { PENSAMIENTO } \\
\text { ALEATORIO } \\
\text { VARIACIONAL }\end{array}$ & \multicolumn{3}{|c|}{$\begin{array}{l}\text { - Interpretar y comparar resultados de estudios con información estadística provenientes de medios de comunicación. } \\
\text { - Diseñar experimentos aleatorios (de las ciencias fisicas, naturales o sociales) para estudiar un problema o pregunta. } \\
\text { - Resolver y plantear problemas usando conceptos básicos de conteo y probabilidad (combinaciones, permutaciones, } \\
\text { espacio muestral, muestreo aleatorio, muestreo con remplazo). }\end{array}$} \\
\hline
\end{tabular}

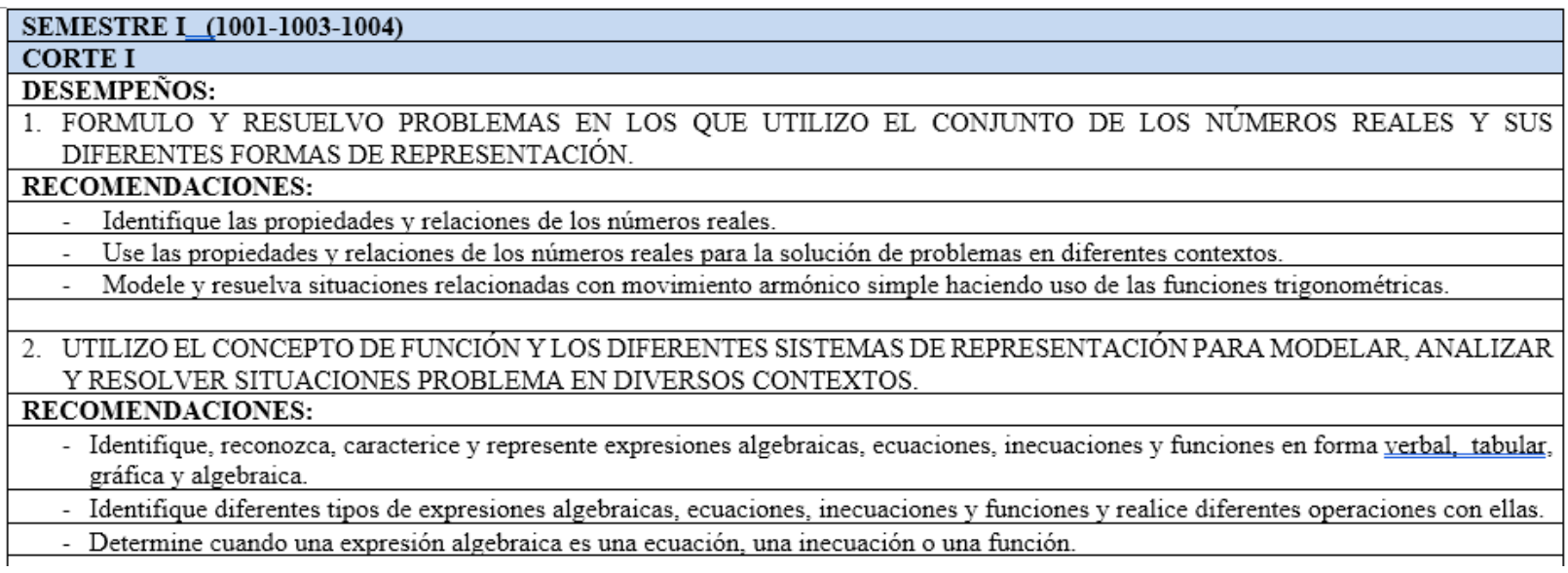

Imagen 8.34 Metas, competencias y desempeños 2016 grado décimo, área de matemáticas, primer corte, IPN

(Anexo 77)

Así, Lucho pone de manifiesto que los temas presentados a lo largo de los tres bloques de observación se corresponden a los contenidos propuestos en el documento y son organizados por el profesor.

Para finalizar este apartado se resumen las características de las componentes del conocimiento especializado que se han identificado durante el periodo de observación, descritas en todo el apartado 8.5 y en los numerales 8.1 .3 , 8.2.3 y 8.3.3:

\section{Componentes y caracterización}




\begin{tabular}{|c|c|c|}
\hline \multirow{4}{*}{ 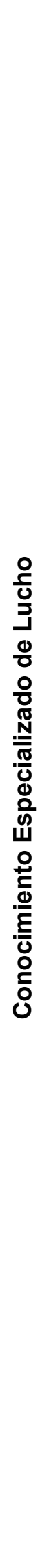 } & $\begin{array}{c}\text { Conocimiento de } \\
\text { temas }\end{array}$ & $\begin{array}{l}\text { Suma y resta de expresiones algebraicas, } \\
\text { solución de ecuaciones e inecuaciones de } \\
\text { primer grado con una variable. } \\
\text { El conocimiento del tema observado se vincula } \\
\text { principalmente a la resolución de enunciados y } \\
\text { ejercicios que son más avanzados a los que } \\
\text { propone en clase; esto es, Lucho se ha } \\
\text { preparado para resolver ejercicios a partir de las } \\
\text { teorías para la solución matemática de dichos } \\
\text { temas. }\end{array}$ \\
\hline & $\begin{array}{l}\text { Estructura } \\
\text { Matemática }\end{array}$ & $\begin{array}{l}\text { Permite dar orientaciones a los estudiantes } \\
\text { acerca de lo que pueden aprender en otros } \\
\text { contextos y en carreras universitarias. } \\
\text { Lucho manifiesta desarrollar este tipo de } \\
\text { conocimiento en cuanto a su preparación para } \\
\text { el ingreso a una carrera de especialización ya } \\
\text { que en esta requiere de una visión general para } \\
\text { la aplicación de un campo particular de las } \\
\text { matemáticas: en este caso, las relaciones de la } \\
\text { teoría de campos y grupos con las estructuras } \\
\text { algebraicas. }\end{array}$ \\
\hline & $\begin{array}{l}\text { Conocimiento de la } \\
\text { práctica }\end{array}$ & $\begin{array}{l}\text { Parece estar limitado a la enunciación de } \\
\text { ejercicios y la explicación de los mismos; esta } \\
\text { limitación puede estar determinada por dos } \\
\text { aspectos: una la falta de espacios } \\
\text { institucionales para realizar las clases de } \\
\text { matemáticas en otro espacio, otra por una } \\
\text { posible carencia de Lucho acerca de cómo } \\
\text { presentar el tema ante los estudiantes. } \\
\text { Se acerca a un conocimiento en el que el } \\
\text { razonamiento de los estudiantes sea el eje } \\
\text { principal en la interacción saber - alumno y en } \\
\text { la que el profesor cumple el papel de mediador. }\end{array}$ \\
\hline & $\begin{array}{l}\text { Características de la } \\
\text { Enseñanza de las } \\
\text { matemáticas }\end{array}$ & $\begin{array}{l}\text { A Lucho le interesa tanto la adquisición de } \\
\text { conceptos, como el desarrollo de } \\
\text { procedimientos y el fomento de actitudes }\end{array}$ \\
\hline
\end{tabular}




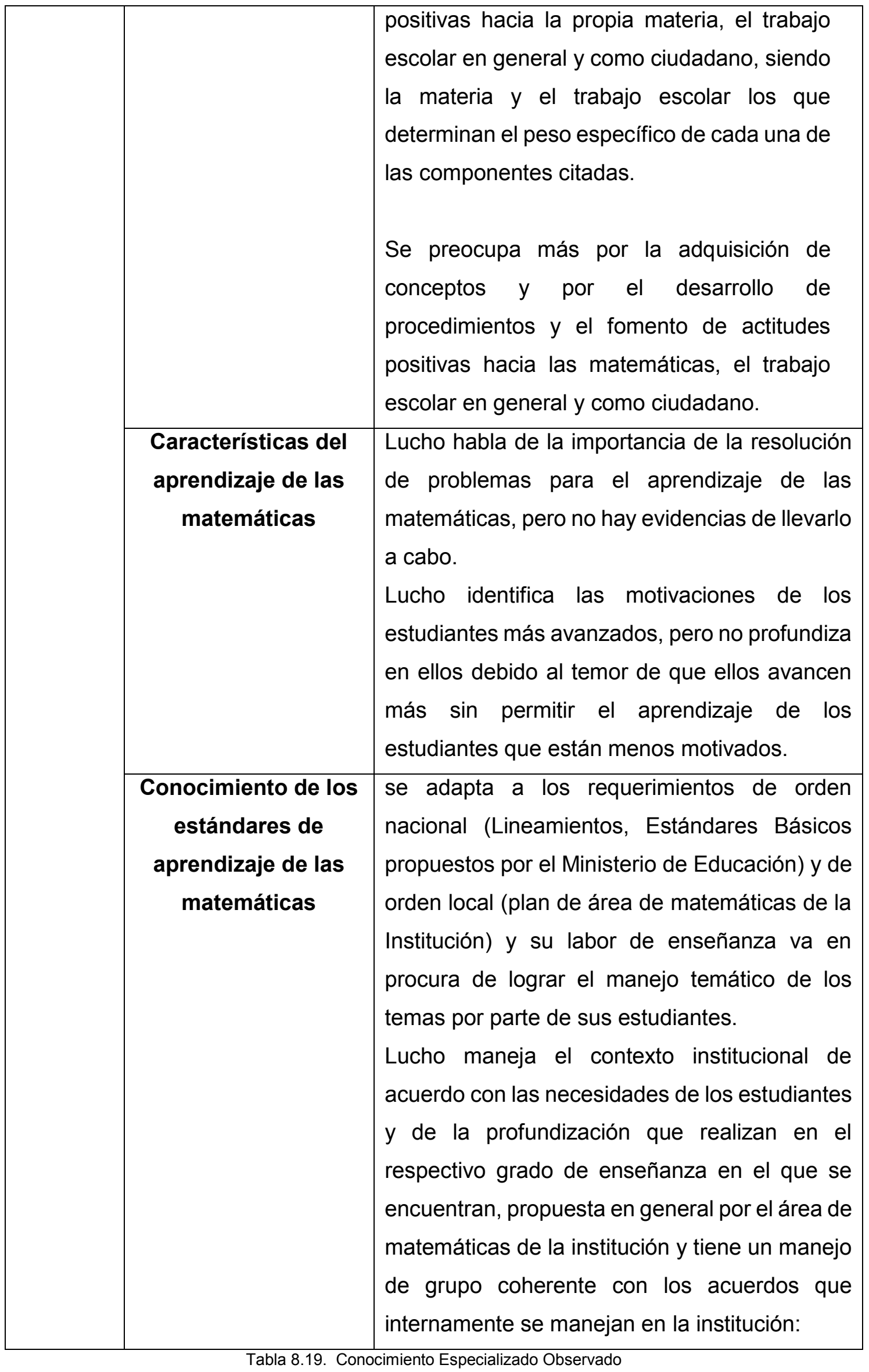




\subsection{Desarrollo Profesional de Lucho}

Este apartado tiene como propósito caracterizar el desarrollo profesional de Lucho a través de lo observado en los bloques I, II y III, en particular considerando otros aspectos que no se referenciaron en el marco teórico dado que surgen durante la práctica y nos permiten caracterizar los cambios que esta sufre.

Lucho cambia las concepciones descritas en el apartado 8.4 lo que permite trasladarlo de una tendencia didáctica tradicional a una tendencia espontaneista, manifiesta más directamente cada una de las componentes de su conocimiento especializado y parece apropiarse de su práctica.

Además, se conjugan otros aspectos que permiten caracterizar los cambios de su práctica y da cuenta de un proceso de reflexión como proceso transversal para lograr esta transformación, los cuales se comentan a continuación:

\subsubsection{Otros aspectos del Desarrollo de Lucho}

La forma como Lucho realiza la actividad en aula se modifica en por lo menos tres aspectos: en la forma en que gestiona la clase; en cómo Lucho se ve a sí mismo durante la gestión de la clase y la comparación entre cómo quiere verse y cómo se ve y, en las estrategias que utiliza frente a situaciones que se dan en el aula y que no tiene previstas.

Con relación al primer aspecto, al preguntar a los estudiantes acerca de la estructura de la clase, se obtiene lo siguiente:

\begin{tabular}{|c|c|c|}
\hline OB01.404 & Isaac & $\begin{array}{l}\text { Si pudiera describir cómo son las clases de matemáticas, qué } \\
\text { se hace en ellas, ¿tu podrías establecer un orden? }\end{array}$ \\
\hline OB01.405 & Estudiante & $\begin{array}{l}\text { Si. El profe llega, saluda, llama lista, siempre por apellidos, } \\
\text { nunca por nombre, procede a explicar los ejercicios, responde } \\
\text { preguntas y nos pone los ejercicios, responde preguntas y nos } \\
\text { pone los ejercicios para practicar. }\end{array}$ \\
\hline
\end{tabular}


Ahora va a cerrar la puerta, decir buenos días, llamar a lista,

OB05.002 Estudiante explicar los ejercicios, responder las dudas que nos salga y luego a hacer los ejercicios.

\begin{tabular}{|c|c|c|}
\hline OB10.104 & Isaac & $\begin{array}{l}\text { ¿Consideras que Lucho ha cambiado algo en su forma de hacer } \\
\text { clases? }\end{array}$ \\
\hline OB10.105 & Estudiante & $\begin{array}{l}\text { Pues si, pero sigue cerrando la puerta al iniciar la clase, ahora } \\
\text { llama lista por nombres y apellidos, explica pero no ejercicios } \\
\text { sino las guías que tenemos que desarrollar, a veces nos pone a } \\
\text { hacer ejercicios del libro para completar lo que hacemos, y nos } \\
\text { orienta en lo que queda pendiente... }\end{array}$ \\
\hline OB12.221 & Isaac & $\begin{array}{l}\text { Si pudieras describir cómo son las clases de matemáticas de } \\
\text { Lucho, qué se hace en ellas, ¿tu podrías establecer un orden? }\end{array}$ \\
\hline OB12.222 & Estudiante & $\begin{array}{l}\text { Si, el profe llega, saluda, llama lista, pero es curioso porque nos } \\
\text { pasa una hoja como en la universidad, nos da materiales o } \\
\text { guías para explorar y luego si hacemos ejercicios, los } \\
\text { vinculamos con lo que estamos estudiando y nos dice que } \\
\text { tenemos que hacer para la siguiente clase. }\end{array}$ \\
\hline
\end{tabular}

Lo anterior permite afirmar que Lucho conforma guiones para cada uno de los bloques observados; esto es, la caracterización predecible de su actuar en el aula de clase que se sintetizan en la tabla 8.20 :

\begin{tabular}{|l|l|l|l|}
\hline & \multicolumn{1}{|c|}{ Bloque I } & \multicolumn{1}{c|}{ Bloque II } & \multicolumn{1}{c|}{ Bloque III } \\
\hline Saludo & $\begin{array}{l}\text { Cierre de puertas } \\
\text { del salón y } \\
\text { saludo } \\
\text { despectivo a los } \\
\text { estudiantes }\end{array}$ & $\begin{array}{l}\text { Cierre de puertas } \\
\text { del aula de clase, } \\
\text { saludo } \\
\text { preguntando } \\
\text { cómo han estado }\end{array}$ & $\begin{array}{l}\text { Saludo } \\
\text { preguntando } \\
\text { cómo han estado, } \\
\text { cómo van en } \\
\text { otras áreas }\end{array}$ \\
\hline Llamado a Lista & $\begin{array}{l}\text { Por apellidos } \\
\text { solamente }\end{array}$ & $\begin{array}{l}\text { Por nombres y yna hoja a } \\
\text { apellidos }\end{array}$ & $\begin{array}{l}\text { En urtir de una } \\
\text { cultura de } \\
\text { autonomía del } \\
\text { estudiante. }\end{array}$ \\
\hline
\end{tabular}




\begin{tabular}{|c|c|c|c|}
\hline Punto de partida & $\begin{array}{l}\text { Explicación de } \\
\text { ejemplos del libro } \\
\text { de texto }\end{array}$ & $\begin{array}{l}\text { Exploración de } \\
\text { las guías a } \\
\text { realizar }\end{array}$ & $\begin{array}{l}\text { Indagación con } \\
\text { guías } \\
\text { conocimiento } \\
\text { previo de los } \\
\text { estudiantes }\end{array}$ \\
\hline Exploración & No se realiza & $\begin{array}{l}\text { Preguntas } \\
\text { orientadoras de } \\
\text { la guía de trabajo }\end{array}$ & $\begin{array}{l}\text { Actividades } \\
\text { propuestas en los } \\
\text { materiales } \\
\text { entregados }\end{array}$ \\
\hline $\begin{array}{l}\text { Desarrollo de } \\
\text { algoritmos, habilidades } \\
\text { y competencias }\end{array}$ & $\begin{array}{l}\text { Ejercicios del } \\
\text { libro de texto }\end{array}$ & $\begin{array}{l}\text { Ejercicios del } \\
\text { libro de texto }\end{array}$ & $\begin{array}{l}\text { Situaciones que } \\
\text { se toman de } \\
\text { diferentes } \\
\text { fuentes, entre } \\
\text { ellas, el libro de } \\
\text { texto }\end{array}$ \\
\hline Relación & No se evidencia & No se evidencia & $\begin{array}{lr}\text { Proposición } & \text { de } \\
\text { ejercicios } & \text { que } \\
\text { tienen } & \text { un } \\
\text { enunciado } & \\
\text { acercándose a } \\
\text { situaciones } \\
\text { problema }\end{array}$ \\
\hline Cierre & $\begin{array}{l}\text { Con el grupo en } \\
\text { desorden, tarea } \\
\text { para la casa }\end{array}$ & $\begin{array}{l}\text { Explicación de } \\
\text { las tareas } \\
\text { pendientes de los } \\
\text { estudiantes }\end{array}$ & $\begin{array}{l}\text { Aclaración de las } \\
\text { actividades de la } \\
\text { siguiente sesión y } \\
\text { recordatorio de } \\
\text { actividades } \\
\text { pendientes en } \\
\text { trabajo } \\
\text { autónomo. }\end{array}$ \\
\hline
\end{tabular}

Tabla 8.20. Guiones identificados a lo largo de la observación

De esta manera, se identifican esquemas que pueden predecir los acontecimientos del quehacer profesional de Lucho y su rol en el aula.

Con relación al segundo aspecto, se le ha preguntado a Lucho lo siguiente: 


\begin{tabular}{lll}
\hline \hline [EN01.131] & Lucho & Listo, luego de esa planeación, ¿Qué hace durante las clases? \\
\hline [EN01.132] Lucho & $\begin{array}{l}\text { Trato de acercarme a la resolución de problemas y para ello trato de } \\
\text { explicar primero el contenido matemático para luego proponer } \\
\text { actividades que los acerquen a estas propuestas }\end{array}$ \\
\hline \hline
\end{tabular}

\begin{tabular}{ll}
\hline \hline [DP04.029] Isaac & $\begin{array}{l}\text { En la entrevista me dijo que las clases las hacía acercándose a la } \\
\text { resolución de problemas, pero no lo veo }\end{array}$ \\
& Pero es cierto, no es así, explico el contenido matemático y me quedo \\
& ahí, hago que los estudiantes repitan ejercicios y es algo lejano, no \\
& coincide eso que digo que hago con lo que realmente quiero hacer, \\
& además los estudiantes no están ni motivados, ni aprendiendo. \\
& Debería empezar a buscar coherencia conmigo para ser coherente \\
& con ellos
\end{tabular}

Definitivamente estoy sólo haciendo explicaciones del libro de texto.

[DP07.029] Lucho Tengo que pensar en un cambio, en transformar, ya tengo una idea y quiero ver si me acerco a lo que como profesor quiero hacer de verdad

\begin{tabular}{lll}
\hline \hline [DP14.010] & Isaac & Cómo te ves ahora? \\
\hline & Me veo como un profesor que busca acercarse a situaciones \\
& problema, me falta mucho, aún estoy lejos, pero veo que mi clase ya \\
& no es tradicional, desde el llamado de lista, hasta la exploración y el \\
& desarrollo de los ejercicios. El mismo hecho que no haya una clase \\
& igual a la otra, explicación ejercitación, hace que note cambios \\
\hline \hline
\end{tabular}

Lucho manifiesta qué es lo que quiere hacer coincidiendo en algunas oportunidades y en otras no; es decir, Lucho construye una imagen de su actuar docente. No obstante, es por medio del diálogo posterior que se tiene con Lucho sobre los resultados del proceso, el cual es espejo de su accionar, que Lucho puede evidenciar si aquello que dice hacer es lo que realmente hace; por lo que requiere de herramientas para analizar los modelos de enseñanza y de aprendizaje que se esconde en su actuar.

El carácter no explícito de las imágenes conlleva a bloquear los cambios en el dominio que lo concretan y favorecen las disociaciones entre el discurso pedagógico y la práctica docente. Es entonces que la toma de conciencia de las imágenes representa parte del desarrollo profesional del profesor y estas se han tomado a partir de la escritura de las fichas de diario y el contraste de lo que ha manifestado realizar. Esta es una pauta que Lucho tiene en cuenta para transformar su práctica y el desarrollo de las sesiones que 
se evidencia del bloque I al bloque II y del bloque II al bloque III.

Finalmente, en la observación se evidencia que Lucho establece una serie de técnicas que surgen a partir del conocimiento matemático y el conocimiento didáctico del contenido matemático:

\begin{tabular}{ll}
\hline \hline [EN01.133] Isaac & $\begin{array}{l}\text { Si surge alguna situación que no espera en el desarrollo de las clases, } \\
\text { ¿cómo hace para solventarla? }\end{array}$ \\
\hline & Empleo una serie de técnicas como los llamados de atención, el \\
& manual de convivencia, los acuerdos académicos, la secuenciación, \\
& las posibles situaciones de clase. Por ejemplo, ahora mismo se que \\
& en el desarrollo de las clases llevo un orden y así voy siguiendo un \\
& camino que va en este orden: expresiones algebraicas racionales, \\
& solución de ecuaciones lineales, solución de inecuaciones lineales, \\
& solución de inecuaciones no lineales y a partir de esta secuenciación, \\
& saber qué me espera en la clase y para ello debo saber hacer los \\
& ejercicios del libro de texto, explicarlos cuando ellos los realicen y \\
& desarrollarlos previamente para luego establecer otras situaciones.
\end{tabular}

Para reorganizar qué era lo que quería reforzar tuve que hacer un [EN02.223] Lucho mapa mental que me permitió plantear la planeación de las otras sesiones, claro, ya no lo tengo porque fue un borrador

El mapa mental de la vez pasada me ayudó a la planeación de las

[EN03.113] Lucho actividades, a entender mejor las matemáticas que quería que ellos aprendieran, por lo que fue la base fundamental para el desarrollo de las sesiones.

En particular, la secuenciación, la planeación de situaciones de clase, los mapas mentales le sirven para la planificación de sus actividades:

\begin{tabular}{|c|c|c|c|}
\hline & Bloque I & Bloque II & Bloque III \\
\hline Secuenciación & $\begin{array}{l}\text { Expresiones } \\
\text { algebraicas } \\
\text { racionales }\end{array}$ & $\begin{array}{lr}\text { Situaciones } & \text { que } \\
\text { involucran } & \\
\text { ecuaciones } & \text { e } \\
\text { inecuaciones } & \\
\text { lineales } & \end{array}$ & $\begin{array}{l}\text { De los números } \\
\text { reales a las } \\
\text { expresiones } \\
\text { algebraicas }\end{array}$ \\
\hline
\end{tabular}




\begin{tabular}{|c|c|c|c|}
\hline & $\begin{array}{ll}\text { Solución } & \text { de } \\
\text { ecuaciones } & \\
\text { lineales } & \\
\text { Solución } & \text { de } \\
\text { inecuaciones } & \\
\text { lineales } & \\
\text { Solución } & \text { de } \\
\text { inecuaciones } & \text { no } \\
\text { lineales } & \end{array}$ & $\begin{array}{l}\text { Diferenciación } \\
\text { entre ecuación, } \\
\text { inecuación } \\
\text { expresión } \\
\text { algebraica }\end{array}$ & $\begin{array}{l}\text { Del lenguaje usual } \\
\text { al lenguaje } \\
\text { algebraico } \\
\text { Situaciones que } \\
\text { involucran } \\
\text { ecuaciones lineales } \\
\text { Situaciones que } \\
\text { involucran } \\
\text { inecuaciones } \\
\text { lineales }\end{array}$ \\
\hline $\begin{array}{ll}\text { Planeación } & \text { de } \\
\text { situaciones } & \text { de } \\
\text { clase } & \end{array}$ & $\begin{array}{l}\text { Saber hacer los } \\
\text { ejercicios del libro } \\
\text { de texto } \\
\text { Explicación de } \\
\text { ejercicios del libro } \\
\text { de texto } \\
\text { Desarrollo de } \\
\text { ejercicios del libro } \\
\text { de texto }\end{array}$ & 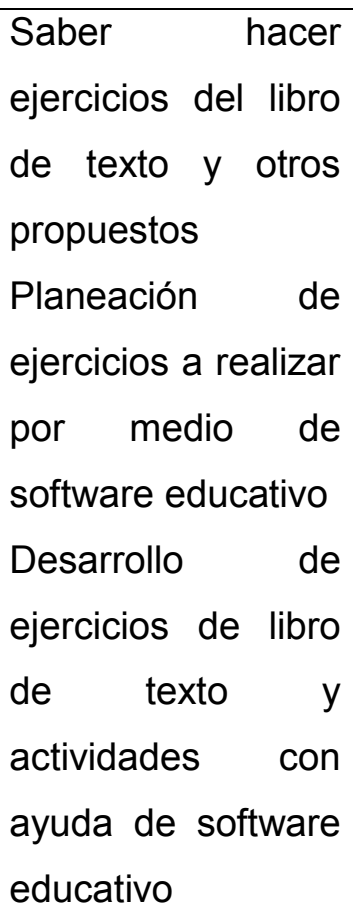 & $\begin{array}{lr}\text { Búsqueda } & \text { de } \\
\text { situaciones } & \text { que } \\
\text { involucren } & \text { la } \\
\text { secuenciación } & \text { del } \\
\text { bloque. } & \\
\text { Elaboración } & \text { y } \\
\text { adaptación } & \text { de } \\
\text { situaciones } & \text { que } \\
\text { involucran } & \\
\text { desarrollo } & \text { y } \\
\text { solución } & \text { de } \\
\text { ecuaciones } & \mathrm{e} \\
\text { inecuaciones } & \end{array}$ \\
\hline Mapas mentales & $\begin{array}{l}\text { No es realizado } \\
\text { para la planeación }\end{array}$ & $\begin{array}{l}\text { Se realizó pero no } \\
\text { se tuvo como } \\
\text { evidencia }\end{array}$ & $\begin{array}{l}\text { Fue realizado para } \\
\text { planeación de } \\
\text { actividades } \\
\text { realizar en el aula } \\
\text { de clase }\end{array}$ \\
\hline
\end{tabular}

\subsubsection{Proceso de reflexión}

Lucho establece los cambios en sus rutinas, imágenes y técnicas por medio de un proceso de reflexión general que se da de la siguiente manera: 
Al finalizar el primer bloque de observación, Lucho manifiesta que los estudiantes no tienen interés por el aprendizaje de las matemáticas [DP05.025]; no toman consciencia de lo que están aprendiendo [DP07.027]; su quehacer en el aula como profesor no es suficiente para que los estudiantes modifiquen su actitud [DP06.019] y no hace lo que quisiera hacer [DP07.028]. De acuerdo con sus propias palabras, Lucho ha "comprendido tiene una situación en el aula de clase que requiere un cambio" [DP07.031, EN03.039].

Lucho comenta que decide transformar su quehacer en el aula [CP08.018] y para ello, entre el periodo de observación del primer y segundo bloque, propone actividades [OB07, OB08, OB09] y tareas para realizar en el aula diferentes a las propuestas en las primeras siete sesiones de clase observadas [CP08.019, OB07, OB08, OB09]. La nueva planeación surge de manera voluntaria por parte del profesor [CP08.017].

En las sesiones del segundo bloque de observación (sesiones 8, 9 y 10) [OB08, OB09, OB10], Lucho pone en práctica su propuesta y la ejecuta [DP08.028, DP09.006, DP09.031, DP10.037]. En la observación se evidencian cambios en la metodología, el uso de recursos no empleados anteriormente tales como las actividades propuestas, las tareas y el uso de software educativo [OB09, OB10, DP09.006, DP09.031, DP10.037], los cuales implican cambios en el rol del estudiante, quien ya no se limita a la realización de ejercicios del libro [NO10.34, DP09.034, DP10.038] sino que utiliza otros elementos como las guías de trabajo mediadas a través de los programas de computador [DP09.035, DP10.039, EN02.230], que a la vez permite ya no la repetición de unas matemáticas escolares constituidas previamente sino la simulación de su construcción en el aula de clase [FD09.04, FD10.03], tal como se analiza y describe en el apartado 8.4. En la entrevista Intermedia Lucho comenta que ha implementado estos cambios de su práctica en otras aulas [EN02.233].

Al finalizar el segundo bloque, Lucho afirma que, si bien en el bloque II logró la movilización de los estudiantes, la motivación de ellos sigue baja [DP10.041]. Comenta que los alumnos siguen entendiendo poco [DP10.045, EN02.252] y aún no logra hacer en sus clases lo que él mismo quisiera hacer [DP10.046, EN02.253].

Terminado el año escolar y en el tiempo de preparación para el nuevo curso, Lucho afirma que ha propuesto nuevamente cambiar la estructura de la clase [CP11.017] y 
para ello diseña actividades y tareas con un enfoque distinto al de las sesiones observadas en los bloques I y II [CP11.019, NO11.028, NO12.005].

Durante el desarrollo de las observaciones del tercer bloque se observan cambios en la práctica de Lucho, en particular, la forma de explicar los contenidos [NO11.030, NO12.013], su rol en la gestión de la clase y la manera que se disponen los estudiantes para el aprendizaje de las matemáticas [FD11.03, FD11.05, FD12.03, FD12.05, FD13.03, FD13.05, FD14.04, FD14.06]. De esta manera, Lucho logra que el alumno realice las actividades y modifique su rol (tal como se describe en el apartado 8.4), participando en cada una de ellas como consecuencia del ambiente propuesto por Lucho [OB14.293]. En la entrevista final Lucho comenta que encuentra más motivados a los estudiantes, facilitando incluso, su proceso de aprendizaje [EN03.152].

Lucho comenta que la propuesta observada en el tercer bloque la llevó a los otros cursos de grado décimo [EN03.193], obteniendo resultados similares a los del curso en el que tuvo acompañamiento por parte del investigador [EN03.194]. En la entrevista final afirma:

En las reflexiones realizadas, el pensar que no quería las situaciones de las primeras clases y que las clases de la segunda parte no son lo que aún quería para que no se repitieran, considero que ahora soy más coherente con lo que quiero hacer y lo que hago en el aula, incluso he movilizado y motivado a los estudiantes y ellos ha entendido los temas y consolidado su aprendizaje, lo cual se evidencia en su proceso de comprensión [EN03.184].

En la entrevista final se le ha preguntado a Lucho si considera haber llevado a cabo un proceso de reflexión sobre su práctica y su respuesta ha sido afirmativa [EN03.175, EN03.176], explicando que la misma la ha llevado durante cuatro momentos:

i) al darme cuenta que la atención de los niños es baja, que les cuesta darse cuenta que no entienden bien los contenidos y cuando caigo en cuenta que lo que estoy haciendo no se parece a lo que quiero hacer [EN03.178],

ii) cuando propongo el cambio de estructura y diseño las actividades y tareas mientras pienso cómo transformar el quehacer en las clases [EN03.179], 
iii) cuando llevo las actividades nuevas y cambio lo que hago dentro de las clases [EN03.180], $y$

iv) reiterar el ejercicio anterior en otras aulas para así revisar lo realizado con el fin de repensar y replantear lo diseñado y realizado [EN03.181].

Lo anterior se puede contrastar con la respuesta a las preguntas ¿Qué pasó con la práctica de Lucho del Bloque I al Bloque II? y ¿Qué pasó con la práctica de Lucho del Bloque II al Bloque III? que se responden con las propias afirmaciones descritas en párrafos anteriores y que se sintetizan en la tabla 8.22:

\begin{tabular}{|c|c|c|c|}
\hline \multicolumn{4}{|c|}{ ¿Qué pasó del Bloque I al Bloque II? } \\
\hline Fase i & Fase ii & Fase iii & Fase iv \\
\hline $\begin{array}{l}\text { Lucho afirma que } \\
\text { se dio cuenta que } \\
\text { sus estudiantes no } \\
\text { están aprendiendo, } \\
\text { no tienen } \\
\text { motivación para las } \\
\text { matemáticas y sus } \\
\text { clases } \\
\text { demasiado } \\
\text { monótonas y no } \\
\text { hace lo que dice } \\
\text { que quiere hacer y } \\
\text { requiere con } \\
\text { urgencia un cambio } \\
\text { para transformar } \\
\text { esa situación. }\end{array}$ & $\begin{array}{l}\text { Para solucionar lo } \\
\text { anterior, Lucho se } \\
\text { propone cambiar la } \\
\text { estructura de la } \\
\text { clase, para ello } \\
\text { comenta que ha } \\
\text { propuesto } \\
\text { actividades y } \\
\text { tareas distintas } \\
\text { para realizar en el } \\
\text { aula. }\end{array}$ & $\begin{array}{l}\text { Lucho ejecuta esa } \\
\text { propuesta y en la } \\
\text { observación se } \\
\text { notan algunos } \\
\text { cambios en la } \\
\text { metolodogía, el uso } \\
\text { de recursos (por } \\
\text { ejemplo } \\
\text { mediación } \\
\text { software } \\
\text { educativo), el papel } \\
\text { del estudiante y la } \\
\text { noción de las } \\
\text { matemáticas } \\
\text { escolares. }\end{array}$ & $\begin{array}{l}\text { Afirma que pone en } \\
\text { marcha dichos } \\
\text { cambios no solo en } \\
\text { el aula que está } \\
\text { siendo observada } \\
\text { sino en los otros } \\
\text { grupos del grado } \\
\text { décimo del IPN. }\end{array}$ \\
\hline \multicolumn{4}{|c|}{ ¿Qué pasó del Bloque I al Bloque II? } \\
\hline Fase i & Fase ii & Fase iii & Fase iv \\
\hline $\begin{array}{l}\text { Lucho se dio } \\
\text { cuenta } \\
\text { movilizó la atención } \\
\text { de los niños, pero, }\end{array}$ & 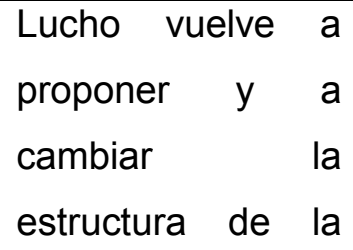 & $\begin{array}{l}\text { Lleva al aula las } \\
\text { nuevas actividades } \\
\text { y tareas cambiando } \\
\text { la forma de hacer }\end{array}$ & $\begin{array}{l}\text { Aplica en otras } \\
\text { aulas la propuesta y } \\
\text { retroalimenta su } \\
\text { quehacer en ellas }\end{array}$ \\
\hline
\end{tabular}




\begin{tabular}{|c|c|c|c|}
\hline $\begin{array}{l}\text { según afirma, su } \\
\text { motivación sigue } \\
\text { baja, } \\
\text { comprensión no es } \\
\text { la adecuada y aún } \\
\text { no hace en aula lo } \\
\text { que realmente dice } \\
\text { que quiere hacer. }\end{array}$ & $\begin{array}{lr}\text { clase. } & \text { Diseña } \\
\text { actividades } & \text { y } \\
\text { tareas } & \text { que } \\
\text { considera } & \text { son } \\
\text { distintas a las } \\
\text { propuestas en las } \\
\text { diez sesiones del } \\
\text { bloque II. }\end{array}$ & $\begin{array}{l}\text { las clases en } \\
\text { aspectos como la } \\
\text { metodología, la } \\
\text { utilización de } \\
\text { recursos, el rol del } \\
\text { estudiante. }\end{array}$ & $\begin{array}{l}\text { para analizar } \\
\text { nuevamente su } \\
\text { práctica y las } \\
\text { preocupaciones } \\
\text { que le han llevado a } \\
\text { proponer una } \\
\text { transformación de } \\
\text { la misma. }\end{array}$ \\
\hline
\end{tabular}




\section{CUARTA PARTE: APORTES Y CONCLUSIONES}

Se comentan los aportes y conclusiones que surgieron a partir del análisis de la práctica de Lucho, la forma en la que se da cumplimiento a los objetivos principales, las limitaciones y las perspectivas de investigación.

\section{CONCLUSIONES: DEL DESARROLLO DE UN PROFESOR AL APORTE A LA TEORÍA}

Luego de presentar, en el capítulo 8, los resultados organizados desde las transcripciones de cada uno de los instrumentos de recolección de información en contraste con los instrumentos de análisis, surgió el interrogante ¿la práctica de Lucho puede aportar a los modelos teóricos empleados con los que se realizó el análisis? ¿de qué manera?

En búsqueda de varias respuestas a ese cuestionamiento, acordes con el estudio realizado y los objetivos planteados, se conformaron varias preguntas acerca de la práctica de Lucho con tres finalidades:

- Describir la práctica de Lucho en términos de la teoría empleada, explicar el desarrollo profesional a partir de sus concepciones y conocimiento especializado y caracterizar la forma en que Lucho piensa y reflexiona en, sobre y para su práctica.

- Validar el modelo planteado y dar cuenta de la forma en la que se llevaron a cabo las acciones enunciadas en el apartado 5.2 para lograr los objetivos principales y dar respuesta a la pregunta de investigación.

- Caracterizar las fuentes de la investigación y la evidencia del trabajo de campo que permiten aportar al modelo empleado otras dimensiones para el análisis de la práctica del profesor.

A continuación, se enuncian y se contestan once preguntas que sintetizan la discusión de resultados, conclusiones y aportes del estudio, y permiten cerrar el ciclo de la investigación: 


\subsection{Al iniciar la observación, ¿hay coherencia entre lo que el profesor dice y lo que el profesor hace?}

El primer acercamiento al profesor ocurre en la entrevista inicial, en ella Lucho se describe como un docente que manifiesta:

i) querer acercar a los estudiantes a las matemáticas a través de estrategias didácticas que rompan con las ideas tradicionales de su enseñanza,

ii) querer hacer de sus clases un espacio en el que exista motivación, por medio de su gestión en el aula, para el aprendizaje de las matemáticas

iii) querer enseñar las matemáticas de una forma que sea entretenida para los estudiantes y para ello se encuentra en una constante búsqueda que le permita a los estudiantes un aprendizaje que motive y los acerque acerque a esta área del conocimiento.

El segundo acercamiento se da en la observación de la práctica de Lucho. Durante el primer bloque de observación hay una tensión entre lo que dice querer hacer y lo que realmente hace: en las fichas de diario y en las declaraciones posteriores él mismo evidencia que su gestión en el aula no logra ser de interés para los estudiantes y nota que ellos no están motivados y supone que tampoco están desarrollando un proceso de aprendizaje.

A lo largo de la observación del primer bloque es posible comparar lo que el profesor cree y lo que hace de la siguiente manera:

\begin{tabular}{|lr|l|l|}
\hline & \multicolumn{1}{|c|}{ Lo que Lucho cree } & \multicolumn{1}{c|}{ Lo que Lucho hace } \\
\hline $\begin{array}{l}\text { ¿Qué conocimiento es } \\
\text { relevante? }\end{array}$ & $\begin{array}{l}\text { Expresiones algebraicas y } \\
\text { la solución de ecuaciones } \\
\text { e inecuaciones lineales }\end{array}$ & $\begin{array}{l}\text { Expresiones algebraicas y } \\
\text { la solución de ecuaciones } \\
\text { e inecuaciones lineales }\end{array}$ \\
\hline $\begin{array}{l}\text { ¿Qué rutinas de } \\
\text { enseñanza } \\
\text { apropiadas? }\end{array}$ & $\begin{array}{l}\text { Aquellas que permitan } \\
\text { motivar al aprendizaje de } \\
\text { las matemáticas mediante } \\
\text { la comprensión de los }\end{array}$ & $\begin{array}{l}\text { Explicación de algunos } \\
\text { ejemplos del libro de texto } \\
\text { Preguntas por parte de los } \\
\text { estudiantes }\end{array}$ \\
\hline
\end{tabular}




\begin{tabular}{|c|c|c|}
\hline & $\begin{array}{l}\text { temas y los algoritmos a } \\
\text { realizar }\end{array}$ & $\begin{array}{l}\text { Realización de ejercicios } \\
\text { del libro de texto por parte } \\
\text { de los estudiantes }\end{array}$ \\
\hline $\begin{array}{l}\text { ¿Qué objetivos deben } \\
\text { lograrse? }\end{array}$ & $\begin{array}{l}\text { Enseñar expresiones } \\
\text { algebraicas y la solución } \\
\text { de ecuaciones e } \\
\text { inecuaciones lineales y } \\
\text { que estas tengan un } \\
\text { sentido en el estudiante } \\
\text { que le permita acercarse al } \\
\text { aprendizaje entendiendo } \\
\text { cómo se solucionan y para } \\
\text { qué se solucionan. }\end{array}$ & $\begin{array}{l}\text { Dar herramientas a los } \\
\text { estudiantes para que sean } \\
\text { capaces de resolver } \\
\text { expresiones algebraicas y } \\
\text { solucionar ecuaciones e } \\
\text { inecuaciones lineales a } \\
\text { partir de la presentación de } \\
\text { ejercicios tipo }\end{array}$ \\
\hline $\begin{array}{l}\text { Características } \\
\text { importantes en el contexto }\end{array}$ & $\begin{array}{l}\text { Gestión en el aula que } \\
\text { facilite la movilización de } \\
\text { los estudiantes. }\end{array}$ & $\begin{array}{l}\text { Los estudiantes no están } \\
\text { comprendiendo y no están } \\
\text { motivados por aprender } \\
\text { matemáticas }\end{array}$ \\
\hline
\end{tabular}

La tabla 9.01, muestra elementos tales como las rutinas de enseñanza, los objetivos que deben lograrse y características importantes en el contexto están en tensión porque no hay correspondencia entre lo que el profesor dice y lo que el profesor hace. No hay certeza si Lucho es consciente de estas inconsistencias en momentos anteriores a la observación, pero a lo largo del primer bloque las pudo poner de manifiesto a través de las fichas de diario, las charlas previas y las declaraciones posteriores.

Durante las últimas sesiones del primer bloque Lucho pone de manifiesto la necesidad de cambiar aspectos de su práctica y de su gestión en el aula a fin de lograr mayor motivación y aprendizaje por parte de los estudiantes. Al preguntarle si las fichas de diario, las charlas previas y las declaraciones posteriores le permitieron darse cuenta de la tensión entre lo que dice y lo que hace, dice creer que sí porque pudo visualizar su quehacer desde otra perspectiva. 


\section{2. ¿Cuál es la visión del profesor de matemáticas sobre sus necesidades respecto de la enseñanza de matemáticas en el cuarto año de secundaria?}

La visión de Lucho acerca de sus necesidades respecto la enseñanza de las matemáticas está centrada en promover el aprendizaje de las matemáticas a través de la motivación y la movilización de los estudiantes: Lucho se interesa en los procesos de aprendizaje de los estudiantes y como consecuencia de ese interés, piensa y diseña tareas y actividades orientadas a que ellos sean el centro de la actividad en el aula.

Al finalizar el primer bloque se puede interpretar que Lucho no está conforme con los resultados de aprendizaje que tiene, no solo con el curso observado sino con los estudiantes de grado décimo en general; se puede afirmar que, Lucho ha pensado que debe plantear acciones para motivar a los estudiantes para el aprendizaje de las matemáticas, hecho que se ve reflejado por la propuesta que elabora y lleva a la práctica durante el segundo bloque y posteriormente durante el tercer bloque.

Lucho decide que en vez de avanzar en contenidos debe promover el aprendizaje de las temáticas hasta ahora abarcadas, intentando motivar y movilizar a los estudiantes. Concibe la cultura escolar más allá de los conocimientos matemáticos, le interesa movilizar las actitudes de los estudiantes a partir de la motivación hacia las matemáticas: su conocimiento especializado y sus concepciones son su propio marco global de referencia (Porlán, Martín del Pozo, Rivero, Harres, Azcaráte \& Camara, 2010).

\section{3. ¿Piensa sobre su práctica? ¿Cómo lo hace?}

Desde la entrevista inicial, Lucho se muestra como un profesor que piensa sobre su práctica; no se tiene evidencia si este ejercicio es explícito, pero sí que quiere entablar una relación con los estudiantes de tal forma que las matemáticas escolares sean más cercanas en cuanto a comprensión y utilidad para ellos.

En el primer bloque se nota un panorama de contradicción: durante el desarrollo de las sesiones su práctica se caracteriza principalmente por los rasgos de la tendencia tradicional cuando anteriormente Lucho mencionó un quehacer docente cercano del desarrollo de la resolución de problemas.

Las charlas previas, las declaraciones posteriores y las fichas de diario le conceden a Lucho la oportunidad de generarse preguntas acerca de su práctica. La reiteración del 
uso de estos instrumentos durante el primer bloque implica la aparición de enunciados que permiten interpretar que Lucho está pensando sobre su práctica y se está acercando a un proceso explícito de reflexión. A partir de la interacción en los diálogos previos y posteriores a las sesiones y a la propuesta de mejora que escribe en las fichas de diario se obtiene que, a medida que avanza el proceso de observación y acompañamiento Lucho se pregunta acerca de cómo acercar a los estudiantes hacia una comprensión de las matemáticas.

Algunas ideas que permiten entender durante el primer bloque que Lucho ha pensado sobre su práctica son:

- Las dificultades que los estudiantes tienen referidas a la comprensión del tema, los ejercicios del libro, la explicación realizada.

- Diferencias con relación a lo que esperaba de los estudiantes y lo que ellos han hecho.

- Necesidad de plantear distintas metodologías para el diseño de la evaluación porque los estudiantes no llegaron a los resultados esperados.

- Elaboración y planificación de actividades que sean más dinámicas con relación a lo propuesto en las clases anteriores

- Inquietud de los estudiantes frente a su proceso de enseñanza, lo que implica que hay que buscar elementos que los movilicen más.

- Búsqueda de elementos para que los estudiantes superen dificultades con relación a las definiciones, niveles de abstracción y características fundamentales e impredecibles.

- Búsqueda de alternativas para sacar a los estudiantes de la dificultad de los alumnos hacia lo particular y la solución sin generalizar

- Los estudiantes no se están movilizando, por tanto, la metodología empleada no es adecuada para el desarrollo de las actividades propuestas. 
Como resultado de la explicitación de las ideas anteriores, surge una ruptura en la práctica de Lucho, la cual incide en el desarrollo de las clases con el grupo observado y las rutinas adoptadas en el aula de clase tienen un cambio que permiten al investigador identificar un posible cambio de conducta en el quehacer profesional de Lucho.

En el segundo bloque, los enunciados que permiten interpretar que Lucho piensa sobre su práctica no corresponden necesariamente a preguntas realizadas por el investigador. Si bien se mantienen las charlas previas, las declaraciones posteriores y la elaboración de las fichas de diario, hay menos rigidez en las respuestas y el diálogo fluye no necesariamente por la pregunta del investigador.

Lucho hace explícita la comprensión acerca de elementos de la clase que no están acordes a sus intereses como docente, considera menester la movilización de los estudiantes hacia contenidos que sean funcionales, para ello, él mismo considera que:

- Es necesario presentar a los estudiantes estrategias alternativas para el aprendizaje de las matemáticas.

- La valoración por parte del alumno de sus aprendizajes y experiencias debe ser un objetivo de aprendizaje.

- Es importante cuestionar a los estudiantes acerca de lo que están haciendo en su actividad grupal e individual.

- La participación responsable en los procesos de enseñanza y aprendizaje es fundamental para el acercamiento de los estudiantes con las matemáticas escolares

Entonces, como consecuencia del ejercicio ya constante de pensar sobre la práctica Lucho reflexiona en y sobre su práctica: la analiza, valora desde su propia perspectiva sus ventajas y limitaciones y se focaliza en el aprendizaje de sus estudiantes, valorando cuáles son las dificultades que encuentran los alumnos (en relación con el modo de trabajo y con los contenidos concretos) y cuál es el grado de dificultad de la propia actividad, cuál es el papel del alumno y su motivación; para ello:

- Expresa las ideas matemáticas haciendo uso de lenguaje, signos y símbolos matemáticos para que los estudiantes aprendan 
- Considera que es importante estar pensando continuamente en cómo realizar adecuadamente el ejercicio de la enseñanza y tener en cuenta las construcciones de los estudiantes.

- Identifica las características correspondientes a la solución de ecuaciones e inecuaciones y cualquier objeto matemático a través de situaciones que involucren a los estudiantes

- Antepone lo actitudinal y lo procedimental sin olvidar los conceptos

- Desarrolla la capacidad para imaginar mentalmente la situación descrita por los estudiantes

- Expresa y justifica la opinión propia y critica (constructivamente) las de los estudiantes

- Toma decisiones razonables, que estén justificadas a partir del constante ejercicio de autoreflexión

Durante la observación, Lucho, inicialmente pensó sobre su práctica y posteriormente reflexionó en, desde y para ella cuando utilizó las fichas de diario, respondió las preguntas de la charla previa y las declaraciones posteriores, y, por medio de ellas se dio cuenta que no había correspondencia entre lo que decía y lo que hacía, para lo cual, se focalizó en tres acciones concretas:

- pensar acerca de la enseñanza: cuando se cuestionó acerca de la metodología que empleaba y se preguntaba si con ella los estudiantes estaban o no aprendiendo.

- pensar cómo aprenden los alumnos: Lucho reconoció los conceptos que son capaces (y que no son capaces) de utilizar los estudiantes y la motivación por el acercamiento de las matemáticas, los cuales perfiló en el segundo y tercer bloque. 
- disposición hacia la acción y la necesidad de salir de rutinas establecidas implícitamente: cuando propuso actividades que tienen el fin de acercar a los estudiantes hacia el aprendizaje de las matemáticas, por ejemplo, las tareas observadas en el segundo y tercer bloque.

\section{4. ¿Manifiesta cambios en su práctica profesional? ¿Cómo lo hace? ¿A qué pueden atribuirse esos cambios?}

En la respuesta anterior, se afirmó que Lucho pasó de pensar sobre su práctica al inicio de la observación a reflexionar en, sobre y para la práctica; esto se corresponde con la problematización de su gestión en aula y la búsqueda de elementos que permitan generar cambios en las actitudes de los estudiantes que los movilice hacia el aprendizaje de las matemáticas, haciendo de su práctica una actividad en la que hay una mayor correspondencia entre lo que dice y lo que hace.

Los aspectos que Lucho modificó, incidieron directamente en la forma en la que gestiona la clase, en particular, la metodología y la forma como entiende que los estudiantes aprenden matemáticas, el cual se relaciona con la evaluación, y se describen a continuación:

\section{Cambios en la Metodología}

El principal cambio que se observa en la práctica de Lucho ocurre cuando modifica el proceso de enseñanza, caracterizado durante el primer bloque por la dupla explicación - desarrollo, para acercarse a una metodología con una perspectiva espontaneista a través del acercamiento a situaciones para la enseñanza de las matemáticas que se observa en los bloques II y III.

La metodología del primer bloque se caracterizó por la repetición de ejercicios tipo y la explicación de manera constante por la presentación de ejemplos y ejercicios que son propios del libro de texto. En el segundo bloque, Lucho utilizó materiales manipulativos y software educativo y expuso los contenidos ya no en su fase final, facilitando la simulación de construcción. Si bien, en este bloque promovió la repetición de ejercicios tipo, estos ya no fueron el centro de sus explicaciones.

En el tercer bloque, Lucho puso en marcha otros recursos que en los dos bloques anteriores no utilizaba: tareas dentro de las sesiones, el trabajo en grupo con un sentido 
de construcción del conocimiento, proponiendo actividades que sustituyen los ejercicios del libro de texto y la simulación de construcción de conocimientos que los estudiantes aún no poseen.

\section{Cambios en la Evaluación}

Durante el primer bloque, Lucho centra la evaluación en calificar, para medir la consecución de los objetivos prefijados, verificando los procesos de aprendizaje mediante la ejecución de pruebas escritas. En el segundo bloque, Lucho aún emplea la evaluación con el propósito de que los estudiantes reproduzcan ejercitaciones sobre los contenidos practicados y el desarrollo de algoritmos, aunque se interesa más por los procedimientos que los estudiantes hacen.

En el tercer bloque la evaluación es realizada a partir de las motivaciones e intereses de los estudiantes, Lucho pregunta a los estudiantes acerca de los avances personales, grupales y estrategias realizadas y se observa coherencia entre las declaraciones sobre la evaluación y lo que ahora hace.

A partir de los cambios observados principalmente en la metodología y la evaluación, se interpreta que durante el primer bloque Lucho identificó los elementos con los cuales no estaba conforme en su práctica y posteriormente, implementó planificaciones durante el segundo y tercer bloque para incentivar el acercamiento de los estudiantes hacia las matemáticas, a través de:

- Organización de la secuenciación temática para el grado de acuerdo con los saberes e intereses de los estudiantes y no por el orden del libro de texto.

- Explicitación de relaciones que se pueden establecer acerca de las matemáticas dentro de la práctica cotidiana a partir de ejemplificaciones y búsqueda de la respuesta a la pregunta para qué sirven las matemáticas que se presentan en las actividades de los últimos dos bloques.

- Diseño de estrategias para la explicación del desarrollo de situaciones matemáticas en aula a través de tareas y situaciones diferentes a las propuestas por el libro de texto que se vuelven más comunes en el aula. 
- Modificación de la forma cotidiana en el ejercicio de la enseñanza de las matemáticas, acudiendo a recursos y medios que no empleaba antes.

- Diferentes planificaciones, actividades y secuenciaciones de acuerdo con la edad, necesidad y contexto de los estudiantes, además del nivel de profundidad de las matemáticas de acuerdo con aspectos institucionales.

- Organización temática y de la clase basada en competencias de acuerdo con los estándares institucionales, internacionales y gubernamentales evidenciados en las planificaciones.

Los cambios en la práctica permiten a Lucho validar argumentos y soluciones en las situaciones que ha problematizado y a la vez, verificar que lo que dice coincide en mayor medida con lo que hace.

\section{5. ¿Con qué asocia las modificaciones de su práctica? ¿Establece para ellos relaciones de causa-efecto? ¿Es este un proceso personal o colaborativo? ¿Por qué?}

Lucho asocia las modificaciones de su práctica con la reflexión, la cual surge cuando se da cuenta, a partir de las interacciones con el investigador, que lo que ha dicho no se corresponde con lo que está haciendo y plantea acciones concretas que se evidencian a lo largo de su gestión durante los bloques II y III. Resultado de dichas acciones surgen nuevas planificaciones, actividades, tareas, metodología y evaluación.

La búsqueda y construcción de elementos que permitan la motivación y la movilización de los estudiantes hacia el aprendizaje de las matemáticas, en particular, las expresiones algebraicas, las ecuaciones y las inecuaciones inicia a mediados de la observación del primer bloque; aunque Lucho decide seguir con las actividades planificadas inicialmente, empieza a tomar fuerza la idea de un cambio el cual se consolida a medida que evidencia que los resultados de los aprendizajes de los estudiantes no son los esperados por él; de esta manera, son causa de las modificaciones de su práctica el significado de las matemáticas escolares, el aprendizaje de las matemáticas, el papel del alumno y el papel del profesor:

Matemáticas escolares: En el primer bloque, las matemáticas escolares se caracterizan como un conjunto de conceptos y reglas que los estudiantes no 
comprenden, lo cual no se corresponde con el desarrollo de competencias matemáticas, el desarrollo de competencias ciudadanas y el desarrollo del ser humano que Lucho considera, tanto en la entrevista inicial como en la entrevista final, son pertinentes en la formación de los alumnos.

Aprendizaje de las matemáticas: Lucho interpreta el aprendizaje como una construcción social a partir de la comprensión y el descubrimiento, hecho que se contradice a lo largo del primer bloque en el que el insumo principal es la memoria, la repetición y la mecanización de ejercicios tipo.

Papel del estudiante: Lucho piensa que el estudiante debería ser el centro del aprendizaje; no obstante, durante el primer bloque el estudiante repite las actividades propuestas y no interviene en el diseño de las actividades, la planificación de la clase o el diseño didáctico; la interacción que se produce entre el profesor y el alumno es desequilibrada, siendo más fuerte el flujo en la dirección profesor a estudiante que la inversa, como consecuencia de la explicación permanente por parte de Lucho en cada una de las actividades propuestas.

Papel del profesor: Limitado al desarrollo del ejercicio de trasmisión verbal de los contenidos de aprendizaje, en el que la actividad predominante es la explicación de ejemplos del libro de texto; Lucho actúa como un mediador entre el conocimiento y lo que dice el libro de texto, atento a revisar los errores de los estudiantes y constatarlos con el libro de texto; cuando en realidad espera ser el mediador y organizador de los aprendizajes de los alumnos.

Las modificaciones de la práctica de Lucho son un proceso personal y se pueden entender como consecuencia de la toma de consciencia de cuando pensó sobre ella y la comprendió (Climent, 2005; Llinares \& Krainer, 2006). Si bien el ejercicio docente observado se ha realizado teniendo en cuenta las indicaciones curriculares y los acuerdos del equipo docente de matemáticas del Instituto Pedagógico Nacional, las reflexiones de Lucho no han sido compartidas con el equipo de área.

Las modificaciones de la práctica también han sido un proceso colaborativo en coherencia con el modelo de Bednarz \& Jean-Luc (2015) en cuanto las reflexiones han surgido como consecuencia del diálogo con el investigador y no como una imposición resultante de dicha interacción, haciendo del diseño y la aplicación de la planificación 
de la gestión en aula de los bloques II y III; una construcción pedagógica y didáctica sustentada únicamente en el conocimiento especializado de Lucho.

\section{6. ¿Qué aspectos de la práctica pueden asociarse a las componentes del conocimiento especializado? ¿Por qué?}

La práctica de Lucho se ha caracterizado por tres elementos: la manera en que gestiona la clase, las estrategias que utiliza frente a situaciones que se dan en el aula y la forma como se ve a sí mismo durante la gestión.

La respuesta a la pregunta planteada en este apartado se abordará en los primeros dos elementos ya que la forma en que Lucho se ve a sí mismo se relaciona en mayor medida con sus concepciones.

La manera en la que gestiona la clase se resumió en la tabla 8.09 del apartado 8.6.1, la cual se presenta nuevamente y describe los aspectos más significativos de la práctica de Lucho observados durante los tres bloques:

\begin{tabular}{|c|c|c|c|}
\hline & Bloque I & Bloque II & Bloque III \\
\hline Saludo & $\begin{array}{l}\text { Cierre de puertas } \\
\text { del salón y saludo } \\
\text { despectivo a los } \\
\text { estudiantes }\end{array}$ & $\begin{array}{l}\text { Cierre de puertas } \\
\text { del aula de clase, } \\
\text { saludo } \\
\text { preguntando cómo } \\
\text { han estado }\end{array}$ & $\begin{array}{l}\text { Saludo preguntando } \\
\text { cómo han estado, } \\
\text { cómo van en otras } \\
\text { áreas }\end{array}$ \\
\hline Llam & $\begin{array}{l}\text { Por apellidos } \\
\text { solamente }\end{array}$ & $\begin{array}{l}\text { Por nombres y } \\
\text { apellidos }\end{array}$ & $\begin{array}{l}\text { En una hoja a partir de } \\
\text { una cultura de } \\
\text { autonomía del } \\
\text { estudiante. }\end{array}$ \\
\hline Pun & $\begin{array}{l}\text { Explicación de } \\
\text { ejemplos del libro } \\
\text { de texto }\end{array}$ & $\begin{array}{l}\text { Exploración de las } \\
\text { guías a realizar }\end{array}$ & $\begin{array}{l}\text { Indagación con guías y } \\
\text { conocimiento previo de } \\
\text { los estudiantes }\end{array}$ \\
\hline Exploración & No se & $\begin{array}{l}\text { Preguntas } \\
\text { orientadoras de la } \\
\text { guía de trabajo }\end{array}$ & $\begin{array}{l}\text { Actividades } \\
\text { propuestas en los } \\
\text { materiales entregados }\end{array}$ \\
\hline $\begin{array}{l}\text { Desarrollo de } \\
\text { algoritmos, }\end{array}$ & $\begin{array}{l}\text { Ejercicios del libro } \\
\text { de texto }\end{array}$ & $\begin{array}{l}\text { Ejercicios del libro } \\
\text { de texto }\end{array}$ & $\begin{array}{l}\text { Situaciones } \text { que se } \\
\text { toman de diferentes }\end{array}$ \\
\hline
\end{tabular}




\begin{tabular}{|c|c|c|c|}
\hline $\begin{array}{l}\text { habilidades y } \\
\text { competencias }\end{array}$ & & & $\begin{array}{l}\text { fuentes, entre ellas, el } \\
\text { libro de texto }\end{array}$ \\
\hline Relación & No se evidencia & No se evidencia & $\begin{array}{l}\text { Proposición de } \\
\text { ejercicios que tienen } \\
\text { un enunciado } \\
\text { acercándose a } \\
\text { situaciones problema }\end{array}$ \\
\hline Cierre & $\begin{array}{l}\text { Con el grupo en } \\
\text { desorden, tarea } \\
\text { para la casa }\end{array}$ & $\begin{array}{l}\text { Explicación de las } \\
\text { tareas pendientes } \\
\text { de los estudiantes }\end{array}$ & $\begin{array}{lr}\text { Aclaración de las } \\
\text { actividades de la } \\
\text { siguiente sesión y } \\
\text { recordatorio } \\
\text { actividades pendientes } \\
\text { en trabajo autónomo }\end{array}$ \\
\hline
\end{tabular}

Tabla 9.02. Guiones identificados a lo largo de la observación de la práctica de Lucho. Elaboración: propia

El saludo, si bien se corresponde a un conocimiento general de cualquier persona se puede interpretar que se vincula en el segundo y tercer bloque con el conocimiento de las características del aprendizaje de las matemáticas en cuanto es posible identificar expectativas de aprendizaje, dificultades, estado de motivación de los estudiantes.

El llamado a lista, que evidencia la asistencia a la clase, puede ser interpretado como un requerimiento institucional, pero con el avance de la observación es posible relacionarlo con el conocimiento de los estudiantes que Lucho lleva a cabo. En la entrevista final, Lucho comenta que ha detectado que la asistencia de algunos estudiantes tiene que ver con lo que se está haciendo en el aula, el tipo de tareas y de actividades que se realizan, afirma que la deserción a las clases de los estudiantes que participaron en la observación del bloque I y II disminuyó y cree que se debe al tipo de actividades que planteó posteriormente, actividades que se fueron alejando a la realización de ejercicios del libro de texto. De esta manera, el llamado a lista incide en el tipo de actividades y recursos que se caracterizan en el conocimiento de la enseñanza de las matemáticas.

El punto de partida, caracterizado en el primer bloque por la explicación de ejemplos del libro de texto en el bloque I, la exploración de las guías a realizar en el bloque II y la indagación con guías y conocimiento previo de los estudiantes en el bloque III se relaciona directamente con las vías, recursos y formas de enseñar matemáticas, las cuales permiten identificar aspectos del conocimiento de la enseñanza de las 
matemáticas de Lucho en cuanto allí propone lo que se va a realizar en el aula, lo cual se correlaciona con el conocimiento de los estándares de aprendizaje de las matemáticas en cuanto lo que Lucho propone en sus planificaciones se vincula con el plan de estudios institucional que hace de referente estandarizado (Muñoz-Catalán, Contreras, Carrillo, Rojas, Motes y Climent, 2015, Climent \& Vasco, 2018).

La exploración, llevada a cabo en el bloque II a través de las preguntas orientadoras de las guías de trabajo y en el bloque III en las actividades propuestas en los materiales entregados a los estudiantes se vincula con el conocimiento de tema en cuanto Lucho sabe de las propiedades que se necesitan para establecer las definiciones de expresión algebraica, ecuación e inecuación que le permitan relacionarlo con otros contextos; el conocimiento de la enseñanza de las matemáticas como estrategia personal para acercar a los estudiantes a los objetos matemáticos estudiado y el conocimiento de las características del aprendizaje de las matemáticas en las formas de interacción entre el tema y la forma en que los estudiantes inicialmente.

El desarrollo de algoritmos, habilidades y competencias que en bloque I y II corresponde al desarrollo de ejercicios del libro de texto y en el bloque III a situaciones que se toman de diferentes fuentes que buscan institucionalizar el conocimiento, se relaciona por su propia génesis con el conocimiento de la enseñanza de las matemáticas, el conocimiento de las características de aprendizaje de las matemáticas y el conocimiento de estándares de aprendizaje de las matemáticas.

La relación, que figura en el bloque III como la proposición de ejercicios que se acercan a situaciones problema, muestra que, a lo largo de la práctica, Lucho recurre a su conocimiento de la Estructura de las Matemáticas para acercar a los alumnos a relaciones entre conceptos avanzados y conceptos elementales, y al conocimiento de las Prácticas Matemáticas para apoyar a los estudiantes en el conocimiento de cómo razonar al establecer expresiones algebraicas, ecuaciones e inecuaciones.

El cierre, que en el primer bloque se caracterizó por el grupo en desorden y la indicación verbal de la tarea, pasó a ser una actividad organizada de aclaración de actividades de las sesiones próximas y actividades pendientes de trabajo autónomo en el bloque III es también un reflejo de cómo los estudiantes aprenden de acuerdo con la edad y el nivel educativo que se encuentran, hecho que ubica esta acción en el conocimiento de las características del aprendizaje de las matemáticas. 
Las relaciones descritas entre la gestión en aula y el Conocimiento Especializado de Lucho se resumen en el siguiente gráfico:

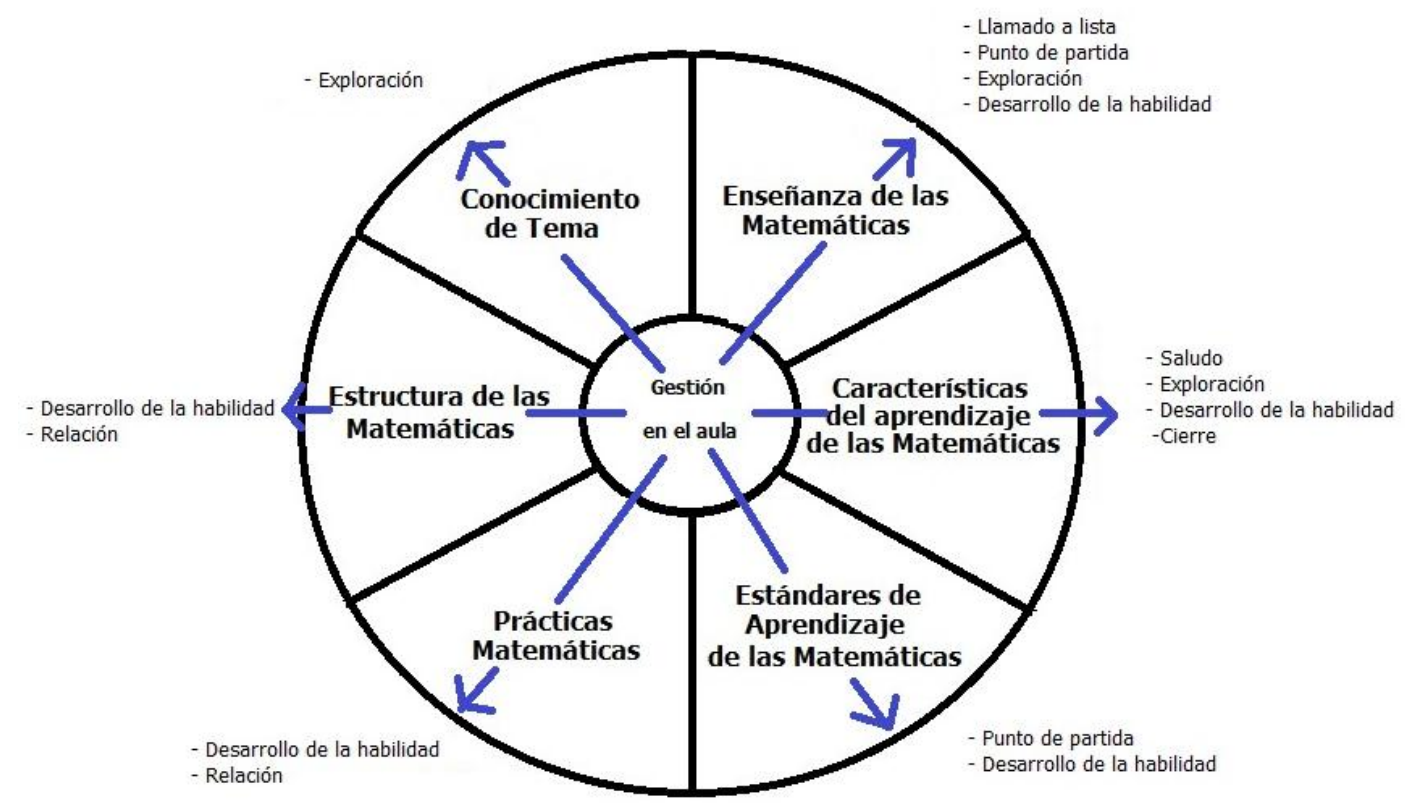

Figura 9.01. Aspectos de la práctica: gestión de la práctica y su relación con el conocimiento especializado de Lucho. Fuente: propia

Otro aspecto de la práctica es el conjunto de estrategias que utiliza frente a situaciones que se dan en el aula; en los siguientes párrafos se describe la relación de las mismas con el conocimiento especializado de Lucho.

El tema principal que Lucho desarrolla en el aula durante los tres bloques es el planteamiento y resolución de expresiones algebraicas, ecuaciones e inecuaciones. Lucho ha manifestado tener conocimiento acerca de las relaciones de este tema con las propiedades de las operaciones en el conjunto de los números reales, en particular la propiedad distributiva de la adición con respecto a la multiplicación que está directamente relacionada con la factorización, el cual pone de manifiesto en el primer bloque.

También, respecto al conocimiento de tema, pone de manifiesto el uso y aplicación de las propiedades de la igualdad y de la desigualdad en las actividades planteadas para el bloque II y III. Complementa su conocimiento con las relaciones del contenido con los sistemas algebraicos, la teoría de cuerpos, la teoría de campos, el análisis matemático, el álgebra en general, entre otras, las cuales comenta con algunos estudiantes y el investigador en algunos momentos de los bloques II y III. 
Lucho puede comprender este tema de las matemáticas escolares desde un punto de vista superior no solo en el contenido sino en la percepción de su organización. Lo puede interpretar como un sistema integrado de conexiones que le permita comprender y desarrollar conceptos avanzados desde perspectivas elementales y conceptos elementales mediante el tratamiento de visiones avanzadas, y por tanto el mismo, hace parte del conocimiento de la estructura matemática en coherencia con la propuesta de Muñoz-Catalán, Contreras, Carrillo, Rojas, Montes, \& Climent (2015).

Identificado el tema foco de su enseñanza, en las siete sesiones del primer bloque se percibe que Lucho conoce acerca de las propiedades entre expresiones algebraicas, ecuaciones e inecuaciones cuando al iniciar cada sesión hace la respectiva explicación de los ejercicios que pone como ejemplo. En el segundo y tercer bloque manifiesta además, tener conocimiento de las propiedades que se necesitan para establecer las definiciones de los objetos matemáticos mediante el uso de lenguaje cotidiano y lenguaje algebraico por medio de las tareas, actividades y explicaciones que propone y desarrolla en el bloque II y III. A través de la explicación y la proposición de tareas y actividades, es posible identificar elementos del conocimiento de tema: Lucho sabe acerca de las expresiones algebraicas, ecuaciones e inecuaciones más allá de lo que los estudiantes aprenden, conocimiento que incluye aspectos de los conceptos que le permiten relacionarlos con contextos reales y aportar elementos que conllevan a la comprensión de diferentes significados que pueden atribuirse a las ecuaciones e inecuaciones y los contextos en los que se sitúan.

Con la explicación de los ejemplos al inicio de las sesiones y el posterior desarrollo de ejercicios durante el bloque I, Lucho brinda a los estudiantes una receta de cómo resolver expresiones algebraicas, ecuaciones e inecuaciones. Mediante el acercamiento visual que propone durante el bloque II y el esquema de razonamiento que está inmerso en las tareas y actividades del bloque III, busca que los estudiantes establezcan y desarrollen soluciones a las ecuaciones e inecuaciones. Estas acciones de cómo el profesor desarrolla la clase hacen parte del conocimiento de la práctica matemática de Lucho.

Los ejemplos y los ejercicios que Lucho brinda a los estudiantes durante las primeras siete sesiones, la planificación de las actividades a desarrollar durante el segundo bloque empleando el software educativo como complemento y refuerzo de la gestión en el aula del primer bloque y las actividades y tareas que propone durante el tercer bloque ponen de manifiesto que Lucho tiene conocimiento de distintas vías, recursos y formas 
de enseñar matemáticas. Su conocimiento de la enseñanza de las matemáticas está conformado por diferentes estrategias que al parecer son personales y que pone en marcha a lo largo de las sesiones observadas.

Aspectos acerca del conocimiento de las características del aprendizaje de las matemáticas se pueden identificar cuando Lucho lleva a cabo la planificación del segundo y tercer bloque. Lucho no está conforme con los resultados obtenidos a lo largo del primer bloque de observación, en particular la baja motivación que tienen los estudiantes y la poca interacción que ellos tienen con las matemáticas. De este modo, durante la práctica Lucho modifica las acciones concretas dentro del aula con el fin acercar a los estudiantes al aprendizaje de las expresiones algebraicas, ecuaciones e inecuaciones lineales.

Todas las acciones observadas están centradas en el conocimiento que Lucho tiene acerca de los contenidos y capacidades que debe aprenderse y desarrollarse en el cuarto año de secundaria a partir de los lineamientos y estándares nacionales e institucionales. Lucho manifiesta tener conocimiento de los contenidos y competencias que se deben desarrollar en el grado correspondiente y su actuar dentro del aula está orientado a la enseñanza de las expresiones algebraicas, ecuaciones e inecuaciones lineales y las relaciones que puedan surgir a lo largo del año escolar.

Los aspectos de la práctica de Lucho que se asocian a las componentes del conocimiento especializado se resumen en la siguiente gráfica: 


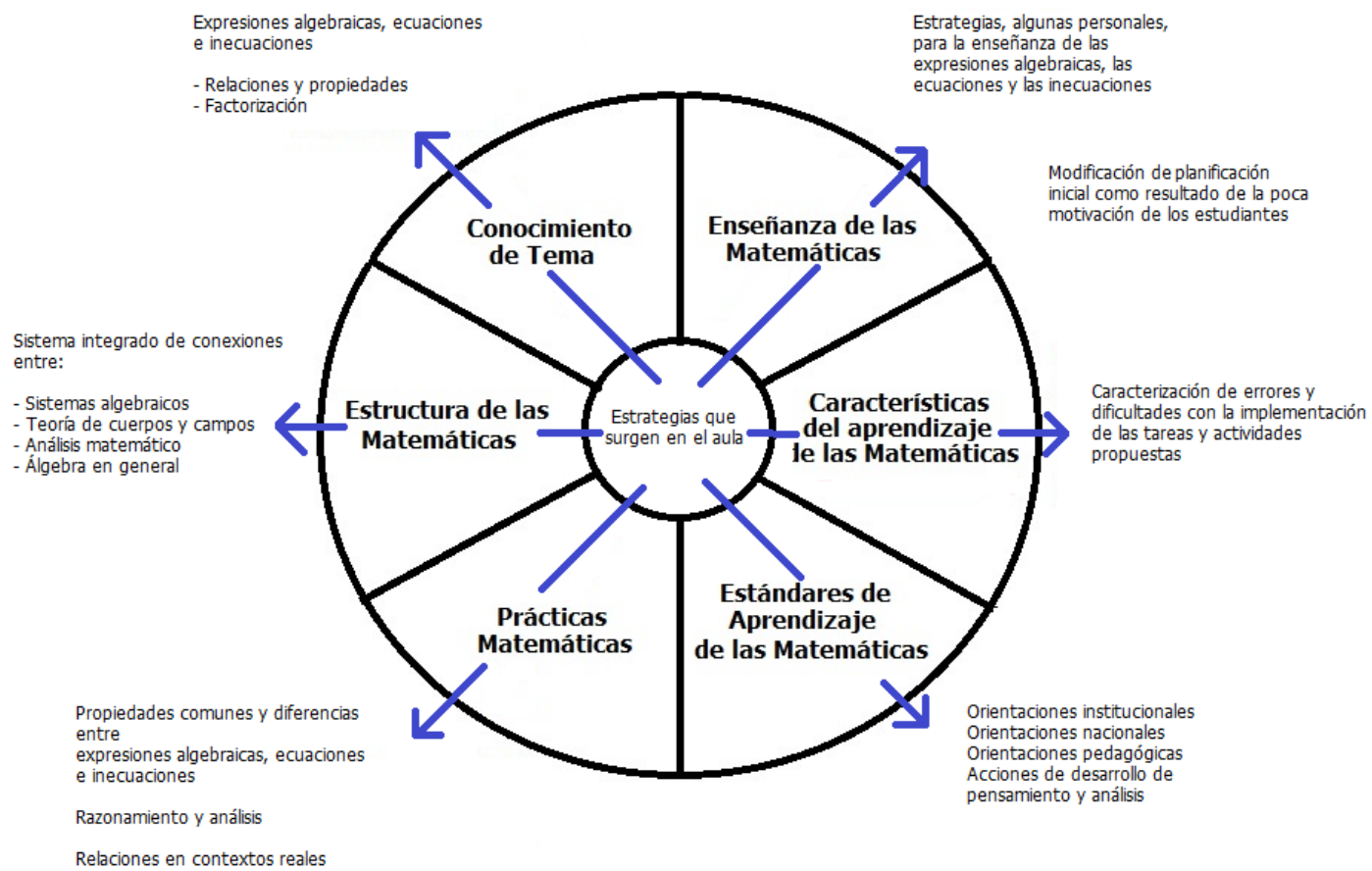

Figura 9.02. Aspectos de la práctica: estrategias que surgen en el aula y su relación con el conocimiento especializado.

Fuente: propia

\section{7. ¿Qué manifestación de las concepciones del profesor pueden asociarse a su conocimiento especializado?}

Las concepciones son, en esencia, factores que dan forma a las decisiones de los profesores sobre qué conocimiento es relevante, qué rutinas de enseñanza son apropiadas, qué objetivos deben lograrse y cuáles son las características importantes en el contexto de la clase. Para el caso particular de Lucho, éstas se manifiestan de manera constante durante su práctica.

A lo largo de la observación se confirma lo afirmado en el marco teórico acerca que lo que el profesor 'cree' y lo que 'hace' puede no coincidir. Hay diferentes elementos que están en conflicto o en armonía y pueden cambiar con el tiempo cuando Lucho entiende que hay aspectos entre lo que dice hacer sobre su práctica y lo que hace en la misma no coinciden.

A continuación, se presenta la relación entre las concepciones asociadas al conocimiento especializado de Lucho. Estas concepciones son posicionamientos que el investigador interpreta posee Lucho a partir del análisis de su práctica en el aula y de sus opiniones sobre la enseñanza y aprendizaje (Carrillo, 1998; Contreras, 1998 y 
Climent, 2005).

\section{Concepción de la Matemática Escolar y conocimiento especializado}

Durante las sesiones observadas se ha apreciado cómo Lucho mostró en sus clases interés por encontrar armonía entre lo que enseña y lo que sus estudiantes aprenden. Así, por ejemplo, en el bloque III se conjugan el concepto de expresiones algebraicas y el lenguaje cotidiano y el proceso de definir. Lucho parece orientar a los alumnos hacia la adquisición de habilidades, enfatizando la comprensión (Serrazina, 1998).

El conocimiento del profesor que se necesita para resolver ecuaciones e inecuaciones con expresiones algebraicas se pone de relieve durante en el bloque I, II y III cuando se abordan las características y las propiedades que las definen. La introducción de la solución de ecuaciones e inecuaciones lineales tanto en el bloque I como en el bloque III es un ejemplo de cómo la concepción de las matemáticas escolares está relacionada con el conocimiento especializado del profesor. Cuando Lucho pide a los alumnos en el bloque III que analicen el lenguaje cotidiano para resolver las situaciones, comparen, establezcan criterios, e identifiquen cómo tienen que resolver el problema, pone en acto su conocimiento de las propiedades necesarias para resolver este tipo de situaciones, interesándole en el bloque III el concepto desde un punto de vista comprensivo por parte de los estudiantes.

Cuando Lucho acepta, refuta, o corrige la expresión de los razonamientos matemáticos de sus alumnos, se ve la interacción entre la gestión de los conocimientos y el papel que tiene el alumno (en el bloque I quiere que expliquen el porqué de su razonamiento matemático de manera implícita y en el bloque III lo hagan de manera explícita).

A lo largo de la observación, Lucho muestra un conocimiento asociado a las dificultades que presentan los alumnos cuando tratan de resolver ecuaciones e inecuaciones. En un primer momento, éste conocimiento lo toma para sí (Bloque I) y es uno de los aspectos en los cuales piensa sobre su práctica inicialmente; posteriormente lo toma para su práctica el cual interviene en el desarrollo de las planificaciones de los bloques II y III.

Las Concepciones de la Matemática Escolar de Lucho que se pueden interpretar a raíz del ejercicio de observación de la práctica de Lucho se pueden asociar a las componentes Conocimiento de Tema, Conocimiento de las Prácticas Matemáticas, 
Conocimiento de la Enseñanza de las Matemáticas y Conocimiento de las Características del aprendizaje de las Matemáticas de la siguiente manera:

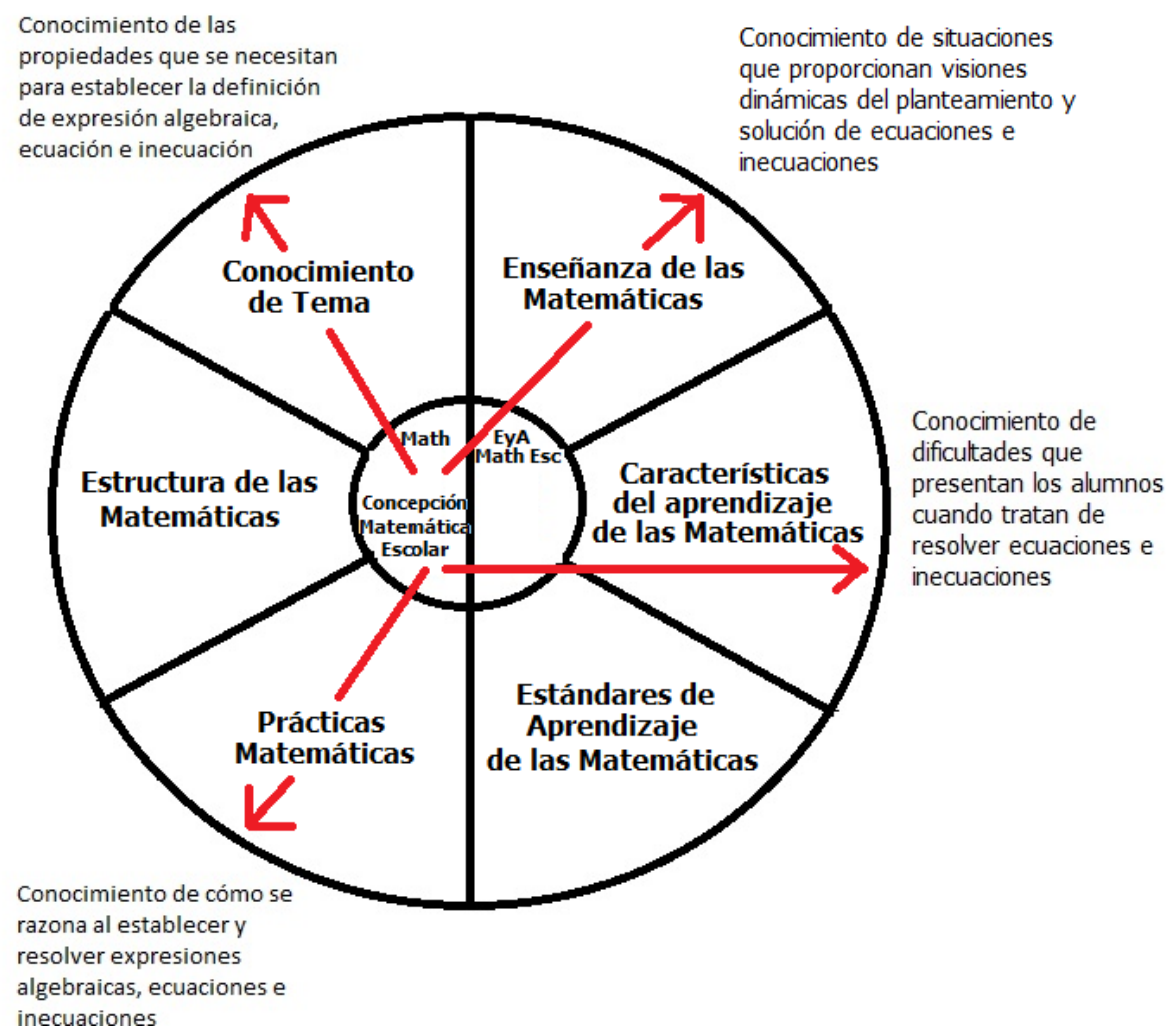

Figura 9.03. Concepciones de la matemática escolar asociadas al conocimiento especializado de Lucho. Fuente: propia

\section{Concepciones sobre Metodología en el aula de matemáticas.}

Durante los tres bloques de observación, se han podido observar diversos indicadores sobre la metodología que Lucho despliega en sus clases.

Para Lucho, una forma de guiar a los alumnos consiste en enfrentarlo con situaciones que para las que aún no poseen procesos de resolución; él considera que así motiva y moviliza a los estudiantes. Esta situación se observa claramente en las sesiones del bloque II y III donde el trabajo se centra en resolver situaciones que implican el uso de expresiones algebraicas y solución de ecuaciones e inecuaciones y se relaciona con:

- el Conocimiento de Tema, por las propiedades que se necesitan para establecer la definición de expresión algebraica, ecuación e inecuación según se vaya necesitando, 
- el Conocimiento de las Prácticas Matemáticas, para enseñar a los estudiantes estrategias de razonamiento y resolución de expresiones algebraicas, ecuaciones e inecuaciones, y

- el Conocimiento de la enseñanza de las matemáticas, en particular de actividades que pueden ser potenciadoras, las cuales pensó a partir de los resultados del bloque $\mathrm{I}$.

El conocimiento sobre la enseñanza de las matemáticas se relaciona con la concepción de Lucho respecto de los materiales manipulativos usados en clase emerge como detonante para que el alumno pase de un pensamiento concreto al abstracto (Gellert, 2000), en las planificaciones y puesta en práctica del segundo y tercer bloque.

A lo largo del desarrollo de las sesiones, está también incluido su conocimiento sobre las formas de interacción de los estudiantes con el contenido matemático, las tareas y actividades en el planteamiento y solución de ecuaciones e inecuaciones. La variedad en la interacción se pone de manifiesto con las planificaciones del bloque II y III, en las que Lucho reconoce algunas características del aprendizaje de las matemáticas.

En este sentido, Lucho conoce de las dificultades a las que se enfrentan los alumnos, y manifiesta conocimiento de cómo profundizar en ellas para transformar dichas dificultades en oportunidades de aprendizaje. El interés del profesor está dirigido a que los alumnos construyan conocimientos a través de las tareas que diseñó en sus planificaciones y en las que prima la construcción individual y colectiva del conocimiento matemático escolar (Restrepo Becerra, 2010). Así, Lucho propone a los alumnos resolver, actividades del libro de texto en el bloque I; plantea tareas específicas tanto individuales como grupales para reafirmar conceptos y ejercitación en el bloque II y tareas que involucran el uso de expresiones algebraicas y la solución de ecuaciones e inecuaciones lineales que se validan a partir del trabajo tanto en pequeños grupos como en gran grupo.

Las concepciones de la metodología asociadas al conocimiento especializado de Lucho se resumen en la siguiente gráfica: 


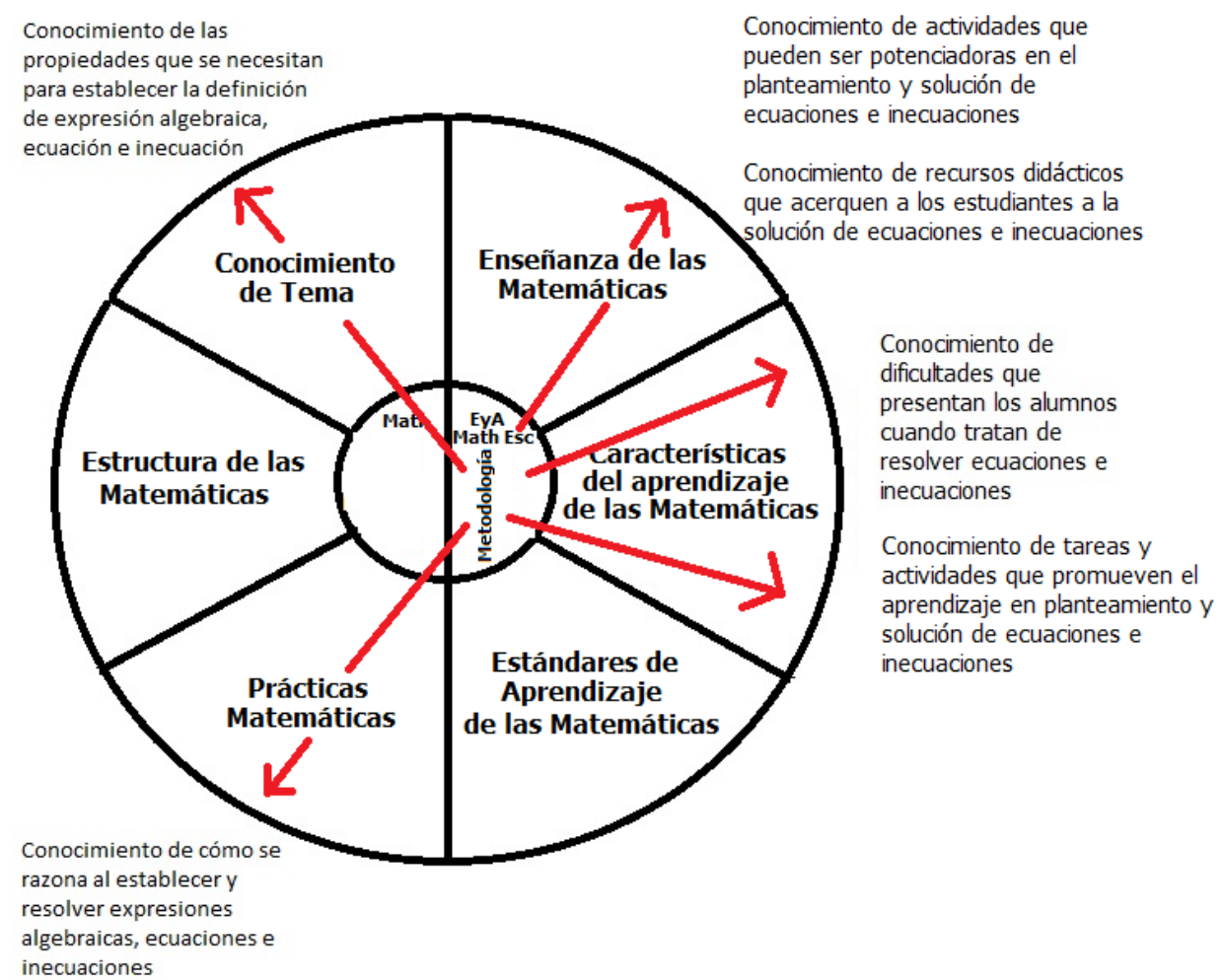

Figura 9.04. Concepciones de la Metodología asociadas al conocimiento especializado de Lucho. Fuente: propia

\section{Concepción del aprendizaje}

Se puede decir que para Lucho, el aprendizaje es un constructo social, hecho que se constata a lo largo de la observación. En el bloque I, ubica al estudiante únicamente como resolutor de cada una de las tareas propuestas, ya que sólo le permite desarrollar las actividades que como profesor considera debe realizar, aunque permite la interacción entre ellos para la solución. En los bloques II y III, los estudiantes toman decisiones tanto en las actividades a desarrollar como los argumentos para usar ecuaciones o inecuaciones, estableciendo conjeturas acerca del significado de la respuesta y situaciones reales, siguiéndole a esa clasificación una comprobación matemática y una generalización adecuada; esto se puede observar en la sesión 11 cuando les pide que discutan acerca de quien ha tenido bien los ejercicios de expresiones algebraicas sobre área y perímetro y su posterior puesta en común.

En la entrevista inicial Lucho comenta de la importancia de la interacción de los objetos matemáticos con los estudiantes; al final de la observación, los estudiantes tienen discusiones entre ellos y con Lucho sobre las características de las expresiones algebraicas, las ecuaciones y las inecuaciones, las cuales permiten la institucionalización del aprendizaje. 
Para Lucho, las argumentaciones se deben llevar a cabo en cualquier afirmación que se realice, siendo el aula un ámbito en el que se enseñe a argumentar lógicamente (Crespo, 2005) y en el que se permita la comprensión antes que la memorización (Barrantes y Blanco, 2006), razón fundamental que Lucho considera en el cambio de su práctica entre lo observado en el bloque I y el bloque III.

Entonces, son los propios estudiantes los que realizan el esfuerzo de tomar conciencia y explicitar qué han aprendido, aunque finalmente se remitan a los libros de texto para comprobar que contenido trabajado es el que se refleja en él. Esta acción permite conocer a Lucho las dificultades que presentan cuando recurren a consultarle cuando los resultados de ellos divergen a los que muestra el libro de texto o el software educativo, las cuales manifiesta identificar a partir de las argumentaciones que el alumno hace.

Así, la concepción de aprendizaje se relaciona con el conocimiento de las características del aprendizaje de las matemáticas y con el conocimiento de los estándares de aprendizaje de las matemáticas de Lucho, el primero a través del conocimiento de las dificultades que presentan los estudiantes al resolver ecuaciones e inecuaciones, el uso del lenguaje cotidiano y matemático asociado a las expresiones algebraicas, las ecuaciones y las inecuaciones; el segundo a partir de los contenidos que se requieren enseñar en cuarto año de secundaria, tal como se observa en la siguiente gráfica: 


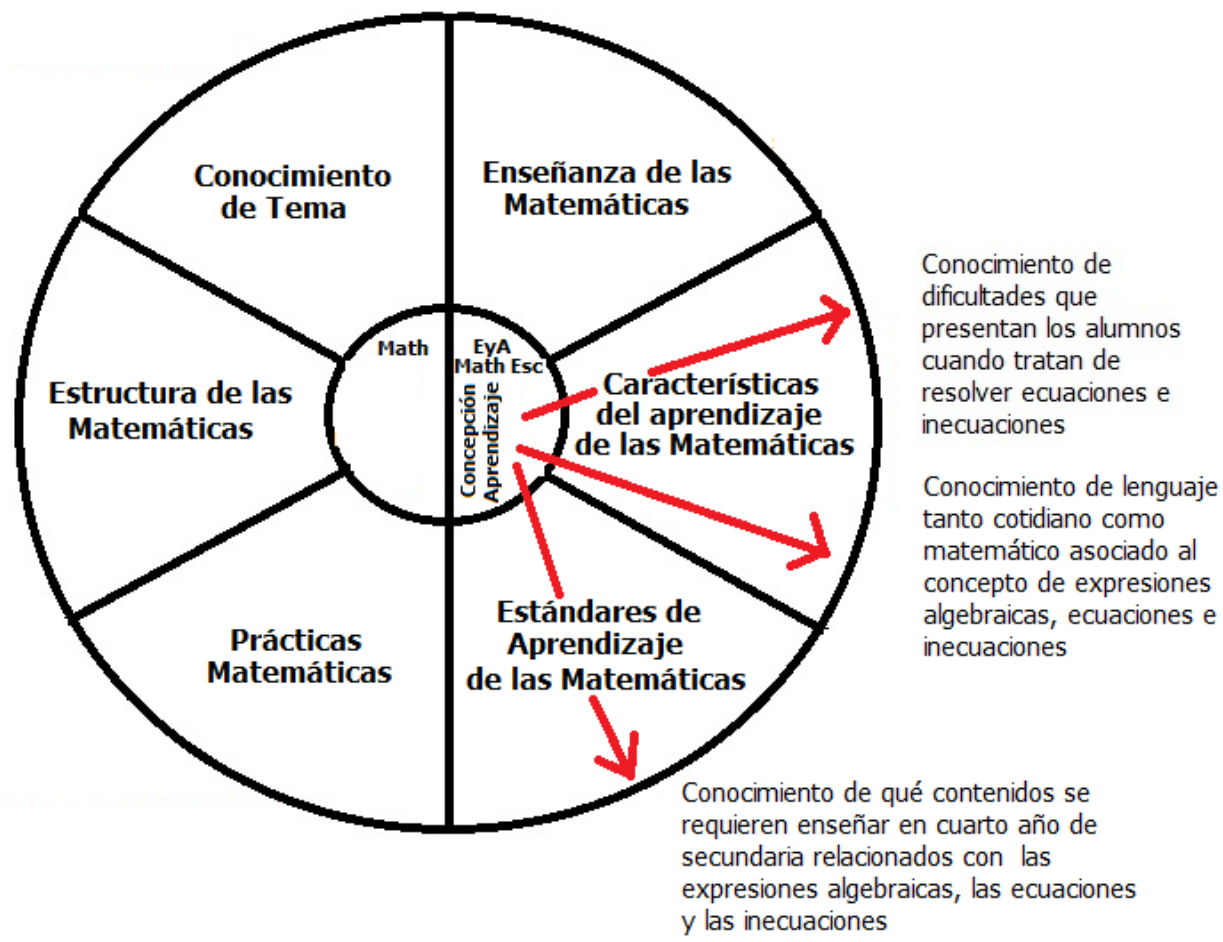

Figura 9.05. Concepción del aprendizaje y su relación con el conocimiento especializado de Lucho. Fuente: propia

\section{Papel del alumno}

El papel que adquiere el alumno a lo largo de las sesiones del segundo y tercer bloque es el de agente que critica los conocimientos que se movilizan en el aula, dando sus argumentos, intercambiando diferentes puntos de vista con sus compañeros $y$, en general, reflexionando sobre el proceso que se está trabajando. Para Lucho, el alumno es quien tiene que tomar conciencia de qué y por qué está aprendiendo. El estudiante asume parte de la responsabilidad del control sobre su aprendizaje cuando comprende que no se puede quedar resolviendo ejercicios del libro de texto (Graent, Hiebert y Wearne, 1998).

A medida que avanza la observación, el alumno interviene constantemente en el aula y sus aportaciones son consideradas por Lucho en todo momento, llegando en ocasiones a utilizar su conocimiento sobre las dificultades, como ocurre en las actividades propuestas en la sesión 12. En este ejemplo, a raíz de la situación del dinero y los porcentajes la intervención de los alumnos preguntando sobre la existencia del riesgo, el profesor manifiesta su conocimiento sobre la importancia de hacer enfrentar a los estudiantes con situaciones poco habituales como la descrita, puesto que cuestiona las suposiciones del alumno, pidiendo explicaciones, y consensua lo entendido con el 
grupo, hecho que proporciona una imagen del conocimiento de las características del aprendizaje de las matemáticas de Lucho.

El último ejemplo muestra, además, la intención de ubicar a los estudiantes en el centro del aprendizaje a través del uso de recursos diferentes al libro de texto y la explicación de los ejemplos por medio de actividades que busquen plantear y potenciar el uso de los objetos matemáticos propios de la observación, acción de se relaciona con el conocimiento de la enseñanza de las matemáticas de Lucho.

Lo anterior también es muestra del conocimiento de las propiedades que se necesitan para establecer la definición y las propiedades de expresión algebraica, ecuación e inecuación, más cuando la intención, a medida que avanza la observación, es que sean los mismos estudiantes quienes las comprendan como resultado de su manipulación como ocurre en el bloque II y no como resultado de la explicación del profesor en la manera como se observa en el bloque I.

Entonces, el cambio del papel del alumno que se observa en la práctica de Lucho está relacionado con:

- el conocimiento de las características del aprendizaje de las matemáticas en cuanto las dificultades que los estudiantes presentan durante el primer bloque, lo que implica diseñar e implementar tareas y actividades que promuevan el aprendizaje de las expresiones algebraicas, las ecuaciones y las inecuaciones;

- el conocimiento de la enseñanza de las matemáticas en procura que las actividades y tareas diseñadas potencien el aprendizaje de los objetos matemáticos relacionados, hecho para el cual se recurre a distintos recursos didácticos que acerquen a los estudiantes a la solución de ecuaciones e inecuaciones desde un punto de vista analítico no repetitivo;

- el conocimiento de tema para apoyar en los procesos de análisis que se median en las actividades y tareas a través de las propiedades que se necesitan para establecer la definición y las propiedades de las expresiones algebraicas, ecuaciones e inecuaciones 


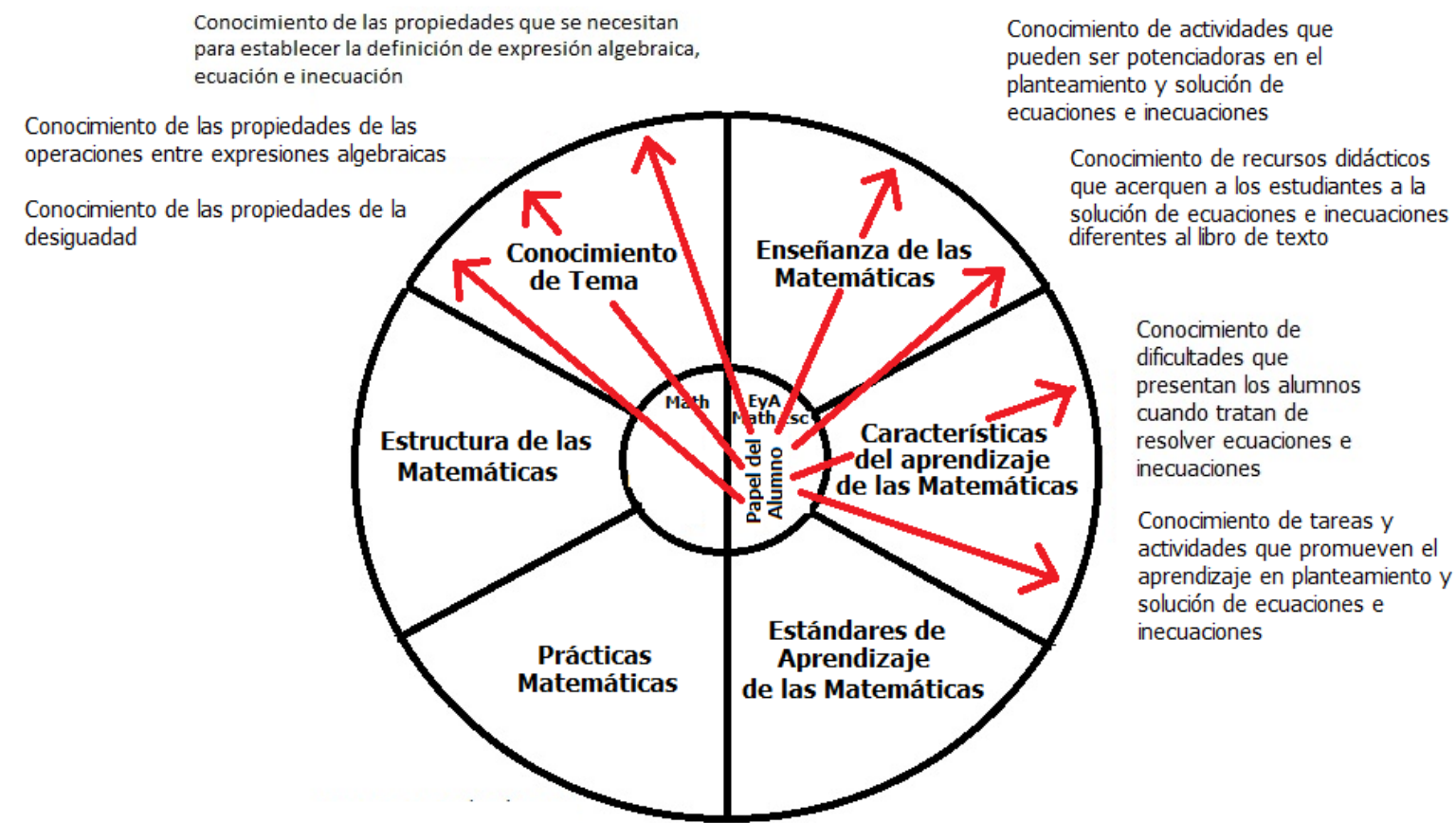

Figura 9.06. Concepciones del papel del alumno relacionadas con el conocimiento especializado de Lucho. Fuente: propia

\section{Papel del profesor}

Lucho aparece como el organizador de las informaciones que se movilizan en el aula (Grant, Heibert y Wearne, 1998). Sus intervenciones aportan elementos para el aprendizaje que en algunos momentos tienen sentido para sus estudiantes, por ejemplo, las situaciones del bloque III cuando introduce las expresiones algebraicas y las ecuaciones e inecuaciones lineales por medio de situaciones. En esas intervenciones es cuando hace visible su conocimiento sobre el tema, cómo entiende la matemática escolar o qué errores quiere corregir a los alumnos. Potencia la reflexión y el desarrollo de estrategias para que los alumnos asuman responsabilidad a la hora de juzgar la adecuación de sus ideas, jugando así un papel de mediador entre el conocimiento y los estudiantes determinante en el proceso de enseñanza (Lezama, 2003), dejando a un lado el protagonismo que tiene en el primer bloque para cederlo a los estudiantes en el tercer bloque.

Además se hace explícito su conocimiento sobre cómo se aprende, pues utiliza en varias ocasiones los aprendizajes anteriores y las experiencias propias de cada uno. Esto se puede ver en el bloque II y III o cuando hace referencia a la similitud de la construcción de la definición de expresión algebraica, ecuación e inecuación lineal. 
El papel de Lucho está entonces mediado a partir de sus concepciones sobre la matemática escolar, la metodología, el aprendizaje y el papel del alumno, a partir de las consideraciones que él mismo plantea a lo largo de la observación y las necesidades que surgen para hacer coincidir lo que piensa con lo que hace, tal como se ha descrito en los apartados anteriores y que se resume en la siguiente gráfica

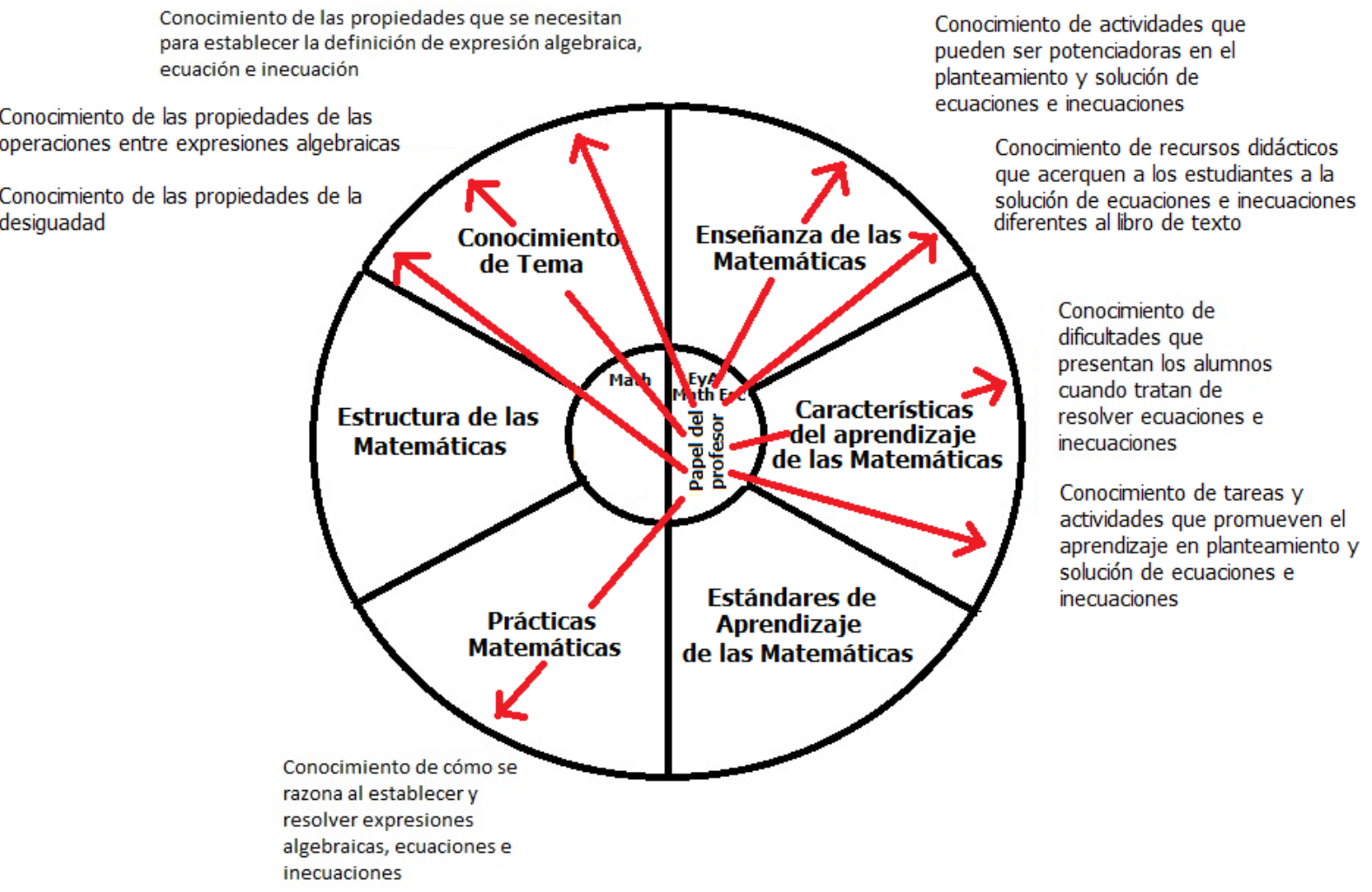

Figura 9.07 Concepciones del papel del profesor y sus relaciones con el conocimiento especializado de Lucho. Fuente: propia

\section{8. ¿Qué aspectos del aula generaron cambios en la práctica de Lucho? ¿A qué los atribuye Lucho? ¿Qué aspectos de su desarrollo profesional permiten entender? ¿Son muestra de su conocimiento especializado?}

En la pregunta 4 se comentó que los cambios en la práctica de Lucho se dieron principalmente en la metodología y la evaluación. La aplicación de los diferentes instrumentos de recolección y análisis de la información permiten entender que los cambios se dieron como consecuencia de los bajos resultados en la actividad evaluativa realizada en la segunda sesión, la falta de motivación de los estudiantes hacia y para el aprendizaje de las matemáticas y la falta de comprensión, por parte de los estudiantes, de los contenidos que está enseñando, durante el bloque I 
Lucho atribuye esas situaciones a su propia gestión, afirma que se encasilló en una situación en la que copia y pega lo que hace el libro sin ningún tipo de correspondencia a lo que quiere hacer como docente, olvidando, en parte, su razón como profesor de matemáticas. Entonces, al pensar y reflexionar en, sobre y para su práctica, decide buscar y aplicar estrategias para motivar y movilizar a los estudiantes en el aprendizaje de las matemáticas.

Durante el desarrollo del primer bloque de observación Lucho asume que en su práctica se presentan diferentes problemas los cuales le hacen pensar en diferentes maneras de actuar y objetivos que plantear (Climent, 2005; Llinares y Krainer, 2006), para dar solución a las situaciones que se están presentando.

Como consecuencia de esa problematización, Lucho comprende algunos aspectos de su práctica, enfocándose en las necesidades de sus estudiantes, replanteando las actividades y la forma de explicar, y evaluando la manera como se produce el aprendizaje, así:

- Realiza una organización secuencial de las matemáticas escolares en el aula con relación al contexto del contenido que propone en el segundo y tercer bloque.

- Propone situaciones y ejercicios en clase que surgen a partir del interés de los estudiantes y no por indicación del libro de texto como ocurría en el primer bloque.

- Usa material concreto, recursos y fuentes para facilitar la explicación de las matemáticas, incluyendo uso de software educativo en el desarrollo del segundo bloque.

- Recurre a formas de explicación de acuerdo con las dinámicas no predecibles en el aula de clase, rompiendo los esquemas que tiene elaborados en su planificación.

- Emplea estrategias no usuales para garantizar el aprendizaje de las matemáticas por parte de los estudiantes, por ejemplo, las tareas y actividades en clase que tienen distintas maneras de ser resueltos. 
- Realiza una organización secuencial de las matemáticas escolares en el aula con relación al contexto del contenido, las competencias a desarrollar y la infraestructura institucional.

Estas acciones permiten entender que Lucho ha problematizado la práctica por medio de la reflexión; ha comprendido su práctica, codificando situaciones que no le gustan de su quehacer como profesor; ha conocido a sus estudiantes para que su práctica los acerque al aprendizaje de las matemáticas.

En la respuesta a la pregunta 6 se hizo la descripción de los elementos de la práctica de Lucho que pueden asociarse a las componentes del conocimiento especializado; en las respuestas de la pregunta 7 se hizo lo mismo con la manifestación de las concepciones de Lucho. En ambas respuestas se listaron ítems que surgieron como resultado del cambio de la práctica, la comprensión de la práctica y el conocimiento de los estudiantes; por tanto, los aspectos del desarrollo profesional que permiten entender los cambios de la práctica de Lucho son muestra de su conocimiento especializado, entre ellos los descritos en la siguiente tabla que reúne los elementos presentados en las respuestas a las preguntas 6 y 7 :

\begin{tabular}{|c|c|c|c|}
\hline & \multicolumn{3}{|c|}{ Problematización de la práctica } \\
\hline & $\begin{array}{l}\text { Cambios de la } \\
\text { práctica }\end{array}$ & $\begin{array}{l}\text { Comprensión de } \\
\text { la práctica }\end{array}$ & $\begin{array}{l}\text { Conocimiento de } \\
\text { estudiantes }\end{array}$ \\
\hline $\begin{array}{l}\text { Tema: permite al } \\
\text { profesor } \\
\text { desenvolverse con } \\
\text { el contenido que } \\
\text { aborda en su } \\
\text { práctica y le } \\
\text { permite tener } \\
\text { consciencia de los } \\
\text { aspectos } \\
\text { matemáticos que } \\
\text { son indispensables }\end{array}$ & $\begin{array}{l}\text { Organización de la } \\
\text { secuenciación } \\
\text { temática para el } \\
\text { grado } \\
\text { correspondiente de } \\
\text { la enseñanza }\end{array}$ & $\begin{array}{l}\text { Preguntas en las } \\
\text { fichas de diario y } \\
\text { entrevistas: } \\
\text { ¿Qué tanto se de } \\
\text { matemáticas? } \\
\text { ¿Qué tanto sé de } \\
\text { matemáticas } \\
\text { escolares? } \\
\text { ¿Qué relaciones } \\
\text { conozco que } \\
\text { existen entre los }\end{array}$ & $\begin{array}{l}\text { Organización } \\
\text { secuencial de las } \\
\text { matemáticas } \\
\text { escolares en el } \\
\text { aula con relación } \\
\text { al contexto del } \\
\text { contenido. }\end{array}$ \\
\hline $\begin{array}{l}\text { Estructura } \\
\text { matemática: }\end{array}$ & $\begin{array}{l}\text { Relaciones que se } \\
\text { pueden establecer }\end{array}$ & $\begin{array}{l}\text { contenidos y las } \\
\text { matemáticas que }\end{array}$ & \\
\hline
\end{tabular}




\begin{tabular}{|c|c|c|c|}
\hline $\begin{array}{l}\text { sistema integrado } \\
\text { de conexiones que } \\
\text { permite } \\
\text { comprender y } \\
\text { desarrollar } \\
\text { conceptos } \\
\text { avanzados desde } \\
\text { perspectivas } \\
\text { elementales }\end{array}$ & $\begin{array}{l}\text { acerca de las } \\
\text { matemáticas } \\
\text { dentro de la } \\
\text { práctica cotidiana. }\end{array}$ & \begin{tabular}{lr}
\multicolumn{2}{l}{ quiero enseñar y } \\
que quiero que \\
aprendan los \\
estudiantes?
\end{tabular} & \\
\hline $\begin{array}{l}\text { Práctica } \\
\text { Matemática: se } \\
\text { refiere a las formas } \\
\text { de conocer, crear o } \\
\text { producir en } \\
\text { matemáticas, } \\
\text { conocimiento de } \\
\text { aspectos de la } \\
\text { comunicación } \\
\text { matemática, del } \\
\text { razonamiento y la } \\
\text { prueba. }\end{array}$ & \begin{tabular}{lr}
\multicolumn{2}{l}{ Estrategias para la } \\
explicación del \\
desarrollo & de \\
situaciones & \\
matemáticas & en \\
aula &
\end{tabular} & & $\begin{array}{l}\text { Desarrollo de } \\
\text { situaciones y } \\
\text { ejercicios } \\
\text { propuestos en } \\
\text { clase y que surgen } \\
\text { a partir del interés } \\
\text { de los estudiantes }\end{array}$ \\
\hline $\begin{array}{l}\text { Enseñanza de las } \\
\text { matemáticas: } \\
\text { conocimiento que } \\
\text { posee el profesor } \\
\text { de distintas } \\
\text { estrategias y } \\
\text { teorías, ya sean } \\
\text { institucionales o } \\
\text { personales de la } \\
\text { enseñanza de las } \\
\text { matemáticas. }\end{array}$ & $\begin{array}{l}\text { Forma cotidiana en } \\
\text { el ejercicio de la } \\
\text { enseñanza de las } \\
\text { matemáticas }\end{array}$ & $\begin{array}{l}\text { Visión teórica } \\
\text { acerca de cómo } \\
\text { enseñar } \\
\text { matemáticas } \\
\text { Visión personal y } \\
\text { concepciones } \\
\text { acerca de cómo } \\
\text { enseñar } \\
\text { matemáticas }\end{array}$ & $\begin{array}{ll}\text { Uso de } & \text { material } \\
\text { concreto, } & \\
\text { recursos, fuentes. } \\
\text { Formas r de } \\
\text { explicación de } \\
\text { acuerdo con las } \\
\text { dinámicas r no } \\
\text { predecibles en el } \\
\text { aula de clase }\end{array}$ \\
\hline \begin{tabular}{lr}
\multicolumn{2}{l}{ Características } \\
del & aprendizaje \\
de & las
\end{tabular} & $\begin{array}{lr}\text { Planificación } & \text { de } \\
\text { actividades } & \text { y } \\
\text { secuenciación } & \text { de }\end{array}$ & $\begin{array}{l}\text { Análisis de lo que } \\
\text { el profesor espera } \\
\text { que aprenda y lo }\end{array}$ & $\begin{array}{lr}\text { Estrategias } & \text { no } \\
\text { usuales } & \text { para } \\
\text { garantizar } & \text { el }\end{array}$ \\
\hline
\end{tabular}




\begin{tabular}{|c|c|c|c|}
\hline $\begin{array}{l}\text { matemáticas: } \\
\text { cómo se aprenden } \\
\text { y piensan los } \\
\text { contenidos } \\
\text { matemáticos y las } \\
\text { formas en que los } \\
\text { estudiantes } \\
\text { interactúan con } \\
\text { cada contenido }\end{array}$ & $\begin{array}{l}\text { acuerdo con la } \\
\text { edad y el contexto } \\
\text { de los estudiantes }\end{array}$ & $\begin{array}{l}\text { que realmente } \\
\text { aprende el } \\
\text { estudiante }\end{array}$ & \begin{tabular}{ll}
\multicolumn{2}{l}{ aprendizaje de las } \\
matemáticas por \\
parte de los \\
estudiantes &
\end{tabular} \\
\hline $\begin{array}{l}\text { Estándares del } \\
\text { aprendizaje de las } \\
\text { matemáticas: } \\
\text { visión de la noción } \\
\text { del conocimiento } \\
\text { curricular que } \\
\text { abarca los grados } \\
\text { de profundidad en } \\
\text { que el profesor } \\
\text { puede conocer el } \\
\text { currículo oficial } \\
\text { visto como el } \\
\text { referente } \\
\text { estandarizado } \\
\text { visión de la noción } \\
\text { del conocimiento } \\
\text { curricular que } \\
\text { abarca los grados } \\
\text { de profundidad en } \\
\text { que el profesor } \\
\text { puede conocer el } \\
\text { currículo oficial } \\
\text { visto como el } \\
\text { referente } \\
\text { estandarizado }\end{array}$ & $\begin{array}{l}\text { Organización } \\
\text { temática y de la } \\
\text { clase y de } \\
\text { competencias de } \\
\text { acuerdo con los } \\
\text { estándares } \\
\text { institucionales, } \\
\text { internacionales y } \\
\text { gubernamentales } \\
\text { evidenciados en } \\
\text { las planificaciones }\end{array}$ & $\begin{array}{l}\text { Importancia de los } \\
\text { estándares en los } \\
\text { procesos de } \\
\text { enseñanza y } \\
\text { aprendizaje de las } \\
\text { matemáticas de } \\
\text { sus estudiantes }\end{array}$ & $\begin{array}{l}\text { Organización } \\
\text { secuencial de las } \\
\text { matemáticas } \\
\text { escolares en el } \\
\text { aula con relación } \\
\text { al contexto del } \\
\text { contenido, las } \\
\text { competencias a } \\
\text { desarrollar, la } \\
\text { infraestructura y } \\
\text { otros }\end{array}$ \\
\hline
\end{tabular}




\section{9. ¿Qué aspectos de la matemática escolar que Lucho transpone en el aula permiten identificar cuál es su relación con el contenido? ¿Es esa relación adecuada para la propuesta de trabajo con los alumnos y su corrección? ¿Cómo posiciona este dominio de conocimiento a Lucho respecto de los alumnos? ¿Influye esta relación en sus concepciones?}

La matemática escolar que Lucho traspone en el aula se modifica a medida que avanza la observación, esto implica que a lo largo del acompañamiento se pueden presentar diferentes relaciones con el contenido, que se explican desde la componente Conocimiento de la Estructura Matemática y Conocimiento de Tema asociados a su Conocimiento Especializado.

Lucho hace una diferenciación en el tratamiento de los contenidos que transpone en el aula: las expresiones algebraicas serán el eje transversal de la gestión en aula y servirán como argumento matemático para la solución de ecuaciones e inecuaciones. Estas últimas las diferencia en tres subtemas: igualdades, desigualdades y representación.

En las igualdades Lucho distingue identidades y ecuaciones, sin recurrir a las primeras durante la observación, sí en el año escolar y clasificando las segundas según el grado y el número de incógnitas. A las desigualdades las vincula con la ecuación asociada, aunque durante el año no aborda desigualdades con más de una incógnita. Como los estudiantes ya distinguen la función lineal y la función cuadrática y sus respectivas representaciones gráficas, Lucho considera que, la representación de dichas funciones favorecerá los procesos de solución que tengan que realizar los estudiantes.

Los sistemas de representación y la fenomenología permiten identificar la relación con el contenido. A lo largo de toda la observación Lucho recurre al lenguaje analítico y simbólico para manipular las expresiones algebraicas que componen la ecuación o inecuación concreta. El uso exclusivo que hace de esta representación durante el primer bloque permite inferir en ese lapso, que Lucho interpreta a las matemáticas como un sistema estático previamente establecido y la matemática escolar es una simplificación del conocimiento matemático disciplinar en el que predomina el uso de terminología y definiciones estándar que se aprenden a partir de procedimientos algorítmicos repetitivos, sin significatividad para los alumnos.

En el segundo y tercer bloque Lucho recurre también a la representación de "la forma" de las ecuaciones y el área de las inecuaciones, el cual es más visual y facilita la 
comprensión de los estudiantes. La representación gráfica se puede hacer con la mediación de software educativo, hecho que indica que Lucho interpreta a la matemática escolar como un conjunto de saberes disciplinares actualizados en el que se pueden algunos conocimientos no disciplinares; aún predominan los procedimientos y algoritmos, pero tiene en cuenta destrezas, razonamientos y la comprensión de los estudiantes.

En el tercer bloque se aprecia el uso de lenguaje tanto numérico, la utilización de tablas de valores y sistemas de aproximación como el verbal cuando se enuncia un problema o al leer una expresión simbólica, que complementa a los sistemas de representación empleados en los dos primeros bloques, hecho que indica que Lucho ahora considera relevante los intereses de los alumnos coherente por el interés por los contenidos matemáticos presentes en la realidad inmediata que manifiesta tanto en la entrevista inicial como final.

Con relación a la fenomenología, Lucho emplea la noción que atiende a la naturaleza de las expresiones algebraicas que aparecen en las ecuaciones e inecuaciones (algebraicas y transcendentes) durante los tres bloques de observación, haciendo referencia a la naturaleza de las expresiones algebraicas en la que es posible identificar algunas situaciones a caracterizar tanto en las ecuaciones como en las inecuaciones:

Ecuaciones algebraicas: localizadas en situaciones algorítmicas, de interpolación polinómica, situaciones de la física como gravedad y movimiento, situaciones numéricas como edades, números consecutivos y repartos y situaciones de perímetros, áreas y volúmenes. En el primer bloque el tratamiento de las ecuaciones algebraicas es únicamente algorítmico, las demás situaciones surgen durante el segundo y tercer bloque.

Inecuaciones: éstas se pueden encontrar en situaciones de solución mecánica y algorítmica, optimización de cantidades, cálculo de edades, volúmenes, áreas y perímetros, situaciones de economía, entre otros. Lucho propone situaciones de solución mecánica únicamente en el bloque I, recurriendo a otras situaciones durante el desarrollo de los bloques I y II.

A medida que avanza la observación, la relación entre las matemáticas escolares y el contenido se adecúa a las necesidades de los estudiantes. Durante el primer bloque, Lucho parece estar limitado a la enunciación de ejercicios y la explicación mecánica de 
los mismos; el posicionamiento que Lucho toma a partir del bloque II le permite dar orientaciones a los estudiantes acerca de lo que pueden aprender en otros contextos y en carreras universitarias teniendo en cuenta los requerimientos de orden nacional y de orden local y su labor de enseñanza, la cual va en procura de lograr tanto la comprensión, motivación y movilización como el manejo temático por parte de sus estudiantes.

Así entonces, el dominio de conocimiento descrito modifica el papel del profesor y el papel del alumno. En cuanto al papel del profesor, pasa de un estado en el la relación entre las matemáticas escolares está limitado al desarrollo del ejercicio de trasmisión verbal de los contenidos de aprendizaje, mediante explicación de lo reflejado en el libro de texto, realizando una reproducción literal de éste, a un estado que se caracteriza por una organización de los contenidos de aprendizaje, los cuales transmite mediante exposición, utilizando estrategias organizativas expositivas como el diseño de tareas, programación con software educativo, entre otros, induciendo e invitando al estudiante a participar en las actividades que promueve, analizando las reacciones y respuestas a sus propuestas.

El alumno, por su parte, deja el perfil de aprendiz a ser parte indirecta de la selección y secuenciación de contenidos y objetivos, a través de la negociación de intereses, y en el diseño didáctico, a través de sus intervenciones en el quehacer del aula, ubicándose más en el centro de la actividad en aula.

Parece ser, que las diferentes relaciones entre el contenido y la matemática escolar que Lucho transpone en el aula influyen en sus concepciones. Por un lado, a través de ellas logra una mayor correspondencia entre lo que dice y lo que hace, por otro, Lucho reconoce que la aproximación a tendencias didácticas como la espontaneista y la investigativa depende, además de la idea que el profesor tenga acerca de las matemáticas y su enseñanza, del papel del alumno y de elementos propios del contexto en el que se llevan a cabo los procesos de enseñanza y aprendizaje. Así, la finalidad personal de Lucho acerca de la movilización y la motivación del estudiante es más flexible en su correspondencia con la resolución de problemas, logrando que lo que dice hacer y lo que hace tenga un mayor grado de coincidencia. 


\subsection{0. ¿Qué aspectos de la relación investigador- profesor provocaron en Lucho situaciones a querer cambiar? ¿Qué decisiones hicieron tomar al investigador las respuestas a las preguntas anteriores?}

Durante la observación, el diálogo entre Lucho y el investigador estuvo mediado por las entrevistas, las charlas previas, las declaraciones posteriores y las declaraciones espontáneas y se puede considerar que las conversaciones antes, durante y después de la actividad en aula provocaron las situaciones a querer cambiar, en particular porque dan cuenta de una forma como Lucho piensa acerca de su práctica.

La presencia del investigador en el aula parece ser otro aspecto que permite que Lucho piense acerca de su práctica. No se tienen argumentos para afirmar cómo sería la práctica de Lucho bajo otro contexto con o sin observador y quizás en el esfuerzo natural de mostrar buenas clases a quien lo acompaña en aula, incidió en que Lucho reconociera para sí mismo aspectos que no están bien para él.

Tanto la observación de aula como los diferentes diálogos establecidos permitieron que Lucho revisara su práctica a través de un trabajo colaborativo (Bednarz \& Jean-Luc, 2015); Lucho manifiesta que gracias a la presencia del investigador en el aula y las preguntas anteriores y posteriores a la práctica tomó consciencia de aspectos que tenía que cambiar y de acuerdo con su gestión en el aula anterior esto no había sucedido previamente. Los resultados de esa colaboración fluyen en el devenir de las conversaciones formales e informales que se tienen con Lucho, porque los instrumentos declaraciones posteriores y charlas previas no tienen un guion establecido, dependen directamente del actuar del profesor y de la planificación de su clase.

El investigador interpreta que Lucho ha problematizado su práctica a causa de su insatisfacción con el resultado de la gestión en el aula y se encuentra con la propuesta que se observa en el bloque II, decide no involucrarse en la preparación de las clases porque considera que Lucho está llevando a cabo un proceso de desarrollo profesional que ha emergido de manera 'personal' y su intervención puede afectarlo. 
9.11. ¿En qué medida el modelo teórico elegido fue suficiente para el análisis de la práctica de Lucho? ¿Cuáles son las fuentes de la investigación, la evidencia del trabajo de campo que permiten aportar a ese modelo otras dimensiones para el análisis? ¿por qué esas dimensiones resultan no sólo necesarias sino además imprescindibles para el ámbito de la educación secundaria?

La pregunta de esta investigación, ¿Qué elementos caracterizan el desarrollo profesional de un profesor de matemáticas de la escuela secundaria?, dio lugar a distintas cuestiones, de diferente naturaleza, los cuales se convirtieron en los objetivos principales:

- Identificar qué componentes del desarrollo profesional de un profesor de matemáticas de secundaria se ponen en evidencia cuando lleva a la práctica su actividad docente.

- Asociar los aspectos de su conocimiento especializado y su práctica, a las componentes de su desarrollo profesional

- Describir los aspectos de su proceso de reflexión y modificación de su práctica.

A partir de estos objetivos, se decidió que la investigación estaría enmarcada dentro de las líneas de trabajo acerca del análisis de la práctica del profesor desde una perspectiva cognitiva, explicando el desarrollo profesional observable por medio de la interpretación de las concepciones del profesor y la caracterización de su conocimiento especializado. En este último aspecto se tuvo especial cuidado, porque, el modelo del conocimiento especializado del profesor de matemáticas ha sido conformado para ser analizado en profesores de primaria. En el caso estudiado fue posible validar que este conocimiento se puede asociar al profesor de matemáticas de secundaria, haciendo del mismo un modelo suficiente para el desarrollo de la investigación, alcanzando los objetivos de investigación, en cuanto fue posible:

6) Analizar aspectos de conocimiento y práctica que definen el desarrollo; posteriormente describir los cambios que se observan en esos aspectos y la relación entre ellos, los cuales se describen en los apartados 8.1.3, 8.2.3, 8.3.3, $8.5,8.6$ y en la respuesta a las preguntas $1,4,8$ y 9

7) Registrar el proceso de reflexión y modificación de la práctica: cómo se produce y cómo se relaciona con el desarrollo. Este registro se describe los apartados 
$8.1 .1,8.1 .4,8.2 .1,8.2 .4,8.3 .1,8.3 .4$ y se sintetiza en la respuesta a las preguntas 3,4 y 5

8) Detectar las concepciones sobre el desarrollo, tanto los términos como la consideración en que se producen, su posible modificación y relación con el desarrollo producido, en los apartados 8.1.2, 8.2.2, 8.3,2, 8.4 y la respuesta de las preguntas 2 y 7

9) Organizar la percepción del desarrollo y la forma que la misma incide con el conocimiento especializado. Esta organización se fue haciendo paulatinamente a lo largo del constante análisis del capítulo 8, sintetizado en el apartado 8.6 y en la respuesta a las preguntas 1 a 10.

10) Recolectar información de la interpretación de propuestas para el aula de clase y cómo índice dicha interpretación en el desarrollo, la cual se hizo a través de los instrumentos de recolección de la información y se sintetizó en los apartados $8.5,8.6$ y en las preguntas $2,5,8,9$ y 10.

En este estudio, la fuente de investigación es la práctica del profesor. Se ha considerado que el conocimiento especializado es de carácter teórico y de fines analíticos, que permite dar una imagen de la relación entre profesor, estudiantes y contenido en el marco de su práctica.

Se entiende entonces, qué, así como la práctica del profesor es dinámica, también lo es su conocimiento especializado. ¿cómo se dinamiza el conocimiento especializado durante la práctica? El trabajo de campo puede aportar algunos elementos:

Al final del proceso de observación Lucho manifestó que tiene más experiencia y como consecuencia de ello cambió su forma de actuar en el aula y modificó su práctica. Las consideraciones de Lucho coinciden con las ideas sobre experiencia y profesional reflexivo de Dewey (1995) que se relacionan con un dominio amplio de las situaciones de práctica heredadas por Contreras y Pérez (2013) quienes señalan que "la práctica, las acciones en que te implicas, el mundo en el que estás activamente inmerso, te dan lecciones y te permiten pensar sobre lo que significa lo que has hecho".

Lucho también manifestó que la reflexión le permitió el cambio de su práctica a partir de acciones que él mismo propició y las cuales incidieron en la interpretación del 
conocimiento especializado que se fue haciendo durante la observación. Como consecuencia del proceso de reflexión el profesor dinamiza su conocimiento especializado de la siguiente manera:

Comprensión: el profesor hace explícita alguna problemática relacionada con el qué hacer dentro del aula de clase o del objeto de enseñanza y aprendizaje. En el caso observado, las situaciones de enseñanza y aprendizaje de expresiones algebraicas, ecuaciones e inecuaciones, la motivación de los estudiantes, y la búsqueda de un mayor acercamiento a las matemáticas por parte de los estudiantes. En esta fase el profesor implícitamente entiende que hay guiones, imágenes o técnicas concretas que debe intervenir porque no está cumpliendo las expectativas que tiene en torno a los procesos de enseñanza y aprendizaje de las matemáticas escolares, tal como lo manifiesta Lucho al terminar las sesiones 5,6 y 7 del primer bloque.

En la comprensión, el profesor entiende que tiene alguna situación que modificar porque encuentra regularidades, contradicciones, hechos relevantes, hechos irrelevantes, y define objetivos concretos para transformarlas, como se puede entrever en las fichas de diario y las declaraciones posteriores de las sesiones 3 a 7 del primer bloque de observación, y las charlas previas de las sesiones 6 y 7 del primer bloque y 8 y 9 del segundo bloque.

Transformación: el profesor pasa por un estado en el que se pregunta sobre el sentido de su enseñanza y realiza interpretaciones críticas que le implican la modificación de representaciones y adaptaciones de su práctica en concordancia con sus concepciones y las necesidades curriculares tanto propias como de sus estudiantes. El profesor no siempre recurre a encontrar los marcos teóricos que lo llevaron a las situaciones foco, sino que replantea las acciones de su quehacer en el aula: para el caso observado, la transformación de Lucho se evidencia en el planteamiento de las actividades entre el primer y segundo bloque y entre el segundo y tercer bloque de observación sin la necesidad de buscar un marco teórico explícito, hecho que se describe en el apartado 8.6 cuando se responde a las preguntas ¿Qué pasó entre el bloque I y el bloque II? y ¿Qué pasó entre el bloque II y el bloque III?

En la transformación, el profesor plantea diferentes acciones para modificar la situación que problematizó y organiza sus guiones, confronta sus imágenes y diseña estrategias para la modificación de sus técnicas concretas tal como lo hace Lucho entre el primer y el segundo bloque de observación y entre el segundo y el tercer bloque. 
Modificación: los procesos de enseñanza y de la actuación observable del docente en el aula cambian, buscando dar respuesta a la pregunta de cómo hacer las cosas de otro modo del modelo reflexivo de Smith (1991). Se observa un quehacer ajustable a sus concepciones (como por ejemplo, la planificación, las actividades y las guías propuestas en el segundo bloque), esto es, el profesor pone en práctica las situaciones propuestas y con base en el objetivo propuesto se pregunta ¿qué podría hacerse distinto para llegar al objetivo? ¿Qué falta por hacer para introducir de la mejor manera esos cambios?

El profesor pone en práctica lo planificado: establece otras rutinas, imágenes y técnicas concretas y las confronta a los contextos en los que se involucra, por ejemplo, las nuevas tareas, las nuevas formas de explicar, y las diferentes formas de enseñar que se observan en el tercer bloque.

Consolidación, entendida como el proceso en el que las rutinas, las imágenes y las técnicas son asimiladas por el profesor en su práctica. El profesor valida y analiza si las acciones realizadas conllevan al alcance de los objetivos establecidos para su práctica. Lucho llevó a cabo la revisión, la reconstrucción y el análisis crítico de la acción propia y su propuesta cuando manifestó que ha llevado las situaciones planteadas a otras aulas y en ellas ha tenido resultados similares a los obtenidos en el aula en la cual fue observado. Lucho consolida su práctica cuando propone las actividades observadas en otras aulas del mismo grado con resultados similares.

Estas dimensiones sobre la forma en que el conocimiento especializado se dinamiza son imprescindibles para el ámbito de la educación secundaria, porque relacionan la acción de pensar y reflexionar en, para y desde la práctica, permitiendo la potenciación del trabajo del profesor como base de la indagación, la confrontación entre teoría y práctica para potencializar el desarrollo profesional, la ampliación de la visión sobre las problematizaciones del profesor, visualizándolas de manera global y sistémica, la confrontación de las concepciones con la práctica, y, la modificación de las prácticas propias a partir de su propio conocimiento especializado. 


\section{PERSPECTIVAS Y LIMITACIONES}

Este capítulo está dedicado a cerrar el ciclo de la investigación, mostrando las reflexiones sobre las limitaciones y las perspectivas del estudio realizado y se estructura en dos partes: en la primera se presentan elementos que han acotado, condicionado y restringido el desarrollo de la investigación; en la segunda las perspectivas que deja esta investigación en el campo del conocimiento especializado y el desarrollo profesional del profesor de matemáticas.

\subsection{Limitaciones}

Este estudio se ha llevado a cabo en unas condiciones derivadas en distintos aspectos que hacen que de ellos emerjan limitaciones y restricciones para el ejercicio académico. Es importante aclarar que se entiende 'limitación' no como algo negativo, sino como un elemento que define y delimita la investigación, en términos de acotarla, y de darle los matices que tiene, reflejando la idiosincrasia en la que ha sido desarrollada. Se comentan las limitaciones en términos de las características que han condicionado el estudio y lo han dotado de las particularidades que tiene.

Realizar una investigación como la aquí presentada, sin intervenir en el quehacer de la práctica del profesor, implica despojar del papel de evaluador al investigador para analizar la acción del docente sin ningún tipo de prejuicio. Las generalizaciones difusas propuestas al caso de Lucho para el desarrollo profesional y su conocimiento especializado, así como los análisis, los resultados y los aportes basados en la sensibilidad teórica que se han llevado a cabo durante el estudio, no pretenden ser exhaustivas; lo son en la medida que los datos, su interpretación y el contraste con la literatura especializada, así lo permiten.

La línea de trabajo que motivó está investigación, estudiar el desarrollo profesional por medio de la interpretación de las concepciones del profesor y la caracterización de su conocimiento especializado, llevó al investigador a centrarse en la observación directa del aula y algún encuentro ocasional con Lucho fuera de ella. La construcción de una representación sintética del desarrollo y conocimiento del profesor se vería enriquecida mediante un mayor contacto con el profesor, lo cual puede complementar la visión obtenida, para indagar sobre las conductas o actuaciones ejecutadas y observadas en las clases, permitiendo analizar el grado en que el profesor es consciente de su 
desarrollo y conocimiento, para identificar si sus intenciones educativas coinciden con las inferidas en el análisis de concepciones realizado.

El contexto teórico de la investigación elegido puede sesgar otras visiones que surjan acerca del conocimiento del profesor, tanto en su conceptualización, como en las consideraciones implícitas que se hacen respecto de este y las relaciones con la reflexión y el desarrollo profesional. Para minimizar los efectos de ese sesgo, durante el estudio se ha realizado una continua revisión de literatura acerca de los modelos de conocimiento profesional y su convergencia con la reflexión y el desarrollo profesional para analizar elementos que coinciden en las ideas generales acerca de la práctica del profesor, y así comprender los motivos que llevan a los diversos autores a desarrollar sus conceptualizaciones en la forma en que lo hacen.

El modelo de conocimiento especializado refleja la forma de entender el conocimiento profesional del investigador que lo desarrolla, en consonancia con las reflexiones de Schoenfeld (1992), con lo que una limitación es la comprensión del contenido del propio modelo y la aparición de aportes realizados en diferentes estudios durante el desarrollo de esta investigación.

Se ha tenido en cuenta la relación entre la teoría y el enfoque metodológico a través de los instrumentos de recolección y análisis de la información para hacer una investigación rigurosa sin extralimitarse en las afirmaciones acerca del profesor. Se valora que la aproximación realizada es teórica, siendo los constructos desarrollo profesional y conocimiento especializado en un principio 'para la investigación', posponiendo a un segundo plano, de forma implícita, el impacto en la realidad del aula, ya que no entró a evaluarse los resultados de aprendizaje de los estudiantes.

Finalmente, en consonancia con el trabajo de Schoenfeld (2001), la percepción del investigador acerca del desarrollo profesional y conocimiento especializado como parte del conocimiento del profesor está influenciada por los constructos teóricos estudiados, pero también por las propias concepciones que éste tiene acerca de las matemáticas, de su aprendizaje y su enseñanza. Los aspectos más relevantes en la formación de profesores, han condicionado en gran medida este estudio, a la vez que lo han impulsado hacia las perspectivas (de consideración del objeto de estudio) que a continuación se describen. 


\subsection{Perspectivas de investigación}

Una investigación no solo ha de aportar resultados, ha de aportar continuidad, y futuras líneas de trabajo en las que seguir desarrollando y ampliando la comprensión de lo estudiado. Así, las perspectivas giran en torno al tema abordado: el desarrollo profesional del profesor por medio de la interpretación de las concepciones y la caracterización de su conocimiento especializado. Se propone investigar en los aspectos que a continuación se describen:

El conocimiento profesional del profesor de matemáticas ha sido uno de los focos principales de reflexión que subyacen a esta tesis. Durante la investigación, el término se ha modificado con los diferentes aportes a la teoría que hacen autores como Carrillo, Contreras, Climent, y Muñoz Catalán quienes se han enfocado en generar un modelo que permita observar el conocimiento del profesor de matemáticas con fines analíticos, categorizándolo en diferentes componentes para dar mayor profundidad a la comprensión.

A lo largo de la investigación se ha comprendido que cada uno de los subdominios contempla a su vez diferentes componentes, que, aunque no se han abordado en este estudio, si pueden ser explorados en mayor profundidad, tal como el conocimiento de la estructura matemática y la diferenciación y la relación con el conocimiento de temas que permiten explorarlos desde diferentes ópticas; para comprender mejor las propias componentes de los subdominios.

La comprensión de cada uno de los subdominios se puede hacer profundizando en cada uno de ellos, comparando y constatando con la práctica de los profesores; así, por ejemplo, se pueden proponer diferenciaciones a los subdominios del conocimiento matemático, en particular el conocimiento de las estructuras matemáticas y analizar qué ocurre entre los profesores de secundaria y los maestros de primaria.

También se puede estudiar cómo el conocimiento matemático influye y afecta a los subdominios del conocimiento didáctico del contenido de estos docentes, valorando las oportunidades que tanto profesores como maestros tienen en el proceso de formación inicial y continua.

Comprender los factores que influyen en la construcción de estas estructuras, el papel de este tipo de conocimiento en la práctica docente, o el impacto que diferentes 
conocimientos de la estructura puedan tener en el aprendizaje de los alumnos, son temas que pueden aportar a la investigación y a la formación de maestros y profesores.

El modelo del conocimiento especializado del profesor de matemáticas es una herramienta importante en la acción de profundizar sobre el conocimiento del profesor a partir de la observación en el aula y la descripción del proceso de desarrollo profesional y detallar en cada una de sus componentes puede aportar a describir de forma más detallada cómo es ese desarrollo, a la vez de caracterizar elementos más puntuales en la transformación de la práctica del profesor.

El modelo de análisis didáctico y el estudio que realiza sobre el contenido, la cognición, la instrucción y la evaluación puede permitir que vincular los componentes que caracterizan el conocimiento especializado e identificar dimensiones del conocimiento profesional del profesor. Por ejemplo, el análisis de evaluación sobre la práctica del profesor observado puede dar información sobre cómo evaluar la resolución de ecuaciones e inecuaciones lineales y comprender así otra parte del conocimiento del profesor.

Siguiendo la caracterización que propone Liljedahl \& otros (2009) quienes proponen que la formación inicial del profesor es una estrella de seis puntas y cada una corresponde a una componente del modelo de conocimiento especializado que se relaciona con los elementos del análisis didáctico; es importante estudiar cómo se conforma cada punta y luego se integra y unifica en el conocimiento necesario para la enseñanza; de esta manera, los organizadores del análisis didáctico promueven desarrollo profesional en cada una de las componentes del conocimiento especializado.

Finalmente, de acuerdo con la propuesta de Godino (2009), es importante caracterizar el conocimiento especializado del formador de profesores a fin de generar información que permita identificar aspectos en los programas de formación de profesores inicial y permanente y evaluar su eficacia y eficiencia: ¿Cuál es el conocimiento especializado de un profesor formador de profesores de matemáticas? ¿Es el conocimiento especializado del profesor de matemáticas una componente del conocimiento especializado del formador de profesores? ¿Se modifica el conocimiento de contenido matemático cuando profundiza en el conocimiento didáctico de contenido matemático del profesor que forma? ¿Se produce desarrollo profesional tanto como formador como profesor de matemáticas cuando se apoya el proceso de desarrollo profesional de un profesor de matemáticas? 
Las perspectivas descritas, las preguntas propuestas y las que quedan para el lector de este documento son necesarias para completar esta investigación, de esta manera se invita a la comunidad de educadores e investigadores en educación matemática, se continúe con la línea de este trabajo. 


\section{REFERENCIAS BIBLIOGRÁFICAS}

Abelson, R. (1979). Differences between belief systems and knowledge systems. Cognitive Science(3), 355-366.

Agudelo-Valderrama, C., Clarke, B., \& \& Bishop, A. (2007). Explanations of Attitudes to Change: Colombian Mathematics Teachers' Conceptions of the Crucial Determinants of Their Teaching Practices of Beginning Algebra. Journal of Mathematics Teacher Education(10), 69-93.

Arbeláez, R. (2005). Concepciones sobre una docencia universitaria de calidad. Estudio diferencial entre universidades y profesores. Valencia: Servei de Publicacions.

Artzt. (1999). A structure to enable pre-service teachers of mathematics to reflect on their teaching. Journal of Mathematics Teacher Education(2), 143 - 166.

Azcárate, P. (2001). El conocimiento profesional didáctico-matemático en la formación inicial de los maestros. Cádiz: Servicio de Publicaciones de la Universidad de Cádiz.

Azcárate, P., \& Cardeñoso, J. (1994). La naturaleza de la matemática escolar: problema de la didáctica de la matemática. Investigación en la Escuela(24), 79-88.

Ball, D. (1990 b). The mathematical understandings that prospective teacher bring to teacher education. Elementary School Journal(90), 449-466.

Ball, D., \& Bass, H. (2009). With an eye on the mathematical horizon: Knowing mathematics for teaching to learners' mathematical futures. Jahrestagung der Gesellschaft für Didaktik der Methematik(43).

Ball, D., Ben-Peretz, M., \& Cohen, R. (2014). Records of practice and the development of collective professional knowledge. British Journal of Educational Studies, 62(3), 317-335.

Ball, D., Thames, M., \& Phelps, G. (2008). Content Knowledge for Teaching: What Makes It Special. Journal of Teacher Education.

Barrantes, M., \& Blanco, L. (2006). A study of Prospective Primary Teachers. Conceptions ofTeaching and Learning School Geometry. Journal of Mathematics Teachers Educations, 9, 411-436.

Bass, S., Didis, M., Erbas, A., Cetinkaya, B., Cakiroglu, E., \& Alacaci, C. (2013). Teachers as investigators of students' written work: Does this approach provide 
an opportunity for profesional development? En B. Ubuz, C. Haser, \& M. Mariotti, Actas del CERME 8. Antalya: ERME.

Bassey, M. (1999). Case Study Research in Educational Settings. Celtic Court: Open University Press.

Bednarz, N., \& Jean-luc, E. (2015). La recherche collaborative. Carrefours de l'education, 39(171).

Bernal, C. (2006). Metodología de la Investigación. Mexico: Prentice Hall.

Blanco, L. (1991 a). Conocimiento y acción en la enseñanza de conceptos matemáticos y la resolución de problemas de profesores de EGB, especialistas en matemáticas con experiencia y estudiantes para profesores. Sevilla: Universidad de Sevilla.

Blanco, L., Mellado, V., \& Ruíz, C. (1995). Conocimiento Didáctico del Contenido de Ciencias y Matemáticas y Formación de Profesores. Revista de Educación(307), 427-446.

Carrillo, J. (1998). Modos de resolver problemas y concepciones sobre la matemática y sup enseñanza: metodología de la investigación y relaciones. Huelva: Universidad de Huelva.

Carrillo, J., \& Rico, L. (1999). The training and performance of primary teachers in mathematics education. The case of Spain. The training and performance of primary teachers in mathematics educations. Madrid: Real Academia de Ciencias Exactas, Físicas y Naturales.

Carrillo, J., Climent, N., Montes, M., Contreras, L., Flores, E., Escudero, D., . . MuñozCatalán, M. (2018). The mathematics teacher's specialised knowledge model. Research in mathematics education, 20, 263-253.

Chiang, F., Miller, R., \& Rowan, B. (1997). Using research on employees performance to study the effects of teachers on student's achievements. Sociology of Education, 70(4), 256-284.

Clark, M., \& Peterson, P. (1990). Procesos de pensamiento de los docentes. En M. Wittrock (Ed.), La investigación de la enseñanza. Profesores y alumnos. Barcelon: Paidós Educador. 
Climent, N. (2005). El desarrollo profesional del maestro de Primaria respecto de la enseñanza de la matemática. Un estudio de caso. Michigan: Proquest Michigan University.

Climent, N., \& Vasco, D. (2018). El estudio del conocimiento especializado de dos profesores de álgebra lineal. PNA. Revista de Investigación en Didáctica de la Matemática, 12(3), 129-146.

Cochran, M., \& Lytle, S. (2003). Más allá de la certidumbre: adoptar una actitud indagadora sobre la práctica. En A. Lieberman, \& L. Miller (Edits.), La indagación como base de la formación del profesorado y la mejora de la educación (págs. 65-79). Barcelona: Octaedro.

Cohen, L., \& Manion, L. (1994). Research Methods in Education. Londres: Routledge.

Contreras, J., \& Pérez, N. (2013). La experiencia y la investigación educativa. En J. Contreras, \& N. Lara (Edits.), Investigar la experiencia educativa (págs. 21-86). Madrid: Ediciones Morata.

Contreras, L. (1998). Resolución de problemas. Un análisis exploratorio de las concepciones de los profesores acerca de su papel en el aula. Tesis doctoral, Universidad de Huelva, Huelva.

Contreras, L. (1999 a). Concepciones de los profesores sobre la resolución de problemas. Huelva: Universidad de Huelva.

Cooney, T. (1998). Conceptualizing the professional development of teachers. Selección de Conferencias del ICME 8, 101-117.

Crespo, C. (2005). El papel de las argumentaciones matemáticas en el discurso escolar. La estrategia de deducción por reducción al absurdo. Tesis de Maestría, IPN, México.

Cresswell, J. (2005). Educational Research: Planning, conducting and evaluating quantitative and qualitative research. Uppe Sadle River: Pearson Education.

Cross, D. (2009). Alignment, cohesion and change: Examining mathematics teacher's belief structures and their influence on instructional practices. Journal of Mathematics Teacher Education, 10, 325-346.

Cross, D. (2015). Dispelling the notion of incosistencies in teachers mathematics beliefs and practices: A 3-year case study. Journal of Mathematics Teacher Education, 18, 173-201. 
Dewey, J. (1933). How we think: A restatement of the relation of reflective thinking to the educative process. Boston: Heath.

Ferreira, R. (2004). Classroom Teaching Modes. Congreso Internacional de Educación Matemática. Copenhague, Dinamarca.

García, M. (1997). Conocimiento profesional del profesor de matemáticas. El concepto de función como objeto de enseñanza-aprendizaje. Sevilla: Universidad de Sevilla.

Gavilán-Izquierdo, J., García-Blanco, M., \& Llinares, S. (2007). Una perspectiva para el análisis de la práctica del profesor de matemáticas. Implicaciones metodológicas. Enseñanza de las Ciencias, 25(2), 157-170.

Gil, D. (1993). Aportaciones de la investigación en didáctica de las ciencias a la formación y actividad del profesorado. Qurriculum, 6(7), 45-66.

Godino, J. (2009). Categorías de análisis de los conocimientos del profesor de matemáticas. UNIÓN, Revista Iberoamericana de Educación Matemática(20), 13-31.

Goetz, J., \& Lecompte, M. (1988). Etnografía y diseño cualitativo en investigación educativa. Madrid: Morata.

Grant, T., Hiebert, J., \& Wearne, D. (s.f.). Observing and Teaching Reform-Minded Lessons: What do theacher see? Journal of Matematics Teacher Education(1), 217-236

Grupo Investigación en la Escuela. (1991). Proyecto Curricular IRES (Doc. I, II, III, IV). Sevilla: Diada.

Guacaneme, E. (2006). Conflictos para precisar el conocimiento disciplinar del profesor de matemáticas.

Guimarães, H. M. (2005). A resolução de problemas no ensino da Matemática: Alguns passos do seu percurso no discurso curricular em Portugal. En L. Santos, A. Canavarro, \& J. Brocardo (Edits.), Educação matemática: Caminhos e encruzilhadas (págs. 275-279). Lisboa, Portugal: APM.

Henningsen, M., \& Stein, M. (1997). Mathematical tasks and student cognition: classroom-based factors that support and inhibit high-level mathematical thinking and reasoning. Journal for Research in Mathematics Education, 28(5). 
Hill, H., Rowan, B., \& Ball, D. (2005). Effects of teachers' mathematical knowledge for teaching on student achievement. American Educational Research Journal, 42(2), 371-406.

Hobbs, L. (2016). The heart of the educator: Aesthetic experience shaping knowledge, identity and passion. En A. Bellochi, K. Otrel-Cass, \& C. Quigley, Beyond cognition in science education: considering the role of emotions, well-being, and aesthetics. Springer.

Jarauta, B., \& Medina, J. (2009). La formación pedagógica inicial del profesorado universitario: repercusión en las concepciones y prácticas docentes. Revista Internacional de Investigación en Educación, 1(2).

Jaworski, B., \& Gellert, U. (2003). Educating new mathematics teachers: integrating theory and practice, and the roles of practising teachers. En A. Bishop, M. Clments, J. Keitel, J. Kilpatrick, \& F. Leung (Edits.), Second International Handbook of Mathematics Education (Vol. 2, págs. 829-875). Dordrecht, The Netherlands: Kluwer Academic Publisher.

Kilpatrick, J. (2009). The mathematics teacher and curriculum change. PNA, 3(3), 107121.

Kuhs, T., \& Ball, D. (1986). Approaches to teachiing mathematics: Mapping the domains of knowledge, skills and disposition. Lansing: Michigan State University, Centre of Teacher Education.

Kuntze, S., Lerman, S., Murphy, B., Kurz-Milcke, E., Siller, H., \& Winbourne, P. (2011). Professional knowledge related to big ideas in mathematics - an empirical study with preservice teachers. En M. Pythak, T. Rowland, \& E. Swoboda, Actas del CER

Lampert, J. (2001). Teaching problems and the problems of teaching. Yale: Yale University Books.

Latorre, A., Del Rincón, D., \& Arnal, J. (1997). Bases metodologícas de la investigación educativa. Barcelon: Hurtado Ediciones.

Lezama, J. (2016). Experiencia docente en matemáticas: narrativas para la construcción de un discurso académico. Perfiles Educativos, 38(Especial), 87-100.

Liljedahl, P., Durand-Guerrier, V., Winslow, C., Bloch, I., Huckstep, P., Rowland, T., . . Grevholm, B. (2009). Components of mathematics teacher training. En R. Even, 
\& D. Ball (Edits.), The Professional Education and Development of Teachers of Mathematics: the 15th ICMI study (págs. 25-33). New York: Springer.

Lima, I. (2014). El conocimiento profesional del profesor de matemáticas y el teorema de los cuatro colores. Tesis de Maestría, Universidad Nacional de General San Martín, Buenos Aires.

Llinares, S. (1998). La investigación 'sobre' el profesor de matemáticas: aprendizaje del profesor y práctica profesional. Aula: Revista de Pedagogía de la Universidad de Salamanca, 10, 153-179.

Llinares, S., \& Krainer, K. (2006). Mathematics (student) teachers and teacher educators as learners. En Á. Gutiérrez, \& P. Boero (Edits.), Handbook of research on the psychology of mathematics education: Past, present and future (págs. 429 - 459). Rotterdam, Netherlands: Sense Publishers.

Llinares, S., \& Valls, J. (2009). The building of pre-service primary teacher's knowledge of mathematics teaching: interactions and online video cases studies. Instruccional of Sciencie, 37(3), 247-271.

Matos, J. (2000). Aprendizagem e prática social: contributos para a construcao de ferramentas de análise da aprendizagem matemática escolar. En J. y. Ponte (Ed.), Espanha e Itália. Actas da Escola de Perao-1999. Lisboa: Sociedade portuguesa de Ciencias da Educacao.

Mertens, D. (2005). Research and evaluation in education and psychology: integranting diversity with quantitative and qualitative methods. Thousand Oaks: Sage.

Montes, M., Flores-Medrano, E., Carmona, E., Huitrado, J., \& Flores, P. (2014). Reflexiones sobre la naturaleza del conocimiento, las creencias y las concepciones. En L. Carrillo, N. Climent, L. Contreras, M. Montes, D. EscuderoÁvila, \& E. Flores-Medrano (Edits.), Un marco teórico para el conocimiento especializado del profesor de Matemáticas. Huelva: Universidad de Huelva Publicaciones.

Muñoz-Catalán, M. (2012). El desarrollo profesional de una maestra novel: Un estudio de caso en un entorno colaborativo centrado en la enseñanza de las matemáticas. Madrid: Editorial Académica Española.

Muñoz-Catalán, M., Contreras, L., Carrillo, J., Rojas, N., Montes, M., \& Climent, N. (2015). Conocimiento especializado del profesor de Matemáticas: un modelo 
análitico para el estudio del conocimiento del profesor de Matemáticas. Gaceta de la RSME, 18(3).

NCTM. (2000). Principles and standards for school mathematics. Reston, Virginia: National Council of Teachers of Mathematics. (Edición en Castellano: Principios y Estándares para la Educación Matemática). Granada: Servicio de Publicaciones de la Sociedad Andaluza de Profesores de Matemáticas 'Thales.

Oliva, A. (1995). Ideas de educadores sobre desarrollo y educación infantil. Revista de educación(375), 375-394.

Pajares. (1992). Teachers' Beliefs and Educational Research: Cleaning up a messy construct. Review of Educational Research, 62(3), 307 - 332.

Ponte, J. (1994). O Desenvolvimento Profissional do Profesor de Matematica. Educacao e Matematica(31), 9-12.

Ponte, J. (2012). Estudiando el conocimiento y el desarrollo profesional del profesorado de matemáticas. En N. Planas, Teoría, crítica y práctica de la educación matemátia. Madrid: Grao.

Ponte, J. P. (2002). Perspectivas teóricas sobre o desenvolvimento professional. Huelva.

Porlán, R. (1995). Las creencias pedagógicas y científicas de los profesores. Enseñanza de las Ciencias de la Tierra(22), 7-13.

Porlán, R., \& Rivero, A. (1998). El conocimiento de los profesores. Sevilla: Diada.

Porlán, R., Martín del Pozo, R., Rivero, A., Harres, J., Azcaráte, P., \& Camara, M. (2010). El cambio del profesorado de ciencias. Enseñanza de las ciencias: revista de investigación y experiencias didácticas, 28(1), 31-46.

Putman, R., \& Borko, H. (2000). What do new views of knowledge and thinging have to Say about reseach on teacher learning? Educational Researcher, 29(1), 4-15.

Raymond, A. (1997). Inconsistency between a beginning elementary school teacher's mathematics beliefs and teaching practice. Journal of Reseach in Mathematics Education, 28(5), 550-576.

Resnick. (1987). Education and learning to think. Washington: National Academic Press. 
Restrepo Becerra, J. (2017). Concepciones sobre competencias matemáticas en profesores de educación básica, media y superior. Revista Boletín Redipe, 6(2), 104-118.

Rowland, T., Turner, F., Thwaites, A., \& Huckstep, P. (2009). Developing Primary Mathematics Teaching: reflecting on practice with the Knowledge Quartet. Londres: SAGE.

Schifter, D., \& Simon, M. (1992). Assessing teacher's development of a constructivist view of mathematics learning. Teaching and Teacher education, 8(2), 187-197.

Schoenfeld, A. (1989). Exploration of student's mathematical beliefs and behavior. Journal of Research in Mathematics Education, 20, 338-355.

Schoenfeld, A. (1992). Research Methods in and for the Learning Sciences. The Journal of the Learning Sciences(2), 137-139.

Schoenfeld, A. (2000b). Models of the teaching process. Journal of Mathematical Behavior, 18(3).

Schoenfeld, A. (2001). Reflections on an Impoverished Education. En L. A. Steen (Ed.), Mathematics and Democracy: The Case for Quantitative Literacy (págs. 49-55). Princenton, NJ: National Council on Education and the Disciplines.

Schoenfeld, A. (2010). How we think. Nueva York: Routledge.

Schoenfeld, A. (2012). How We Think: A Theory of Human-decision making, with a focus on teaching. En S. Cho (Ed.), The Proceedings of the 12th International Congress on Mathematical Education. Seúl, Corea del Sur.

Schön, D. (1983). The reflective practitioner. Londres: Basic Books.

Schwab, J. (1979). Education and the structure of the disciplines. En I. Westbury, \& N Wilkof, Science, curriculum and liberal education. Chicago: Universidad de Chicago.

Serrazina, L. (1998). Teacher's professional development in a period of radical change in primary mathematics education in Portugal. Lisboa: APM.

Shulman, L. (1986). Those who understand: knowledge growth in teaching. Educational Researcher, 15(2).

Shulman, L. (1987). Knowledge and Teaching: Foundations of the New Reform. Harvard Educational Review, 57(1). 
Shulman, L., \& Grossman, P. (1988). Knowledge growth in teaching: A final report to the Spencer Foundation. Standford CA: Standford University.

Smith, J. (1991). Una pedagogía crítica de la práctica en el aula. Revista de Educación(294), 275-300.

Thompson, A. (1991). Teachers' Beliefs and Conceptions: A Synthesis of Research. En

D. Grouws, Handbook of Research on Mathematics Teaching and Learning. Nueva York: McMillan \& NCTM. .

Villella, J. (2007). Matemática escolar y libros de texto. Un estudio desde la didáctica de la matemática. Buenos Aires: Universidad Nacional de San Martín. Miño y Dávila Editores.

Wilson, M., \& Cooney, T. (2002). Mathematics teacher change and development. En G. Leder, E. Pehkonen, Törner, \& D (Edits.), Beliefs: A hidden variable in mathematics education? Dordrecht: Kluwer Academic Publishers.

Wilson, S., Shulman, L., \& Richert, A. (1987). '150 different ways' of knowing: Representation of knowledge in teaching. En J. Calderheath, Exploring Teachers' Thinking. Londres: Cassel Education.

Yin, R. (1993). Applications of case study research. Newbury Park, California: Sage. 


\section{LISTA DE ANEXOS}

A continuación, se presenta la lista de anexos correspondientes a la memoria de investigación. En la versión impresa se adjunta en cd, en la versión digital se pueden encontrar en el enlace:

https://drive.google.com/drive/folders/1GLvEnkqyXt3WziGqVwP OrA1NBG9BG9e?us $\mathrm{p}=$ sharing

\begin{tabular}{|c|c|}
\hline Anexo & Descripción \\
\hline Anexo 01 & $\begin{array}{l}\text { Un acercamiento matemático al estudio de las expresiones } \\
\text { algebraicas, las ecuaciones y las inecuaciones de una sola } \\
\text { variable }\end{array}$ \\
\hline Anexo 02 & Manual de GrafEq: transcripción y escaneado de original \\
\hline Anexo 03 & Entrevista Inicial \\
\hline Anexo 04 & Charla Previa Bloque I Sesión 01 \\
\hline Anexo 05 & Observación Bloque I Sesión 01 \\
\hline Anexo 06 & $\begin{array}{l}\text { Notas de observación y Declaración espontánea Bloque I Sesión } \\
01\end{array}$ \\
\hline Anexo 07 & Declaración posterior Bloque I Sesión 01 \\
\hline Anexo 08 & $\begin{array}{l}\text { Ficha de diario Bloque I Sesión 01: transcripción y escaneado de } \\
\text { original }\end{array}$ \\
\hline Anexo 09 & Charla Previa Bloque I Sesión 02 \\
\hline Anexo 10 & Observación Bloque I Sesión 02 \\
\hline Anexo 11 & $\begin{array}{l}\text { Notas de observación y Declaración espontánea Bloque I Sesión } \\
02\end{array}$ \\
\hline Anexo 12 & Declaración posterior Bloque I Sesión 02 \\
\hline Anexo 13 & $\begin{array}{l}\text { Ficha de diario Bloque I Sesión 02: transcripción y escaneado de } \\
\text { original }\end{array}$ \\
\hline Anexo 14 & Charla Previa Bloque I Sesión 03 \\
\hline Anexo 15 & Observación Bloque I Sesión 03 \\
\hline Anexo 16 & $\begin{array}{l}\text { Notas de observación y Declaración espontánea Bloque I Sesión } \\
03\end{array}$ \\
\hline Anexo 17 & Declaración posterior Bloque I Sesión 03 \\
\hline Anexo 18 & $\begin{array}{l}\text { Ficha de diario Bloque I Sesión 03: transcripción y escaneado de } \\
\text { original }\end{array}$ \\
\hline Anexo 19 & Charla Previa Bloque I Sesión 04 \\
\hline
\end{tabular}




\begin{tabular}{|c|c|}
\hline Anexo 20 & Observación Bloque I Sesión 04 \\
\hline Anexo 21 & $\begin{array}{l}\text { Notas de observación y Declaración espontánea Bloque I Sesión } \\
04\end{array}$ \\
\hline Anexo 22 & Declaración posterior Bloque I Sesión 04 \\
\hline Anexo 23 & $\begin{array}{l}\text { Ficha de diario Bloque I Sesión 04: transcripción y escaneado de } \\
\text { original }\end{array}$ \\
\hline Anexo 24 & Charla Previa Bloque I Sesión 05 \\
\hline Anexo 25 & Observación Bloque I Sesión 05 \\
\hline Anexo 26 & $\begin{array}{l}\text { Notas de observación y Declaración espontánea Bloque I Sesión } \\
05\end{array}$ \\
\hline Anexo 27 & Declaración posterior Bloque I Sesión 05 \\
\hline Anexo 28 & $\begin{array}{l}\text { Ficha de diario Bloque I Sesión 05: transcripción y escaneado de } \\
\text { original }\end{array}$ \\
\hline Anexo 29 & Charla Previa Bloque I Sesión 06 \\
\hline Anexo 30 & Observación Bloque I Sesión 06 \\
\hline Anexo 31 & $\begin{array}{l}\text { Notas de observación y Declaración espontánea Bloque I Sesión } \\
06\end{array}$ \\
\hline Anexo 32 & Declaración posterior Bloque I Sesión 06 \\
\hline Anexo 33 & $\begin{array}{l}\text { Ficha de diario Bloque I Sesión 06: transcripción y escaneado de } \\
\text { original }\end{array}$ \\
\hline Anexo 34 & Charla Previa Bloque I Sesión 07 \\
\hline Anexo 35 & Observación Bloque I Sesión 07 \\
\hline Anexo 36 & $\begin{array}{l}\text { Notas de observación y Declaración espontánea Bloque I Sesión } \\
07\end{array}$ \\
\hline Anexo 37 & Declaración posterior Bloque I Sesión 07 \\
\hline Anexo 38 & $\begin{array}{l}\text { Ficha de diario Bloque I Sesión 07: transcripción y escaneado de } \\
\text { original }\end{array}$ \\
\hline Anexo 39 & Charla Previa Bloque II Sesión 08 \\
\hline Anexo 40 & Observación Bloque II Sesión 08 \\
\hline Anexo 41 & $\begin{array}{l}\text { Notas de observación y Declaración espontánea Bloque II Sesión } \\
08\end{array}$ \\
\hline Anexo 42 & Declaración posterior Bloque II Sesión 08 \\
\hline Anexo 43 & $\begin{array}{l}\text { Ficha de diario Bloque II Sesión 08: transcripción y escaneado de } \\
\text { original }\end{array}$ \\
\hline Anexo 44 & Charla Previa Bloque II Sesión 09 \\
\hline Anexo 45 & Observación Bloque II Sesión 09 \\
\hline
\end{tabular}




\begin{tabular}{|c|c|}
\hline Anexo 46 & $\begin{array}{l}\text { Notas de observación y Declaración espontánea Bloque II Sesión } \\
09\end{array}$ \\
\hline Anexo 47 & Declaración posterior Bloque II Sesión 09 \\
\hline Anexo 48 & $\begin{array}{l}\text { Ficha de diario Bloque II Sesión 09: transcripción y escaneado de } \\
\text { original }\end{array}$ \\
\hline Anexo 49 & Charla Previa Bloque II Sesión 10 \\
\hline Anexo 50 & Observación Bloque II Sesión 10 \\
\hline Anexo 51 & $\begin{array}{l}\text { Notas de observación y Declaración espontánea Bloque II Sesión } \\
10\end{array}$ \\
\hline Anexo 52 & Declaración posterior Bloque II Sesión 10 \\
\hline Anexo 53 & $\begin{array}{l}\text { Ficha de diario Bloque II Sesión 10: transcripción y escaneado de } \\
\text { original }\end{array}$ \\
\hline Anexo 54 & Entrevista intermedia \\
\hline Anexo 55 & Charla Previa Bloque III Sesión 11 \\
\hline Anexo 56 & Observación Bloque III Sesión 11 \\
\hline Anexo 57 & $\begin{array}{l}\text { Notas de observación y Declaración espontánea Bloque III Sesión } \\
11\end{array}$ \\
\hline Anexo 58 & Declaración posterior Bloque III Sesión 11 \\
\hline Anexo 59 & $\begin{array}{l}\text { Ficha de diario Bloque III Sesión 11: transcripción y escaneado de } \\
\text { original }\end{array}$ \\
\hline Anexo 60 & Charla Previa Bloque III Sesión 12 \\
\hline Anexo 61 & Observación Bloque III Sesión 12 \\
\hline Anexo 62 & $\begin{array}{l}\text { Notas de observación y Declaración espontánea Bloque III Sesión } \\
12\end{array}$ \\
\hline Anexo 63 & Declaración posterior Bloque III Sesión 12 \\
\hline Anexo 64 & $\begin{array}{l}\text { Ficha de diario Bloque III Sesión 12: transcripción y escaneado de } \\
\text { original }\end{array}$ \\
\hline Anexo 65 & Charla Previa Bloque III Sesión 13 \\
\hline Anexo 66 & Observación Bloque III Sesión 13 \\
\hline Anexo 67 & $\begin{array}{l}\text { Notas de observación y Declaración espontánea Bloque III Sesión } \\
13\end{array}$ \\
\hline Anexo 68 & Declaración posterior Bloque III Sesión 13 \\
\hline Anexo 69 & $\begin{array}{l}\text { Ficha de diario Bloque III Sesión 13: transcripción y escaneado de } \\
\text { original }\end{array}$ \\
\hline Anexo 70 & Charla Previa Bloque III Sesión 14 \\
\hline Anexo 71 & Observación Bloque III Sesión 14 \\
\hline
\end{tabular}




\begin{tabular}{|l|l|}
\hline Anexo 72 & $\begin{array}{l}\text { Notas de observación y Declaración espontánea Bloque III Sesión } \\
14\end{array}$ \\
\hline Anexo 73 & Declaración posterior Bloque III Sesión 14 \\
\hline Anexo 74 & $\begin{array}{l}\text { Ficha de diario Bloque III Sesión 14: transcripción y escaneado de } \\
\text { original }\end{array}$ \\
\hline Anexo 75 & Entrevista final \\
\hline Anexo 76 & Metas, competencias y desempeños 2015 IPN, grado décimo \\
\hline Anexo 77 & Metas, competencias y desempeños 2016 IPN, grado décimo \\
\hline Anexo 78 & $\begin{array}{l}\text { Documento área de matemáticas IPN 2015 } \\
\text { especializado del profesor de matemáticas como elemento de su } \\
\text { desarrollo profesional" }\end{array}$ \\
\hline Anexo 79 &
\end{tabular}

